\title{
MEASUREMENT AND ANALYSIS OF THE STANDBY POWER OF TWENTY- SEVEN PORTABLE ELECTRIC SPAS
}

\author{
A Thesis \\ presented to \\ the Faculty of the Mechanical Engineering Department \\ California Polytechnic State University, San Luis Obispo
}

\author{
In Partial Fulfillment \\ of the Requirements for the degree \\ Master of Science \\ by
}

Andrew Ian Hamill

September 2012 
(C) 2012

Andrew Ian Hamill

ALL RIGHTS RESERVED 


\section{COMMITTEE MEMBERSHIP}

TITLE:

MEASUREMENT AND ANALYSIS OF THE STANDBY

POWER OF TWENTY-SEVEN PORTABLE ELECTRIC

SPAS

AUTHOR:

Andrew Ian Hamill

DATE SUBMITTED: August 2012

COMMITTEE CHAIR: Dr. Andrew Kean

Advisor and Committee Chair

Mechanical Engineering Dept.

COMMITTEE MEMBER: Dr. Glen Thorncroft

Committee Member

Mechanical Engineering Dept.

COMMITTEE MEMBER: Dr. Chris Pascual

Committee Member

Mechanical Engineering Dept. 


\begin{abstract}
MEASUREMENT AND ANALYSIS OF THE STANDBY POWER OF TWENTY SEVEN PORTABLE ELECTRIC SPAS

Andrew I. Hamill
\end{abstract}

Portable electric spas are typically the largest electrical load in homes that have one. In recent years, the California Energy Commission's California code of regulations, Title 20 has been revised to regulate the maximum allowable standby power for a portable electric spa based on the spa volume. The goal of this regulation is to require improvements to the lowest performing models, for which simple and cost effective improvements are readily available, without eliminating average or better performing products.

In this research, the standby power of twenty seven portable electric spas was measured and compared to the Title 20 requirement. These tests resulted in nine of the twenty seven spas not meeting the allowable standby power. Analysis demonstrates that simple and inexpensive improvements to these nine spas would likely cause the spas to pass the Title 20 requirement. Additionally, temperature normalization developed in this research have been adopted by the California Energy Commission and included in revisions to Title 20 .

Keywords: Portable electric spa, power measurement, California Energy Commission, energy efficiency. 


\section{ACKNOWLEDGEMENTS}

I would like to thank my advisor, Dr. Andrew Kean, for initially providing me with this project and for his patient assistance, guidance and encouragement throughout the project.

I would also like to thank my friend and coworker Dr. Jerry Wyss for the countless hours he invested in reviewing this thesis. If it wasn't for his input and prodding I don't think I would have ever completed it.

Thank you to Dr. Glen Thorncroft, Carvin DiGiovanni of the APSP, Gary Fernstrom and Lianne Williams of PG\&E, Angelo Pugliese of DimensionOne Spas, all the spa manufacturers, and everyone else who provided valuable input without which this would not have been possible.

Finally, I thank my parents. Thank you for your love and support throughout this process and particularly for pushing me to complete it. This thesis is dedicated to you. 


\section{Table of Contents}

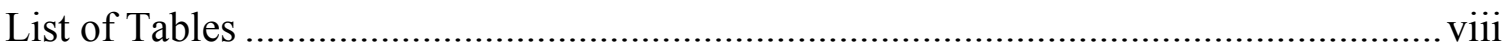

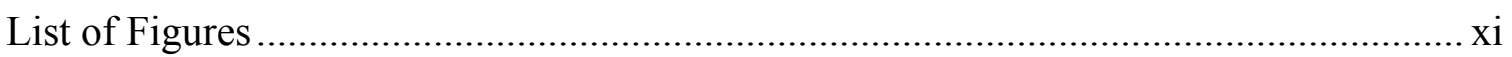

\section{Chapters}

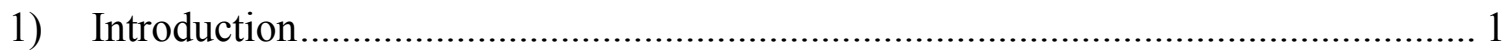

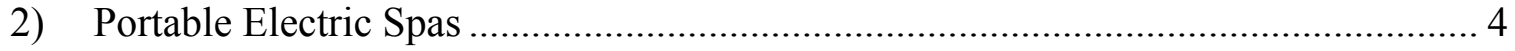

3) Regulation of Portable Electric Spas ................................................................ 9

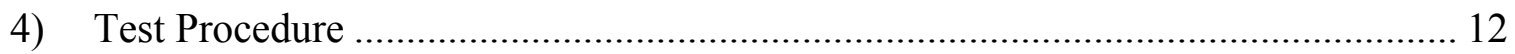

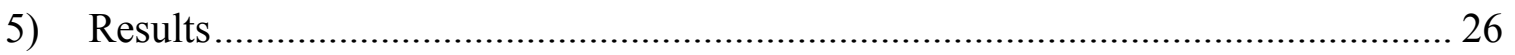

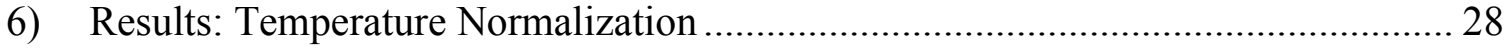

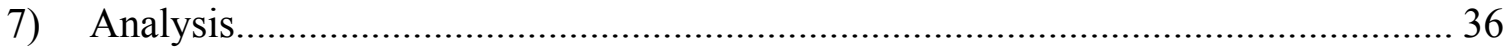

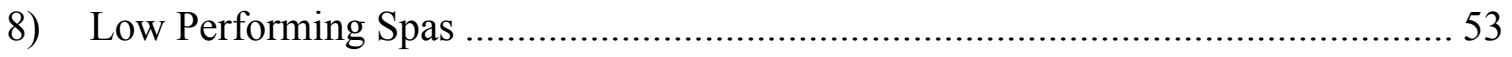

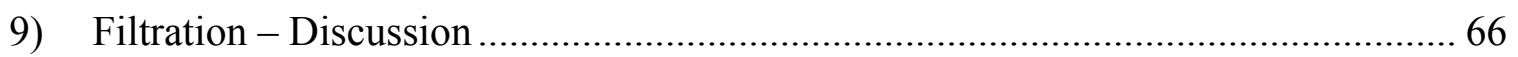

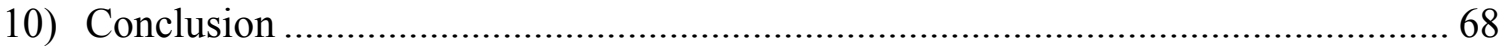

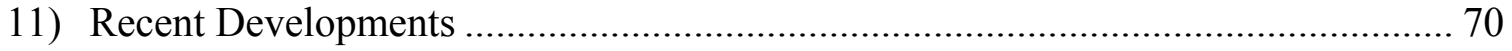

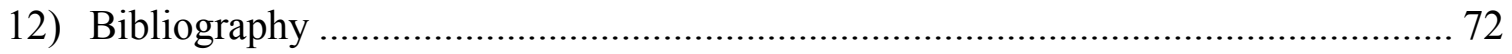




\section{Appendices}

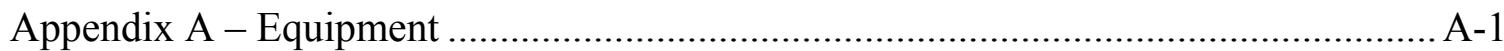

Appendix B - Calibration Certification Documents........................................... B-1

Appendix C - Equipment Accuracy and Error Propagation.................................... C-1

Appendix D - Calculations........................................................................... D-1

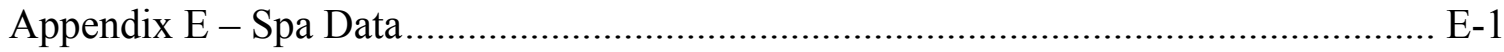




\section{List of Tables}

Table 1: Summary of test results 26

Table 2: Summary of test results with power normalized using equation 9 with $\Delta \mathrm{T}_{\text {ideal }}$ equal to $37^{\circ} \mathrm{F}$. 32

Table 3: Categorized power demands contributing to the total standby

power.

Table 4: Approximate percent contributions to the total standby power of each type of power usage.

Table 5: Average operating time per day of various spa cycles.

Table 6: Comparison of heat transfer thickness and equivalent insulation thickness for each spa test.

Table 7: Naming convention for the correlation strength based on the magnitude of the Pearson product-moment correlation coefficient. 48

Table 8: Pearson product-moment correlation coefficients for the correlation between the normalized margin and various other variables 49

Table 9: Pearson product-moment correlation coefficients for the correlation between the measured power and various other variables. 50

Table 10: Power reduction required to bring each of the failed spas into compliance with Title 20. 54

Table 11: Summary of the performance of Spa D and proposed changes. 54

Table 12: Power usage details for spas not meeting the Title 20 standard. 56 
Table 13: Summary of the performance of Spa J and proposed changes. ...................... 57

Table 14: Summary of the performance of Spa N and proposed changes.......................58

Table 15: Summary of the performance of Spa $\mathrm{O}$ and proposed changes......................59

Table 16: Summary of the performance of Spa Q and proposed changes..................... 60

Table 17: Summary of the performance of Spa R and proposed changes..................... 61

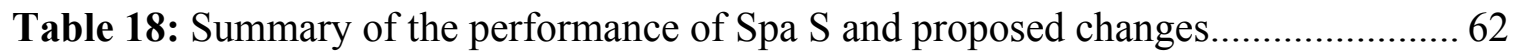

Table 19: Summary of the performance of Spa Y and proposed changes..................... 63

Table 20: Summary of the performance of Spa AA and proposed changes................... 64

Table A-1: Resolution of data recorded by Balboa Spa Testing Software ................. A-10

Table A-2: Accuracy of Hioki 3196-20 digital power analyzers with 9660 clamp-on current sensors (Hioki, 2007)...................................................... A-12

Table C-1: Comparison of temperature readings from the data acquisition system (DAQ) and NIST-certified Fluke data Logger for test chamber

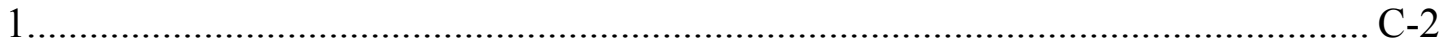

Table C-2: Comparison of temperature readings from the DAQ and NIST-certified Fluke data Logger for test chamber 2 ................................... C-2

Table C-3: Comparison of temperature readings from the DAQ and

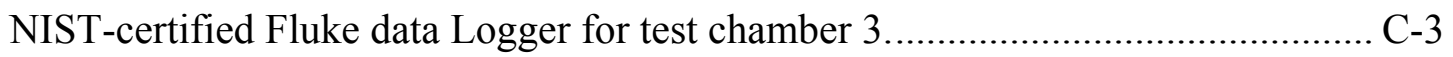

Table C-4: Equations for the actual temperature as a function of the measured DAQ temperature and uncertainties at 95\% confidence. C-5

Table C-5: Number of measurements excluded from error calculation due to mis-timing of the two power measurement tools C-8 
Table C-6: Error in instantaneous power reading (in watts) between the Data Acquisition System and the NIST-certified Hioki Digital Power Analyzers before and after applying a filter eliminating low power values. C-11

Table C-7: Error in instantaneous power reading (in watts) between the Data Acquisition System and the NIST-certified Hioki Digital Power Analyzers for the combined data measured during the testing of spas $\mathrm{B}, \mathrm{C}, \mathrm{M}, \mathrm{R}, \mathrm{U}$, and $\mathrm{V}$

Table C-8: Uncertainty in the allowable standby power for all twentyseven spas measured.

Table D-1: Energy and power lost for various volumes of liquid water escaping through evaporation during 72-hour test. D-1

Table D-2: Calculation of spa external surface area, A, and the ratio of the surface area to the volume raised to the $2 / 3$ power. D-3

Table D-3: J-Type thermocouple voltage for temperatures ranging from $46.4^{\circ} \mathrm{F} \quad\left(8^{\circ} \mathrm{C}\right)$ to $105.8^{\circ} \mathrm{F} \quad\left(41^{\circ} \mathrm{C}\right)$ (Omega Engineering, Inc., Thermocouples). D-5 


\section{List of Figures}

Figure 1: Simple diagram of typical portable electric spa components........................ 4

Figure 2: Photo showing the front of the insulated test chambers used in

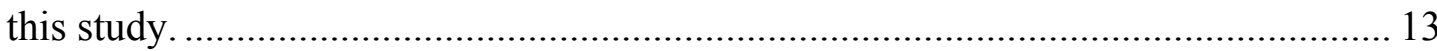

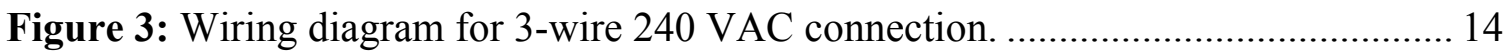

Figure 4: Wiring diagram for 4-wire $240 \mathrm{VAC}$ connection. ..................................... 15

Figure 5: Wiring diagram for 6-wire $240 \mathrm{VAC}$ connection. ...................................... 16

Figure 6: Location of J-type thermocouples for primary and secondary

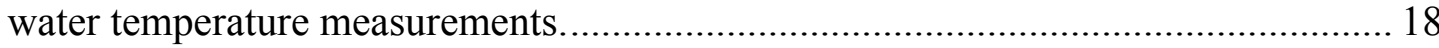

Figure 7: Photo of the computer used for data collection with the Balboa

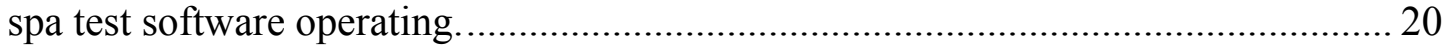

Figure 8: Block diagram of the power measurement system.................................. 21

Figure 9: Block diagram of the temperature measurement system. …........................ 21

Figure 10: Example of non-physical fluctuations and the adjusted curve.................... 23

Figure 11: Measured standby power compared with CEC allowable

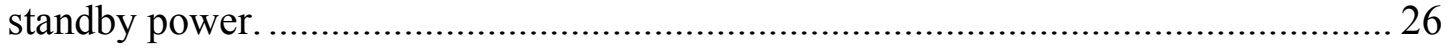

Figure 12: Plots of the water and air temperature profiles for two spas for a portion of their respective tests.

Figure 13: Plot of the standby power for the tested spas normalized using

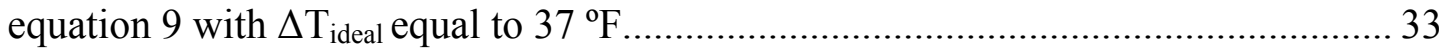

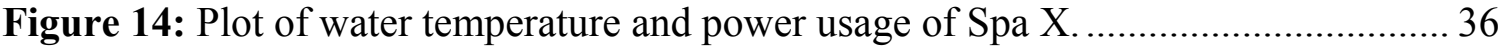


Figure 15: One dimensional heat transfer model of cooling of hot tub with exterior surface area "A", insulation thermal conductivity " $\mathrm{k}$ ", and average insulation thickness " $\mathrm{x}$ ". 43

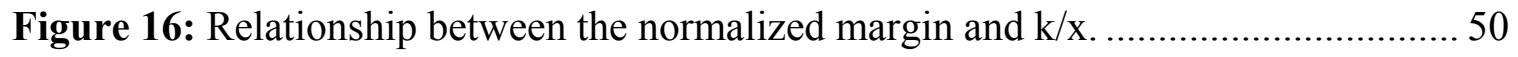

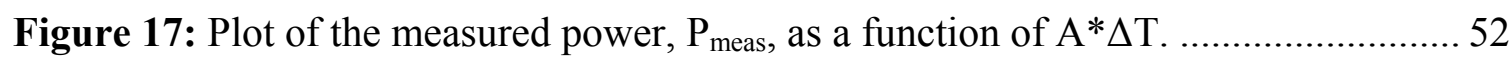

Figure A-1: Photo showing the front of the insulated test chambers used in this study A-2

Figure A-2: Photo showing the rear of the test chambers with the LG air conditioners installed.

Figure A-3: Air Conditioner built-in thermistor with $100 \mathrm{k} \Omega$ resistor added in parallel. A-4

Figure A-4: Connecticut Electric ground fault circuit interrupter connected to test chamber one. A-5

Figure A-5: Accuracy curve of the DLJ75 bronze water meter. A-6

Figure A-6: ADAM 4019+ 8-Channel Analog Input Module as installed in one of the test chamber electrical boxes A-8

Figure A-7: Measurlogic DTS 300 Multi-Channel Power Meter as installed in one of the test chamber electrical boxes.

Figure A-8: One of the Fluke Hydra Series II Data Loggers used to verify the accuracy of the data acquisition system temperature measurements. A-11

Figure C-1: Examples of "synchronization errors" caused by delay between the measurement of the NST-certified Hioki digital power analyzers and DAQ during the testing of spa B C-7 
Figure D-1: Plot of J-type thermocouple voltage spanning the range of temperatures encountered during spa testing. ............................................. D-6 


\section{1) Introduction}

State and Federal energy standards for household appliances have been shown to improve appliance efficiency and to reduce the growth of per-capita energy consumption (Mufson, 2007). In 2006, the state of California extended efficiency standards to all-electric spas in an effort to promote energy conservation. These standards are embodied in a formula proposed by researchers and adopted by the California Energy Commission that regulates maximum average standby power usage of portable electric spas, which are not otherwise regulated by federal energy standards. The purpose of this thesis is to measure the actual performance of twenty-seven spas and to compare that performance to the proposed efficiency formula. These measurements help to assess if the proposed regulatory formula will be effective in reducing energy consumption. This report describes the test methodology, the results and recommendations for next steps.

\section{Background}

"Portable electric spas are pre-fabricated, self-contained electric spas or hot tubs, as opposed to 'in-ground' units (such as those attached to a pool), other permanently installed residential spas, public spas, or spas that are operated for medical treatment or physical therapy" (Davis Energy Group [DEG], 2004, p. 1). Portable electric spas are typically the largest electrical load in homes that have one (DEG, 2004). In 2004, the Davis Energy Group, under contract by Pacific Gas and Electric (PG\&E), published Analysis of Standards for Portable Electric Spas. The purpose of this report was to

document information and data helpful to the California Energy Commission (CEC) in 
the development of new standards for portable electric spas. The study's authors intended to develop a standard that would "require improvements to the lowest performing models, for which simple and cost effective improvements are readily available, without eliminating average and better performance products" (DEG, 2004, p. 14). In developing their standard, the authors acknowledged that the energy used by the spas is expected to be roughly proportional to the spa's surface area, but that "spa area" is not easily defined and there is no standard for measuring it. The spa volume, however, is a much simpler quantity to measure. Using dimensional analysis, the Davis Energy Group developed a standard that approximates surface area by raising the spa volume, $V$ (gallons), to the $2 / 3$ power (note that for a cube: Area $=$ Length $^{2}$ and Volume $=$ Length $^{3}$, so Volume ${ }^{2 / 3}=$ Area). The end result was a standard requiring that the standby power, $P$ (watts), of portable electric spas sold shall not be greater than the value determined by the equation:

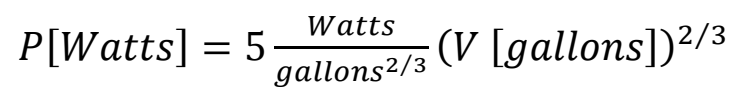

In this equation, standby power describes the average power used by the spa when the heated spa is operating but is covered and not in use. In this "standby" phase, energy is used only to maintain the spa's temperature and to keep the water mixed and filtered (DEG, 2004). This will be discussed further in later chapters.

After the approval of Title 20, several portable electric spa manufacturers expressed concerns and requested that the test procedure be refined and clarified. The Association of Pool and Spa Professionals (APSP), a trade association representing the pool and spa industry, began working as a technical consultant with PG\&E to develop revisions. With 
this in mind, in 2008 the APSP and PG\&E hired the National Pool Industry Research Center (NPIRC) at Cal Poly State University in San Luis Obispo, CA to evaluate the performance of 27 portable electric spas from various manufacturers and to document the spas' performance compared to this standard. The testing of these spas was carried out from June to September 2008. This report presents the tests performed, the results, and suggestions for improving low performing spas. 


\section{2) Portable Electric Spas}

"Portable electric spas are pre-fabricated, self-contained electric spas or hot tubs, as opposed to 'in-ground' units (such as those attached to a pool), other permanently installed residential spas, public spas, or spas that are operated for medical treatment or physical therapy" (DEG, 2004, p. 1). The term "portable" in referring to the spas represents the fact that the units are prefabricated and install quickly and easily, but is not meant to imply that the units are likely to be moved by the user.

\section{Spa Architecture}

Figure 1 provides a simple diagram of various typical spa components. These components are the shell, the cabinet, the cavity, the equipment enclosure, and the cover.

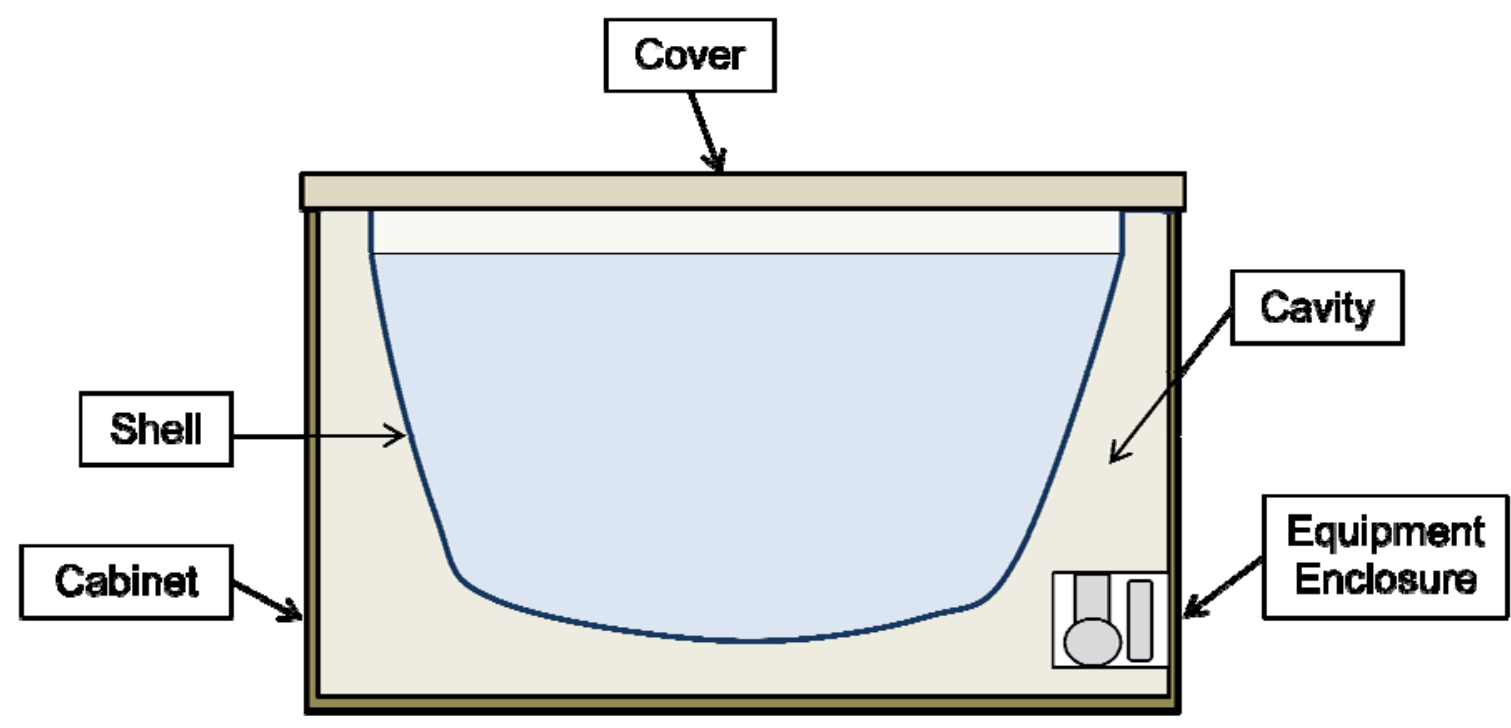

Figure 1: Simple diagram of typical portable electric spa components. 


\section{Shell, Cabinet, Cavity and Equipment Enclosure:}

The shell is the "tub" portion that will contain the water volume and is generally made of molded acrylic or fiberglass. The exterior cabinet is generally made of wood or a plastic. The cavity between the shell and the exterior cabinet is usually filled to some degree with foam or fiberglass insulation. Some manufacturers fill the entire cavity with insulation while others leave the cavity mostly empty and instead insulate the interior surface of the cabinet wall to create an insulated volume of warm air around the shell. The cavity also contains wood or metal structural supports and a network of plastic plumbing channeling water to the heater, filter, pumps and jets. Many spas have an equipment enclosure where the pumps, heater, and control electronics are housed. In some cases there is no defined enclosure, rather these components are placed somewhere within the cavity.

All spas evaluated in the study fit the description above with the exception of spas $\mathrm{K}, \mathrm{L}$ and $\mathrm{M}^{1}$. These spas are made entirely of a vinyl-covered foam shell. There is no external cabinet. The pump is housed in a separate, foam-insulated enclosure with insulated piping connecting it to the spa.

\section{Cover:}

Spa covers are typically made from closed cell foam (such as expanded polystyrene or rigid polyurethane) wrapped in vinyl. Covers generally have a hinge down the middle allowing the cover to be folded in half when opening. This hinge is usually one to two

\footnotetext{
${ }^{1}$ The twenty seven spas tested were each assigned a one or two-letter designation. These letter designations are used rather than manufacturer and model names throughout this paper when referring to specific spas.
} 
inches wide and may or may not be insulated, depending on the manufacturer. The perimeters of the covers usually have a two to three inch vinyl skirt which is meant to over-lap with the exterior cabinet and create a tight seal. When covered and operating, the air space between the water's surface and the cover become saturated with warm water vapor. The seal is meant to prevent this water vapor from escaping. A theoretical analysis of water evaporation suggests that $9 \mathrm{MJ}$ of energy are lost for every gallon of water that escapes during the 72-hour standby test. This results in an average increase in standby power of 35 watts per gallon lost over the 72-hour test (see calculations in Appendix D), indicating that the seal performance contributes significantly to the overall efficiency of the spa.

\section{Heating System:}

Most of spas in the current study use an electrical resistance heater to heat and maintain the water temperature. The heaters in this study ranged from 850 watts to over 4000 watts. Spas K, L and M are exceptions to this and use the heat generated by the pumps to heat the water without using a standalone heater. According to the Davis Energy Group, over half of the energy consumed by a typical spa during its lifetime is due to heating (2004).

\section{Pumping System:}

The pumping system contains one or more centrifugal pumps and is used to circulate and filter the water as well as supply water to the jets during use. Most spa models have high 
speed or multi-speed pumps for the jets, and these pumps may also be used for the filtration and circulation functions. Other spa models use separate, small pumps for filtration and circulation.

\section{Energy Use}

In general, portable electric hot tubs use energy in three different modes: startup, standby, and use. Startup describes the period when the spa is initially filled with water and that water is brought up to the set temperature. In the case of the spas in the study, the startup period took anywhere from five to over twenty-four hours for the water to be warmed to the test temperature of $102{ }^{\circ} \mathrm{F}^{2}$. Because of this long startup time, most portable electric spas are usually kept in standby mode.

Standby mode describes the time when the heated spa is operating but not in use. During the time the cover is on and comfort features like the jets are turned off. In standby mode, energy is used to maintain the water temperature and to circulate and filter the water. Standby mode represents approximately $75 \%$ of the spa's lifetime energy use, and is therefore considered representative of the spa's efficiency (DEG, 2004).

Use mode describes the time when the cover is off and the spa is occupied. Jets and other power consuming features are generally used in this mode. Power consumption during

${ }^{2} 102{ }^{\circ} \mathrm{F}$ was selected because this is the test temperature required by Title 20 . In addition, $102{ }^{\circ} \mathrm{F}$ represents a typical temperature at which a consumer might keep their portable electric hot tub. 
this mode is higher than during standby, but only lasts for a short amount of time - the Davis Energy Group study assumes one hour per day (2004). 


\section{3) Regulation of Portable Electric Spas}

Recognizing the need to conserve resources, the California Energy Commission has chosen to regulate portable electric spas, which are not otherwise regulated by Federal Energy Standards. This decision is logical since spas are typically the largest energyconsuming appliance in households that have one (DEG, 2004). The CEC accepted a recommendation by the Davis Energy Group for the regulation to focus just on standby use. This section will first provide the exact legal definition of the regulation and the legal definition of the required test procedure to measure compliance. It will then discuss the scientific basis for the regulation.

\section{Legal Definition of the California Electric Portable Spas Energy Regulation and Test Procedure}

The California Energy Commission defines the standby Power requirement in California Code of Regulations, Title 20. Public utilities and energy, Division 2. State Energy Resources Conservation and Development Commission, as follows:

$\S$ 1605.3. State Standards for Non-Federally-Regulated Appliances.

(g) Pool Heaters, Residential Pool Pumps, and Portable Electric Spas.

(6) Portable Electric Spas.

The standby power of portable electric spas manufactured on or after January 1, 2006, shall be not greater than $5\left(\mathrm{~V}^{2 / 3}\right)$ watts where $\mathrm{V}=$ the total volume, in gallons (p. 234). 
The California Energy Commission defines the required test procedure to measure the standby power of portable electric spas in California Code of Regulations, Title 20. Public utilities and energy, Division 2. State Energy Resources Conservation and Development Commission, as follows:

$\S 1604$. Test Methods for Specific Appliances.

(g) Pool Heaters, Portable Electric Spas, and Residential Pool Pumps.

(2) Test Method for Portable Electric Spas

The test method for portable electric spas is as follows:

Minimum continuous testing time shall be 72 hours.

The water temperature shall remain at or above the test temperature of $102^{\circ} \mathrm{F}$ for the duration of the test.

The ambient air temperature shall remain at or below the test temperature of $60^{\circ} \mathrm{F}$ for the duration of the test.

The standard cover that comes with the unit shall be used during the test.

The test shall start when the water temperature has been at $102^{\circ} \mathrm{F}$ for at least four hours.

Record the total energy use for the period of test, starting at the end of the first heating cycle after the four hour stabilization period, and finishing at the end of the first heating cycle after 72 hours has elapsed.

The unit shall remain covered and in the default operation mode during the test. Energy-conserving circulation functions, if present, must not be enabled if not appropriate for continuous, long-term use. 
Data reported shall include: spa identification (make, model, $\mathrm{S} / \mathrm{N}$, specifications); volume of the unit in gallons; cover R-value; supply voltage; average relative humidity during test; minimum, maximum, and average water temperatures during test; minimum, maximum, and average ambient air temperatures during test; date of test; length of test ( $\mathrm{t}$, in hours); total energy use during the test $(\mathrm{P}$, in Wh); and standby power (P/t, in watts) (pp. 189-190).

\section{Discussion of the portable electric spas regulation}

As stated above, the Title 20 standard requires that a portable electric spa's standby power must be less than or equal to the standby power determined by Equation 1 .

$$
\left.P[\text { Watts }]=5 \frac{\text { Watts }_{\text {gallons }}^{2 / 3}}{\text { g }}[\text { gallons }]\right)^{2 / 3}
$$

Heat transfer increases proportionally with the surface area of a body. Since the largest driver for spa energy usage is due to heating (stated by DEG and demonstrated later in Analysis) it follows that a power regulation based on the surface area would be most useful. The Davis Energy Group found that the spa surface area "is not easily defined and there is no standard for measuring it" (2004, p. 11), so they developed Equation 1 as a way to set a "maximum standby [power] indexed to total spa surface area" (p. 11), which “increases linearly with total spa surface area" (p.11). 


\section{4) Test Procedure}

Twenty-seven portable electric spas were tested following the test procedure Portable Electric Spa Stand-by Energy Test Protocol, Draft \#10 (Association of Pool and Spa Professionals [APSP], 2008b). For each test the spa was operated in standby mode with the water temperature at $102^{\circ} \mathrm{F}$ or above, and the surrounding air temperature maintained at or below $60^{\circ} \mathrm{F}$. Each test lasted a minimum of 72 hours, with the beginning and ending of each test determined from the criteria specified in the test procedure.

\section{Test Chamber Setup}

For conducting the tests, three insulated test chambers were built. A photograph of the front view of the chambers is shown in Figure 2. The dimensions of each chamber were $10 \mathrm{ft}$ by $10 \mathrm{ft}$ by $8 \mathrm{ft}$ tall. The chamber structures were framed using $1 \mathrm{x} 4$ boards, and the walls, floors, and ceilings were made from 2 inch thick polyisocyanurate commercial insulation sheathing with aluminum foil radiant barriers on each side. DOW TUFF-R commercial insulation sheathing (R-13) and RMax Thermasheath-3 (R-12.9) were both used. In addition, the floor insulation was covered in $1 / 2$ " thick ACX plywood to protect the insulation and provide a smooth surface for the spas to be placed on. Each chamber was equipped with a window air conditioner to control the chamber air temperature. The air conditioners were modified to achieve lower temperatures. The details of this are discussed in the Equipment section in Appendix A. 


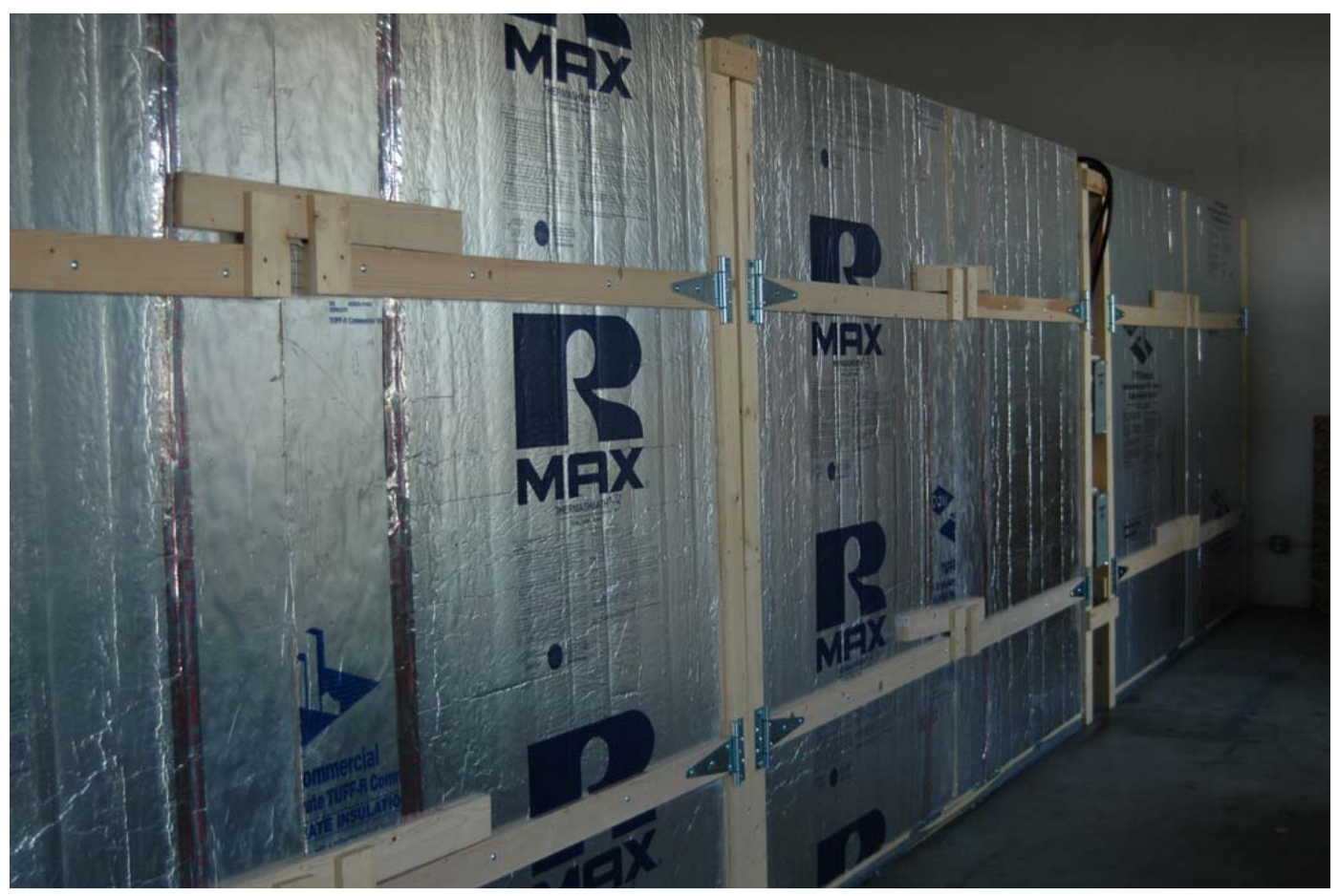

Figure 2: Photo showing the front of the insulated test chambers used in this study. From right to left the chambers are numbered chamber one, two and three.

Each chamber was set up with a dedicated $240 \mathrm{~V}$ electrical supply wired through a ground fault circuit interrupter (GFCI) panel. Safety standards require the use of ground fault circuit interrupters with portable electric hot tubs. If an electric short to ground is detected, the GFCI shuts off power to the circuit. From the GFCI, the spa could be connected to 120 VAC power through a standard 3-prong connection, or connected to 240 VAC power using a 3-, 4-, or 6-wire connection as described in Figures 3, 4 and 5. 


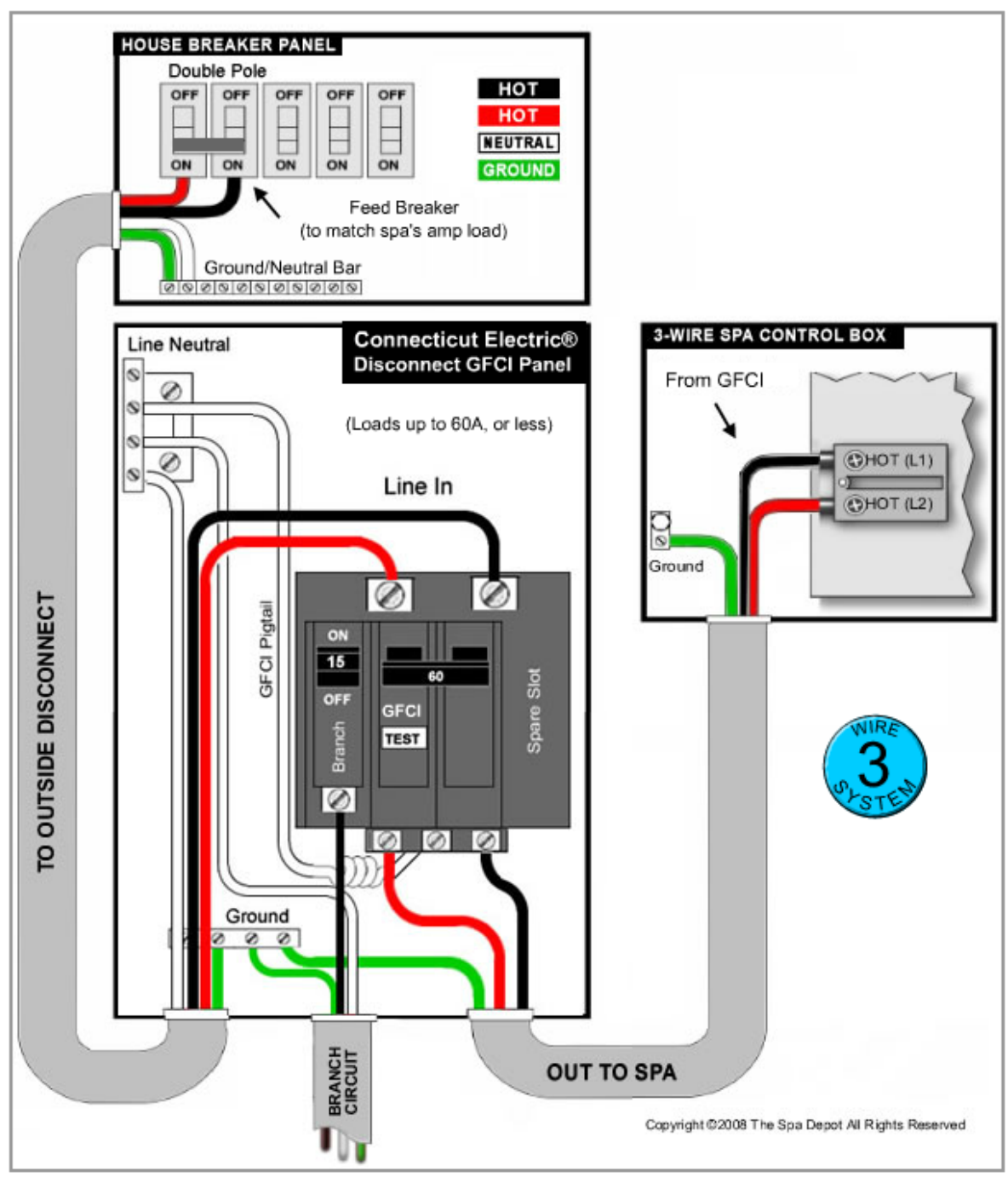

Figure 3: Wiring diagram for 3-wire 240 VAC connection. The two "hot" wires (red and black) each carry 120 volts and are phased 180 degrees apart. Together they supply 240 volts. The green wire is the ground which carries no current except when a short circuit to ground occurs, causing the circuit breaker to trip. Image from Hot tub wiring diagram. http://www.spadepot.com/spacyclopedia/wiring-hot-tub-spa.htm. Copyright 2008 by The Spa Depot. Used with permission. 


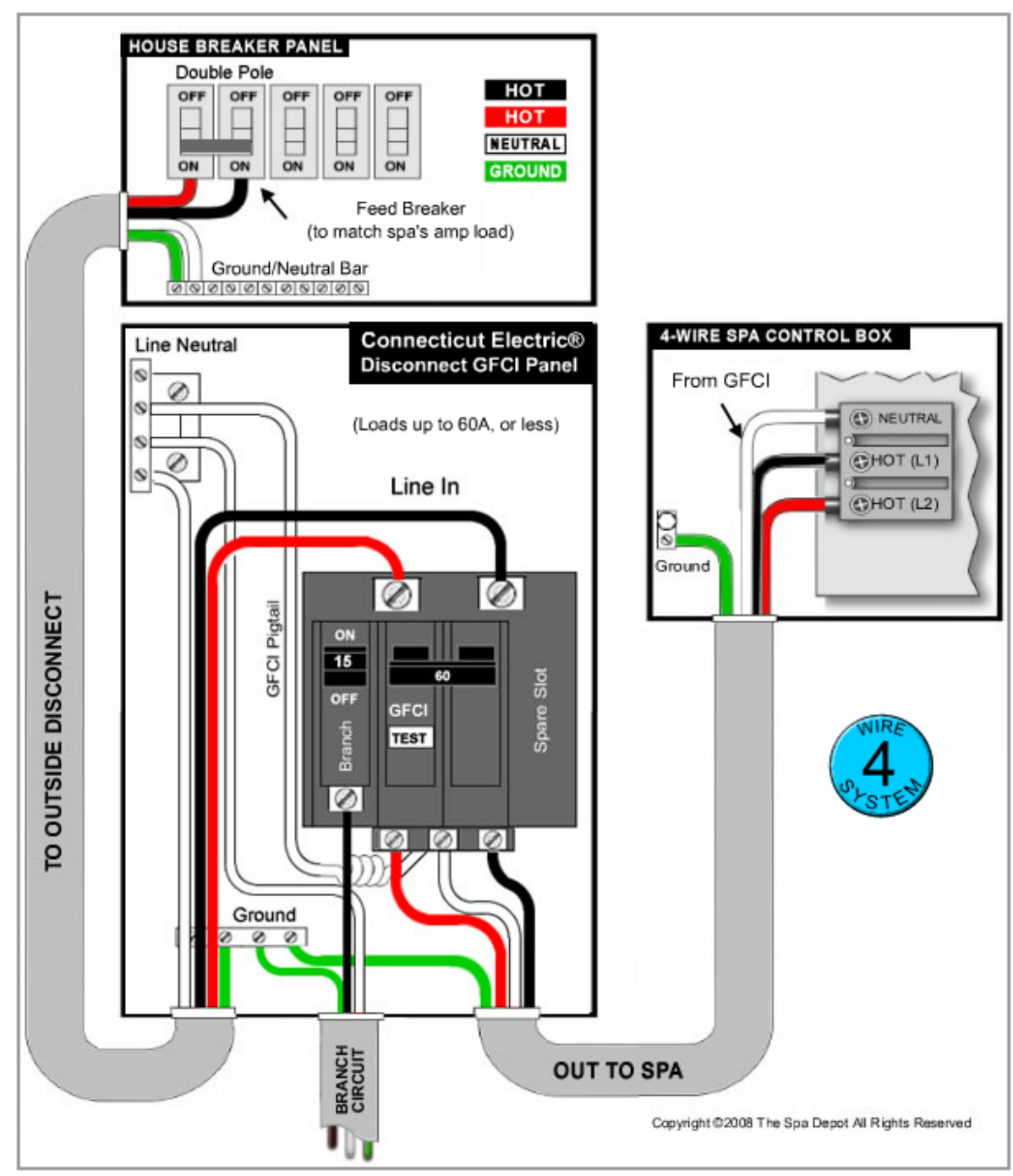

Figure 4: Wiring diagram for 4-wire 240 VAC connection. The two "hot" wires (red and black) each carry 120 volts and are phased 180 degrees apart. Together they supply 240 volts. The combination of one "hot" wire and the neutral (white) wire provides 120 volts. The ground wire (green) carries no current except when a short circuit to ground occurs, causing the circuit breaker to trip. Image from Hot tub wiring diagram. http://www.spadepot.com/spacyclopedia/wiring-hot-tub-spa.htm. Copyright 2008 by The Spa Depot. Used with permission. 


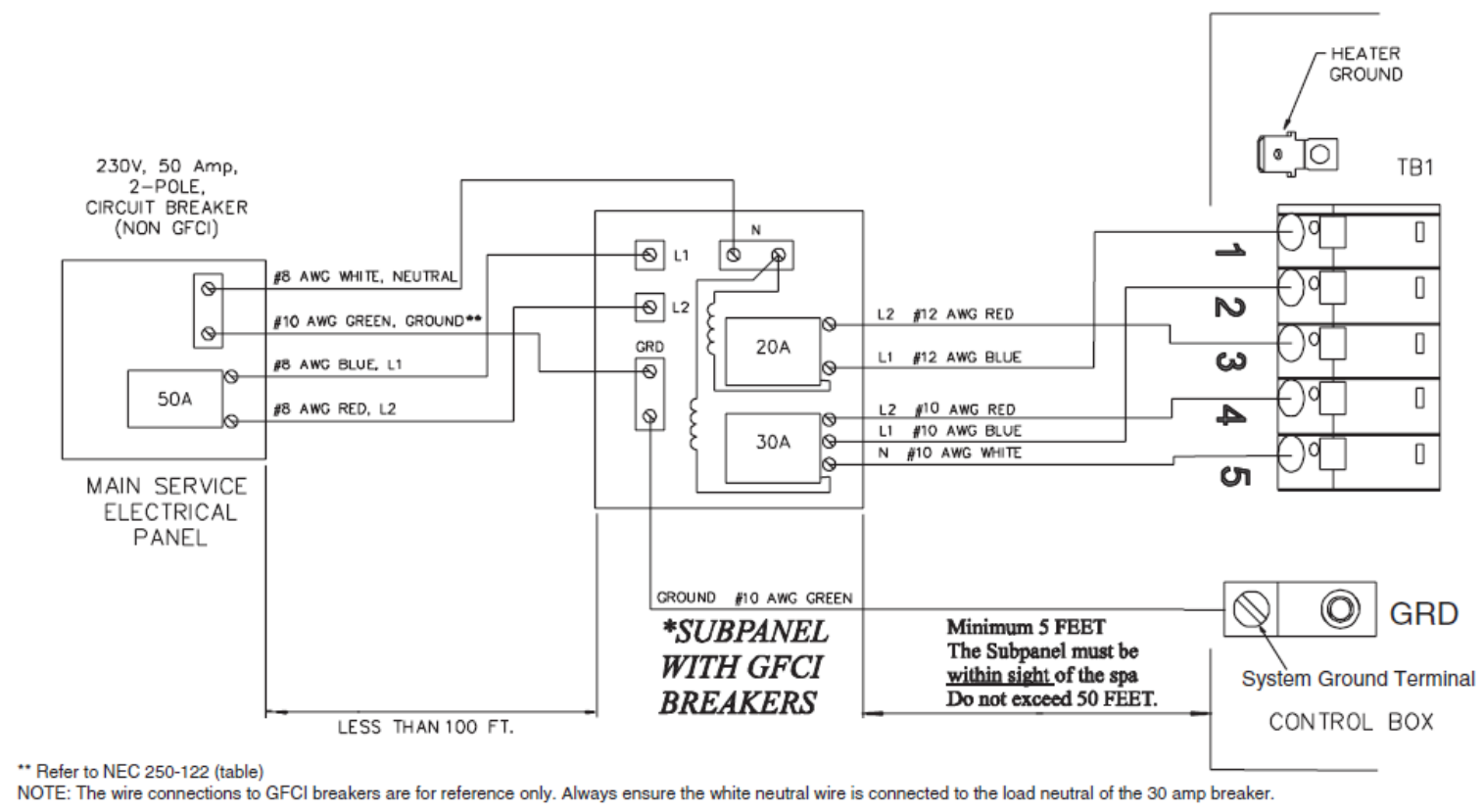

Figure 5: Wiring diagram for 6-wire 240 VAC connection. This configuration is like the four-wire setup, except two separate GFCl breakers are used. In this setup, one GFCl powers the heater while a second GFCl powers the pumps and accessories. This wiring configuration was unique to spa W and required the standard GFCl subpanel to be replaced with a subpanel supplied by the manufacturer. Image from Owner's manual, HotSpring portable spas. Copyright 2007 by Watkins Manufacturing Corporation.

\section{Spa Placement and Electrical Connection}

The spas were placed inside the test chamber centered with at least one foot of space between the spa and the chamber wall on every side. For safety, electrical power was disconnected from the chamber at the GFCI while the spa was electrically connected using the required configuration described above.

\section{Spa Startup}

Spas were filled to the level recommended by the manufacturer supplied literature. Using a hose fitted with a Daniel L. Jerman Co. DLJ75 bronze water meter, the spa was filled to the desired level and the volume of water, in gallons, was recorded. This is the tested 
volume, V, used for the calculation of the allowable standby power in Equation 1. Once the spa was filled, the GFCI was reset to supply power to the spa, and the pumps were primed and started using the procedure described in each spa's owner's manual. Using the control panel, the spa temperature was set to $102^{\circ} \mathrm{F}$.

\section{Thermocouple Placement}

Two $\mathrm{J}$ type thermocouples were used to measure the spa water temperature, and a third $\mathrm{J}$ type thermocouple was used to measure the chamber air temperature. The water thermocouples were inserted in holes in a Styrofoam float measuring approximately one foot by one foot and four inches thick that floated at the surface of the water. The primary thermocouple was located in the center of the foam with the second (redundant) thermocouple located between 3 to 6 inches away. The ends of the thermocouples sank between 5-6 inches below the water surface. The Styrofoam float was fixed in place with the main thermocouple either 1 foot away from the skimmer opening or approximately in the center of the spa if the spa did not have a skimmer. The Styrofoam was held in place by attaching string to the float and using duct tape to secure the end of the string to the outside surface of the spa. This arrangement is shown in Figure 6. 


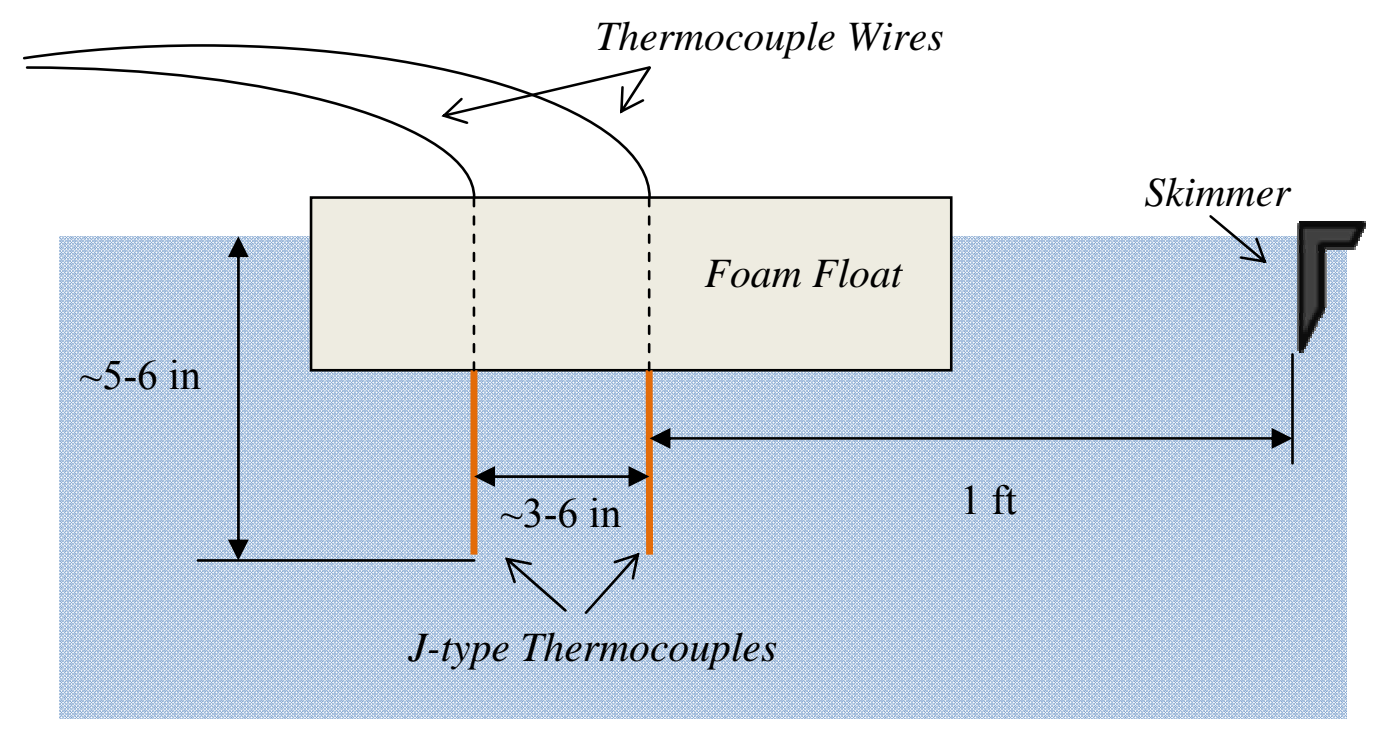

Figure 6: Location of J-type thermocouples for primary and secondary water temperature measurements. The primary thermocouple was located approximately one foot away from the skimmer opening or at approximately the center of the spa if it did not have a skimmer.

The air temperature thermocouple was hung from the ceiling of the test chamber so that the end of the thermocouple hung between 1 and 1.5 feet above the surface of the spa cover and approximately 6 inches from the wall of the chamber. The thermocouple was also wrapped with a paper cone to reduce direct airflow on the thermocouple, maintaining roughly static air conditions immediately around the thermocouple.

Once the spa was turned on and heating to the $102^{\circ} \mathrm{F}$ set point, the chamber air conditioner was turned on and the test chamber was closed. Once the temperature of the spa stabilized, if the water temperature dropped below $102^{\circ} \mathrm{F}$ or rose significantly above this value the spa water set point was adjusted until the water stabilized to a temperature near $102{ }^{\circ} \mathrm{F}$ without dropping below this value. Likewise, if the air temperature rose above $60{ }^{\circ} \mathrm{F}$, the chamber air set point was adjusted until it maintained a temperature near 
but not above $60^{\circ} \mathrm{F}$. The fan on the air conditioner was set to run continuously, so that air was constantly circulated within the test chamber.

\section{Testing}

Spa test software developed by Balboa Instruments was used to record the power and temperature data. This software simultaneously monitored this data for each of the three test chambers and saved the data for each chamber into a tab-delimited text file once per minute. The software is further described in the equipment section of Appendix A.

Recording of power and temperature data using the Balboa spa test software (see Figure 7) began once the temperatures reached the desired range. After starting to record this data, the doors of the test chamber remained closed until after the test had finished. After the spa and air temperatures had been stable for four hours, the end of the first filter cycle, purge cycle, or heat cycle marked the beginning of the 72 hour test period. The test period continued until the end of the first filter cycle, purge cycle, or heat cycle that began at least 72 hours after the beginning of the test period. In most cases the test was run for at least one more cycle after the test period could be considered finished. Data recording stopped upon test completion. 


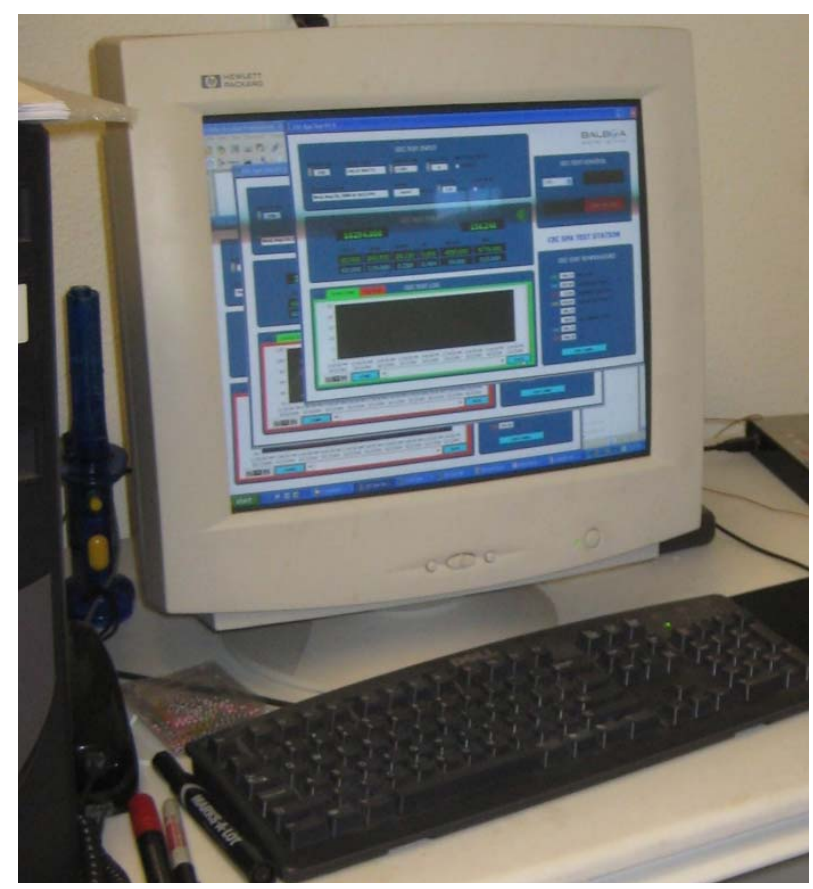

Figure 7: Photo of the computer used for data collection with the Balboa spa test software operating.

\section{Total Spa Capacity}

After test completion the power to the spa was shut off at the GFCI, and the total water capacity of the spa was measured. With the water meter connected to the hose the spa was filled with additional water until the spa was on the verge of over-flowing and spilling onto the floor. The number of gallons added was recorded. The total spa capacity was determined by adding the number of gallons added to the tested volume. To determine the total spa capacity it was assumed that the amount of water lost to evaporation during the test period was negligible. Since the spas remained fitted with the manufacturer-supplied cover during the test, this assumption is justified.

In practice, the total spa capacity is not a useful volume. This volume does not reflect the volume of water during use, nor does it generally reflect the volume of water specified by 
the manufacture's literature. Nevertheless, measurement of this quantity was required by the test procedure, so the quantity was measured and recorded for each spa.

\section{Recorded Data}

During each test, the voltage, current, power factor, power and temperature readings were recorded once every minute by the data acquisition system and saved to a tab-delimited text file. Block diagrams of the data acquisition are shown in

Figure 8 and Figure 9. The components of the data acquisition system are further described in Appendix A.

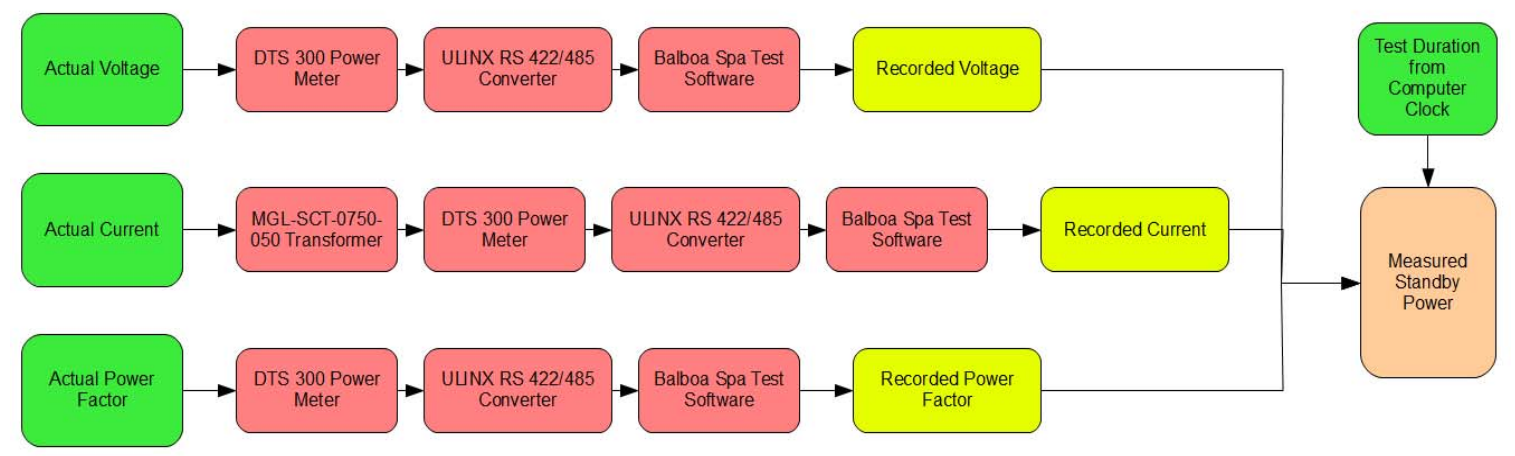

Figure 8: Block diagram of the power measurement system. Arrows indicate the flow of data. More details of each component of the system can be found in Appendix A.

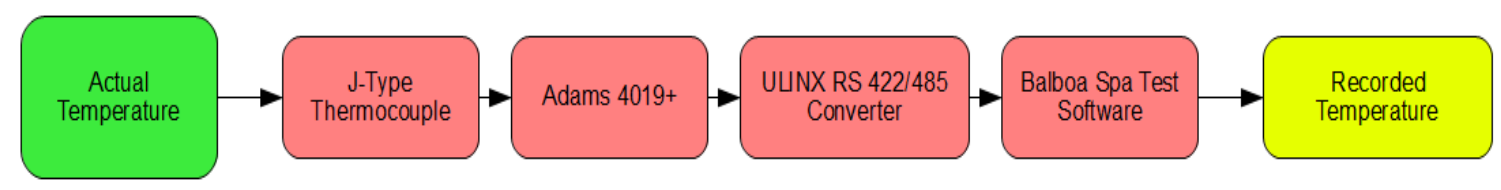

Figure 9: Block diagram of the temperature measurement system. Arrows indicate the flow of data. More details of each component of the system can be found in Appendix A.

The power factor is defined as the ratio of real power to the load over the apparent power in the circuit. The apparent power is the product of the current and the voltage of the 
circuit, and the real power is the power available in the circuit to do work. Only the real power is considered in measuring the standby power.

For analysis purposes, the actual temperature of the complete volume of water in the spa was assumed to be equal to the temperature measured by the primary water temperature thermocouple. Similarly, the temperature of the entire volume of air within the chamber was assumed to be equal to the temperature recorded by the air temperature thermocouple.

\section{Data Analysis - Temperature}

\section{Non-Physical Fluctuations}

The recorded spa and air temperature measurements fluctuated rapidly. Generally, the magnitude of these fluctuations was small (fractions of a degree Fahrenheit per minute) and could be explained physically by fluctuations in the fluid temperature immediately around the thermocouples. In some cases the magnitudes of the fluctuations were quite large, too large to represent a physical change-for instance, a sudden drop of several degrees Fahrenheit in one minute followed by a sudden climb of a similar magnitude the next minute. 


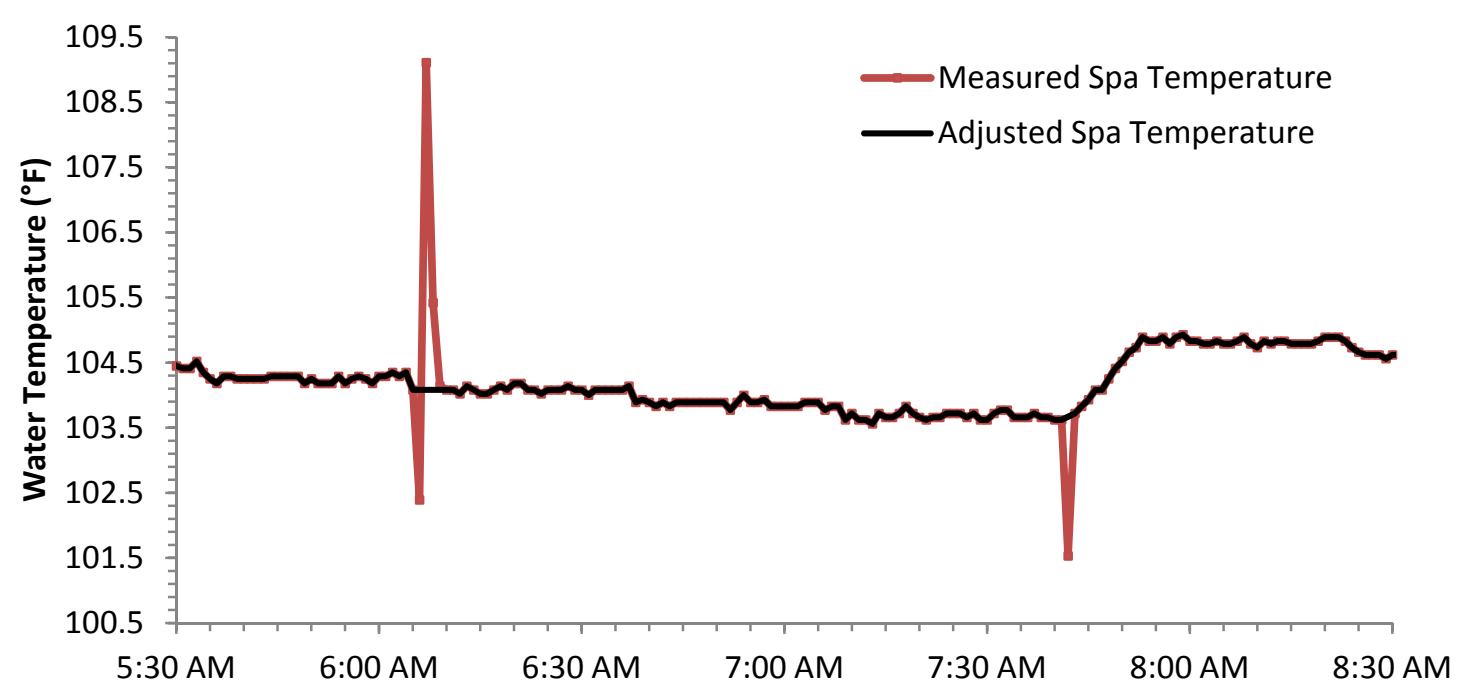

Figure 10: Example of non-physical fluctuations and the adjusted curve. This plot shows a sample of the spa water temperature measured during testing of Spa Y.

These non-physical fluctuations in recorded temperature were considered erroneous, so the data were adjusted to remove them. To adjust for these readings, the erroneous values were changed to the mean of the temperatures for the readings before and after the fluctuation. For all the spas tested, less than one percent of the temperature measurements were adjusted, and therefore the adjustments do not have a significant effect on the accuracy of the results. In addition, the test protocol required that a reading be taken only once every four minutes (APSP, 2008b), so, with four times the required sampling rate, up to $75 \%$ of the measure values could be discarded while still meeting the specified requirements. 


\section{Maximum, Minimum and Average Temperatures}

With the erroneous readings removed, the maximum, minimum and average (mean) temperatures were determined for the chamber air temperature and the spa water temperature.

\section{Data Analysis - Power}

The Balboa spa test software used in this study only recorded the instantaneous power to within \pm 10 watts, despite the fact that the resolution of the equipment is much greater than that. This did not give the type of resolution that was desirable. The measured readings of voltage, current and power factor were captured with better resolution, so instead of using the recorded power, the power was calculated using the equation

$$
P_{i}=V_{i} * I_{i} * P F_{i}
$$

where $P_{i}$ is the power for a particular reading, $i$, in watts, and $V_{i}, I_{i}$, and $P F_{i}$ are the voltage, current, and power factor for that same reading. Assuming that the power remained constant in between each reading, the energy consumption associated with a particular reading was determined from the equation

$$
E_{i}[\text { watt }- \text { hour }]=\frac{P_{i}[\mathrm{watt}] * 1 \mathrm{~min}}{60[\mathrm{~min} / \mathrm{hr}]}
$$

Where $E_{i}$ is the energy consumption associated with the measured power in watt-hours. The average standby power during the test was then determined from the equation

$$
P_{\text {standby }}[\text { watts }]=\frac{\sum_{i=1}^{n} E_{i}[\text { watt }- \text { hours }]}{\text { Duration }[\text { hours }]}=\frac{\sum_{i=1}^{n} E_{i}[\text { watt }- \text { hours }]}{\frac{n[\text { samples }]}{60[\text { samples } / \text { hour }]}}
$$


Where $P_{\text {standby }}$ is the measured standby power in watts, and $n$ is the total number of points (or samples) in the test period collected at one minute intervals.

Once the measured standby power has been determined, a comparison can be made between the measured standby power and the allowable standby power, calculated using Equation 1 from before

$$
\left.P[\text { Watts }]=5 \frac{\text { Watts }_{\text {gallons }}^{2 / 3}}{\text { V }^{2}}[\text { gallons }]\right)^{2 / 3}
$$

Where $P_{\text {allow }}$ is the allowable standby power based on the tested volume, and $V$ is the volume of water used during the test, in gallons.

\section{Deviations from Required Test Procedure}

Deviations occurred between the procedure as it was performed and the procedure required by Title 20. The primary deviations only pertain to the recorded spa identification data, which did not affect the determination of the measured standby power. The spa serial number and specifications were not recorded, and for many cases the R-value of the cover was not available from the manufacturer. In addition, the relative humidity was not measured and recorded during the test. This would have been an interesting quantity to have available in assessing the results, but is not a critical measurement since the calculation of the measured standby power is not dependent on it. 


\section{5) Results}

A summary of the initial results for each spa tested is presented in Table 1 and Figure 11 below. More detailed results for each spa, including plots of the water temperature and power usage can be found in Appendix E. For each spa, a smoothed curve for the water temperature is also plotted. The smoothed curve was achieved with three passes of a sliding average applied to the spa temperature data with a smoothing width of 15 points. The Matlab function "fastsmooth.m” was used for this (O’Haver, 2008).

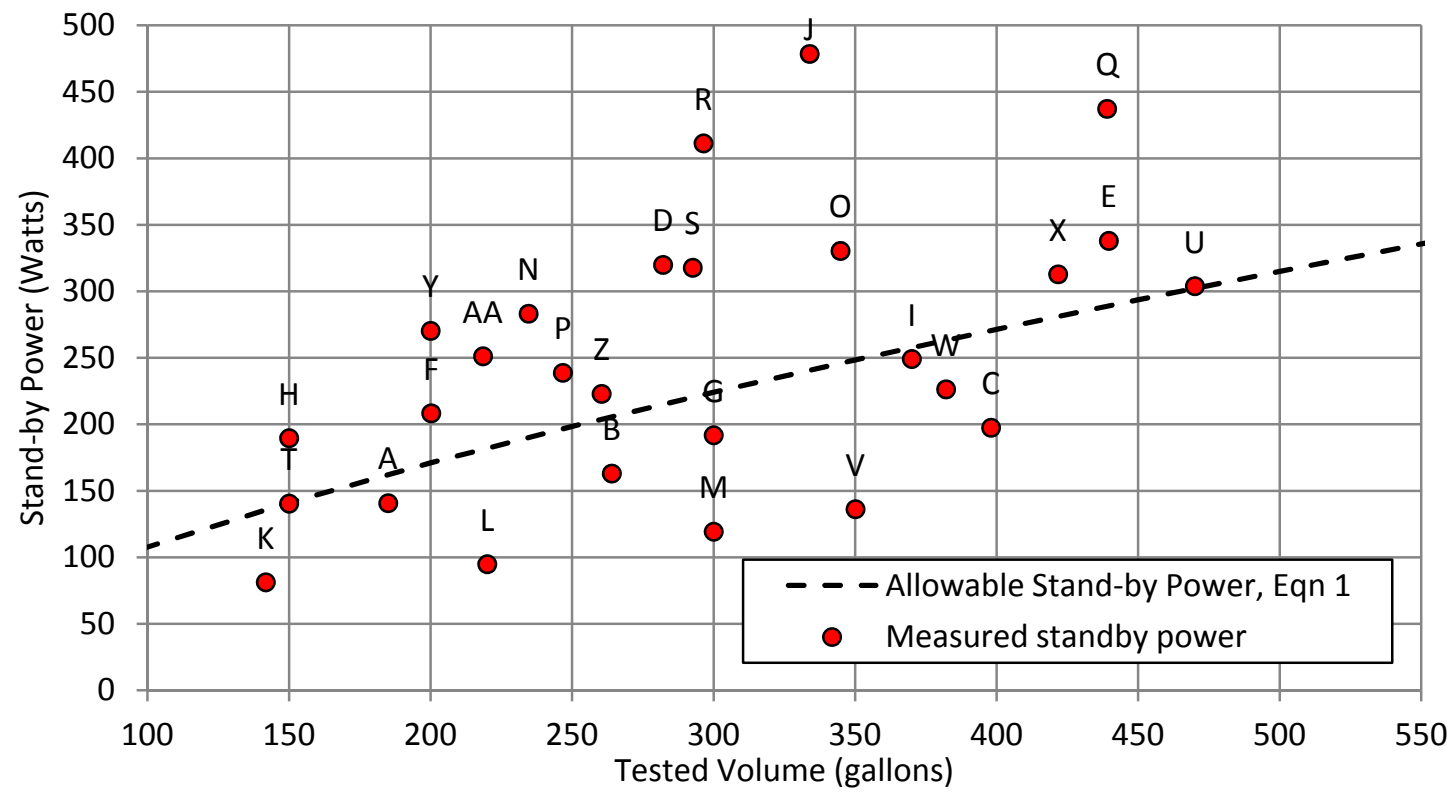

Figure 11: Measured standby power compared with the allowable standby power from Equation 1.

In Table 1 below, margin is defined using the equation

$$
\text { Margin }=\frac{P_{\text {meas }}-P_{\text {allow }}}{P_{\text {allow }}} \cdot 100 \%
$$

where $\mathrm{P}_{\text {meas }}$ is the measured standby power in watts and $\mathrm{P}_{\mathrm{allow}}$ is the allowable standby power in watts (determined from Equation 1). A positive margin means that the measured standby power is greater than the standby power allowed by Title 20 . 
Table 1: Summary of test results. The rightmost column lists the percent difference between the measured and the allowable standby power.

\begin{tabular}{|c|c|c|c|c|}
\hline Spa & $\begin{array}{c}\text { Tested } \\
\text { Volume }^{3} \text { (gal) }\end{array}$ & $\begin{array}{l}\text { Standby Pc } \\
\text { Measured }^{4}\end{array}$ & $\begin{array}{c}\text { wer (watts) } \\
\text { Allowable }\end{array}$ & Margin \\
\hline$A$ & 185 & 141 & 162 & $-13 \%$ \\
\hline B & 264 & 163 & 206 & $-21 \%$ \\
\hline C & 398 & 197 & 271 & $-27 \%$ \\
\hline D & 282 & 320 & 215 & $49 \%$ \\
\hline$E$ & 440 & 338 & 289 & $17 \%$ \\
\hline$F$ & 200 & 208 & 171 & $22 \%$ \\
\hline G & 300 & 192 & 224 & $-14 \%$ \\
\hline $\mathrm{H}$ & 150 & 190 & 141 & $34 \%$ \\
\hline 1 & 370 & 249 & 258 & $-3 \%$ \\
\hline$J$ & 334 & 479 & 241 & $99 \%$ \\
\hline K & 142 & 81 & 136 & $-40 \%$ \\
\hline L & 220 & 95 & 182 & $-48 \%$ \\
\hline M & 300 & 119 & 224 & $-47 \%$ \\
\hline $\mathrm{N}$ & 235 & 283 & 190 & $49 \%$ \\
\hline $\mathrm{O}$ & 345 & 330 & 246 & $34 \%$ \\
\hline$P$ & 247 & 239 & 197 & $21 \%$ \\
\hline Q & 439 & 437 & 289 & $51 \%$ \\
\hline $\mathrm{R}$ & 296 & 411 & 222 & $85 \%$ \\
\hline$S$ & 293 & 318 & 220 & $44 \%$ \\
\hline $\mathrm{T}$ & 150 & 140 & 141 & $0 \%$ \\
\hline$U$ & 470 & 304 & 302 & $1 \%$ \\
\hline V & 350 & 136 & 248 & $-45 \%$ \\
\hline W & 382 & 226 & 263 & $-14 \%$ \\
\hline$x$ & 422 & 313 & 281 & $11 \%$ \\
\hline Y & 200 & 270 & 171 & $58 \%$ \\
\hline Z & 260 & 223 & 204 & $9 \%$ \\
\hline AA & 219 & 251 & 181 & $38 \%$ \\
\hline
\end{tabular}

${ }^{3}$ The tolerance of the tested volume is \pm 0.14 gallons.

${ }^{4}$ The tolerance of the measured standby power is $\pm \frac{\sqrt{2}}{v^{1 / 3}}$ watts (maximum error is $\pm 0.27 \mathrm{~W}$ ). 


\section{6) Results: Temperature Normalization}

While testing was under way we noticed significant swings between the maximum and minimum temperatures of the spa water and the chamber air temperature. In general, the control systems for water heaters and air conditioners are unable to maintain the temperature at a single, fixed value. Instead the systems operate until a certain target temperature is reached and then shut down until the temperature drifts outside some programmed tolerance. Ideally, the systems would operate such that these tolerances are very small, but this did not always turn out to be the case.

During testing, the largest swing from minimum water temperature to maximum water temperature was approximately $3^{\circ} \mathrm{F}$. The swings in chamber air temperature were more pronounced with the mean swing in the air temperature during a test being $6.6^{\circ} \mathrm{F}$ and the maximum swing in air temperature being $9.5^{\circ} \mathrm{F}$. The temperature swings during the testing of two spas are displayed in Figure 12. 

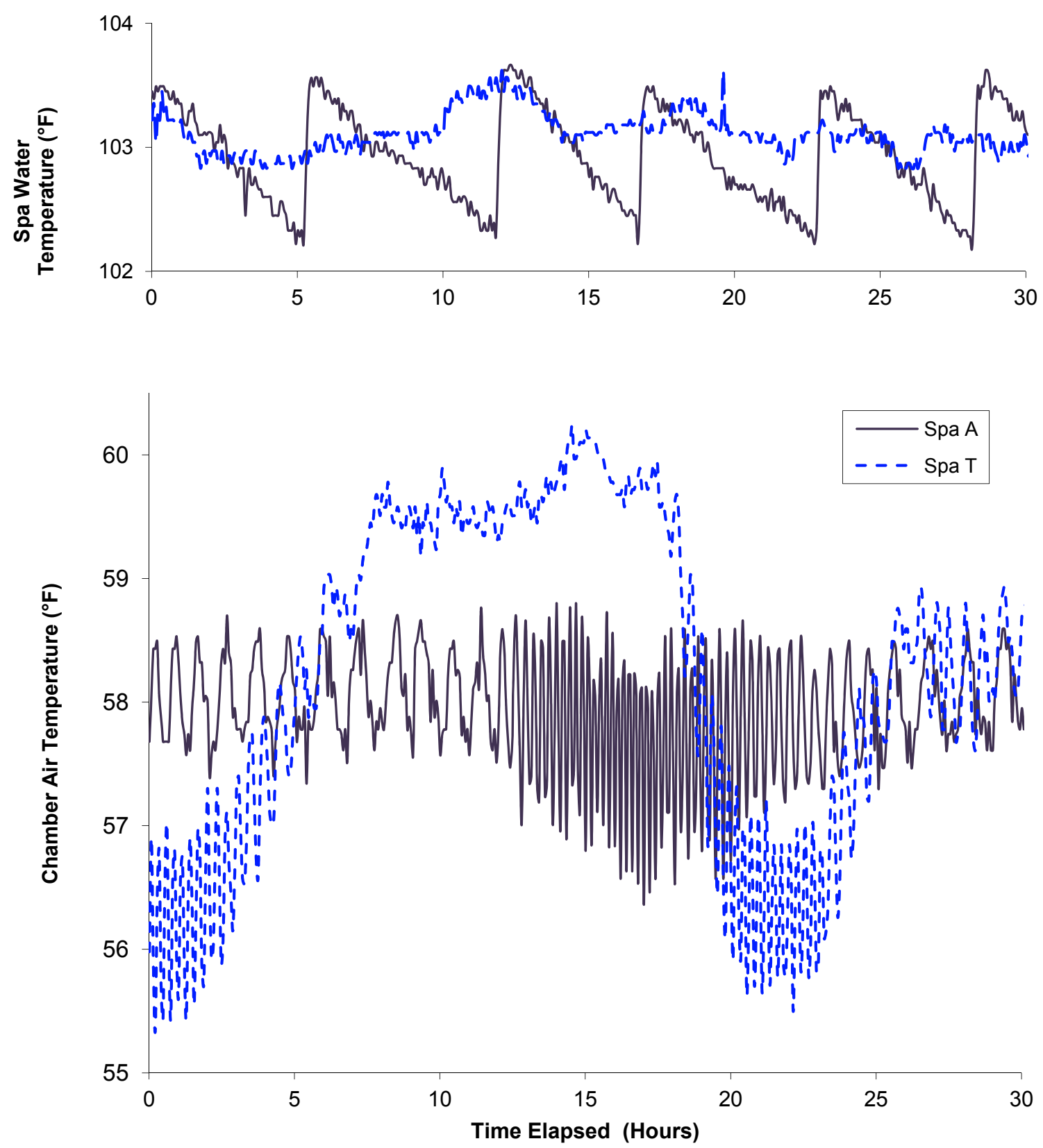

Figure 12: Plots of the water and air temperature profiles for two spas for a portion of their respective tests. Notice the significant differences between the temperature profiles of each test.

The values of the mean air and water temperatures also varied between tests. The mean water temperature remained relatively close to the target value of $102{ }^{\circ} \mathrm{F}$ and only varied between tests by about two degrees Fahrenheit - from the target value of $102{ }^{\circ} \mathrm{F}$ to about $104^{\circ} \mathrm{F}$. The mean chamber air temperature, on the other hand, fell significantly below the 
target value of $60{ }^{\circ} \mathrm{F}$ - to as low as $52{ }^{\circ} \mathrm{F}$ on average during one test - and ranged from $52{ }^{\circ} \mathrm{F}$ to $58^{\circ} \mathrm{F}$ between all the tests.

These deviations in temperature combine to result in the total difference between the mean chamber air temperature and mean spa water temperature for the tests ranging from $44{ }^{\circ} \mathrm{F}$ to $51{ }^{\circ} \mathrm{F}$. This is a difference of $5 \%$ to $21 \%$ above the nominal temperature difference of $42{ }^{\circ} \mathrm{F}$. Some deviation is to be expected from the measurement of water temperature since different spas can be expected to perform differently; however, such changes in average chamber air temperature are unexpected since the same three chambers were used for each test.

This behavior brought to light limitations in the climate control equipment used in the chambers, which (as mentioned in Appendix A) were commercial window air conditioners that had been modified to operate at lower temperatures. These limitations are important because the heat lost from each spa increases as the difference between the water and the chamber temperatures increases. The equations for the rates of heat transfer per unit area for heat transfer by conduction, convection, and radiation are given by Equations 6, 7, and 8, respectively. In the case of the spa testing, heat is lost by the spa to the chamber through a combination of these three modes.

$$
\begin{aligned}
& q_{\text {cond }}^{\prime \prime}=k \frac{T_{s 1}-T_{s 2}}{L} \\
& q_{\text {conv }}^{\prime \prime}=h\left(T_{s}-T_{\infty}\right) \\
& q^{\prime \prime}{ }_{\text {rad }}=\varepsilon \sigma\left(T_{s}^{4}-T_{\text {sur }}^{4}\right)
\end{aligned}
$$


Since such significant deviations in the temperature difference are present, it is important that the measured temperature difference be taken into account for the spas to be judged consistently, and to ensure that no spa "fails" merely because the temperature difference during the test was different than the ideal conditions.

As a result of this concern, we developed a normalization using the average temperature difference which the APSP and PG\&E have discussed applying to the standby power. Something like this technique is discussed in the Davis Energy Group's CASE report, where some test data were "normalized to $60^{\circ} \mathrm{F}$ average outdoor temperature" (DEG, 2004, p. 8), but the specifics of the normalization used by the Davis Energy Group are not further discussed. For the normalization in this study, the following equation is to be used:

$$
P_{\text {norm }}=P_{\text {meas }} \frac{\Delta T_{\text {ideal }}}{\Delta T_{\text {meas }}}
$$

where $\Delta T_{\text {ideal }}$ is an idealized temperature difference between the water and ambient temperatures, $\Delta T_{\text {meas }}$ is the measured temperature difference, and $P_{\text {meas }}$ is the measured standby power.

A value of $37^{\circ} \mathrm{F}$ has been selected for the value of $\Delta T_{\text {ideal }}$. This value is based on updated temperature tolerances for the air and water temperatures that were proposed in the CEC Staff Report "2008 Appliance Efficiency Rulemaking” (California Energy Commission [CEC], 2008). The test protocol used in the current study specifies that the water temperature must be maintained at $102{ }^{\circ} \mathrm{F}$ or above, and the air temperature must be maintained at $60^{\circ} \mathrm{F}$ or below. 
As of 2009, revisions made to Title 20 have changed these temperature requirements. Additionally, the revisions require the use of the temperature normalization equation (Equation 9 above). For future testing the water temperature is to be maintained at $102 \pm$ $2^{\circ} \mathrm{F}$, and the chamber air temperature is to be maintained at $60 \pm 3^{\circ} \mathrm{F}$ (CEC, 2009). With these tolerances adopted the minimum allowable temperature difference is $37^{\circ} \mathrm{F}$. A summary of the results for each spa with this normalization applied are presented in Table 2 and Figure 13 below. The "Normalized Margin" in the table is defined using the equation

$$
\text { Normalized Margin }=\frac{P_{\text {norm }}-P_{\text {allow }}}{P_{\text {allow }}} \cdot 100 \%
$$

Where $\mathrm{P}_{\text {norm }}$ is the normalized standby power in watts and $\mathrm{P}_{\text {allow }}$ is the allowable standby power in watts (determined from Equation 1). A positive normalized margin means that the normalized standby power is greater than the standby power allowed by Title 20 .

Table 2: Summary of test results with power normalized using Equation 9 with $\Delta \boldsymbol{T}_{\text {ideal }}$ equal to 37 ${ }^{\circ} \mathrm{F}$.

\begin{tabular}{c|c|c|c|c|c|} 
Spa & \multicolumn{2}{c}{$\begin{array}{c}\text { Standlby Power } \\
\text { [watt] }\end{array}$} & $\begin{array}{c}\Delta \boldsymbol{T} \\
\text { [w] }\end{array}$ & $\begin{array}{c}\text { Normalized } \\
\text { Power } \\
\text { [watt] }\end{array}$ & $\begin{array}{c}\text { Normalized } \\
\text { Margin }\end{array}$ \\
\hline A & 141 & 162 & 44.9 & 116 & $-29 \%$ \\
B & 163 & 206 & 46.0 & 131 & $-36 \%$ \\
C & 197 & 271 & 47.3 & 154 & $-43 \%$ \\
D & 320 & 215 & 45.2 & 262 & $22 \%$ \\
E & 338 & 289 & 45.2 & 277 & $-4 \%$ \\
F & 208 & 171 & 46.8 & 165 & $-4 \%$ \\
G & 192 & 224 & 44.3 & 160 & $-28 \%$ \\
H & 190 & 141 & 51.2 & 137 & $-3 \%$ \\
I & 249 & 258 & 47.5 & 194 & $-25 \%$ \\
\hline
\end{tabular}

\footnotetext{
${ }^{5}$ The tolerance of the measured standby power is $\pm \frac{\sqrt{2}}{\mathrm{~V}^{1 / 3}}$ watts (maximum error is $\pm 0.27 \mathrm{~W}$ ).
} 


\begin{tabular}{|c|c|c|c|c|c|}
\hline Spa & $\begin{array}{r}\text { Standb } \\
\text { Measured }^{5}\end{array}$ & $\begin{array}{l}\text { Power } \\
\text { tt] } \\
\text { Allowable }\end{array}$ & $\begin{array}{c}\Delta T \\
{\left[{ }^{\circ} F\right]}\end{array}$ & $\begin{array}{c}\text { Normalized } \\
\text { Power } \\
\text { [watt] }\end{array}$ & $\begin{array}{c}\text { Normalized } \\
\text { Margin }\end{array}$ \\
\hline $\mathrm{J}$ & 479 & 241 & 49.6 & 357 & $48 \%$ \\
\hline K & 81 & 136 & 47.5 & 63 & $-53 \%$ \\
\hline L & 95 & 182 & 48.9 & 72 & $-61 \%$ \\
\hline $\mathrm{M}$ & 119 & 224 & 45.7 & 97 & $-57 \%$ \\
\hline $\mathrm{N}$ & 283 & 190 & 47.7 & 220 & $15 \%$ \\
\hline $\mathrm{O}$ & 330 & 246 & 47.7 & 256 & $4 \%$ \\
\hline$P$ & 239 & 197 & 46.1 & 192 & $-3 \%$ \\
\hline$Q$ & 437 & 289 & 49.0 & 330 & $14 \%$ \\
\hline $\mathrm{R}$ & 411 & 222 & 47.0 & 324 & $46 \%$ \\
\hline$S$ & 318 & 220 & 47.3 & 248 & $13 \%$ \\
\hline $\mathrm{T}$ & 140 & 141 & 45.6 & 114 & $-19 \%$ \\
\hline U & 304 & 302 & 46.0 & 244 & $-19 \%$ \\
\hline V & 136 & 248 & 48.1 & 105 & $-58 \%$ \\
\hline W & 226 & 263 & 46.2 & 181 & $-31 \%$ \\
\hline$X$ & 313 & 281 & 46.3 & 250 & $-11 \%$ \\
\hline$Y$ & 270 & 171 & 46.0 & 218 & $27 \%$ \\
\hline Z & 223 & 204 & 47.3 & 174 & $-14 \%$ \\
\hline $\mathrm{AA}$ & 251 & 181 & 47.1 & 198 & $9 \%$ \\
\hline
\end{tabular}

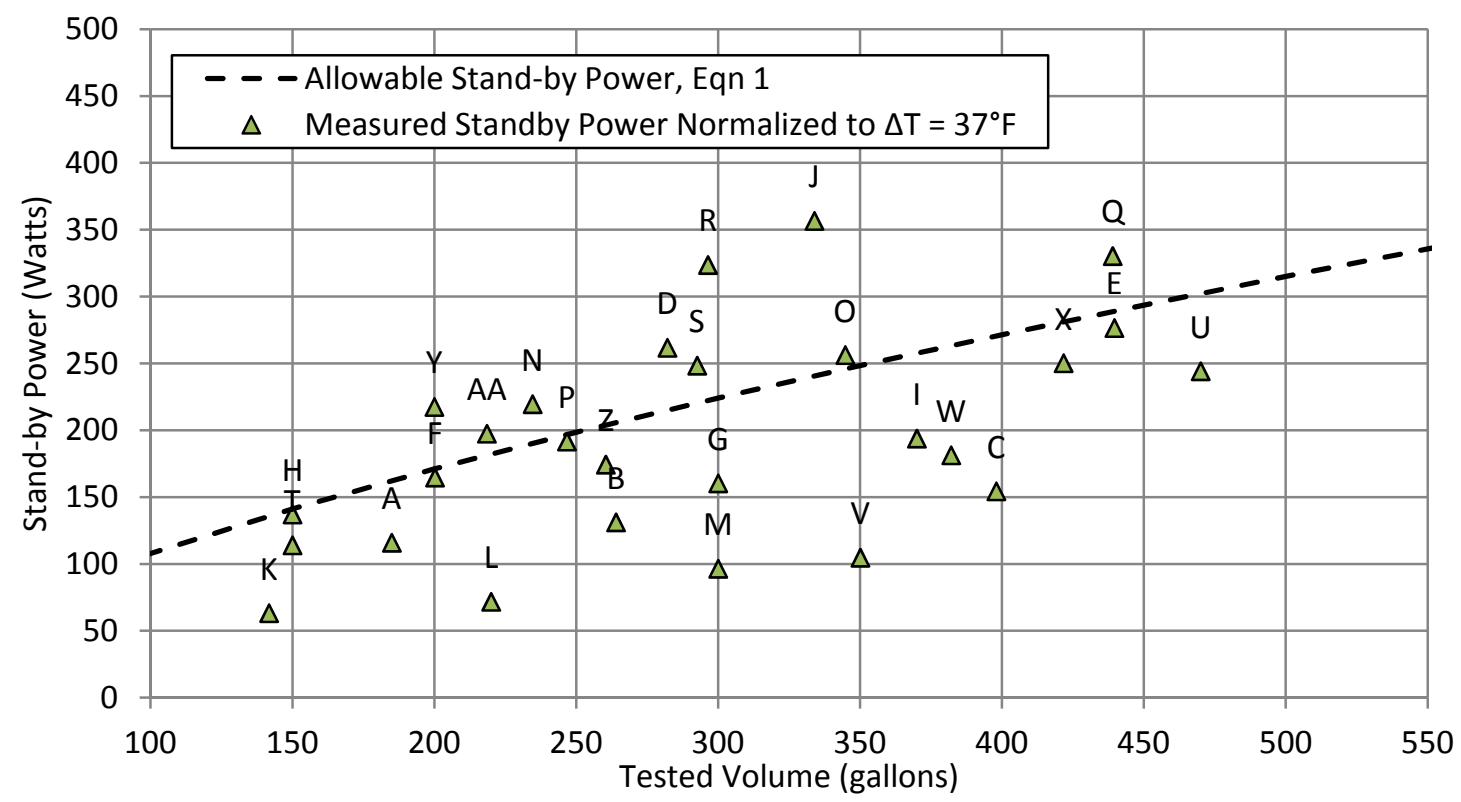

Figure 13: Plot of the standby power for the tested spas normalized using Equation 9 with $\Delta \boldsymbol{T}_{\text {ideal }}$ equal to $37^{\circ} \mathrm{F}$. 
This normalization is only an approximation based on the assumption that the heat loss (and therefore, to a large extent the power demand) is linearly proportional to the temperature difference. In the case of heat transfer by conduction and convection (see Equations 6 and 7 above), this is a fairly safe assumption. The rate of heat transfer by conduction is only a function of the temperature difference and the material and geometric properties. Likewise, the rate of heat transfer by convection is a function of the temperature difference and the heat transfer coefficient which depends on the geometric, fluid and flow properties. In both cases the fluid and material properties are functions of temperature as well, but they are generally weak functions of temperature, so for small temperature changes these dependencies can be ignored. Unlike these, the rate of heat transfer by radiation (see Equation 8 above) is a function of the difference of the temperatures to the fourth power. In addition, it is a function of the chamber wall temperature, not the chamber air temperature, which was not measured during testing. Because of this, the rate of energy lost by radiation cannot be assumed to be accurately represented with the current normalization. This normalization, then, inherently must assume that the relative effect of radiation is small compared to the other heat transfer modes.

Some evidence is available that linear normalization by temperature difference generally reflects the actual behavior. A 2004 study by the Alberta Research Council measured portable eight spas at room temperature $\left(19.5\right.$ to $\left.21^{\circ} \mathrm{C}\right)$ and at sub-freezing temperatures $\left(-11\right.$ to $\left.-14^{\circ} \mathrm{C}\right)$. In each test the water was between $40^{\circ} \mathrm{C}$ and $42^{\circ} \mathrm{C}$. Their study found that in the sub-freezing test (where the average temperature delta between the air and water 
was approximately 2.6 times greater than at room temperature) the average power of the spas increase by average factor of 2.7 - a linear effect (Advanced Material, Alberta Research Council, Inc., 2004). 
Hamill 36

\section{7) Analysis}

\section{Power Usage}

Plots of the water temperature and power usage for each spa are presented in Appendix E.

An example plot is presented in Figure 14 below.
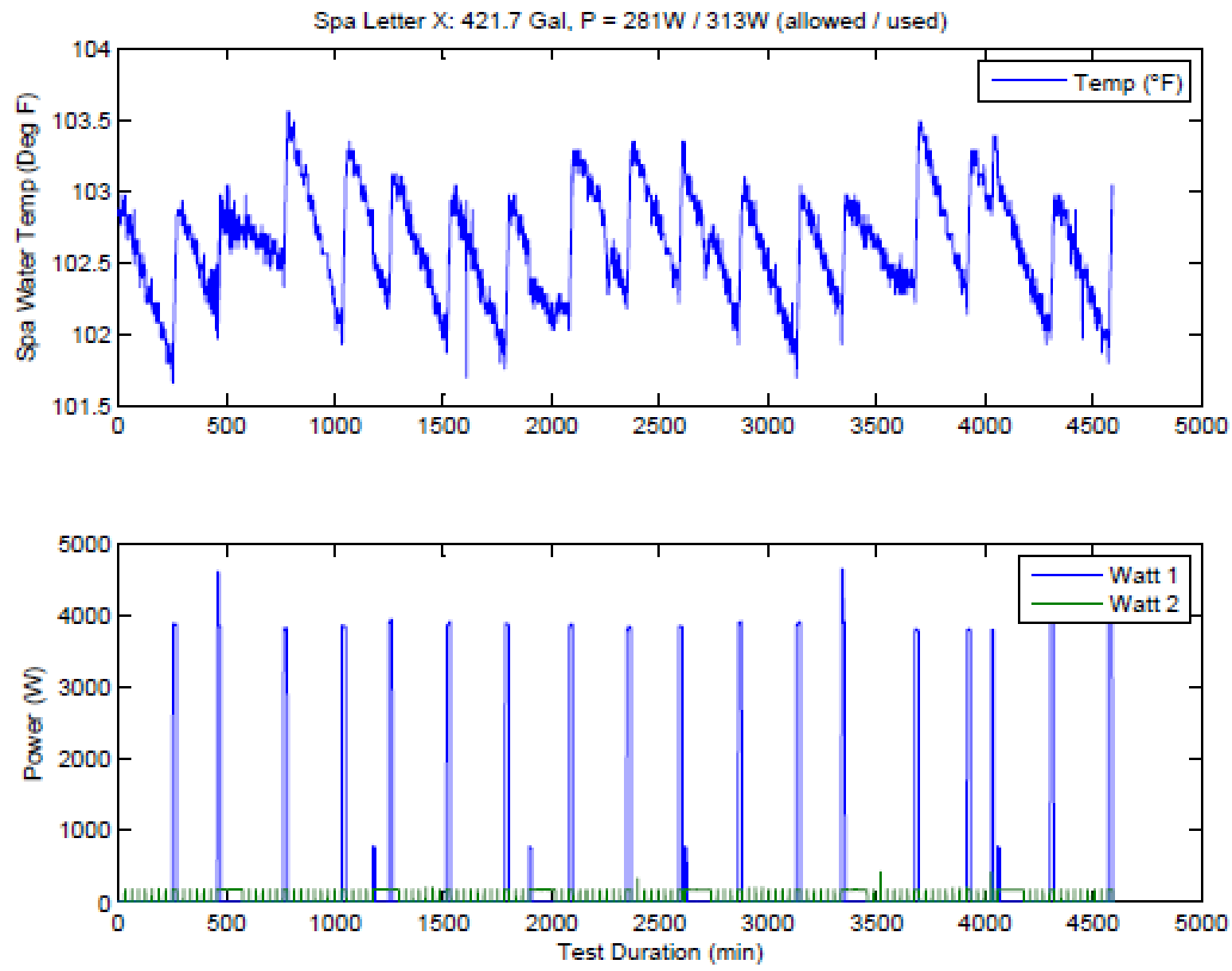

Figure 14: Plot of water temperature and power usage of Spa X. Similar plots for each spa are presented in Appendix E.

For each of the 27 portable electric spas tested, the power usage was examined and categorized into four groups based on the pattern of usage: "Heater Cycle", "Filtration 
Cycle", "Pulses", and "Constant Filtration". The total power used by the spa is the sum of these categories, or:

$$
P=P_{\text {Heater cycle }}+P_{\text {Filtration cycle }}+P_{\text {Pulses }}+P_{\text {Constant Filtration }}
$$

"Heater Cycle" - This describes the cycles with the greatest power demand. During these cycles the spa's heater (typically 1-4 kW) is in use along with the pumps ${ }^{6}$. These cycles typically run as needed when the temperature drops below the set point as opposed to at a set frequency and duration. The purpose of these cycles it to maintain the spa water temperature within the set range.

"Filtration Cycle" - This describes power cycles where the pumps are in use but not the heater. These cycles typically run on a set time schedule. The purpose of these cycles is to circulate water through the filters to maintain high water quality.

"Pulses" - This describes a power demand where the pumps frequently "pulse" on for a short duration (typically one to two minutes) before shutting off again. The purpose for these cycles is not clear though some possible benefits are:

- To circulate the water over the thermometer element to ensure an accurate reading of the average water temperature.

- To circulate warm water into the pipes in order to prevent possible freezing.

\footnotetext{
${ }^{6}$ In the case of spas $\mathrm{K}, \mathrm{L}$ and $\mathrm{M}$, there is no dedicated heater. Rather, these spas use the heat generated by the motor to warm the water. These cycles were still classified as "heater cycles" because the patterns of use are more like those of other heater cycles than filtration cycles.
} 
- To circulate the water in the pipes to prevent bacterial growth that can occur if left stagnant.

"Constant Filtration" - This describes a constant (or nearly constant) power demand indicative of a low power circulation pump running continuously. This pump will continuously circulate the water providing filtration and inhibiting bacterial growth.

The categorized power is presented in Table 3 below. For each category, the following are presented: the average power demand, $\mathrm{D}$, in watts; the average cycle duration, $\mathrm{t}$, in minutes; the average period of each cycle (the average time between the start of subsequent cycles), $\tau$, in minutes; and the resulting contribution to the standby power, $\mathrm{P}$, are presented. The contribution is determined by the equation

$$
P_{*}[\text { Watt }]=D_{*}[\text { Watt }] \cdot \frac{t_{*}[\mathrm{~min}]}{f_{*}[\mathrm{~min}]}
$$

Table 4 presents the approximate percentage that each type of power usage contributes to the total standby power. 
Table 3: Categorized power demands contributing to the total standby power.

\begin{tabular}{|c|c|c|c|c|c|c|c|c|c|c|c|c|c|c|c|c|c|c|c|c|c|c|c|c|c|c|}
\hline 5 & $N$ & $\prec$ & $\times$ & $\Sigma$ & $<$ & $\subset$ & -1 & $\omega$ & ס & 0 & D & 0 & $z$ & 3 & $r$ & $\pi$ & $c$ & - & I & Q & $\pi$ & $m$ & $\nabla$ & 0 & ( & $>\quad 0$ \\
\hline$\vec{\omega}$ & $\vec{N}$ & $\begin{array}{l}0 \\
0 \\
\text { N }\end{array}$ & $\begin{array}{l}0 \\
0 \\
N \\
N\end{array}$ & \begin{tabular}{|l}
$\omega$ \\
0 \\
$\delta$
\end{tabular} & $\underset{\vec{N}}{\vec{D}}$ & 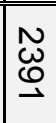 & $\begin{array}{l}\vec{\Theta} \\
\mathrm{E}\end{array}$ & 空 & రి & $\begin{array}{l}\omega \\
\vec{\sigma} \\
\text { ज }\end{array}$ & $\begin{array}{l}\omega \\
\stackrel{\vec{a}}{\sigma} \\
\end{array}$ & $\underset{\infty}{\omega}$ & $\stackrel{\omega}{\vec{\Delta}}$ & $\overrightarrow{\vec{D}}$ & $\vec{D}$ & $\overrightarrow{0}$ & $\mid \begin{array}{l}\overrightarrow{0} \\
\stackrel{+}{\omega} \\
\end{array}$ & $\stackrel{\vec{N}}{\omega}$ & $\begin{array}{l}\vec{\omega} \\
\vec{\infty}\end{array}$ & $\stackrel{N}{\vec{Z}}$ & $\begin{array}{l}N \\
\vec{G} \\
\text { V }\end{array}$ & $\mid \begin{array}{c}\vec{\omega} \\
\underline{\omega} \\
\underline{\underline{n}}\end{array}$ & N & $\begin{array}{l}0 \\
8 \\
8 \\
0\end{array}$ & \begin{tabular}{|l|l}
$\omega$ & $c$ \\
$\infty$ & $c$ \\
$\delta$ & $c$ \\
$\delta$ & $f$
\end{tabular} & 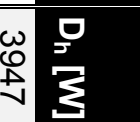 \\
\hline w & 8 & $\vec{N}$ & $\vec{v}$ & $\vec{\sigma}$ & $\stackrel{N}{A}$ & $\stackrel{N}{\longrightarrow}$ & or & $\vec{\omega}$ & $\overrightarrow{\vec{\Xi}}$ & 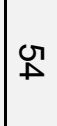 & $\stackrel{N}{A}$ & $\underset{\infty}{\infty}$ & $\vec{v}$ & $\vec{z}$ & $\stackrel{N}{\perp}$ & $v$ & $\mathbf{N}$ & $\vec{\infty}$ & $N$ & $\overrightarrow{0}$ & 0 & $\stackrel{N}{\triangle}$ & $\vec{\omega}$ & $\overrightarrow{0}$ & $\vec{D}$ & $\vec{\circ} \frac{\vec{s}}{\vec{z}}$ \\
\hline $\overrightarrow{8}$ & 京 & $\frac{N}{N}$ & ज्ञ & $\vec{J}$ & $\stackrel{2}{ \pm}$ & $\underset{\mathscr{W}}{\mathcal{U}}$ & Ñ & $\frac{\omega}{\infty}$ & $\begin{array}{l}N \\
0 \\
N\end{array}$ & 悎 & ज् & $\frac{\sigma}{\sigma}$ & 岕 & $\vec{N}$ & $|\vec{\omega}|$ & 8 & $\vec{\varphi}$ & N & \begin{tabular}{|l|}
$\tilde{W}$ \\
$\widetilde{G}$
\end{tabular} & 辛 & $\begin{array}{l}N \\
\text { O } \\
\perp\end{array}$ & $\begin{array}{l}\omega \\
O \\
O\end{array}$ & N & ज्ञ & $\begin{array}{ll}\omega & c \\
\mathscr{Q} & f \\
0 & f\end{array}$ & 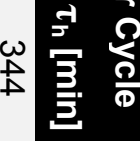 \\
\hline $\begin{array}{l}N \\
\vec{u} \\
0\end{array}$ & \begin{tabular}{|l|}
$\vec{\phi}$ \\
+ \\
$\dot{0}$
\end{tabular} & \begin{tabular}{|l}
$\vec{c}$ \\
ch \\
$\dot{\sigma}$
\end{tabular} & $\begin{array}{l}N \\
\omega \\
\tilde{N}\end{array}$ & $\begin{array}{l}\vec{\infty} \\
\stackrel{v}{v}\end{array}$ & $\begin{array}{l}\vec{\omega} \\
+\dot{\sigma} \\
\dot{\sigma}\end{array}$ & $\begin{array}{c}N \\
\vec{N} \\
6\end{array}$ & $\overrightarrow{\vec{\Xi}}$ & $\underset{\vec{D}}{\vec{D}}$ & $\begin{array}{l}0 \\
8 \\
0 \\
0\end{array}$ & $\begin{array}{l}\omega \\
\vec{v} \\
\overrightarrow{-}\end{array}$ & $\begin{array}{l}\overrightarrow{0} \\
0 \\
0\end{array}$ & $\overrightarrow{\vec{v}}$ & $\stackrel{\vec{v}}{\vec{v}}$ & \begin{tabular}{|l|}
$\overrightarrow{\vec{\omega}}$ \\
$\dot{\omega}$
\end{tabular} & $\begin{array}{l}\wp \\
+ \\
\infty\end{array}$ & $\frac{\infty}{\dot{\omega}}$ & 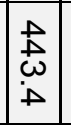 & $\begin{array}{l}\vec{N} \\
\text { or }\end{array}$ & $\begin{array}{c}\vec{N} \\
\dot{+} \\
0\end{array}$ & $\begin{array}{l}0 \\
\infty \\
\infty \\
\infty\end{array}$ & $\begin{array}{l}1 \\
0 \\
\dot{\sigma}\end{array}$ & $\mid \begin{array}{l}N \\
\mathcal{W} \\
\omega \\
\omega\end{array}$ & $\begin{array}{l}N \\
\text { O } \\
\text { or }\end{array}$ & $\begin{array}{l}\vec{N} \\
\stackrel{2}{0} \\
0\end{array}$ & \begin{tabular}{|l|l}
$\vec{\omega}$ & $\vec{f}$ \\
0 & $\vec{f}$ \\
0 & 0
\end{tabular} & 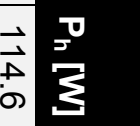 \\
\hline 今 & $\mid \begin{array}{l}0 \\
\infty \\
\text { cr }\end{array}$ & \begin{tabular}{|l|}
$\omega$ \\
$\mathscr{O}$ \\
$ठ$
\end{tabular} & $\stackrel{N}{\vec{V}}$ & ' & ' & $\vec{\sigma}$ & $\vec{\nabla}$ & 1 & ' & ฮั & $\begin{array}{l}0 \\
\mathbb{N} \\
\infty\end{array}$ & $\begin{array}{l}\omega \\
\pm \\
\forall\end{array}$ & \begin{tabular}{|l|}
$\tilde{\omega}$ \\
$\tilde{\omega}$
\end{tabular} & ' & ' & ' & $\overrightarrow{0}$ & $\mid \begin{array}{l}\omega \\
\mathscr{W} \\
\infty\end{array}$ & $\stackrel{\omega}{N}$ & ' & $\overrightarrow{\vec{N}}$ & $\mid \begin{array}{l}\overrightarrow{0} \\
\text { or }\end{array}$ & $\mid$\begin{tabular}{|l}
$\omega$ \\
$N$ \\
$\infty$
\end{tabular} & $\vec{\omega}$ & $\vec{\omega}$ & $\vec{\omega}$ \\
\hline 8 & 8 & $\vec{N}$ & $\vec{N}$ & ' & ' & N & $\vec{\omega}$ & 1 & ' & N & \& & \begin{tabular}{|l}
$\omega$ \\
g
\end{tabular} & 崖 & ' & ' & ' & $\overrightarrow{\mathrm{O}}$ & $\vec{O}$ & $\vec{N}$ & ' & $\mathcal{N}$ & $\vec{N}$ & $\overrightarrow{\mathrm{O}}$ & $\overrightarrow{\mathrm{O}}$ & $\overrightarrow{\mathrm{O}}$ & $\overrightarrow{\mathrm{N}}$ \\
\hline N & N & Nิ & N & ' & ' & $\overrightarrow{+}$ & $\vec{\infty}$ & ' & ' & N & Ñ & N & N & ' & ' & ' & N & N & N & ' & $\begin{array}{l}\omega \\
\delta \\
\delta\end{array}$ & N & N & N & N̦ & N \\
\hline$\stackrel{N}{N}$ & $\begin{array}{l}\tilde{N} \\
\omega \\
\infty\end{array}$ & $\begin{array}{l}9 \\
0 \\
0\end{array}$ & $\begin{array}{l}\omega \\
\Omega \\
i\end{array}$ & ' & & $\begin{array}{l}\infty \\
\infty \\
0 \\
0\end{array}$ & $\begin{array}{l}\vec{N} \\
\vdots \\
\square\end{array}$ & ' & ' & $\frac{N}{\dot{\omega}}$ & 吕 & $\vec{\omega}$ & $\frac{\vec{\omega}}{\vec{\sigma}}$ & ' & I & & $\left|\begin{array}{c}\omega \\
\omega \\
\tilde{N}\end{array}\right|$ & $\underset{\square}{\mathscr{D}}$ & \begin{tabular}{|l|}
$\sigma$ \\
$\omega$ \\
$G$
\end{tabular} & ' & $\mid \begin{array}{l}N \\
\infty \\
0 \\
0\end{array}$ & $\left|\begin{array}{c}0 \\
N \\
\sigma\end{array}\right|$ & $\begin{array}{l}0 \\
\pm \\
\dot{y}\end{array}$ & $\mid \begin{array}{l}N \\
N \\
0\end{array}$ & \begin{tabular}{l|l}
$N$ & $N$ \\
$\omega$ & $\underline{\sigma}$
\end{tabular} & N \\
\hline N & $\begin{array}{l}N \\
\infty \\
0\end{array}$ & \begin{tabular}{|l|}
$\omega$ \\
$\mathscr{O}$ \\
0
\end{tabular} & $\stackrel{\sim}{\vec{v}}$ & & ' & $\vec{\sigma}$ & ' & जे & $\vec{N}$ & $\overrightarrow{8}$ & ' & ' & ' & ' & ' & ' & $\overrightarrow{0}$ & \begin{tabular}{|l}
$\omega$ \\
0 \\
$\infty$
\end{tabular} & $\underset{N}{\omega}$ & $\vec{\omega}$ & $\overrightarrow{8}$ & $\begin{array}{l}\overrightarrow{0} \\
\text { ज्ञ }\end{array}$ & $\begin{array}{l}\underset{N}{N} \\
\infty\end{array}$ & $\vec{\omega}$ & 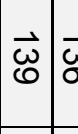 & $\vec{\omega} \stackrel{0}{\stackrel{\sigma}{\sigma}}$ \\
\hline$N$ & $N$ & $\rightarrow$ & $\rightarrow$ & 8 & ' & $\vec{a}$ & ' & 8 & 8 & 8 & ' & I & ' & 1 & ' & ' & $\rightarrow$ & $\rightarrow$ & $N$ & 8 & 8 & $\rightarrow$ & $\rightarrow$ & $\rightarrow$ & $\rightarrow$ & 3 \\
\hline$\omega^{\omega}$ & $\underset{N}{\omega}$ & $\stackrel{\omega}{\rightarrow}$ & $\stackrel{\omega}{\underline{\omega}}$ & ' & ' & ○ & ' & ' & ' & ' & ' & ' & ' & ' & ' & ' & $\stackrel{\omega}{\underline{\omega}}$ & $\stackrel{\omega}{\underline{\omega}}$ & $\underset{N}{N}$ & ' & ' & $\stackrel{\omega}{\underline{\omega}}$ & $\stackrel{\omega}{\rightarrow}$ & $\stackrel{\omega}{\underline{\omega}}$ & $\stackrel{\omega}{\underline{\omega}}$ & $\stackrel{\omega}{\stackrel{f}{\sigma}}$ \\
\hline $\begin{array}{l}\vec{\sigma} \\
\sigma\end{array}$ & $\begin{array}{l}\vec{v} \\
\infty\end{array}$ & $\begin{array}{l}\vec{N} \\
\sigma\end{array}$ & $\begin{array}{l}v \\
0\end{array}$ & $\mid \begin{array}{l}\omega \\
0 \\
0\end{array}$ & ' & $\begin{array}{l}\omega \\
\omega\end{array}$ & ' & जु & $\begin{array}{l}\vec{A} \\
\stackrel{N}{0}\end{array}$ & 용 & I & ' & ' & ' & I & ' & $\mid \begin{array}{l}\infty \\
\triangleright \\
\end{array}$ & $\begin{array}{l}\vec{N} \\
\infty\end{array}$ & 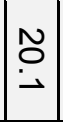 & $\mid \begin{array}{l}\vec{\omega} \\
\overrightarrow{0}\end{array}$ & $\begin{array}{l}\overrightarrow{8} \\
0\end{array}$ & $\vec{\sigma}$ & $\begin{array}{l}\overrightarrow{0} \\
\text { o̊ }\end{array}$ & $\overrightarrow{\dot{A}}$ & $\vec{c}$ & $\stackrel{0}{\frac{0}{3}}$ \\
\hline 心 & N & $\mid \begin{array}{l}\tilde{\omega} \\
\mid\end{array}$ & $\begin{array}{l}\omega \\
\vec{\sigma}\end{array}$ & N & $\vec{\omega}$ & 岂 & $\vec{D}$ & $\stackrel{\omega}{\infty}$ & $\stackrel{\oplus}{\vec{\Xi}}$ & $\vec{\omega}$ & $\tilde{\omega}$ & $\begin{array}{l}\omega \\
\text { ज } \\
\text { v }\end{array}$ & $\left|\begin{array}{l}N \\
\infty \\
\omega\end{array}\right|$ & $\overrightarrow{\overrightarrow{0}}$ & Or & $\stackrel{\infty}{\rightarrow}$ & $\begin{array}{l}+ \\
\infty \\
\omega\end{array}$ & N & $\overrightarrow{0}$ & $\overrightarrow{\mathrm{O}}$ & N & \begin{tabular}{|l}
$\omega$ \\
$N$ \\
$N$
\end{tabular} & $\left|\begin{array}{l}\omega \\
\vec{\sigma}\end{array}\right|$ & $\overrightarrow{0}$ & $\vec{\Omega}$ & Y \\
\hline or & $\begin{array}{l}N \\
N \\
\omega\end{array}$ & $\vec{J}$ & $\frac{\omega}{\omega}$ & N & $\vec{\omega}$ & 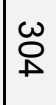 & $\vec{D}$ & $\frac{\omega}{\infty}$ & $\stackrel{\Delta}{\vec{\Delta}}$ & $\vec{\omega}$ & $\begin{array}{l}\tilde{\omega} \\
\widetilde{U} \\
\mathcal{O}\end{array}$ & 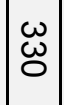 & $\left|\begin{array}{c}N \\
\infty \\
\omega\end{array}\right|$ & $\overrightarrow{\overrightarrow{0}}$ & ज् & $\stackrel{\infty}{\rightarrow}$ & $\vec{D}$ & $\frac{N}{0}$ & $\overrightarrow{8}$ & $\overrightarrow{\vec{O}}$ & $\mid \begin{array}{l}0 \\
0 \\
\infty\end{array}$ & $\left|\begin{array}{l}\omega \\
\mathbb{W} \\
\infty\end{array}\right|$ & \begin{tabular}{|l}
$\omega$ \\
N \\
$O$
\end{tabular} & $\overrightarrow{0}$ & $\vec{\Phi} \mid \vec{\Phi}$ & 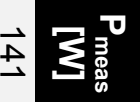 \\
\hline$\vec{\circ}$ & No & $\vec{\circ}$ & $\vec{\circ}$ & 웅 & $\frac{1}{0}$ & $\vec{\circ}$ & 웅 & 융 & 융 & 융 & $\vec{\circ}$ & $\stackrel{0}{\circ}$ & 윰 & 윰 & 유 & $\therefore$ & $\vec{\circ}$ & $\vec{\circ}$ & $\stackrel{0}{\circ}$ & $\begin{array}{l}N \\
\circ \\
\circ\end{array}$ & 유 & $\overrightarrow{0}$ & $\frac{1}{0}$ & $\overrightarrow{0}$ & \begin{tabular}{l|l}
$N$ \\
$\stackrel{0}{0}$
\end{tabular} & 웅 \\
\hline
\end{tabular}


Table 4: Approximate percent contributions to the total standby power of each type of power usage.

\begin{tabular}{|c|c|c|c|c|}
\hline \multirow{2}{*}{ Spa } & \multicolumn{4}{|c|}{ \% Contribution to Standby Power } \\
\hline & $\begin{array}{c}\text { Heater } \\
\text { Cycle }\end{array}$ & $\begin{array}{l}\text { Filter } \\
\text { Cycle }\end{array}$ & $\begin{array}{l}\text { Constant } \\
\text { Filtration }\end{array}$ & Pulses \\
\hline A & $81 \%$ & $16 \%$ & & $3 \%$ \\
\hline B & $83 \%$ & $14 \%$ & & $3 \%$ \\
\hline C & $86 \%$ & $11 \%$ & & $2 \%$ \\
\hline D & $79 \%$ & $17 \%$ & & $3 \%$ \\
\hline $\mathrm{E}$ & $72 \%$ & $23 \%$ & & $5 \%$ \\
\hline $\mathrm{F}$ & $38 \%$ & $14 \%$ & $48 \%$ & \\
\hline G & $30 \%$ & & $70 \%$ & \\
\hline $\mathrm{H}$ & $63 \%$ & $27 \%$ & & $10 \%$ \\
\hline 1 & $69 \%$ & $26 \%$ & & $5 \%$ \\
\hline $\mathrm{J}$ & $92 \%$ & $7 \%$ & & $1 \%$ \\
\hline $\mathrm{K}$ & $100 \%$ & & & \\
\hline $\mathrm{L}$ & $100 \%$ & & & \\
\hline M & $100 \%$ & & & \\
\hline $\mathrm{N}$ & $54 \%$ & $46 \%$ & & \\
\hline $\mathrm{O}$ & $50 \%$ & $50 \%$ & & \\
\hline $\mathrm{P}$ & $80 \%$ & $20 \%$ & & \\
\hline Q & $72 \%$ & $5 \%$ & $23 \%$ & \\
\hline $\mathrm{R}$ & $65 \%$ & & $35 \%$ & \\
\hline $\mathrm{S}$ & $53 \%$ & & $47 \%$ & \\
\hline $\mathrm{T}$ & $8 \%$ & $92 \%$ & & \\
\hline $\mathrm{U}$ & $70 \%$ & $29 \%$ & & $1 \%$ \\
\hline V & $100 \%$ & & & \\
\hline W & $83 \%$ & & $17 \%$ & \\
\hline $\mathrm{X}$ & $86 \%$ & $11 \%$ & & $2 \%$ \\
\hline$Y$ & $72 \%$ & $24 \%$ & & $5 \%$ \\
\hline Z & $82 \%$ & $10 \%$ & & $8 \%$ \\
\hline AA & $85 \%$ & $9 \%$ & & $7 \%$ \\
\hline Mean & $72 \%$ & $24 \%$ & $40 \%$ & $4 \%$ \\
\hline Median & $79 \%$ & $17 \%$ & $41 \%$ & $3 \%$ \\
\hline
\end{tabular}

As can be seen in Table 3, the power demand during a spa heating cycle has a wide range, spanning anywhere from 706 watts to 4331 watts, with a median demand of 3141 watts. From Table 4, the overall percent contribution of the heater cycle to the standby power had a very wide range, from $8 \%$ to $100 \%$ of the total power with a median 
contribution of $79 \%$. Worth noting is that the spa with the lowest percentage of power contributed by the heater, spa T, utilizes a "thermally sealed" architecture where the cavity between the shell and exterior cabinet is mostly empty, and heat generated by the pump motors warms air in this cavity to provide significant insulation and allowing infrequent use of the heater. In fact, while in standby mode spa T used its heater only 10 minutes per day which is less than 10 percent of the mean usage of the 27 spas (see Table 5).

Table 5 lists the average amount of time heater cycles and filter cycles operate per day. The most common amount of filtration for spas not utilizing a constant circulation pump is about 4 hours (240 minutes) of dedicated filtration cycles per day. Taking into consideration the fact that the spa's filtration system is utilized during a heater cycle as well, the median total amount of filtration is 5.6 hours per day.

Table 5: Average operating time per day of various spa cycles.

\begin{tabular}{|c|c|c|c|}
\hline Spa & \multicolumn{3}{c}{ Average time operating per day } \\
& $\begin{array}{r}\text { Heater Cycle } \\
\text { [min] }\end{array}$ & $\begin{array}{c}\text { Filter Cycle } \\
\text { [min] }\end{array}$ & $\begin{array}{c}\text { Total Filtration* } \\
\text { [hours] }\end{array}$ \\
\hline A & 42 & 240 & 4.7 \\
B & 52 & 240 & 4.9 \\
C & 62 & 240 & 5.0 \\
D & 85 & 240 & 5.4 \\
E & 84 & 240 & 5.4 \\
F & 53 & 100 & 24.0 \\
G & 39 & & 24.0 \\
H & 136 & 240 & 6.3 \\
I & 60 & 240 & 5.0 \\
J & 158 & 240 & 6.6 \\
K & 108 & & 1.8 \\
L & 128 & & 2.1 \\
\hline
\end{tabular}




\begin{tabular}{|c|c|c|c|}
\hline \multirow[t]{2}{*}{ Spa } & \multicolumn{3}{|c|}{ Average time operating per day } \\
\hline & $\begin{array}{c}\text { Heater Cycle } \\
\text { [min] }\end{array}$ & $\begin{array}{l}\text { Filter Cycle } \\
\text { [min] }\end{array}$ & $\begin{array}{c}\text { Total Filtration* } \\
\text { [hours] }\end{array}$ \\
\hline M & 156 & & 2.6 \\
\hline $\mathrm{N}$ & 70 & 720 & 13.2 \\
\hline $\mathrm{O}$ & 79 & 720 & 13.3 \\
\hline$P$ & 80 & 120 & 3.3 \\
\hline Q & 143 & 40 & 24.0 \\
\hline $\mathrm{R}$ & 548 & & 24.0 \\
\hline S & 59 & & 24.0 \\
\hline $\mathrm{T}$ & 10 & 1073 & 18.0 \\
\hline$U$ & 130 & 720 & 14.2 \\
\hline V & 47 & & 0.8 \\
\hline W & 87 & & 24.0 \\
\hline$x$ & 97 & 240 & 5.6 \\
\hline Y & 69 & 240 & 5.1 \\
\hline Z & 213 & 120 & 5.5 \\
\hline AA & 252 & 120 & 6.2 \\
\hline Mean & 113 & 323 & 10.3 \\
\hline Median & 84 & 240 & 5.6 \\
\hline $\begin{array}{l}{ }^{*} \text { Since wate } \\
\text { cycles, the } \\
\text { hours if a cc }\end{array}$ & $\begin{array}{l}\text { ered during he } \\
\text { ration time is } \\
\text { circulation pu }\end{array}$ & $\begin{array}{l}\text { cycles as u } \\
\text { um of each } \\
\text { used. }\end{array}$ & $\begin{array}{l}\text { as filtration } \\
\text { ese, or } 24\end{array}$ \\
\hline
\end{tabular}

Spa V performed very well compared to the Title 20 standard with a normalized standby power $58 \%$ below the standard. This spa is not a production model and was actually built by the particular manufacturer in order to push the limits of electrical efficiency in a spa. Looking at Tables 3 through 5 it appears one way in which this was achieved was by minimizing the heating cycles and eliminating dedicated filtration cycles altogether. In fact, the water in spa V is only filtered during the heating cycles, which results in filtration for only about 40 minutes per day. With the amount of filtration being less than one fifth the median value of the other spas, it begs the question of whether this is enough filtration to maintain high water quality - and, in fact, after testing was completed on spa 
$\mathrm{V}$, that spa was observed to have a bad smell and evidence of an algae or bacterial grown was observed after draining the spa.

Six of the spas tested made use of a dedicated constant circulation pump. For the spas which used this type of pump, the median demand by the circulation pump was 118 watts. Note, however, that spa $\mathrm{W}$ required only 39 watts for constant circulation which is significant since spa $\mathrm{W}$ is one of the largest (by volume) spas tested. This suggests that lower power options are available for the other spas utilizing constant filtration.

\section{Insulation Performance Comparison}

The performance of the insulation can be compared for each spa to get a better understanding of the spas relative performance. For this, I assumed the heat lost by the spa can be represented by one dimensional heat transfer between two parallel surfaces of equal area (Figure 15).

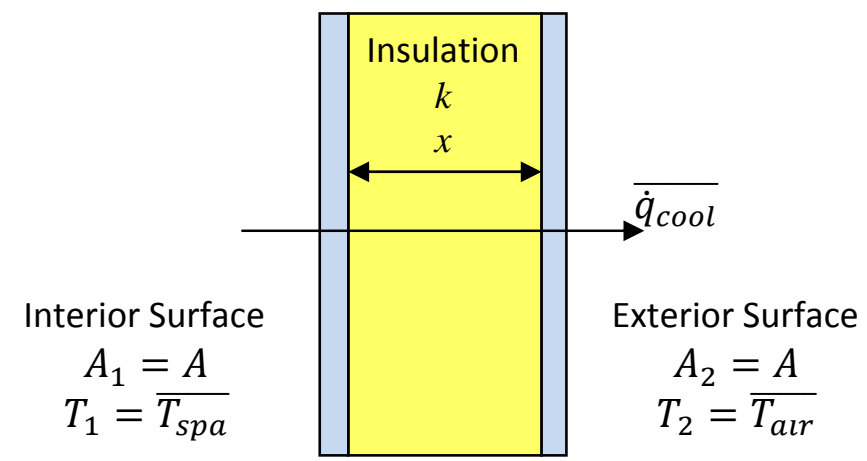

Figure 15: One dimensional heat transfer model of cooling of hot tub with exterior surface area "A", insulation thermal conductivity " $k$ ", and average insulation thickness " $x$ ". 
This analysis assumes the following:

- Heat transfer from the interior surface of the hot tub to the exterior surface of the hot tub is entirely due to conduction.

- One dimensional heat transfer between two surfaces of area equal to the exterior surface area of the hot tubs.

- The temperature difference between the conducting surfaces is equal to the difference between the average spa water temperature and the average air temperature during each test.

With these assumptions, I turned to Fourier's heat equation for conduction.

$$
\dot{q}=\frac{k A \Delta T}{x}[W]
$$

It would be useful to be able to compare the thermal conductivity of the insulation used in the construction of each spa, $\mathrm{k}$, and the average thickness of each spa's insulation, $\mathrm{x}$. Both of these are unknown values, so instead I rearranged this equation to present the thermal conductivity divided by the insulation thickness as a function of the rate of heat transfer, surface area, and temperature difference between the conducting surfaces.

$$
\frac{k}{x}=\frac{\dot{q}}{A \Delta T}\left[\frac{W}{m^{2} K}\right]
$$

For the rate of heat transfer, it makes the most sense to use the rate at which the spas cool between heating cycles, later referred to as the "cooling rate". Using only the cooling rate when the heaters were not in use provides the strongest representation of the spa insulation while avoiding differences due to different heater and pump configurations. 
The instantaneous cooling rate, $\dot{q}_{c o o l}$, can be calculated by taking the first time derivative of the energy equation.

$$
\begin{gathered}
q=m c \Delta T \\
\dot{q}=\frac{d q}{d t}=m c \frac{d T}{d t}=\rho V c \frac{d T}{d t}
\end{gathered}
$$

The average rate of cooling is then determined by summing all the temperature differences.

$$
\dot{q}_{c o o l, a v g}=\rho V c \sum \frac{\Delta T_{i}}{\Delta t}=\frac{\rho V c}{(n-1)} \sum_{i=2}^{n} \frac{T_{i}-T_{i-1}}{t_{i}-t_{i-1}}
$$

Using Matlab, I found the difference between all adjacent temperature values over the duration of each. For this, I used the values from the smoothed temperature curves since the raw temperature data was too noisy to provide a meaningful result using this method. Then, I found the average of all the values where the spa was cooling $\left(\mathrm{T}_{\mathrm{i}}-\mathrm{T}_{\mathrm{i}-1}<0\right)$. Multiplying this by the volume, water density, and specific heat of water, and dividing by the time between each measurement ( 1 minute) gave the average cooling rate $^{7}$.

The exterior spa surface area (A) was calculated using the dimensions listed in the user manual for each hot tub. The details of these calculations are presented in Appendix D.

For the temperature difference in Equation 13, the difference between the average air temperature and the average water temperature during each test was used.

\footnotetext{
${ }^{7}$ For this calculation, the following values for water at $102^{\circ} \mathrm{F}$ are used: specific heat, $\mathrm{c}=4.179 \frac{\mathrm{kJ}}{\mathrm{kg} \cdot \mathrm{K}}$; water density, $\rho=992.2 \frac{\mathrm{kg}}{\mathrm{m}^{3}}$.
} 
Table 6 compares the insulation of the 27 spas. For comparison, an equivalent insulation thickness, $\mathrm{x}^{\circ}$, is calculated using the equation below. This value assumes rigid polyurethane foam insulation with thermal conductivity $0.026 \frac{\mathrm{W}}{\mathrm{mK}}\left(\mathrm{R}\right.$-value of $\left.5.5 \frac{\mathrm{ft}^{2} \cdot{ }^{\circ} \mathrm{F} \cdot \mathrm{h}}{\mathrm{BTU} \cdot \mathrm{in}}\right)$ (BING, 2006). This is a typical insulation material available to spa manufacturers.

$$
\begin{gathered}
x^{\circ}=\frac{A \Delta T}{\dot{q}_{c o o l, a v g}} \cdot k \\
x^{\circ}[\text { in }]=\frac{A \Delta T}{\dot{q}_{\text {cool,avg }}}\left[\frac{m^{2} K}{W}\right] \cdot\left(0.026 \frac{W}{m K}\right) \cdot\left[\frac{100 \mathrm{~cm}}{m}\right]\left[\frac{1 \text { in }}{2.54 \mathrm{~cm}}\right]
\end{gathered}
$$

Notice that the equivalent insulation thickness, $\mathrm{x}^{\circ}$, ranges from 1.1 inches to 4.8 inches with a mean value of 2.5 inches. If we ignore the spas which did not pass the Title 20 requirement, the mean equivalent insulation value increases to 2.9 inches. 
Table 6: Comparison of heat transfer thickness and equivalent insulation thickness for each spa test. Spas which did not meet the Title 20 standard are shown in blue text.

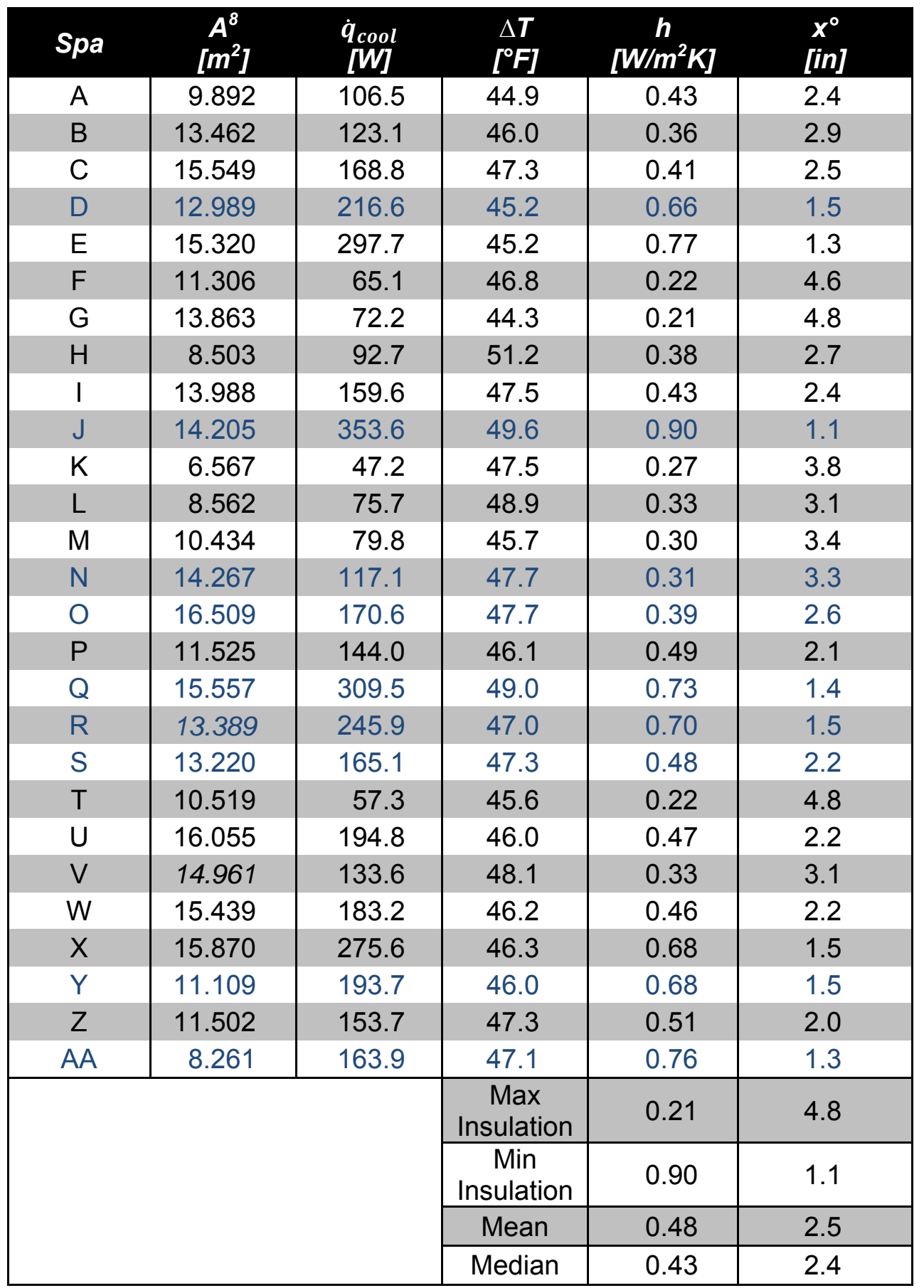

\footnotetext{
${ }^{8}$ See calculation of external spa surface area in Appendix D.
} 


\section{Correlations Between Variables}

The Pearson product-moment correlation coefficient, calculated using Equation 20 below, is commonly used to measure the correlation between two variables $\mathrm{X}$ and $\mathrm{Y}$. The coefficient, $r$, has a value between +1 and -1 . R-values for which the absolute value approaches one are more strongly correlated, while r-values for which the absolute value approaches zero are less correlated.

$$
r=\frac{\sum_{i=1}^{n}\left(X_{i}-\bar{X}\right)\left(Y_{i}-\bar{Y}\right)}{\sqrt{\sum_{i=1}^{n}\left(X_{i}-\bar{X}\right)^{2}} \sqrt{\sum_{i=1}^{n}\left(Y_{i}-\bar{Y}\right)^{2}}}
$$

For the purposes of this discussion the strength of the correlations will be defined according to Table 7 .

Table 7: Naming convention for the correlation strength based on the magnitude of the Pearson product-moment correlation coefficient.

\begin{tabular}{|c|c|}
\hline Correlation Strength & Magnitude of $\boldsymbol{r}, \boldsymbol{r} \mid$ \\
\hline None & $0.0 \leq|r| \leq 0.1$ \\
\hline Weak & $0.1<|r| \leq 0.3$ \\
\hline Medium & $0.3<|r| \leq 0.6$ \\
\hline Strong & $0.6<|r| \leq 0.8$ \\
\hline Very Strong & $0.8<|r| \leq 1.0$ \\
\hline
\end{tabular}

Table 8 presents the calculated Pearson product-moment correlation coefficients, $r$, for the correlations between the normalized margin and several other variables. Notice that the normalized margin is not correlated to the volume or volume to the $2 / 3$ power. Since these values do not correlate one can conclude that a spa's performance compared to the 
standard is not dependent on its size. In other words, a large spa is just as likely to pass or fail the Title 20 standard as a smaller spa.

Table 8: Pearson product-moment correlation coefficients for the correlation between the normalized margin and various other variables.

\begin{tabular}{|c|c|c|c|}
\hline $\begin{array}{c}\text { Dependent } \\
\text { Variable, "Y' }\end{array}$ & $\begin{array}{c}\text { Independent } \\
\text { Variable, "X" }\end{array}$ & $\begin{array}{c}\text { Correlation } \\
\text { Coefficient, } \boldsymbol{r}\end{array}$ & $\begin{array}{c}\text { Correlation } \\
\text { Strength }\end{array}$ \\
\hline \multirow{4}{*}{ Normalized Margin } & $\mathrm{V}$ & 0.028 & None \\
\cline { 2 - 4 } & $\mathrm{V}^{2 / 3}$ & 0.038 & None \\
\cline { 2 - 4 }$\left(\frac{\text { Pnorm }_{\text {nollow }}-P_{\text {allow }}}{P_{\text {allow }}} 100 \%\right)$ & $\mathrm{k} / \mathrm{X}$ & 0.676 & Strong \\
\cline { 2 - 4 } & $\mathrm{A}$ & 0.204 & Weak \\
\cline { 2 - 4 } & $\begin{array}{c}\text { Total Filtration } \\
\text { Time }\end{array}$ & 0.355 & Medium \\
\cline { 2 - 4 } & $\mathrm{P}_{\mathrm{h}}$ & 0.646 & Strong \\
\cline { 2 - 4 } & $\mathrm{P}_{\mathrm{f}}$ & 0.294 & Weak \\
\hline
\end{tabular}

Also interesting is that the normalized margin compared to the standard is more strongly correlated to the heating power of a spa than the filtration power, and similarly, the normalized margin is strongly correlated to $\mathrm{k} / \mathrm{x}$. This suggests that for most spas, the power required to keep the spas heated is a large driver of how well the spa will perform compared to the Title 20 standard, which makes sense since (as shown earlier in this chapter) the heater power is on average the largest contributor to the standby power. Improving the insulation performance of a spa should then be a large focus in efforts to reduce standby power. 


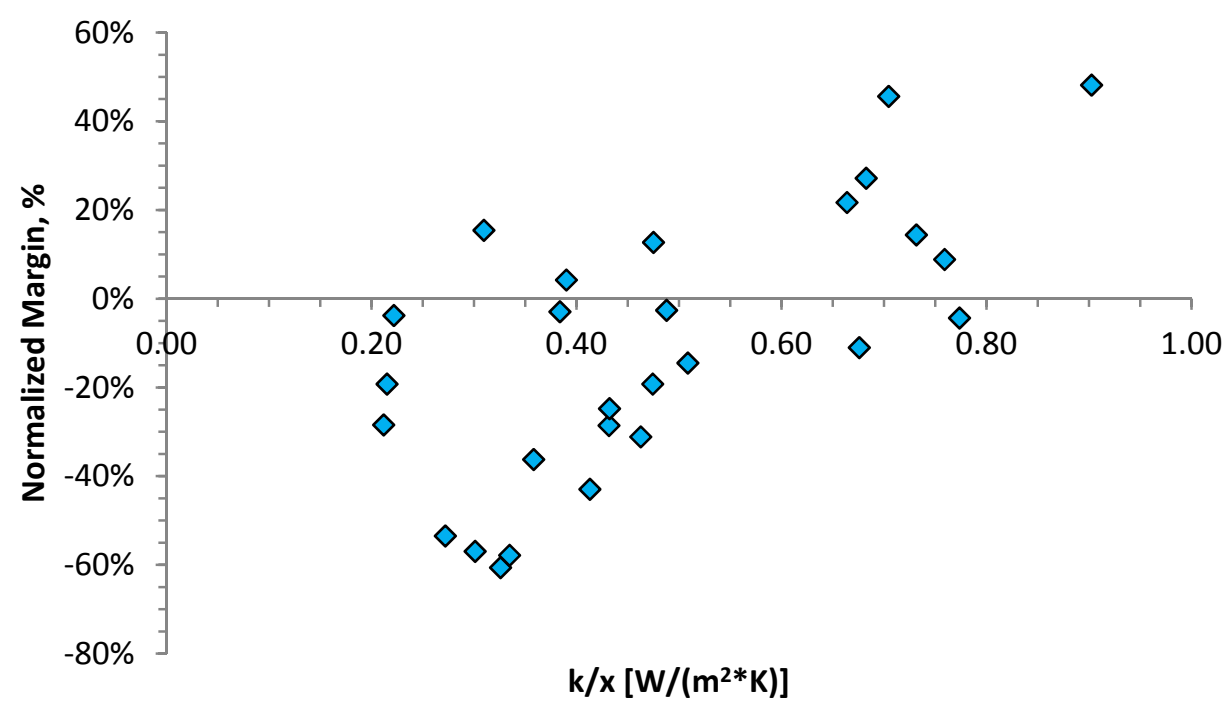

Figure 16: Relationship between the normalized margin and $\mathrm{k} / \mathrm{x}$. Notice the general trend that lower values of $\mathrm{k} / \mathrm{x}$ result in lower normalized margin - that is, lower standby power use compared to the standard.

The correlation coefficients between the measured power, $\mathrm{P}_{\text {meas }}$, and other variables are presented in Table 9. Notice there is some correlation between the measured power and values such as the volume, surface area and heating demand. The correlation of measured power and average temperature difference $(\Delta T)$ is quite weak. If Fourier's heat equation (Equation 13) applies, as I assume it does, this may be unexpected. However, this lack of correlation can be due to differences in geometry and insulation characteristics between the spas tested.

Table 9: Pearson product-moment correlation coefficients for the correlation between the measured power and various other variables.

\begin{tabular}{|c|c|c|c|}
\hline $\begin{array}{c}\text { Dependent } \\
\text { Variable, "Y" }\end{array}$ & $\begin{array}{c}\text { Independent } \\
\text { Variable, "X" }\end{array}$ & $\begin{array}{c}\text { Correlation } \\
\text { Coefficient, } \boldsymbol{r}\end{array}$ & $\begin{array}{c}\text { Correlation } \\
\text { Strength }\end{array}$ \\
\hline \multirow{3}{*}{ Measured Power } & $\mathrm{V}$ & 0.524 & Medium \\
\cline { 2 - 4 } & $\mathrm{V}^{2 / 3}$ & 0.531 & Medium \\
\cline { 2 - 4 } & $\mathrm{A}$ & 0.579 & Medium \\
\cline { 2 - 4 } $\mathrm{P}_{\text {meas }}$ & $\Delta \mathrm{T}$ & 0.174 & Weak \\
\cline { 2 - 4 } & $\mathrm{A}^{*} \Delta \mathrm{T}$ & 0.612 & Strong \\
\hline
\end{tabular}


When considering the product of the average temperature difference and the surface area instead of the temperature difference alone, a strong correlation exists with the measured power. As shown in Fourier's heat equation for conduction (Equation 13), the conductive heat transfer rate, $\dot{q}$, is equal to $\frac{k A \Delta T}{x}$. As discussed previously, each spa's measured power, $\mathrm{P}_{\text {meas, }}$ is largely used to counteract this rate of heat loss. Logically, then, the power, $\mathrm{P}_{\text {meas, }}$ should strongly correlate with $\frac{k A \Delta T}{x}$. However, since independent measurements of $\mathrm{k} / \mathrm{x}$ for each spa are not available the closest correlation that can be shown is a correlation with the independent quantity $\mathrm{A}^{*} \Delta \mathrm{T}$. It can be reasonably hypothesized that this correlation should only grow stronger if the value of $\mathrm{k} / \mathrm{x}$ for each spa was known, or if the test was repeated with the same spa at different temperatures.

Figure 17 below graphically demonstrates the strong relationship between these values. The correlation between these variables gives compelling evidence that the measured power for a given spa is nearly proportional to the average temperature difference. This is a strong indicator that the use of the temperature normalization equation (Equation 9) is valid; however, further investigation should be performed to verify this. Testing a sample of spas each at several average temperature differences should provide evidence to confirm or reject this assumption. 
Hamill 52

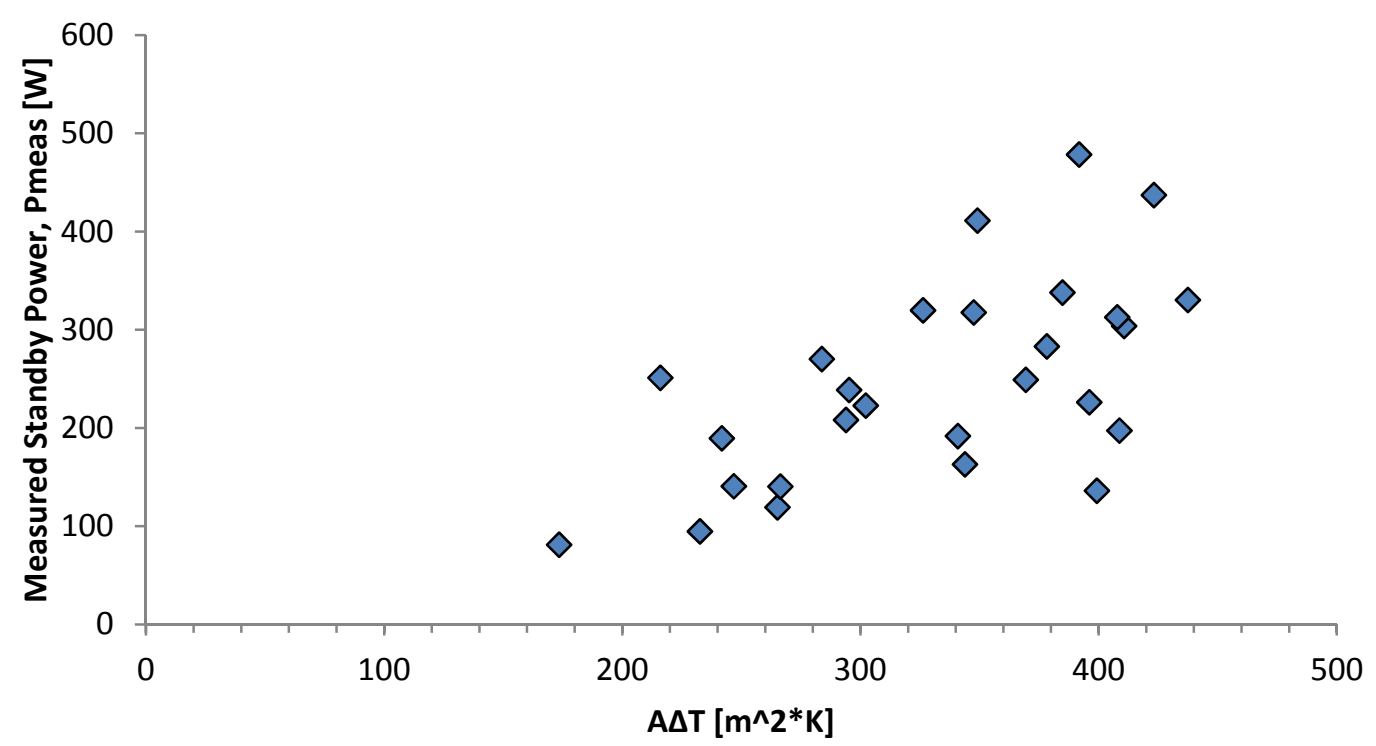

Figure 17: Plot of the measured power, $P_{\text {meas }}$, as a function of $A^{*} \Delta T$. Note that the relationship appears strongly correlated. 


\section{8) Low Performing Spas}

Spas D, J, N, O, Q, R, S, Y, and AA did not meet the Title 20 regulation even after the application of temperature normalization. As was shown in the correlation analysis in the previous chapter, the size of these spas spanned across the range of spa volumes tested, so it doesn't appear that the regulation has a bias towards any particular size spa. The following is an analysis of each of these nine spas, and a discussion of possible measures to improve their performance in the future.

Table 10 lists the spas which did not meet the Title 20 requirement and lists the reduction in the standby power required in order to bring each spa into compliance. Table 12 presents the detailed power use for spas not meeting the requirement. In assessing the spas and considering improvements to reduce the power three factors were considered:

1. What is the frequency and duration of filtration cycles? A typical amount of filtration used by several manufacturers is to run filtration for four hours per day. $^{9}$

2. If a continuous circulation pump is used, what is the power used to operate that pump? Are other options available that would require less power?

3. How does the equivalent insulation thickness, $x^{\circ}$, compare to the 2.9 inch average of the passing spas?

\footnotetext{
${ }^{9}$ For the sake of comparison I assume that four hours of filtration per day is a sufficient amount of filtration for all models in this study. In reality many factors affect the amount of filtration needed such as the volume of water in the spa, type of filter used, and the flow rate through the filter. These factors are all ignored here.
} 
A fourth consideration could be whether or not the pulse power could be reduced or eliminated altogether, but since the pulse power contributes such a small percentage to the overall standby power it was not considered for improvements here.

Table 10: Power reduction required to bring each of the failed spas into compliance with Title 20. The required power reduction is scaled by the normalization factor since the reduction would need to be realized in the actual measured power at the temperatures tested.

\begin{tabular}{|c|c|c|c|}
\hline Spa & $\begin{array}{c}\boldsymbol{P}_{\text {above }}[\boldsymbol{W}] \\
\left(\boldsymbol{P}_{\text {norm }}-\boldsymbol{P}_{\text {allow })}\right.\end{array}$ & $\begin{array}{c}\text { Normalization } \\
\text { Factor } \\
\left(37^{\circ} F / \Delta T\right)\end{array}$ & $\begin{array}{c}\text { Req. Power } \\
\text { Reduction [W] } \\
\left(P_{\text {above }}{ }^{*} \Delta T / 37^{\circ} F\right)\end{array}$ \\
\hline $\mathrm{D}$ & 46.7 & 0.818 & 57.1 \\
\hline$J$ & 116.0 & 0.745 & 155.7 \\
\hline$N$ & 29.4 & 0.775 & 37.9 \\
\hline $\mathrm{O}$ & 10.5 & 0.776 & 13.5 \\
\hline Q & 41.6 & 0.756 & 55.1 \\
\hline $\mathrm{R}$ & 101.5 & 0.787 & 128.9 \\
\hline S & 28.1 & 0.782 & 35.9 \\
\hline$Y$ & 46.5 & 0.805 & 57.8 \\
\hline AA & 16.1 & 0.786 & 20.5 \\
\hline
\end{tabular}

The required reduction in power to meet the Title 20 standard, $\mathrm{P}_{\text {reduce, }}$, is calculated using the equation:

$$
P_{\text {reduce }}=\left(P_{\text {norm }}-P_{\text {allow }}\right) \frac{\Delta T}{37^{\circ} \mathrm{F}}
$$

Table 11: Summary of the performance of Spa D and proposed changes.

\begin{tabular}{|c|c|c|c|}
\hline Spa D & \multicolumn{3}{|c|}{$P_{\text {meas }} 320 \mathrm{~W} / P_{\text {reduce }} 57 \mathrm{~W}$} \\
\hline Contributor & Usage & Assessment & Proposed Change \\
\hline \multirow[b]{2}{*}{ Filtration Cycles } & 4 hours / day & \multirow[b]{2}{*}{ Usage typical } & \multirow[b]{2}{*}{ None } \\
\hline & $\begin{array}{c}55 \mathrm{~W} \text { contribution to } \\
\mathrm{P}_{\text {standby }}\end{array}$ & & \\
\hline $\begin{array}{l}\text { Constant } \\
\text { Circulation }\end{array}$ & $\mathrm{n} / \mathrm{a}$ & $\mathrm{n} / \mathrm{a}$ & $\mathrm{n} / \mathrm{a}$ \\
\hline Insulation & $\begin{array}{c}h=0.66 \mathrm{~W} / \mathrm{m}^{2} \mathrm{~K} \\
\mathrm{x}^{\circ}=1.5 \mathrm{inch}\end{array}$ & $\begin{array}{c}\text { Equivalent } \\
\text { insulation } \\
\text { thickness is less } \\
\text { than } 2.9 \text { inch } \\
\text { average }\end{array}$ & Improve Insulation \\
\hline
\end{tabular}


Spa D uses a multi-speed pump and heater configuration. The measured standby power of 320 watts needs to be reduced by approximately 57 watts in order to bring this spa into compliance with the Title 20 standard.

As shown in Table 11, spa D utilizes programmed filtration cycles which filter the water on average for four hours per day. This usage is consistent with a typical amount of filtration used by other spas in this study. It may be possible to reduce the amount of filtration, but it is unclear whether this could compromise the water quality. Therefore, changes to the filtration cycles are not proposed as a viable way to reduce the standby power.

The primary driver in spa D's failure to meet the Title 20 standard appears to be its less than adequate insulation $-\mathrm{x}^{\circ}=1.5$ inches for spa $\mathrm{D}$ compared to an average $\mathrm{x}^{\circ}=2.9$ inches for spas passing the Title 20 standard.. The following equation was used to calculate the minimum thickness of R5.5 $\left(\mathrm{k}=0.026 \frac{\mathrm{W}}{\mathrm{mK}}\right)$ insulation to be added to the spa in order to bring the spa into compliance.

$$
x^{\circ}+x^{+}=\frac{A \Delta T}{\left(\dot{q}_{\text {cool,avg }}-P_{\text {reduce }}\right)} \cdot k
$$

Rearranging for the thickness of insulation to be added, $\mathrm{x}^{+}$,

$$
x^{+}=\frac{A \Delta T}{\left(\dot{q}_{\text {cool,avg }}-P_{\text {reduce }}\right)} \cdot k-x^{\circ}
$$

For spa D, we estimate a minimum of 0.6 inches of R5.5 insulation needs to be added in order to bring the compliance with Title 20 . 
Table 12: Power usage details for spas not meeting the Title 20 standard.

\begin{tabular}{|c|c|c|c|c|c|c|c|c|c|c|}
\hline \multicolumn{2}{|c|}{ Spa } & $\mathrm{D}$ & $\mathrm{J}$ & $\mathrm{N}$ & $\mathrm{O}$ & $Q$ & $\mathrm{R}$ & $S$ & $\mathrm{Y}$ & AA \\
\hline \multirow{4}{*}{ 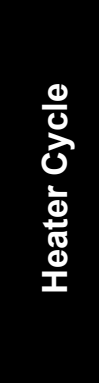 } & $D_{h}[W]$ & 4225 & 4043 & 3141 & 3108 & 3165 & 706 & 4078 & 4092 & 1233 \\
\hline & $t_{h}[\mathrm{~min}]$ & 13 & 22 & 17 & 28 & 54 & 111 & 13 & 12 & 35 \\
\hline & $f_{h}[\mathrm{~min}]$ & 222 & 197 & 361 & 516 & 544 & 292 & 318 & 242 & 199 \\
\hline & $P_{h}[W]$ & 250.5 & 443.4 & 151.7 & 171.3 & 315.1 & 269.0 & 167.4 & 195.6 & 215.9 \\
\hline \multirow{4}{*}{ 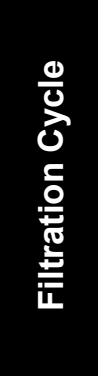 } & $D_{f}[W]$ & 328 & 199 & 263 & 347 & 767 & - & - & 390 & 265 \\
\hline & $t_{f}[\mathrm{~min}]$ & 120 & 120 & 360 & 360 & 20 & - & - & 120 & 60 \\
\hline & $f_{f}[\min ]$ & 720 & 720 & 720 & 720 & 720 & - & - & 720 & 720 \\
\hline & $P_{f}[W]$ & 54.7 & 33.2 & 131.6 & 173.3 & 21.3 & - & - & 65.0 & 22.1 \\
\hline \multirow{4}{*}{ 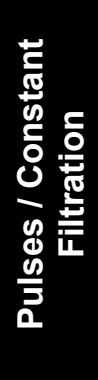 } & $D_{0}[W]$ & 328 & 199 & - & - & 100 & 142 & 150 & 390 & 265 \\
\hline & $\mathbf{t}_{\mathrm{o}}[\mathrm{min}]$ & 1 & 1 & - & - & $\infty$ & $\infty$ & $\infty$ & 1 & 2 \\
\hline & $f_{o}[\mathrm{~min}]$ & 31 & 31 & - & - & - & - & - & 31 & 32 \\
\hline & $P_{0}[W]$ & 10.6 & 6.4 & - & - & 100.0 & 142.0 & 150.0 & 12.6 & 16.6 \\
\hline \multicolumn{2}{|c|}{$\sum P_{*}$} & 316 & 483 & 283 & 345 & 437 & 411 & 318 & 273 & 255 \\
\hline \multicolumn{2}{|c|}{$P_{\text {meas }}[\mathbf{W}]$} & 320 & 478 & 283 & 330 & 437 & 411 & 318 & 270 & 251 \\
\hline \multicolumn{2}{|c|}{$\begin{array}{c}\% \text { Error } \\
\left(\Sigma \mathbf{P}_{*}-\mathbf{P}_{\text {meas }}\right) / \mathbf{P}_{\text {meas }}\end{array}$} & $-1 \%$ & $1 \%$ & $0 \%$ & $4 \%$ & $0 \%$ & $0 \%$ & $0 \%$ & $1 \%$ & $1 \%$ \\
\hline
\end{tabular}


Table 13: Summary of the performance of Spa $\mathrm{J}$ and proposed changes.

\begin{tabular}{|c|c|c|c|}
\hline Spa J & \multicolumn{3}{|c|}{$P_{\text {meas }} 478 \mathrm{~W} / P_{\text {reduce }} 156 \mathrm{~W}$} \\
\hline Contributor & Usage & Assessment & Proposed Change \\
\hline \multirow[b]{2}{*}{ Filtration Cycles } & 4 hours / day & \multirow[b]{2}{*}{ Usage typical } & \multirow[b]{2}{*}{ None } \\
\hline & $\begin{array}{c}33 \mathrm{~W} \text { contribution to } \\
\mathrm{P}_{\text {standby }}\end{array}$ & & \\
\hline $\begin{array}{l}\text { Constant } \\
\text { Circulation }\end{array}$ & $\mathrm{n} / \mathrm{a}$ & $\mathrm{n} / \mathrm{a}$ & $\mathrm{n} / \mathrm{a}$ \\
\hline Insulation & $\begin{array}{c}h=0.90 \mathrm{~W} / \mathrm{m}^{2} \mathrm{~K} \\
\mathrm{x}^{\circ}=1.1 \text { inch }\end{array}$ & $\begin{array}{c}\text { Equivalent } \\
\text { insulation } \\
\text { thickness is much } \\
\text { less than } 2.9 \text { inch } \\
\text { average }\end{array}$ & Improve Insulation \\
\hline
\end{tabular}

Spa J utilized a configuration with a $240 \mathrm{~V}$ heater and $240 \mathrm{~V}$ jet pumps, and a lower power $120 \mathrm{~V}$ circulation pump which runs separately from the heater and jet pumps. The circulation pump operated during periodic filtration cycles. The measured standby power of 478 watts needs to be reduced by 156 watts to pass the Title 20 standard. See Table 13.

Like spa D, spa J utilizes programmed filtration cycles which filter the water on average for four hours per day. Again, this usage is typical and no change is proposed.

Spa J's equivalent insulation thickness of 1.1 inches is significantly below the average value of the passing spas of 2.9 inches. Therefore, the insulation should be improved. From Equation 23 a minimum increase of 0.9 inches of R5.5 insulation is needed to bring this spa into compliance. 
Table 14: Summary of the performance of Spa $\mathrm{N}$ and proposed changes.

\begin{tabular}{|c|c|c|c|}
\hline Spa N & \multicolumn{3}{|c|}{$P_{\text {meas }} 283 \mathrm{~W} / P_{\text {reduce }} 38 \mathrm{~W}$} \\
\hline Contributor & Usage & Assessment & Proposed Change \\
\hline \multirow[b]{2}{*}{ Filtration Cycles } & 12 hours / day & \multirow{2}{*}{$\begin{array}{l}\text { Greater than } \\
\text { typical usage }\end{array}$} & \multirow{2}{*}{$\begin{array}{l}\text { Decrease duration } \\
\text { filtration cycles }\end{array}$} \\
\hline & $\begin{array}{c}132 \mathrm{~W} \text { contribution to } \\
\mathrm{P}_{\text {standby }}\end{array}$ & & \\
\hline $\begin{array}{l}\text { Constant } \\
\text { Circulation }\end{array}$ & $\mathrm{n} / \mathrm{a}$ & $\mathrm{n} / \mathrm{a}$ & $\mathrm{n} / \mathrm{a}$ \\
\hline Insulation & $\begin{array}{c}\mathrm{h}=0.31 \mathrm{~W} / \mathrm{m}^{2} \mathrm{~K} \\
\mathrm{x}^{\circ}=3.3 \text { inch }\end{array}$ & $\begin{array}{c}\text { Greater than } \\
\text { average insulation }\end{array}$ & None \\
\hline
\end{tabular}

Spa N's measured standby power of 283 watts must be reduced by 38 watts to bring it into compliance with the Title 20 standard. Spa $\mathrm{N}$ has better than average insulation, so no changes to the insulation are necessary. The programmed filtration cycles, however, are set to run for twelve hours per day, three times the typical duration of four hours per day (see Table 14). The filtration cycles present the clearest opportunity to reduce the standby power at little or no cost.

With the filtration cycle contributing $132 \mathrm{~W}$ to the standby power (Table 3), reducing the amount of filtration by $29 \%$ to 8.5 hours per day would adequately decrease the total standby power and bring this spa into compliance. 8.5 hours of filtration per day is still well above the typical amount of filtration used by other spas, so this reduction should not pose a risk to the water quality. In fact, further reductions to the duration of filtration are feasible, and reducing the filtration to four hours per day could reduce the measured power by as much as $88 \mathrm{~W}$ to a standby power of $195 \mathrm{~W}$. 
Table 15: Summary of the performance of Spa O and proposed changes.

\begin{tabular}{|c|c|c|c|}
\hline Spa 0 & \multicolumn{3}{|c|}{$P_{\text {meas }} 330 \mathrm{~W} / P_{\text {reduce }} 14 \mathrm{~W}$} \\
\hline Contributor & Usage & Assessment & Proposed Change \\
\hline \multirow[b]{2}{*}{ Filtration Cycles } & 12 hours / day & \multirow{2}{*}{$\begin{array}{l}\text { Greater than } \\
\text { typical usage }\end{array}$} & \multirow{2}{*}{$\begin{array}{l}\text { Decrease duration } \\
\text { filtration cycles }\end{array}$} \\
\hline & $\begin{array}{c}173 \mathrm{~W} \text { contribution to } \\
\mathrm{P}_{\text {standby }}\end{array}$ & & \\
\hline $\begin{array}{l}\text { Constant } \\
\text { Circulation }\end{array}$ & $\mathrm{n} / \mathrm{a}$ & $\mathrm{n} / \mathrm{a}$ & $\mathrm{n} / \mathrm{a}$ \\
\hline Insulation & $\begin{array}{c}\mathrm{h}=0.39 \mathrm{~W} / \mathrm{m}^{2} \mathrm{~K} \\
\mathrm{x}^{\circ}=2.6 \text { inch }\end{array}$ & Average insulation & None \\
\hline
\end{tabular}

As presented in Table 15, spa O's measured standby power of 330 watts must be reduced by 14 watts to bring it into compliance with the Title 20 standard. Similarly to spa N, spa O's insulation is about average when compared to the other spas tested, so no changes to the insulation are necessary. Also like spa N, the programmed filtration cycles, currently set to run for twelve hours per day, present the clearest opportunity to reduce the standby power at little or no cost.

The filtration cycle contributes $173 \mathrm{~W}$ to the standby power (Table 3). Reducing the amount of filtration by $9 \%$ to 10.9 hours per day would adequately decrease the total standby power and bring this spa into compliance with Title 20 . This is still much greater than the typical amount of filtration used by other spas, so the reduction should not pose a risk to the water quality. Further reducing to the duration of filtration to four hours per day could reduce the measured power by as much as $115 \mathrm{~W}$ to a standby power of 215 W. 
Table 16: Summary of the performance of Spa Q and proposed changes.

\begin{tabular}{|c|c|c|c|}
\hline Spa Q & \multicolumn{3}{|c|}{$P_{\text {meas }} 437 \mathrm{~W} / P_{\text {reduce }} 55 \mathrm{~W}$} \\
\hline Contributor & Usage & Assessment & Proposed Change \\
\hline \multirow[b]{2}{*}{ Filtration Cycles } & 40 min / day & \multirow[b]{2}{*}{ Sufficient } & \multirow[b]{2}{*}{ None } \\
\hline & $\begin{array}{l}21 \mathrm{~W} \text { contribution to } \\
\mathrm{P}_{\text {standby }}\end{array}$ & & \\
\hline $\begin{array}{l}\text { Constant } \\
\text { Circulation }\end{array}$ & 100 W, 24 hours / day & $\begin{array}{c}\text { Lower than } \\
\text { average power for } \\
\text { constant circulation }\end{array}$ & None \\
\hline Insulation & $\begin{array}{c}h=0.73 \mathrm{~W} / \mathrm{m}^{2} \mathrm{~K} \\
\mathrm{x}^{\circ}=1.4 \text { inch }\end{array}$ & $\begin{array}{c}\text { Equivalent } \\
\text { insulation thickness } \\
\text { is much less than } \\
2.9 \text { inch average }\end{array}$ & Improve Insulation \\
\hline
\end{tabular}

Spa Q's measured standby power of 437 watts must be reduced by 55 watts to bring it into compliance with the Title 20 standard. Spa Q utilizes a circulation pump which continually operates at 100 watts. This is lower than the average power used by circulation pumps, thus no changes to this are proposed. The equivalent insulation thickness of 1.4 inches is significantly less than the average value of the passing spas of 2.9 inches. Therefore, the insulation should be improved in order to bring this spa into compliance.

From Equation 23, a minimum increase of 0.3 inches of R5.5 insulation is needed to bring this spa into compliance. This is presented in Table 16. Further improvements could be realized by increasing the insulation thickness to 2.9 inches, though this is not necessary to meet the Title 20 requirement. 
Table 17: Summary of the performance of Spa $R$ and proposed changes.

\begin{tabular}{|c|c|c|c|}
\hline Spa R & \multicolumn{3}{|c|}{$\mathbf{P}_{\text {meas }} \mathbf{4 1 1} \mathbf{W} / \mathbf{P}_{\text {reduce }} \mathbf{1 2 9} \mathbf{~ W}$} \\
\hline Contributor & Usage & Assessment & Proposed Change \\
\hline Filtration Cycles & $\mathrm{n} / \mathrm{a}$ & $\mathrm{n} / \mathrm{a}$ & $\mathrm{n} / \mathrm{a}$ \\
\hline $\begin{array}{c}\text { Constant } \\
\text { Circulation }\end{array}$ & $142 \mathrm{~W}, 24$ hours / day & $\begin{array}{c}\text { Greater than } \\
\text { average power for } \\
\text { constant circulation }\end{array}$ & $\begin{array}{c}\text { Possibly reduce } \\
\text { size of circulation } \\
\text { pump }\end{array}$ \\
\hline Insulation & $\mathrm{h}=0.70 \mathrm{~W} / \mathrm{m}^{2} \mathrm{~K}$ & $\begin{array}{c}\text { Equivalent } \\
\text { insulation thickness } \\
\text { is much less than } \\
2.9 \text { inch average }\end{array}$ & Improve Insulation \\
\hline
\end{tabular}

Spa R's measured standby power of $411 \mathrm{~W}$ must be reduced by $129 \mathrm{~W}$ in order to meet the Title 20 standard (see Table 17). One possible method to reduce the power would be to replace the circulation pump with a lower power alternative. This could significantly reduce the circulation power demand (perhaps reducing it as much as $103 \mathrm{~W}$ if a pump like spa W's is used), but this alone could not reduce the power enough to bring the spa into compliance. Therefore, the insulation needs to be improved in order for this spa to pass the Title 20 requirement.

If the circulation pump remains unchanged, a minimum increase of 1.6 inches of R5.5 insulation is required to bring the spa into compliance. This would bring the equivalent thickness of insulation to 3.1 inches. If, instead, the circulation pump power demand is reduced to $100 \mathrm{~W}$, only 0.8 inches of additional R5.5 insulation is required. 
Table 18: Summary of the performance of Spa S and proposed changes.

\begin{tabular}{|c|c|c|c|}
\hline Spa S & \multicolumn{3}{|c|}{$\mathbf{P}_{\text {meas }} \mathbf{3 1 8} \mathbf{W} / \mathbf{P}_{\text {reduce }} \mathbf{3 6} \mathbf{~ W}$} \\
\hline Contributor & Usage & Assessment & Proposed Change \\
\hline Filtration Cycles & $\mathrm{n} / \mathrm{a}$ & $\mathrm{n} / \mathrm{a}$ & $\mathrm{n} / \mathrm{a}$ \\
\hline $\begin{array}{c}\text { Constant } \\
\text { Circulation }\end{array}$ & $150 \mathrm{~W}, 24$ hours / day & $\begin{array}{c}\text { Greater than } \\
\text { average power for } \\
\text { constant circulation }\end{array}$ & $\begin{array}{c}\text { Possibly reduce } \\
\text { size of circulation } \\
\text { pump }\end{array}$ \\
\hline Insulation & $\begin{array}{c}\text { Equivalent } \\
\mathrm{h}=0.48 \mathrm{~W} / \mathrm{m}^{2} \mathrm{~K}\end{array}$ & $\begin{array}{c}\text { insulation thickness } \\
\text { is less than } 2.9 \\
\text { inch average }\end{array}$ & $\begin{array}{c}\text { Possibly improve } \\
\text { insulation }\end{array}$ \\
\hline
\end{tabular}

Spa S's measured standby power of $318 \mathrm{~W}$ must be reduced by $36 \mathrm{~W}$ in order to meet the Title 20 standard (see Table 18). The $36 \mathrm{~W}$ decrease could be achieved either by improving the insulation or replacing the circulation pump with a lower power alternative.

If the circulation pump remains unchanged, a minimum increase of 0.6 inches of R5.5 insulation would bring the spa into compliance. This would bring the equivalent thickness of insulation to 2.8 inches, just below the mean equivalent thickness of the passing spas. If, instead, the circulation pump power demand is reduced by $36 \mathrm{~W}$ or more, no changes to the insulation would be required. 
Table 19: Summary of the performance of Spa $Y$ and proposed changes.

\begin{tabular}{|c|c|c|c|}
\hline Spa Y & \multicolumn{3}{|c|}{$P_{\text {meas }} 270 \mathrm{~W} / P_{\text {reduce }} 58 \mathrm{~W}$} \\
\hline Contributor & Usage & Assessment & Proposed Change \\
\hline \multirow[b]{2}{*}{ Filtration Cycles } & 4 hours / day & \multirow[b]{2}{*}{ Usage typical } & \multirow[b]{2}{*}{ None } \\
\hline & $\begin{array}{c}65 \mathrm{~W} \text { contribution to } \\
\mathrm{P}_{\text {standby }}\end{array}$ & & \\
\hline $\begin{array}{l}\text { Constant } \\
\text { Circulation }\end{array}$ & $\mathrm{n} / \mathrm{a}$ & $\mathrm{n} / \mathrm{a}$ & $\mathrm{n} / \mathrm{a}$ \\
\hline Insulation & $\begin{array}{c}h=0.68 \mathrm{~W} / \mathrm{m}^{2} \mathrm{~K} \\
\mathrm{x}^{\circ}=1.5 \mathrm{inch}\end{array}$ & $\begin{array}{c}\text { Equivalent } \\
\text { insulation thickness } \\
\text { is much less than } \\
2.9 \text { inch average }\end{array}$ & Improve Insulation \\
\hline
\end{tabular}

Spa Y's measured standby power of 270 watts must be reduced by 58 watts to bring it into compliance with the Title 20 standard (see Table 19). This spa's equivalent insulation thickness of 1.5 inches is significantly less than the average value of the passing spas of 2.9 inches. Therefore, the insulation should be improved in order to bring this spa into compliance.

From Equation 23 a minimum increase of 0.6 inches of R5.5 insulation is needed to bring this spa into compliance. This would bring the equivalent insulation thickness to 2.1 inches. Further improvements could be realized by increasing the insulation thickness to 2.9 inches. 
Table 20: Summary of the performance of Spa AA and proposed changes.

\begin{tabular}{|c|c|c|c|}
\hline \multirow{2}{*}{ Spa AA } & \multicolumn{3}{|c|}{$\mathbf{P}_{\text {meas }} \mathbf{2 5 1} \mathbf{~ W} / \mathbf{P}_{\text {reduce }} \mathbf{2 1} \mathbf{~ W}$} \\
\hline Contributor & Usage & Assessment & Proposed Change \\
\cline { 2 - 4 } Filtration Cycles & $22 \mathrm{~W}$ contrs / day & $\begin{array}{c}\text { Usage less than } \\
\text { typical, but } \\
\text { sufficient when } \\
\text { filtration during } \\
\text { heating cycles is } \\
\text { considered }\end{array}$ & None \\
\hline $\begin{array}{c}\text { Constant } \\
\text { Circulation }\end{array}$ & $\mathrm{n} / \mathrm{a}$ & $\mathrm{n} / \mathrm{a}$ & $\mathrm{n} / \mathrm{a}$ \\
\hline Insulation & $\mathrm{h}=0.76 \mathrm{~W} / \mathrm{m}^{2} \mathrm{~K}$ & $\begin{array}{c}\text { Equivalent } \\
\text { insulation thickness } \\
\text { is much less than } \\
2.9 \text { inch average }\end{array}$ & Improve Insulation \\
\hline
\end{tabular}

Spa AA's measured standby power of 251 watts must be reduced by 21 watts to bring it into compliance with the Title 20 standard (see Table 20). The amount of filtration probably should not be reduced to any less than its current two hours per day setting as this is already below the typical values used by most other spas.

This spa's equivalent insulation thickness of 1.3 inches is very low and should be improved in order to bring this spa into compliance.

From Equation 23 an increase of only 0.2 inches of R5.5 insulation is needed to bring this spa into compliance. This would bring the equivalent insulation thickness to 1.5 inches. Any further increases to the equivalent insulation thickness could also significantly reduce the required standby power. 


\section{Summary}

This analysis demonstrates that for each of the spas which failed to meet the standby power requirement solutions exist that can bring the spas into compliance. Moreover, these improvements can be implemented for little or no cost. These can include modest improvements to the insulation, replacement of a pump with a lower power model, or simply reprogramming the default duration or frequency of filtration cycles. The particulars of how these improvements could best be implemented rely on the existing design of each spa, and each spa should be analyzed in more detail by the manufacturer to ensure that any measures taken are targeted for maximum benefit. 


\section{9) Filtration - Discussion}

In the previous section, I make the assumption that a "good" amount of filtration for a portable electric spa is four hours per day or more. This assumption is based on my observation of common settings used by several of the spas in this study. This also assumes that the amount of time the filtration cycles operate is the most significant factor in determining if the filtration is sufficient. Other significant factors that have been ignored include: the volume of water in the spa, the volumetric flow rate of the water through the filters, the particle size captured by the filter, and the effect of stagnant vs. moving water on fungal and bacterial growth. Additional factors likely affect this as well.

According to Rich Martin of NSF International (formerly the National Sanitation Foundation), the safety standards for public spas typically require complete volumetric turnover every 30 minutes (personal communication, December 30, 2011). There is no equivalent industry requirement for portable electric spas (Jess Tudor of Coverplay, Inc., personal communication, November 23, 2008), but it seems safe to assume that manufacturers would want their spas to provide sufficient filtration to maintain sanitary conditions. If we assume that the 30 minute turnover is a good standard for portable electric hot tubs as well, for a 300 gallon hot tub (about middle of the range of spa volumes tested), this would require a flow rate of 10 gallons per minute.

Considering that during standby mode a spa is not in use and the cover is in place, it's clear that no additional material is introduced during standby mode that will need to be filtered. All material to be filtered is be introduced to the spa while in use, and generally 
during use the jets will be operating - flowing water through the filters in excess of 100 gallons per minute ${ }^{10}$. So during use, portable electric spas exceed the minimum flow rate required to effectively filter out all material introduced during use. Any additional water circulation during standby mode may serve other purposes, but does not seem to be necessary for removing foreign material from the spa.

With this in mind, it may be possible to control the filtration system such that after a certain period of non-use, when all the "filterable" material can be expected to have been trapped by the filters, the frequency or duration of filtration cycles is lessened to further reduce the standby power. In assessing the feasibility of such a setting the presence of non-filterable materials and organisms would have to be considered, as well as the presence or absence of cleaning chemicals in the water. It would also be necessary to consider other purposes for water circulation during standby mode such as the need to mix the water to maintain uniform temperature or to prevent stagnant water in pipes from freezing during winter.

\footnotetext{
${ }^{10}$ Flow rate estimated from a sample of jet pumps advertised on www.spaguts.com, www.yourpoolhq.com, and www.backyardplus.com.
} 


\section{0) Conclusion}

In establishing the regulation equation the Davis Energy Group sought to "require improvements to the lowest performing models, for which simple and cost effective improvements are readily available, without eliminating average and better performance products" $(2004$, p. 14). In the case of the 27 spas in this study, it appears they met their goal.

Of the 27 portable electric spas tested in this study, nine failed to meet the regulation. There wasn't one single reason that caused all nine to fail; however, in line with the regulation's intention, analysis indicates that each of these nine spas could be brought into compliance using relatively simple and inexpensive improvements. These improvements include moderate improvements to the insulation, reprogramming filtration cycles, and retrofitting spas with lower power circulation pumps.

Besides validating the intention of the Title 20 regulation, this study resulted in amendments and clarifications in the law. Most notably, this study identified the need for tighter control of the air and water temperatures during the test, and the effects these temperatures could have on the measured standby power. This resulted in amendments to Title 20 which specified tighter tolerances for the water and air temperatures, and also amendments adopting the temperature normalization equation developed in this study (Equation 9). The revised Title 20 regulation has been adopted by other states and also 
included in the APSP-14 standard for portable electric spa energy efficiency (discussed in the next chapter).

In addition, this study resulted in important findings such as an indication that the use of temperature normalization is valid, as well as demonstrating that the size of a spa does not give it an advantage or disadvantage in passing the Title 20 regulation. Further research into this topic would be valuable to further understand these and other related topics. 


\section{1) Recent Developments}

In the time since the testing at Cal Poly was completed, standards regulating the energy usage of portable electric spas have gone into effect in Connecticut (2009), Oregon (2009), Washington (2010), Arizona (2012), and Florida (2012) (Appliance Standards Awareness Project). In each of these states the standard was based on California's Title 20 regulation (Arizona, 2009; APSP, 2007; Grepps, 2011; Schechner, 2012; Washington State Legislature, 2012).

In addition, one of APSP's goals in funding the spa testing at Cal Poly was to develop a new APSP spa efficiency standard (APSP, 2008a). This document, which I will refer to as APSP-14, has been written, and on January 4, 2011 it was approved by the American National Standards Institute in partnership with the International Code Council. APSP-14 was written based off of Title 20, and was intended to meet the requirements for adoption by federal, state and local governments (APSP, 2011).

Notable aspects of APSP-14 include the following:

1. The core of APSP-14 is based on the Title 20 standard for portable electric spas including resolutions adopted in August 2008. The definition of the allowable standby power (Equation 1), the use of temperature normalization as described in Chapter 6 of this report, the

2. APSP-14 standardizes the fill volume of the spa. The fill volume is defined as "the halfway point between the bottom of the skimmer opening and the 
overflow level of the spa. In the absence of a wall skimmer, the fill volume is 6 inches (152 mm) below the overflow level of the spa" (APSP, 2011, pp. 1).

3. APSP-14 addresses the filtration concerns mentioned in Chapter 9 of this report. The standard requires a minimum filtration rate of " 12 water turns within a 24-hour period" (APSP, 2011, pp.3).

4. APSP-14 utilizes the temperature normalization equation developed during this study (Equation 9) in determining the standby power of the spa.

5. APSP-14 requires labeling to indicate the measured standby power. This is defined as "Per ANSI-14 Measured Standby Power Consumption XXXX Watts (Maximum Allowable Standby Power Consumption XXXX Watts)" (APSP, 2011, pp. 4)

\footnotetext{
APSP has been making efforts to encourage the adoption of APSP-14 into future state or federal government regulations. These include bills pending in New York state as well as a federal energy bill. In addition APSP-14 has been adopted into the International Code Council's IGCC “Green” Code (APSP, 2010).
} 


\section{2) Bibliography}

Advantech Co., Ltd. (2008, May). ADAM 4000 series data acquisition modules user's manual, edition 10.6.

Advanced Materials, Alberta Research Council, Inc. (2004). Summary report, thermal performance test of spas. Edmonton, Alberta, Canada: Author. Retrieved from http://www.arcticspas.com/wp-content/uploads/2011/09/Thermal-PerformanceTest-of-Spas.pdf

Arizona House of Representatives. (2009) House Bill 2332. Retrieved March 31, 2012 from http://www.azleg.gov/legtext/49leg/1r/bills/hb2332s.pdf

Appliance Standards Awareness Project. Portable Electric Spas. Retrieved March 31, 2012 from http://www.appliance-standards.org/product/portable-electric-spas

Association of Pool and Spa Professionals. (2007, October 31) Industry Currents January 31, 2007. Retrieved March 29, 2012, from http://www.apsp.org/utility/showArticle/?ObjectID=329\&find=title\%2020\&happ $=$ siteAdministrator

Association of Pool and Spa Professionals. (2008, January 23) Industry Currents January 23, 2008. Retrieved March 29, 2012, from http://www.apsp.org/utility/showArticle/?ObjectID=340\&find=title\%2020\&happ $=$ siteAdministrator 
Association of Pool and Spa Professionals. (2008, June 13) Portable spa stand-by energy test protocol, final version (draft \#10), rev. 20080613.

Association of Pool and Spa Professionals, (2010, June 6) Hot Tub Council News.

Retrieved March 31, 2012 from http://www.apsp.org/Public/Groups/CouncilsCommittees/HotTubCouncil/HTCNewsletter/index.cfm

Association of Pool and Spa Professionals, (2011, January 4) American National Standard for Portable Hot Tub Energy Efficiency (ANSI/APSP/ICC-14 2011). Alexandria, VA: Association of Pool and Spa Professionals.

BING, Federation of European Rigid Polyurethane Foam Associations. (2006, October 19). Thermal insulation materials made of rigid polyurethane foam (PUR/PIR). Brussels, Belgium: Author. Retrieved from http://www.pueurope.eu/site/fileadmin/Reports_public/BING_TECH_REP_on_Thermal_insulat ion_materials_made_of_rigid_polyurethane_foam.pdf

B\&B Electronics. (2006). Models: USOPTL4 and USPTL4, connect and isolate an RS422/485 network to your USB port (USxPTL4-1207ds). Retrieved from http://www.bb-elec.com/bb-elec/literature/USxPTL4-1207ds.pdf

California Energy Commission. (2008, August). 2008 Appliance efficiency rulemaking, phase 1, part b, docket \# 08-AAER-1B; Staff Report (CEC Publication No. CEC400-2008-023). Sacramento, CA: California Energy Commission. Retrieved from http://www.energy.ca.gov/2008publications/CEC-400-2008-023/CEC-400-2008023.pdf 
California Energy Commission. (2008, August). California code of regulations, Title 20. Public utilities and energy, Division 2. State Energy Resources Conservation and Development Commission (CEC Publication No. CEC-140-2008-001-REV1). Sacramento, CA: California Energy Commission Chief Counsels’ Office. Retrieved from http://www.energy.ca.gov/2008publications/CEC-140-2008001/CEC-140-2008- 001-REV1.pdf

California Energy Commission. (2009, August). 2009 Appliance Efficiency Regulations. (CEC Publication No. CEC-400-2009-013). Sacramento, CA: California Energy Commission Chief Counsels' Office. Retrieved July 7, 2012, from http://www.energy.ca.gov/2009publications/CEC-400-2009-013/CEC-400-2009013.PDF

Daniel L. Jerman Co. DLJ epoxy coated bronze water meters, models DLJ 50, DLJ 75, DLJ 7575, DLJ 100. Hackensack, NJ: Author. Retrieved February 11, 2009, from http://www.jerman.com/dljto1.pdf

Davis Energy Group, Energy Solutions. (2004, May 12). CASE Initiative for Title 20 Standards Development: Analysis of standards options for portable electric spas. Prepared for Pacific Gas and Electric Company. Retrieved from http://www.energy.ca.gov/appliances/2003rulemaking/documents/case_studies/C ASE_Portable_Spa.pdf

Fluke. (2002, March) Data Acquisition, detailed specifications, 2680A series - NetDAQ Hydra Series (Fluke Document No. 1264012 D-ENG-N Rev C). Everett, WA: 
Author. Retrieved January 4, 2012 from

http://assets.fluke.com/software/daq/1264012_.PDF

Grepps, Lisa. (2011, August 8) APSP Standard becomes federal law through the Virginia Graeme Baker pool and spa safety act. Retrieved March 31, 2012 from http://www.apsp.org/utility/showDocumentFile/?objectID=714.

Hioki. (2007, December 28). Hioki power quality analyzer 3196 (Hioki Document No. 3196E9-7ZE-00P). Japan: Author. Retrieved January 1, 2012, from http://www.deltatechnique.com/images/3196.pdf

Measurlogic. DTS 101 \& 105 single phase energy meters. Retrieved May 8, 2009, from http://www.measurlogic.com/MonitorsMeters/DinRailMount/Resources/DTS\%20 101-105\%20Sheet-09R2.pdf

Measurlogic. DTS 300, multi-channel power meter / transducer. Retrieved September 12, 2008, from http://www.measurlogic.com/MonitorsMeters/DinRailMount/Resources/DTS300s heet-07R.pdf

Measurlogic. MLG-SCT series, split-core current transformers. Retrieved September 12, 2008, from http://www.measurlogic.com/Resources/MLG-SCTseries-07R.pdf

Moran, M.J., \& Shapiro, H.N. (2004). Fundamentals of engineering thermodynamics $5^{\text {th }}$ edition. Hoboken, NJ: John Wiley \& Sons, Inc. 
Mufson, Steven. (2007, February 17) In energy conservation, Calif. sees light. The Washington Post, Retrieved August 5, 2009 from http://www.washingtonpost.com/wpdyn/content/article/2007/02/16/AR2007021602274.html

O'Haver, T.C. (2008, May 21) Fast smoothing function, fastsmooth.m Retrieved September 21, 2011, from http://www.mathworks.com/matlabcentral/fileexchange/19998-fast-smoothingfunction

Omega Engineering, Inc. (2005, May 5) Revised thermocouple reference tables, type J (Omega Document No. Z-203). Retrieved February 3, 2009, from http://www.omega.com/temperature/z/pdf/z203.pdf

Omega Engineering, Inc. Thermocouples - an introduction. Retrieved January 2, 2012, from http://www.omega.com/prodinfo/thermocouples.html

Rainer, Leo. (2008, May 9). Proposal Information Template for: Portable Electric Spa Test Method Revisions. Davis Energy Group: prepared for Pacific Gas and Electric Company. Retrieved from http://www.energy.ca.gov/appliances/2008rulemaking/documents/2008-0515_workshop/other/PGE_Proposal_Information_Template_for_Portable_Electric _Spa_Test_Method_Revisions.pdf

Rmax. (2008, June). Thermasheath-3 wall insulation. Retrieved from http://rmaxinc.com 
Schechner, Dan (2012, January 13). United They Stand Industry advocates emphasize the importance of working together for the common good. Pool \& Spa News. Retrieved March 31, 2012 from http://www.poolspanews.com/2012/011/011associations.html

The Spa Depot. Hot tub wiring diagram. [Adobe Flash image]. Retrieved December 31, 2011, from http://www.spadepot.com/spacyclopedia/wiring-hot-tub-spa.htm

Thorncroft, Glen E. (2005). ME 236 Thermal Measurements, spring 2005 course pack. San Luis Obispo, CA: El Corral Publications.

Washington State Legislature. (2012, January 4) Revised Code of Washington 19.260.040 Minimum efficiency standards..Retrieved March 31, 2012 from http://apps.leg.wa.gov/rcw/default.aspx?cite=19.260\&full=true

Watkins Manufacturing Corporation. (2007, November). Owner’s manual, HotSpring portable spas (Watkins Manufacturing Part No.301496, Rev A). Vista, CA: Author. Retrieved from http://www.hotspring.com/sites/default/files/pdfs/ownersmanual/hot-spring_spas_owners_manual_2008.pdf 


\section{A. Appendix A - Equipment}

The following equipment was used during the spa testing.

\section{Test Chamber Equipment}

\section{Insulated Test Chambers}

Three square, insulated test chambers were built with dimensions $10 \mathrm{ft}$ by $10 \mathrm{ft}$ by $8 \mathrm{ft}$ tall. Each spa was tested in one of the three chambers. The structures were framed using $2 \times 4$ 's, and the walls, floors, and ceilings were made from 2 inch thick polyisocyanurate commercial insulation sheathing with aluminum foil radiant barriers on each side. DOW TUFF-R commercial insulation sheathing (R-13) and RMax Thermasheath-3 (R-12.9) were both used. In addition, the floor insulation was covered in $1 / 2$ " thick ACX plywood to protect the insulation and provide a smooth surface for the spas to be placed on. 


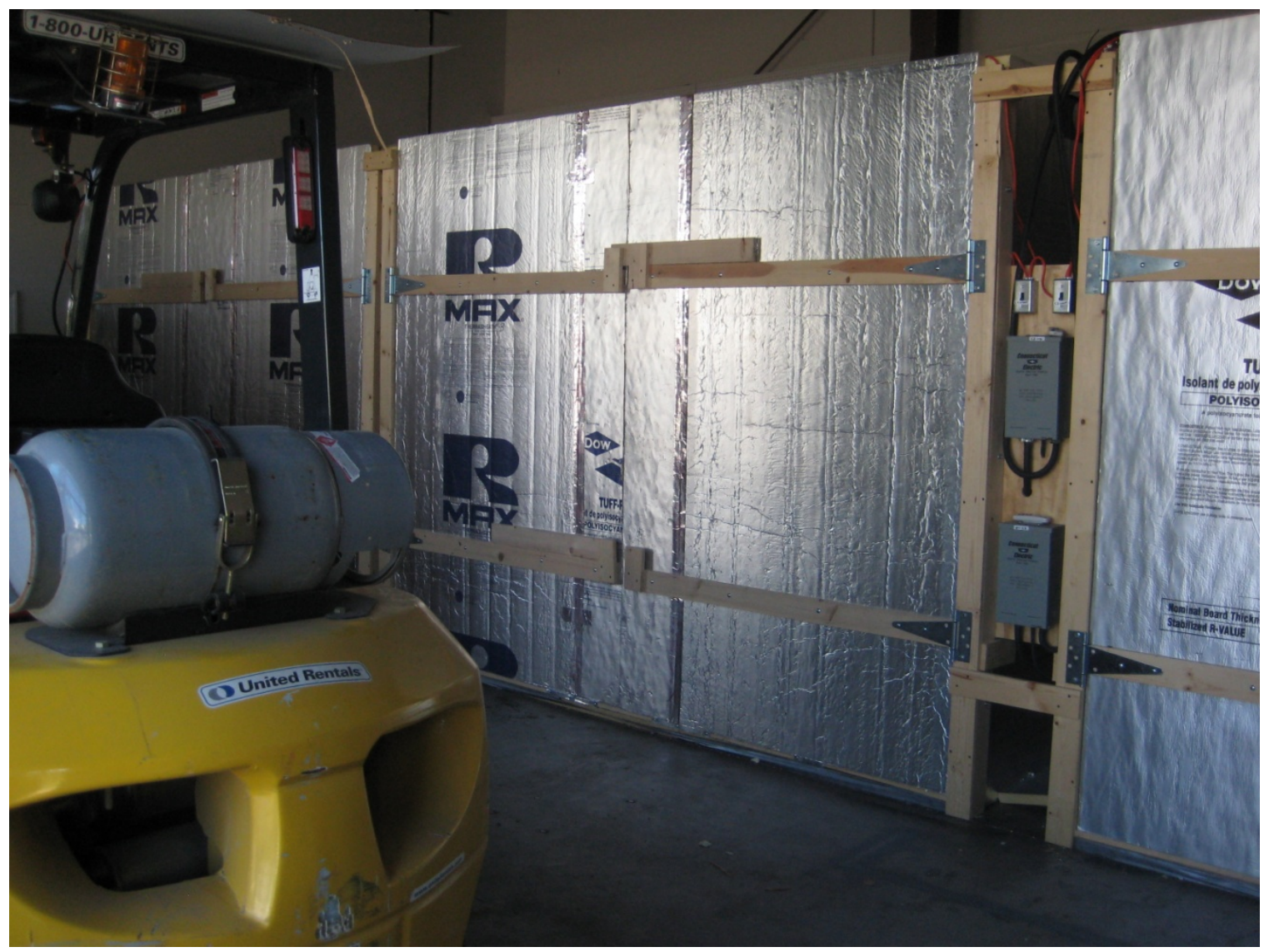

Figure A-1: Photo showing the front of the insulated test chambers used in this study. Centered in the photo is test chamber two, with test chamber one on the right and test chamber three on the left. Also shown is the forklift used to place the spas into the chambers.

\section{LG Air Conditioners}

One LG brand home window air conditioner was used per test chamber to control the air temperature within the chamber. For chamber one, an LG model number LWHD1000CR air conditioner was used. This air conditioner was rated with a cooling capacity of 10,000 BTU/h, input of $1050 \mathrm{~W}$ and an EER of 9.5 BTU/W-hr. For chambers two and three, LG model number LWHD1200FR air conditioners were used. This model was rated with a cooling capacity of $11,500 \mathrm{BTU} / \mathrm{h}$, input of $1170 \mathrm{~W}$ and an EER of $9.8 \mathrm{BTU} / \mathrm{W}-\mathrm{hr}$. 


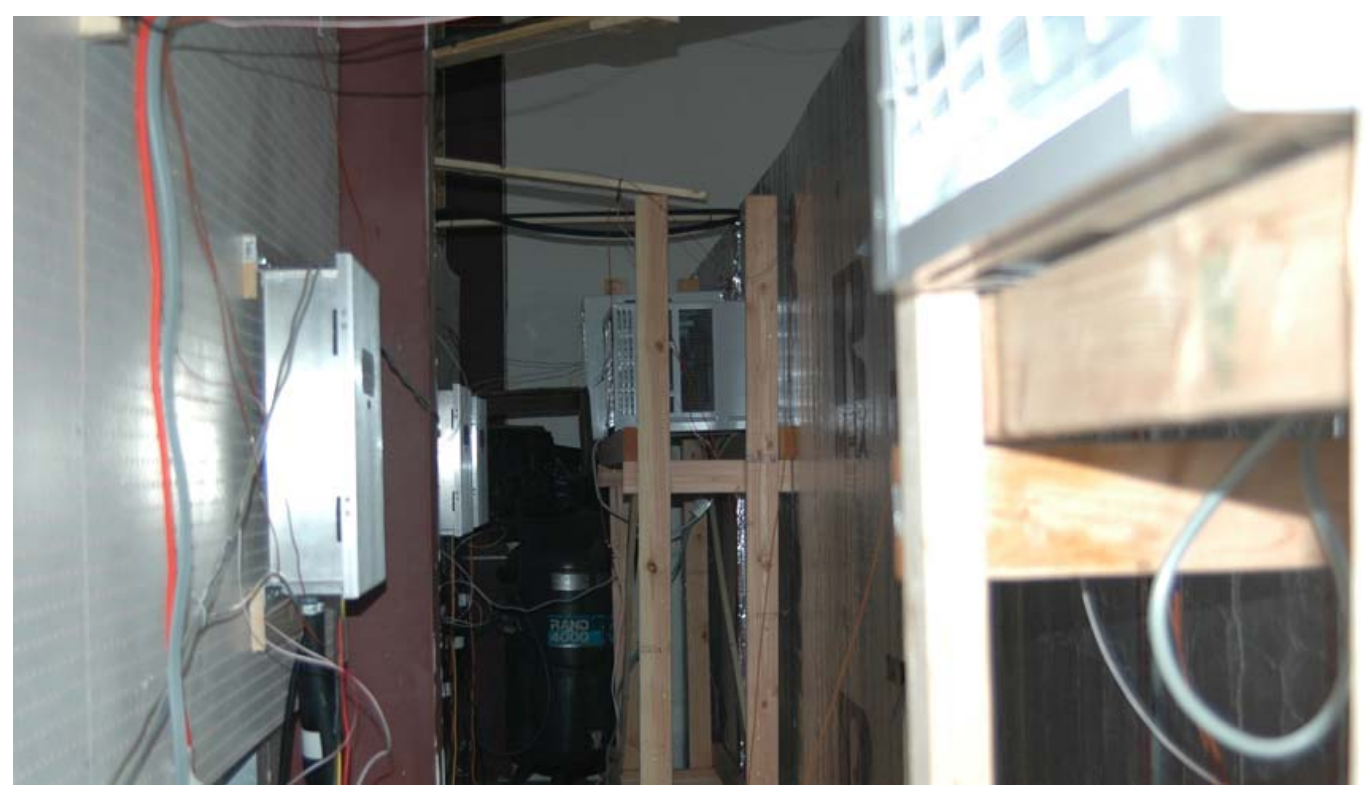

Figure A-2: Photo showing the rear of the test chambers with the LG air conditioners installed. Also shown are the three electrical boxes (one per chamber) mounted on the wall on the left side of the photo.

The temperature at which the chambers were to be kept (at or below $60^{\circ} \mathrm{F}$ ) was below the range of allowable set temperatures for the air conditioners, so it was necessary to modify the units to allow operation of the air conditioners at a lower temperature.

The air conditioners use thermistors installed in the return air paths to monitor the room air temperature. The resistances of the thermistors decrease at warmer temperatures and increase at cooler temperatures. The air conditioner will turn on when the resistance drops below a set threshold and turn off when the resistance rises beyond a set threshold. To force the air conditioners to operate below their minimum set temperatures, $100 \mathrm{k} \Omega$ resistors were soldered in parallel to each thermistor as shown in Figure A-3 (Angelo Pugliese of Dimension One Spas, personal communication, November 7, 2008). These reduced the equivalent resistance of the thermister circuit. This "tricked" the air 
conditioners into sensing that the chambers were warmer than they actually were, causing them to cool below the normal range.

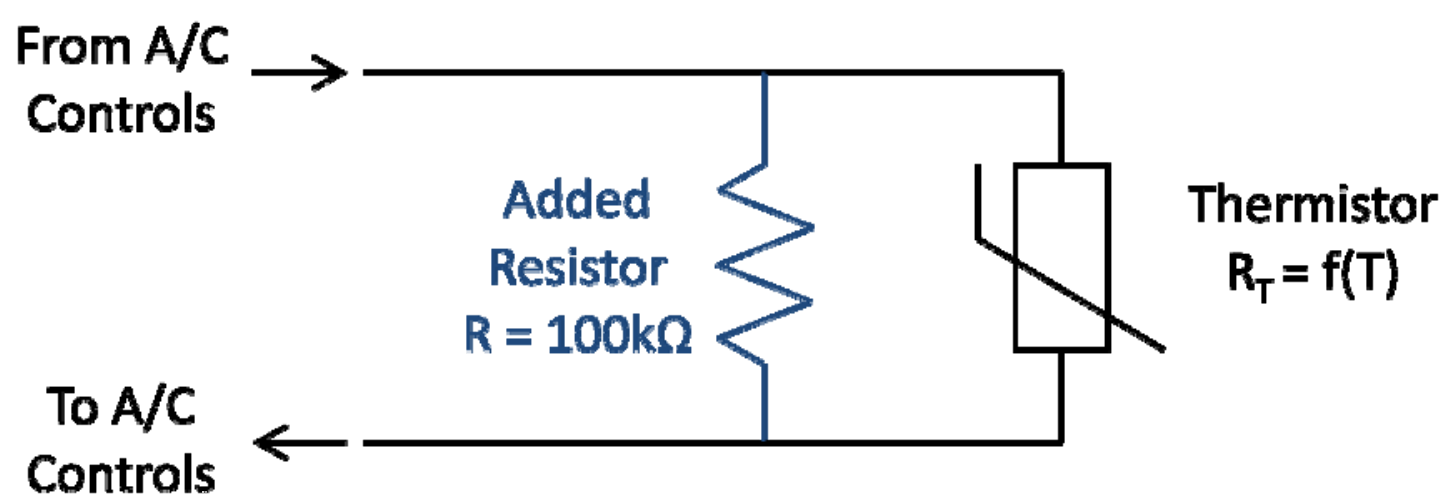

Figure A-3: Air Conditioner built-in thermistor with $100 \mathrm{k} \Omega$ resistor added in parallel.

\section{Connecticut Electric Ground Fault Circuit Interrupters}

In compliance with safety requirements and manufacturers recommendations, each chamber was equipped with a ground fault circuit interrupter (GFCI) made by Connecticut Electric. All electrical power was supplied to the spas through the GFCI. In the event of a short to ground the GFCI would "trip", cutting off all power to the spa. The GFC was also used to shut off power to the spa circuit while installing the wiring to each spa. 


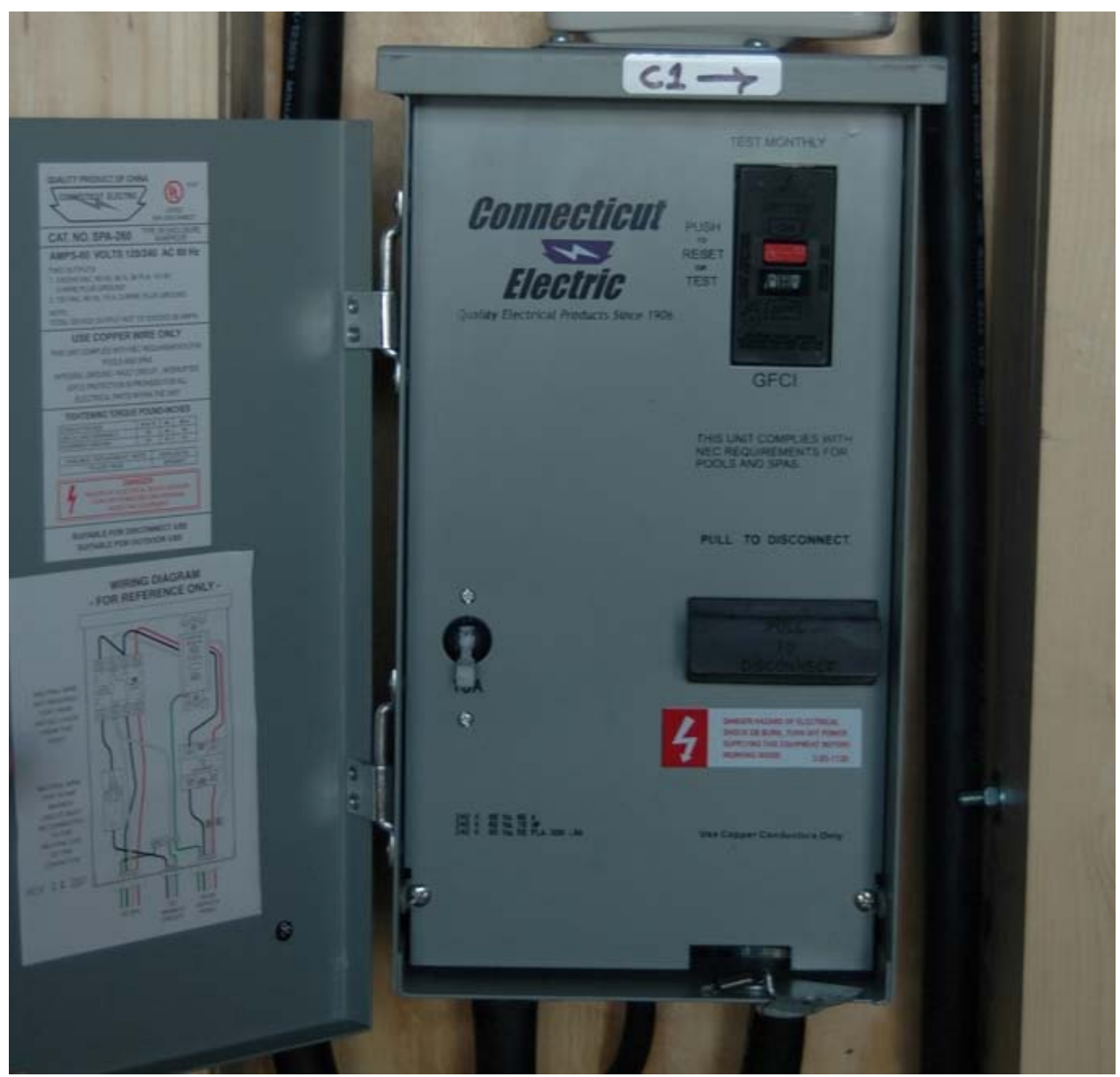

Figure A-4: Connecticut Electric ground fault circuit interrupter connected to test chamber one.

\section{Measurement / Data Acquisition System Equipment}

\section{DLJ75 Bronze Water Meter}

A 5/8"x3/4" DLJ75 bronze water meter from Daniel L. Jerman Co. was used to measure the volume of water added to each spa. This water meter is a multijet impeller meter. The error of the water meter is reported as $\pm 1.5 \%$ of the reading in the low flow range $(<1$ gpm), with greater accuracy reported at higher flow rates. While filling the spas in this study, flow rates were typically on the range of 5-15 gpm. According to the manufacturer, at this range the error in the water meter should produce results with 
approximately 100\% accuracy (Jon Jerman Jr., personal communication February 11, 2009). Based on this we can assume that the errors in the water meter accuracy are negligible compared with the uncertainty due to the water meter's resolution.

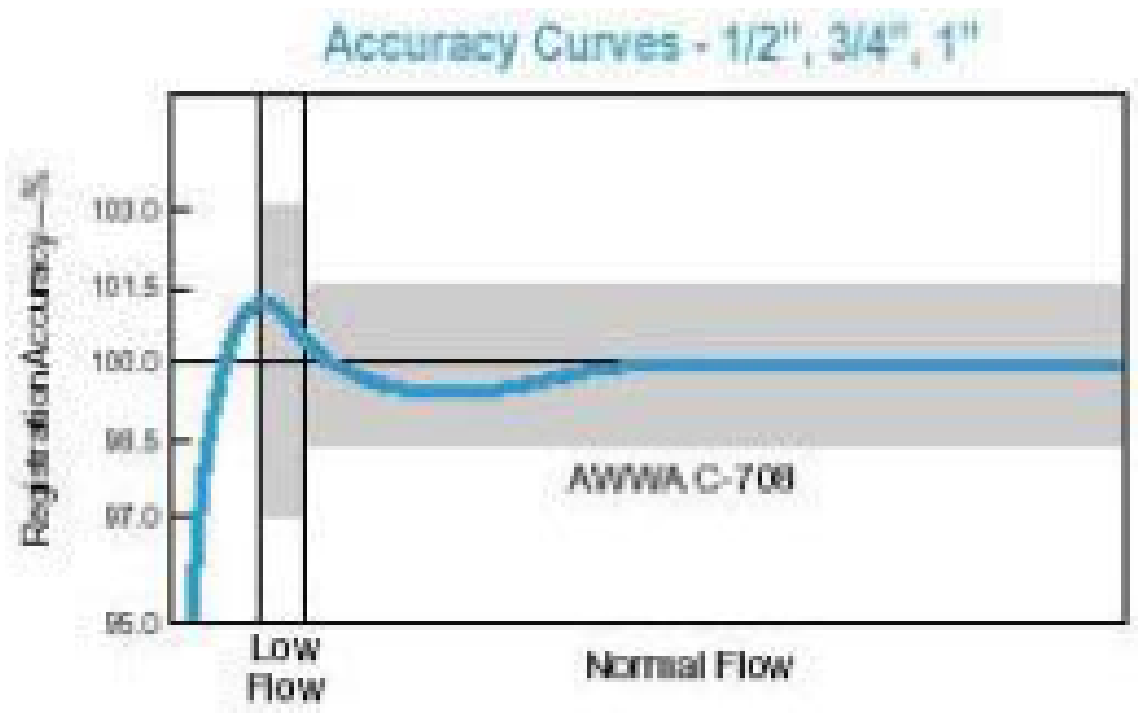

Figure A-5: Accuracy curve of the DLJ75 bronze water meter. Low flow is defined for this water meter as $1 / 4 \mathrm{gpm}$, with normal flow for this water meter defined as 1-20 gpm. During the filling of the hot tubs, the flow rate was maintained in the $5-15 \mathrm{gpm}$ range. Image from $D L J$ epoxy coated bronze water meters, models DLJ 50, DLJ 75, DLJ 7575, DLJ100. Copyright Daniel L. Jerman Co.

The water meter has a resolution of $1 / 10$ of a gallon with the needle able to drift over $\mathrm{a} \pm$ $1 / 10$ gallon range. Based on this, the uncertainty of the water meter is assumed to be \pm 1/10 gallon.

\section{J-Type Thermocouples}

J-type thermocouples were used to measure the temperature during testing. One J-type thermocouple was used to measure the air temperature within each chamber, while two Jtype thermocouples were used to measure the spa water temperature. 
J-type thermocouples are typically used on a range from 0 to $750{ }^{\circ} \mathrm{C}$ (32 to $1382{ }^{\circ} \mathrm{F}$ ) (Omega Engineering, Inc., Thermocouples) and have a sensitivity of approximately $0.0287 \mathrm{mV}$ per ${ }^{\circ} \mathrm{F}$, or $34.8^{\circ} \mathrm{F}$ per $\mathrm{mV}$ in the tested range. ${ }^{1}$

\section{ADAM 4019+ 8-Channel Analog Input Module}

One Adams 4019+ data acquisition module was used with each chamber to read the Jtype thermocouples from that chamber and transfer the data to the computer. The module can be set up for several different input ranges. An input range of $\pm 100 \mathrm{mV}$ was used. The manual reports the accuracy of the $4019+$ as $\pm 0.1 \%$ of full scale or better (Advantech Co., Ltd., 2008). This gives $\pm 0.1 \mathrm{mV}$ accuracy, which would translate to a temperature accuracy of approximately $\pm 3.5{ }^{\circ} \mathrm{F}^{2}$. However, comparisons between thermocouple measurements with the ADAM 4019+ and a NIST traceable thermocouple reader demonstrate an accuracy of within $\pm 1^{\circ} \mathrm{F}$. This is shown in the following section.

\footnotetext{
${ }^{1}$ Thermocouple sensitivity calculated in Appendix E. The tested range is from the minimum measured air temperature of $47.76^{\circ} \mathrm{F}$ to the maximum measured water temperature of $105.73^{\circ} \mathrm{F}$.

${ }^{2}$ Value is based on J-type thermocouple sensitivity of $0.0287 \mathrm{mV}$ per ${ }^{\circ} \mathrm{F}$ calculated in Appendix E.
} 


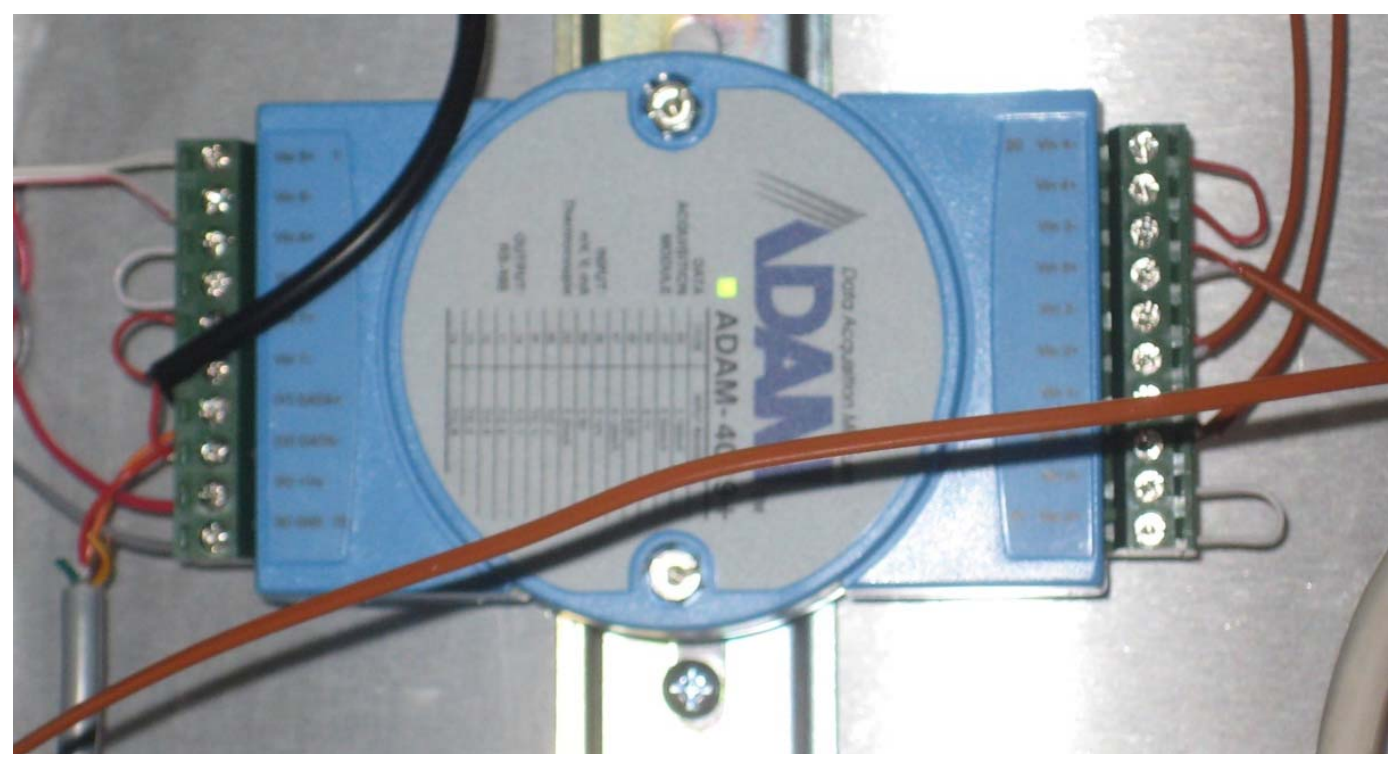

Figure A-6: ADAM 4019+ 8-Channel Analog Input Module as installed in one of the test chamber electrical boxes (boxes previously shown in Figure A-2).

\section{Measurlogic DTS 300 Multi-Channel Power Meter / Transducer}

One Measurlogic DTS 300 Multi-Channel Power Meter was used with each chamber to measure the voltages, currents, and power factors for that chamber and send the data to the computer. Measurlogic MGL-SCT-0750-050 transformers were used along with the DTS 300 to read the currents. The accuracies of the voltage, current and power factor are each reported by the manufacturer as $\pm 0.5 \%$ of the full scale (Measurlogic, DTS 300). In addition the MGL-SCT-0750-050 transformers used to measure the current have an accuracy of $\pm 1 \%$ (Measurlogic, MLG-SCT series). 


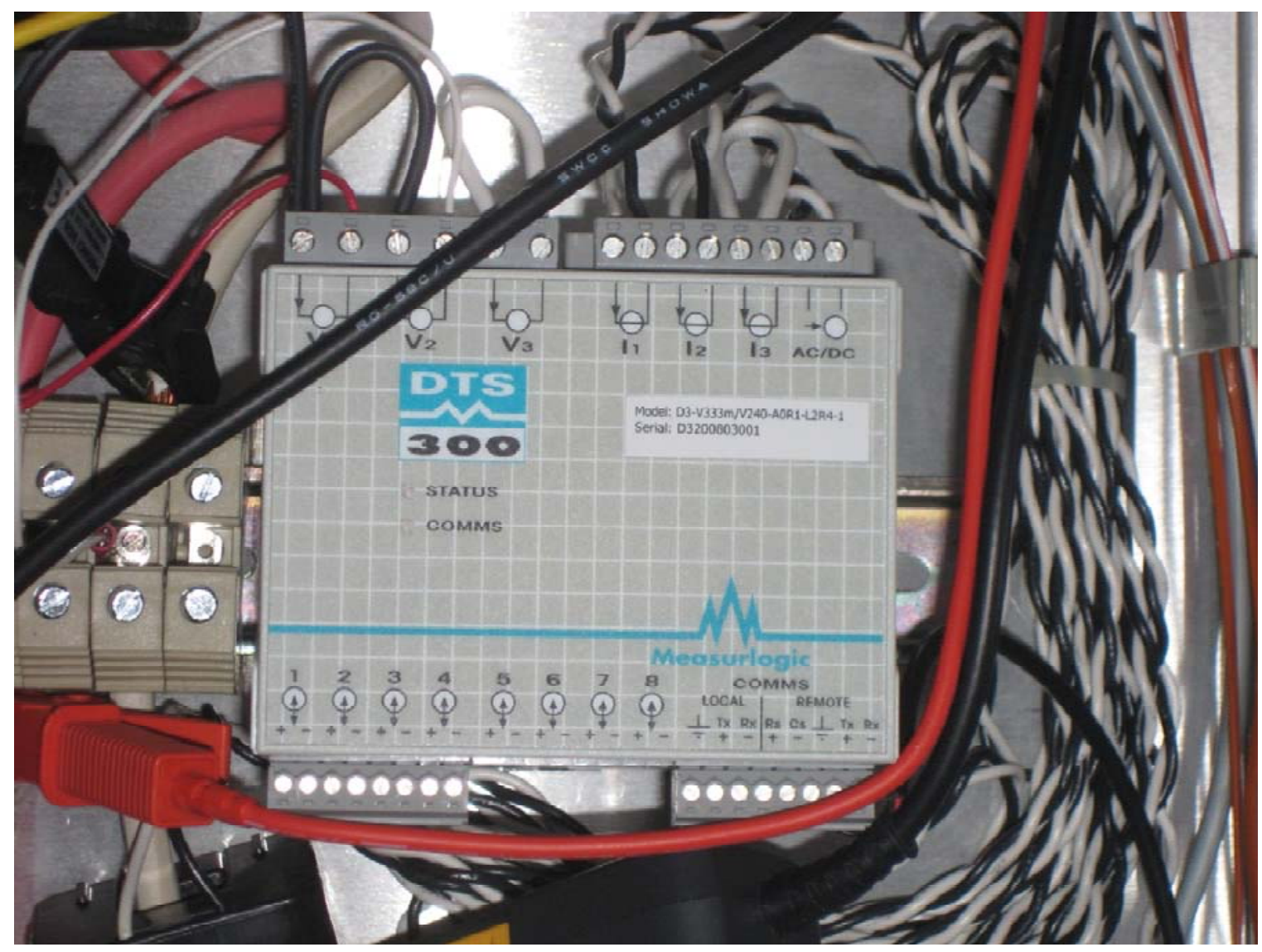

Figure A-7: Measurlogic DTS 300 Multi-Channel Power Meter as installed in one of the test chamber electrical boxes (boxes previously shown in Figure A-2).

\section{B\&B Electronics ULINX USB to RS 422/485 Converter}

A B\&B Electronics ULINX USB to RS 422/485 Converter, Model Number USPTL4, was used to convert the serial port data coming from the Measurlogic DTS 300 and the Adam 4019+ to a format readable by the computer's USB drive. It is assumed that this device does not contribute any errors to the measurements. 


\section{Balboa Spa Testing Software}

Spa testing software developed by Balboa was used to read the temperature and electrical data for each test chamber and record the data onto the computer in a tab-separated text file. The resolutions of the recorded data are presented in Table A-1.

Table A-1: Resolution of data recorded by Balboa Spa Testing Software

\begin{tabular}{|c|c|}
\hline Parameter & Resolution \\
\hline Current & $0.01 \mathrm{~A}$ \\
\hline Voltage & $0.1 \mathrm{~V}$ \\
\hline Power Factor & 0.001 \\
\hline Power & $10 \mathrm{~W}$ \\
\hline Temperature & $0.01^{\circ} \mathrm{F}$ \\
\hline
\end{tabular}

Due to the poor resolution of the recorded power, this value was ignored and the power was calculated as the product of the current, voltage and power factor (see Equation 2). 


\section{Data Acquisition Verification Equipment}

The following equipment was used to verify the accuracy of the data acquisition system and provide traceability to NIST.

\section{Fluke Hydra Series II Data Logger, Model 2635A}

Three Fluke Hydra Series II data loggers, one per chamber, were used along with J-type thermocouples to verify the accuracy of the primary temperature measurement equipment. The reported accuracy of the data loggers with J-type thermocouples with 3sigma confidence $\left(99.7 \%\right.$ confidence) is $\pm 0.37^{\circ} \mathrm{C}$ (Fluke, 2002), which translates to \pm $0.67^{\circ} \mathrm{F}$. These data loggers were calibrated on July 10,2008 with standards traceable to NIST, and were certified to be within the manufacturer's reported accuracy. The calibration certificates for each data logger can be found in Appendix B.

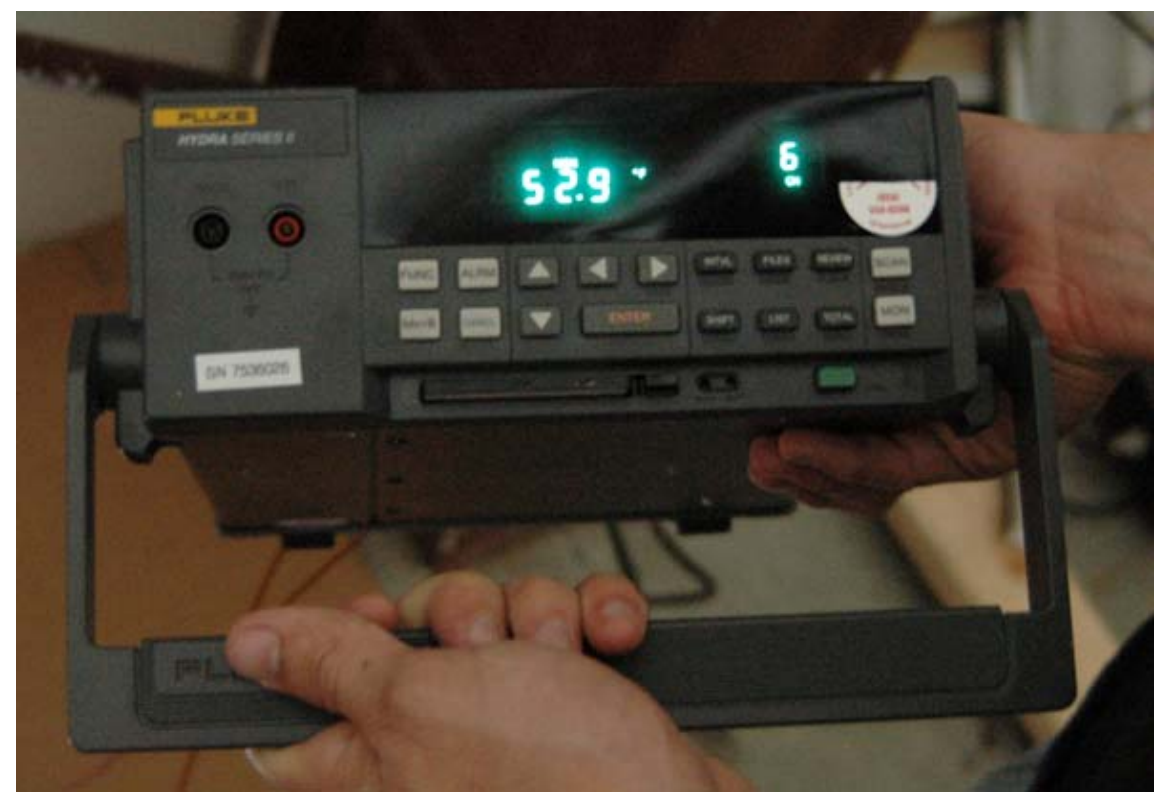

Figure A-8: One of the Fluke Hydra Series II Data Loggers used to verify the accuracy of the data acquisition system temperature measurements. 


\section{Hioki Digital Power Analyzers, Model \#3196-20 with 9660 Clamp-on Current}

\section{Sensors}

Three Hioki digital power analyzers, one per chamber, were used to verify the accuracy of the power measurement equipment. These power analyzers were calibrated on September 26, 2007 with standards traceable to NIST, and were certified to be within the manufacturer's reported accuracy. The calibration certificates for each power analyzer can be found in Appendix B. The manufactures reported accuracies are listed in Table

\section{A-2.}

Table A-2: Accuracy of Hioki 3196-20 digital power analyzers with 9660 clamp-on current sensors (Hioki, 2007).

\begin{tabular}{|c|c|c|}
\hline Measurement & Range & Accuracy \\
\hline Voltage & 0 to $300 \mathrm{~V}$ & $\pm 0.2 \%$ reading $\pm 0.1 \%$ full scale \\
\hline Current & 0 to $50 \mathrm{~A}$ & $\begin{array}{r} \pm 0.2 \% \text { reading } \pm 0.1 \% \text { full scale }+ \\
\text { clamp on sensor accuracy }\end{array}$ \\
\hline Active Power & 0 to $15 \mathrm{~kW}$ & $\begin{array}{r} \pm 0.2 \% \text { reading } \pm 0.1 \% \text { full scale }+ \\
\text { clamp on sensor accuracy }\end{array}$ \\
\hline Power Factor & -1.000 to +1.000 & \pm 0.001 \\
\hline Clamp-on sensor & 0 to $50 \mathrm{~A}$ & $\pm 0.3 \%$ reading $\pm 0.02 \%$ full scale \\
\hline
\end{tabular}




\section{B. Appendix B - Calibration Certification Documents}




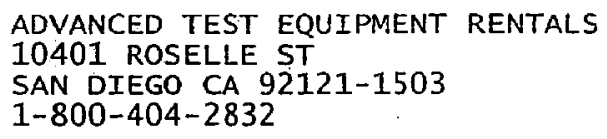

Printed:07/10/2008

At: $11: 59: 22$

CERTIFIED FOR:

Dimension one spas 2611 Business Park Dr Vista, CA 92083
CERTIFICATION NUMBER: C000003439

CALIBRATION CERTIFICATE

Date DUE: 07/10/2009

CALIBRATION DATE: $07 / 10 / 2008$

Advanced Test Equipment hereby certifies that the following instrument(s) meet a 11 manufacturer's pubijshed specifications and have been calibrated using standards whose accuracies are traceable to the National Institute of standards and Technology, have been derived from acceptable values of natural constants, or have been derived by ratio type of self-calibration techniques.

$\begin{array}{llll}\text { MFG } & \text { MODEL } & \text { SERIAL \# } & \text { DESCRIPTION } \\ \text { FLUK } & 2635 \mathrm{~A} & 7860030 & \text { Hydra Datalogger }\end{array}$

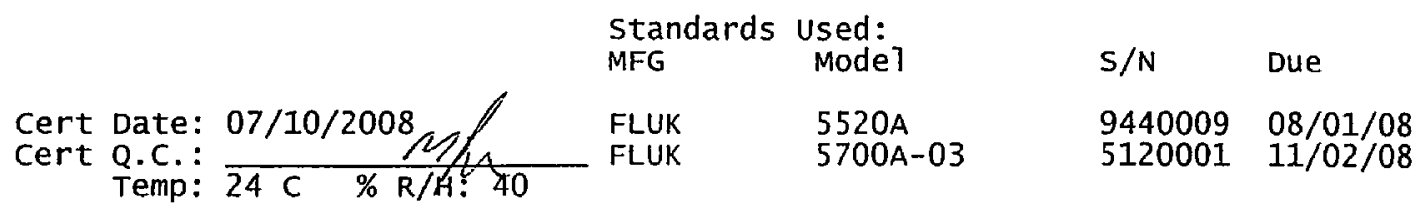

Signature:

STANDARD CALIBRATION

ADVANCED TEST EQUIPMENT RENTALS

10401 ROSELLE ST
SAN DIEGO, CA $92121-1503$ 
B-3

\author{
AOVANCED TEST EQUIPMENT RENTALS \\ 10401 ROSELLE ST \\ SAN DIEGO CA 92121-1503 \\ $1-800-404-2832$
}

Printed:07/10/2008

At $: 12: 03: 12$

CERTIFIED FOR :

Dimension one Spas

2611 Business Park Dr vista, CA 92083
CERTIFICATION NUMBER: CO00003441

CALIBRATION CERTIFICATE

Date Due: 07/10/2009

CALIBRATION DATE: 07/10/2008

\begin{abstract}
Advanced Test Equipment hereby certifies that the following instrument(s) meet a11 manufacturer's published specifications and have been calibrated using standards whose accuracies are traceable to the National Institute of standards and Technology, have been derived from acceptable values of natural constants, or have been derived by ratio type of self-calibration techniques.
\end{abstract}

MFG MODEL SERIAL \# DESCRIPTION

FLUK 2635A 7730012 Hydra Datalogger

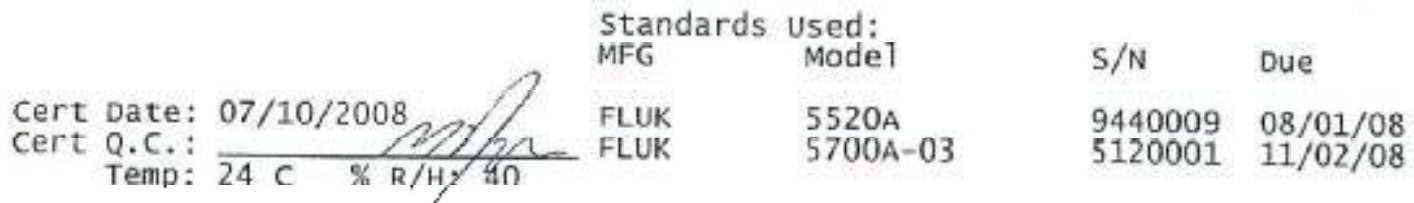

Signature:

STANDARD CAETBRATION

CERTIFIED BY:

ADVANCED TEST EQUIPMENT RENTALS

10401 ROSELLE ST

SAN DIEGO, CA 92121-1503 


\author{
ADVANCED TEST EQUIPMENT RENTALS \\ 10401 ROSELLE ST \\ SAN DIEGO CA 92121:-1503 \\ 1-800-404-2832
}

Printed:07/10/2008

At: $12: 01: 30$

CERTIFIED FOR:

Dimension one Spas

2611 Business Park Dr

vista, CA 92083
CERTIFICATION NUMBER: C000003440

CALIBRATION CERTIFICATE

Date Due: 07/10/2009

CALIBRATION DATE: 07/10/2008
CERTIFIED BY:

ADVANCED TEST EQUIPMENT RENTALS 10401 ROSELLE ST

SAN DIEGO, CA 92121-1503

Advanced Test Equipment hereby certifies that the following instrument(s) meet a77 manufacturer's published specifications and have been calibrated using standards whose accuracies are traceable to the National Institute of standards and Technology, have been derived from acceptable values of natural constants, or have been derived by ratio type of self-calibration techniques.

$\begin{array}{llll}\text { MFG } & \text { MODEL } & \text { SERIAL \# } & \text { DESCRIPTION } \\ \text { FLUK } & 2635 A & 7536026 & \text { Hydra Data7ogger }\end{array}$

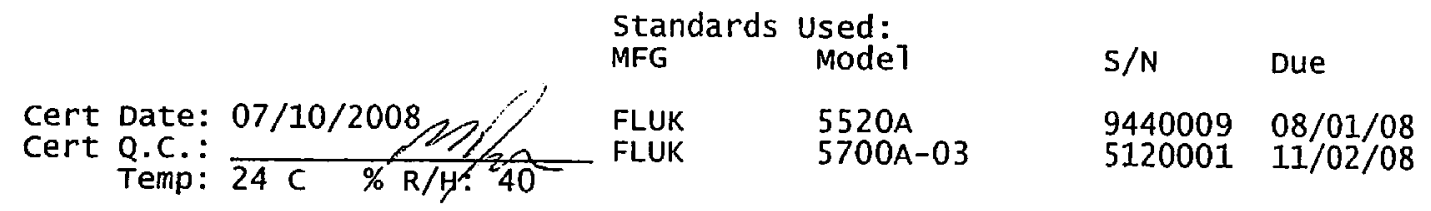

Signature:

STANDARD SAETBRATION 


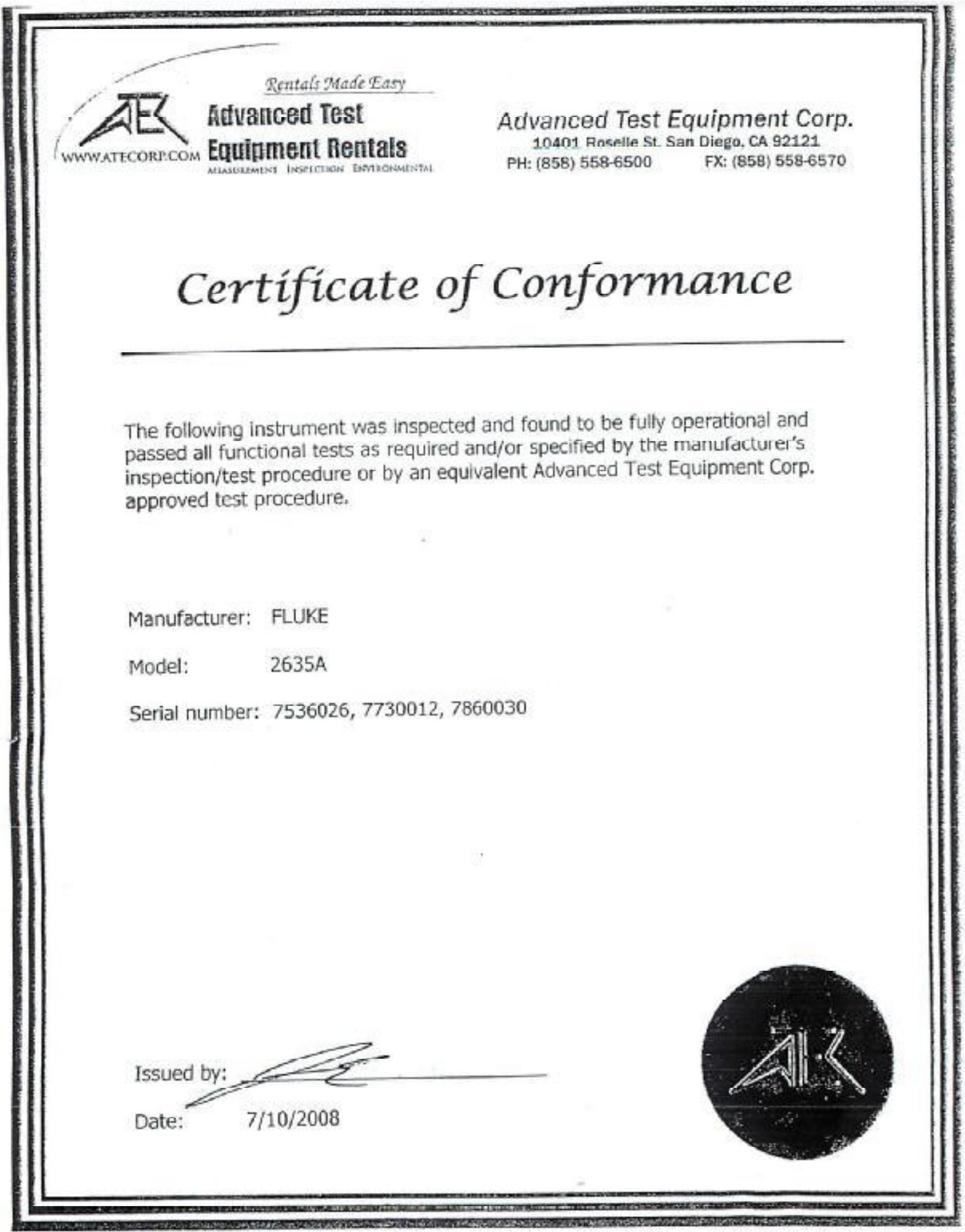




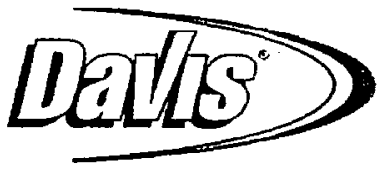

Calibration Laboratory

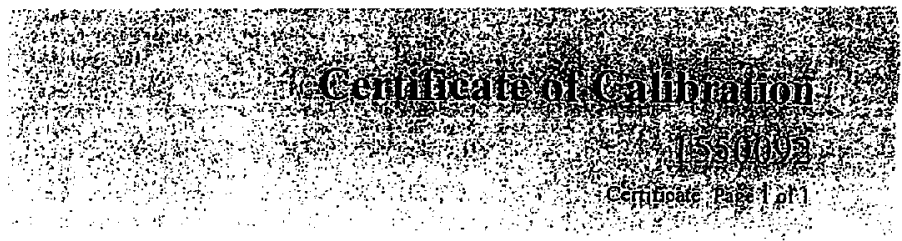

fustrumen focntification
Company ID: 100738

DIMENSION ONE SPAS

2611 BUSINESS PARK DRIVE

VISTA, CA., 92083

Instrument ID: 132

Manufacturer: HIOKI

Description: DIGITAL POWER ANALYZER

Accuracy: Mir. Specifications

PO Number: RM92807

Model Number: 3196-20

Serial Number. 51028209

Sertineate fntormaliom

\author{
Reason For Service: CALIBRATION \\ Type of Cal: NORMAL \\ As Found Condilion: IN TOLtKANCE \\ As Left Condition: LEFT AS FOUND \\ Procedure: T.0.33K1-4-2022-1 DIGITAL POWER ANALYZER \\ Remarks:
}

Technician: JULIO NETTO

Cal Date: $26 \mathrm{Sep} 2007$

Cal Due Late: $26 \mathrm{Sep} 2008$

Interval: 12 MONTHS

Temperature: $22.0 \mathrm{C}$

Humidity: $40.0 \%$

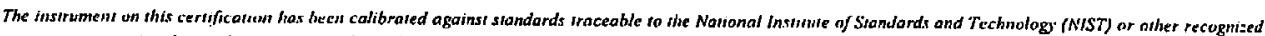

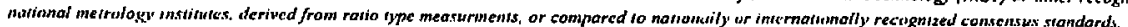

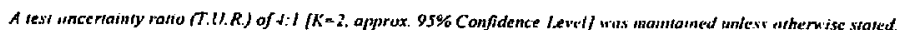

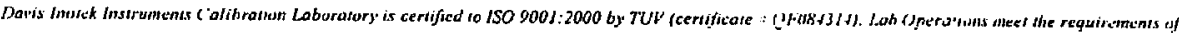

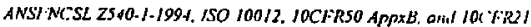

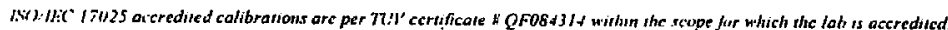

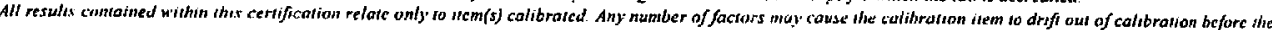
insurumen's calibrasion interval has expired.

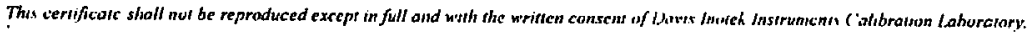

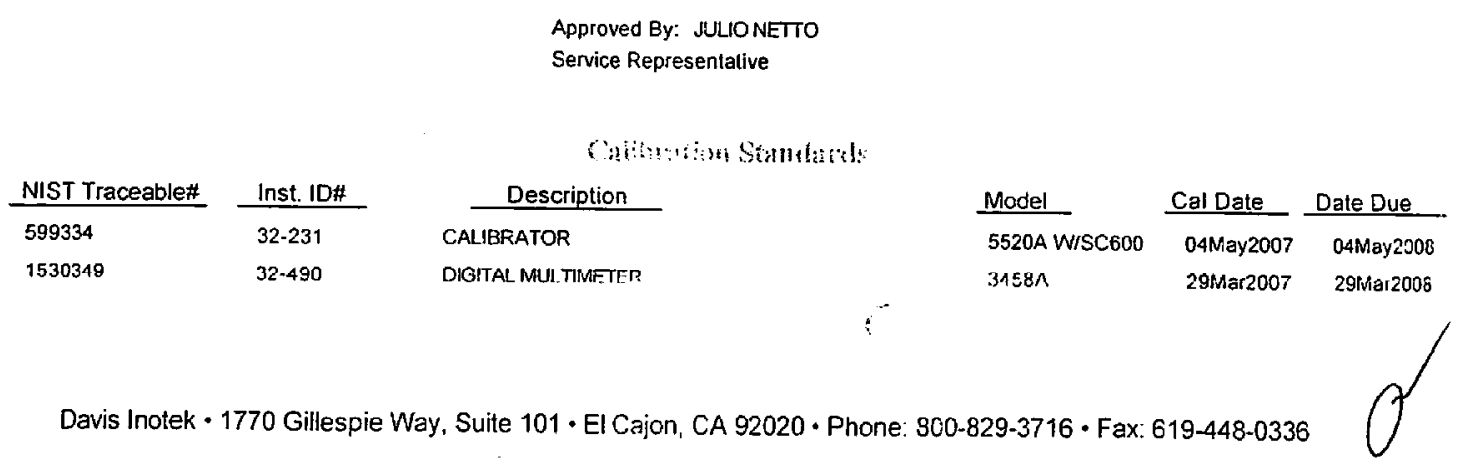




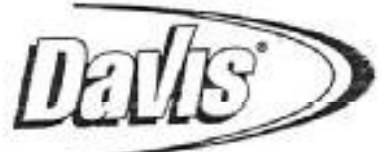

Calibration Laboratory

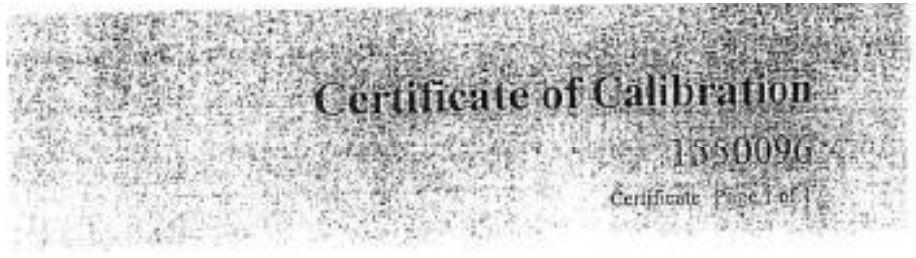

Inst - wat tentilication

Company ID: 100738

PO Number: RM92807

DIMENSION ONE SPAS

2611 BUSINESS PARK DRIVE

VITA, CA, 92083

Instrument ID: 127

Manufacturer: HIOKI

Model Number: $3195-20$

Description: DIGITAL POWER ANALYZER

Serial Number. 50420380

Certi mate foforttatius

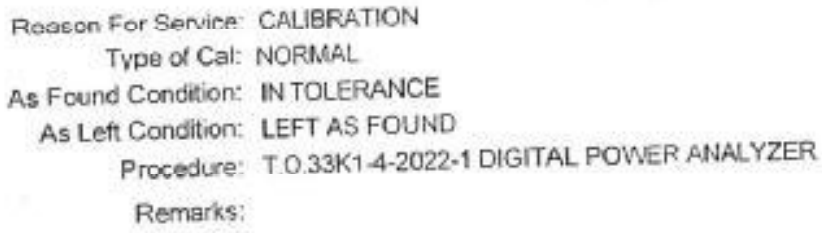

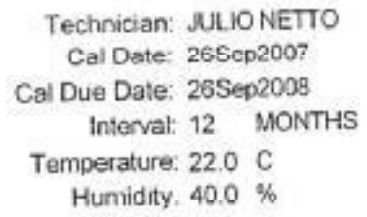

\footnotetext{
The

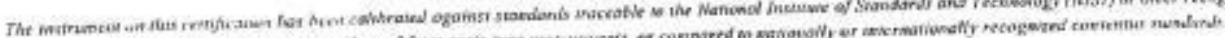

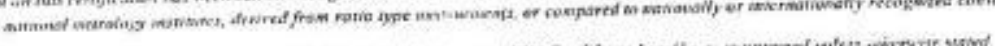

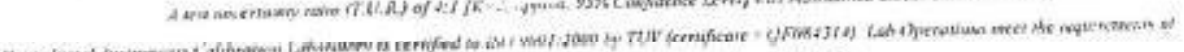

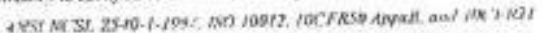

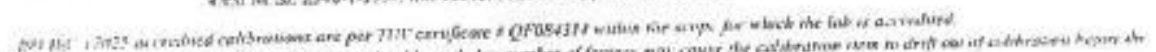

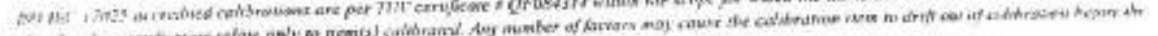

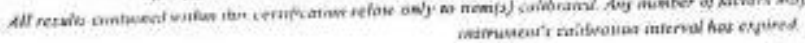

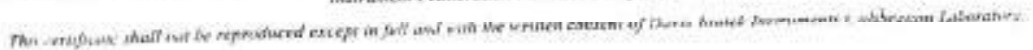

Approved tsy: JTHONETTO

Service ficpresentative

\begin{tabular}{|c|c|c|c|c|c|}
\hline NIST Traceable H & Inst ID\# & Description & Model & Cal Date - & Date Gue \\
\hline 599334 & $32-231$ & CAUIBRATOR & 5520 A WOSCEAO0 & $0410 y 2607$ & $040 \% 2008$ \\
\hline 1530349 & 32,490 & DGGIAL MULTIUE: : & $3458 \mathrm{~A}$ & $29 \mathrm{Mar} 20 \mathrm{Ct}$ & zedarase: \\
\hline
\end{tabular}

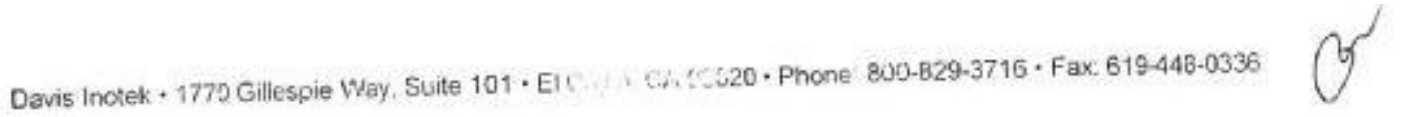




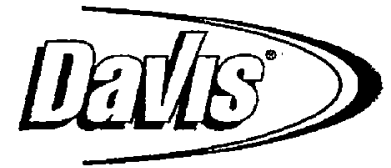

Calibration Laboratory

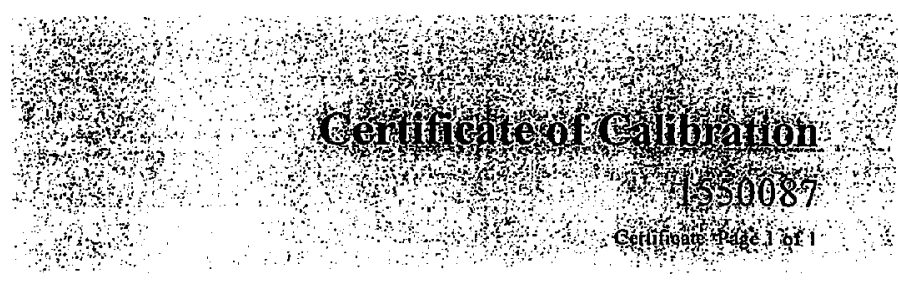

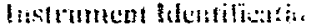

PO Number: RM92807

Company ID: 100738

DIMENSION ONE SPAS

2611 BUSINESS PARK DRIVE

VISTA, CA., 92083

Instrument ID: 126

Model Number: $3196-20$

Manufacturer: HIOKI

Serial Number: $\mathbf{5 1 1 1 9 2 1 0}$

Description: DIGITAL POWER ANALYZER

Accuracy: Mfr. Specifications

Reason For Service: CALIBRATION

Type of Cal: NORMAL

As Found Condition: IN TOLERANCE

As Left Condition: LEFT AS FOUND

Procedure: T.0.33K1-4-2022-1 DIGITAL POWER ANALYZER

Remarks:
Cerfitcate Intizumatim

\author{
Technician: JULIO NETTO \\ Cal Date: $26 \operatorname{Sep} 2007$ \\ Cal Due Date: 26Sep2008 \\ Interval: 12 MONTHS \\ Temperature: $22.0 \mathrm{C}$ \\ Humidity: $40.0 \%$
}

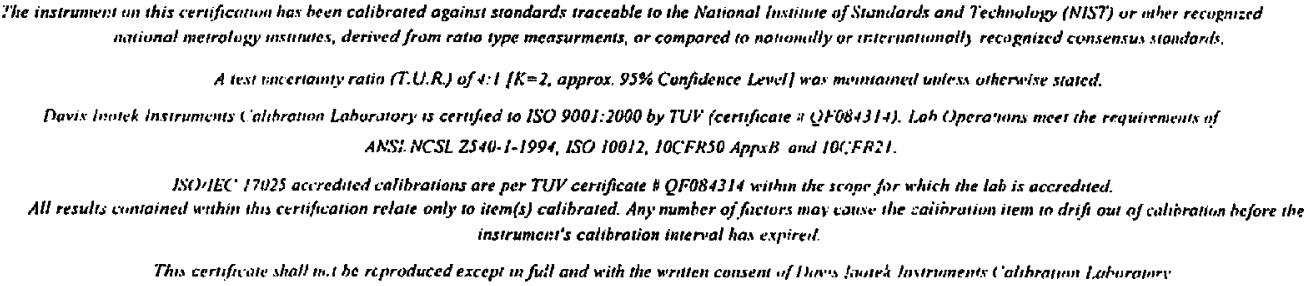

Catimation Standarit

\begin{tabular}{lll} 
NIST Traceable\# & Inst. IDH \\
\cline { 1 - 1 } 599334 & $32-231$ \\
1530349 & $32-490$
\end{tabular}

$\frac{\text { Description }}{\text { CALIBRATOR }}$

\begin{tabular}{|c|c|c|}
\hline Model & Cal Date & Date Due \\
\hline $5520 \mathrm{~A}$ WISC600 & $04 \mathrm{May} 2007$ & 04 May 2008 \\
\hline $3458 \mathrm{~A}$ & 29Mar2007 & 29Mar200e \\
\hline
\end{tabular}

Davis Inotek • 1770 Gillespie Way, Suite 101 • El Cajon, CA 92020 • Phonє: 800-829-3716 - Fax: 619-448-0336 


\section{Appendix C - Equipment Accuracy and Error Propagation}

\section{NIST Traceability of Temperature Measurements}

The test procedure requires that the accuracies of the temperature and power measurements be verified against NIST (National Institute of Standards and Technology) certified equipment. To verify the temperature measurements one NIST-certified Fluke Hydra Series II Data Logger was used per chamber with two J-type thermocouples - one located next to the chamber air temperature thermocouple, and one submerged in the spa water near the primary and secondary water temperature thermocouples. The air and water temperatures recorded by the data acquisition system were compared with those of the Fluke Data Loggers at eleven times over the course of ten days. The three tables below display the temperature measurements for all three test chambers as compared to the NIST-certified Fluke Data Loggers. At the time of testing, the accuracy of the Fluke Data Loggers with J-type thermocouples were certified to be $\pm 0.67^{\circ} \mathrm{F}$. Scanned copies of the calibration documents can be found in Appendix B. 
Table C-1: Comparison of temperature readings from the data acquisition system (DAQ) and NIST-certified Fluke data Logger for test chamber 1 . All values are given in units of ${ }^{\circ} \mathrm{F}$.

\begin{tabular}{|c|c|c|c|c|c|c|}
\hline \multirow[b]{2}{*}{ Reading } & \multicolumn{2}{|c|}{ Air Temperature } & \multicolumn{2}{|c|}{ Spa Temperature } & \multicolumn{2}{|c|}{ Error (DAQ - Fluke) } \\
\hline & $D A Q$ & Fluke & $D A Q$ & Fluke & Air & Spa \\
\hline 1 & 57.74 & 58.0 & 102.22 & 101.9 & -0.26 & 0.32 \\
\hline 2 & 58.87 & 58.7 & 102.66 & 102.3 & 0.17 & 0.36 \\
\hline 3 & 58.22 & 58.4 & 103.22 & 102.9 & -0.18 & 0.32 \\
\hline 4 & 58.32 & 58.4 & 103.10 & 102.7 & -0.08 & 0.40 \\
\hline 5 & 57.88 & 57.8 & 103.29 & 102.9 & 0.08 & 0.39 \\
\hline 6 & 57.95 & 58.1 & 103.10 & 102.9 & -0.15 & 0.20 \\
\hline 7 & 54.69 & 54.9 & 102.87 & 102.7 & -0.21 & 0.17 \\
\hline 8 & 54.96 & 55.6 & 102.93 & 102.7 & -0.64 & 0.23 \\
\hline 9 & 58.43 & 58.6 & 102.45 & 102.1 & -0.17 & 0.35 \\
\hline 10 & 67.24 & 66.8 & 103.39 & 102.9 & 0.44 & 0.49 \\
\hline \multirow[t]{4}{*}{11} & 64.21 & 63.6 & 103.39 & 102.8 & 0.61 & 0.59 \\
\hline & \multicolumn{4}{|c|}{ Mean error, $\bar{x}$} & -0.04 & 0.35 \\
\hline & \multicolumn{4}{|c|}{ Standard deviation, $s^{a}$} & 0.35 & 0.12 \\
\hline & \multicolumn{4}{|c|}{ Total population error uncertainty (95\% Confidence) ${ }^{b}$} & 0.81 & 0.29 \\
\hline
\end{tabular}

Table C-2: Comparison of temperature readings from the DAQ and NIST-certified Fluke data Logger for test chamber 2 . All values are given in units of ${ }^{\circ} \mathrm{F}$.

\begin{tabular}{|c|c|c|c|c|c|c|}
\hline \multirow[b]{2}{*}{ Reading } & \multicolumn{2}{|c|}{ Air Temperature } & \multicolumn{2}{|c|}{ Spa Temperature } & \multicolumn{2}{|c|}{ Error (DAQ - Fluke) } \\
\hline & $D A Q$ & Fluke & $D A Q$ & Fluke & Air & Spa \\
\hline 1 & 58.99 & 59.2 & 102.39 & 102.1 & -0.21 & 0.29 \\
\hline 2 & 59.30 & 58.9 & 102.76 & 102.0 & 0.40 & 0.76 \\
\hline 3 & 59.72 & 59.7 & 101.97 & 101.3 & 0.02 & 0.67 \\
\hline 4 & 55.71 & 55.2 & 102.39 & 101.6 & 0.51 & 0.79 \\
\hline 5 & 54.44 & 53.6 & 102.76 & 102.1 & 0.84 & 0.66 \\
\hline 6 & 54.11 & 53.4 & 102.87 & 102.1 & 0.71 & 0.77 \\
\hline 7 & 55.38 & 55.1 & 102.28 & 101.6 & 0.28 & 0.68 \\
\hline 8 & 56.36 & 56.3 & 102.33 & 101.7 & 0.06 & 0.63 \\
\hline 9 & 59.14 & 59.2 & 102.33 & 101.7 & -0.06 & 0.63 \\
\hline 10 & 55.00 & 54.7 & 104.93 & 104.4 & 0.30 & 0.53 \\
\hline \multirow[t]{4}{*}{11} & 54.86 & 54.4 & 104.89 & 104.4 & 0.46 & 0.49 \\
\hline & \multicolumn{4}{|c|}{ Mean error, $\bar{x}$} & 0.30 & 0.63 \\
\hline & \multicolumn{4}{|c|}{ Standard deviation, $s^{a}$} & 0.33 & 0.15 \\
\hline & \multicolumn{4}{|c|}{ Total population error uncertainty (95\% Confidence) $^{b}$} & 0.76 & 0.34 \\
\hline
\end{tabular}

a. Calculated from the population standard deviation $s=\sqrt{\frac{1}{n-1} \sum_{i=1}^{n}\left(x_{i}-\bar{x}\right)}$

b. Calculated from the equation $u= \pm t s \sqrt{\frac{1}{n}+1}$ with $t=2.228$ (95\% confidence $\left.w / n=11\right)$ 
Table C-3: Comparison of temperature readings from the DAQ and NIST-certified Fluke data Logger for test chamber 3 . All values given in units of ${ }^{\circ} \mathrm{F}$.

\begin{tabular}{|c|c|c|c|c|c|c|}
\hline \multirow[b]{2}{*}{ Reading } & \multicolumn{2}{|c|}{ Air Temperature } & \multicolumn{2}{|c|}{ Spa Temperature } & \multicolumn{2}{|c|}{ Error (DAQ - Fluke) } \\
\hline & $D A Q$ & Fluke & $D A Q$ & Fluke & Air & Spa \\
\hline 1 & 59.03 & 58.8 & 102.70 & 102.2 & 0.23 & 0.50 \\
\hline 2 & 58.80 & 58.7 & 102.49 & 102.0 & 0.10 & 0.49 \\
\hline 3 & 59.45 & 59.4 & 102.60 & 102.0 & 0.05 & 0.60 \\
\hline 4 & 55.88 & 55.9 & 103.93 & 103.1 & -0.02 & 0.83 \\
\hline 5 & 56.15 & 56.2 & 103.45 & 102.7 & -0.05 & 0.75 \\
\hline 6 & 57.11 & 57.0 & 103.45 & 102.7 & 0.11 & 0.75 \\
\hline 7 & 52.87 & 53.0 & 102.70 & 102.1 & -0.13 & 0.60 \\
\hline 8 & 54.38 & 54.5 & 102.66 & 102.0 & -0.12 & 0.66 \\
\hline 9 & 57.01 & 56.8 & 103.22 & 102.7 & 0.21 & 0.52 \\
\hline 10 & 52.60 & 52.2 & 105.35 & 104.4 & 0.40 & 0.95 \\
\hline \multirow[t]{4}{*}{11} & 52.77 & 52.2 & 105.35 & 104.3 & 0.57 & 1.05 \\
\hline & \multicolumn{4}{|c|}{ Mean error, $\bar{x}$} & 0.12 & 0.70 \\
\hline & \multicolumn{4}{|c|}{ Standard deviation, $s^{a}$} & 0.22 & 0.19 \\
\hline & \multicolumn{4}{|c|}{ Total population error uncertainty (95\% Confidence) $^{b}$} & 0.51 & 0.43 \\
\hline
\end{tabular}

a. Calculated from the population standard deviation $s=\sqrt{\frac{1}{n-1} \sum_{i=1}^{n}\left(x_{i}-\bar{x}\right)}$

b. Calculated from the equation $u= \pm t s \sqrt{\frac{1}{n}+1}$ with $t=2.228(95 \%$ confidence $w / n=11)$

The error is defined as the difference between the temperature readings from the Data Acquisition System and the NIST-certified Fluke Data logger. The error is assumed to be normally distributed. The error between the DAQ and Fluke readings for any temperature measurement can be assumed with $95 \%$ confidence to fall into the range given by

$$
x=\bar{x} \pm t s \sqrt{\frac{1}{n}+1}
$$

Where $x$ is the error between the DAQ and Fluke readings, $\bar{x}$ is the mean error (or measurement offset) between the Fluke data loggers and the DAQ, $t$ is the student- $t$ statistic for the sample size and confidence level $(t=2.228$ for a sample size of 11 and 
$95 \%$ confidence), $s$ is the standard deviation of the sample, and $n$ is the number of measurements in the sample.

The actual temperature can then be determined from the temperature measured by the data acquisition system, plus the measurement offset, plus or minus the root sum square of the Fluke uncertainty and the population uncertainty between the Fluke and DAQ measurements. This is shown in equation 25 below.

$$
T=T_{D A Q}+\bar{x}_{F l u k e, D A Q} \pm\left[\left(U_{F l u k e}\right)^{2}+\left(t s \sqrt{\frac{1}{n}+1}\right)^{2}\right]^{1 / 2}
$$

From the information above and with the Fluke data logger accuracies of $\pm 0.67^{\circ} \mathrm{F}$ the actual temperature as a function of the DAQ system temperature for each chamber using equation 25. Table C-4 presents these functions as well as the upper and lower limits of the uncertainty between the temperatures measured by the data acquisition system and the actual temperature. 
Table C-4: Equations for the actual temperature as a function of the measured DAQ temperature and uncertainties at $95 \%$ confidence.

\begin{tabular}{|c|c|c|c|}
\hline & \multicolumn{3}{|c|}{ Air Temperature } \\
\hline & Function & Upper Limit & Lower Limit \\
\hline Chamber 1 & $T_{\text {Air }}=T_{A i r, D A Q}-0.04^{\circ} \mathrm{F} \pm 1.05^{\circ} \mathrm{F}$ & $+1.01^{\circ} \mathrm{F}$ & $-1.08^{\circ} \mathrm{F}$ \\
\hline Chamber 2 & $T_{A i r}=T_{A i r, D A Q}+0.30^{\circ} \mathrm{F} \pm 1.01^{\circ} \mathrm{F}$ & $+1.31^{\circ} \mathrm{F}$ & $-0.71^{\circ} \mathrm{F}$ \\
\hline \multirow[t]{3}{*}{ Chamber 3} & $T_{A i r}=T_{A i r, D A Q}+0.12^{\circ} \mathrm{F} \pm 0.84^{\circ} \mathrm{F}$ & $+0.96^{\circ} \mathrm{F}$ & $-0.72^{\circ} \mathrm{F}$ \\
\hline & \multicolumn{3}{|c|}{ Spa Temperature 1} \\
\hline & Function & Upper Limit & Lower Limit \\
\hline Chamber 1 & $T_{S p a 1}=T_{S p a 1, D A Q}+0.35^{\circ} \mathrm{F} \pm 0.29^{\circ} \mathrm{F}$ & $+0.63^{\circ} \mathrm{F}$ & $+0.06^{\circ} \mathrm{F}$ \\
\hline Chamber 2 & $T_{S p a 1}=T_{S p a 1, D A Q}+0.63^{\circ} \mathrm{F} \pm 0.34^{\circ} \mathrm{F}$ & $+0.97^{\circ} \mathrm{F}$ & $+0.29^{\circ} \mathrm{F}$ \\
\hline \multirow[t]{3}{*}{ Chamber 3} & $T_{S p a 1}=T_{S p a 1, D A Q}+0.70^{\circ} \mathrm{F} \pm 0.43^{\circ} \mathrm{F}$ & $+1.13^{\circ} \mathrm{F}$ & $+0.27^{\circ} \mathrm{F}$ \\
\hline & \multicolumn{3}{|c|}{ Spa Temperature 2} \\
\hline & Function & Upper Limit & Lower Limit \\
\hline Chamber 1 & $T_{S p a 2}=T_{S p a 2, D A Q}+0.14^{\circ} \mathrm{F} \pm 0.27^{\circ} \mathrm{F}$ & $+0.41^{\circ} \mathrm{F}$ & $-0.14^{\circ} \mathrm{F}$ \\
\hline Chamber 2 & $T_{S p a 2}=T_{S p a 2, D A Q}+0.17^{\circ} \mathrm{F} \pm 0.32^{\circ} \mathrm{F}$ & $+0.50^{\circ} \mathrm{F}$ & $-0.15^{\circ} \mathrm{F}$ \\
\hline Chamber 3 & $T_{\text {Spa } 2}=T_{\text {Spa } 2, D A Q}+0.40^{\circ} \mathrm{F} \pm 0.37^{\circ} \mathrm{F}$ & $+0.78^{\circ} \mathrm{F}$ & $+0.03^{\circ} \mathrm{F}$ \\
\hline
\end{tabular}




\section{NIST Traceability of Power Measurements and Filtration Erroneous Power Measurements}

To verify the accuracy of the power measurement equipment, three Hioki Digital Power Analyzers (Model \#3196-20) were obtained, one per chamber, and connected to the electrical supply for each chamber, alongside the primary data acquisition system. The Hioki Digital Power Analyzers had been calibrated and are traceable to equipment certified by the National Institute of Standards and Technology, or NIST. Scanned copies of the calibration documents can be found in Appendix B.

During the testing of six spas data were simultaneously measured with both the DAQ equipment and the Hioki Digital Power Analyzers. The data was then compared to assess the accuracy of the data acquisition equipment.

\section{Instantaneous Power}

The accuracy of the DAQ was assessed by a direct comparison of the instantaneous power measured by DAQ and the NIST-certified Hioki power meters. Before this comparison, first artificial synchronization errors were identified and excluded. The term "synchronization errors" is used here to describe differences between in the measured data sets resulting from delays between when each device recorded a measurement rather than real inaccuracies in the measurement system. Figure C-1 shows examples of synchronization errors. 

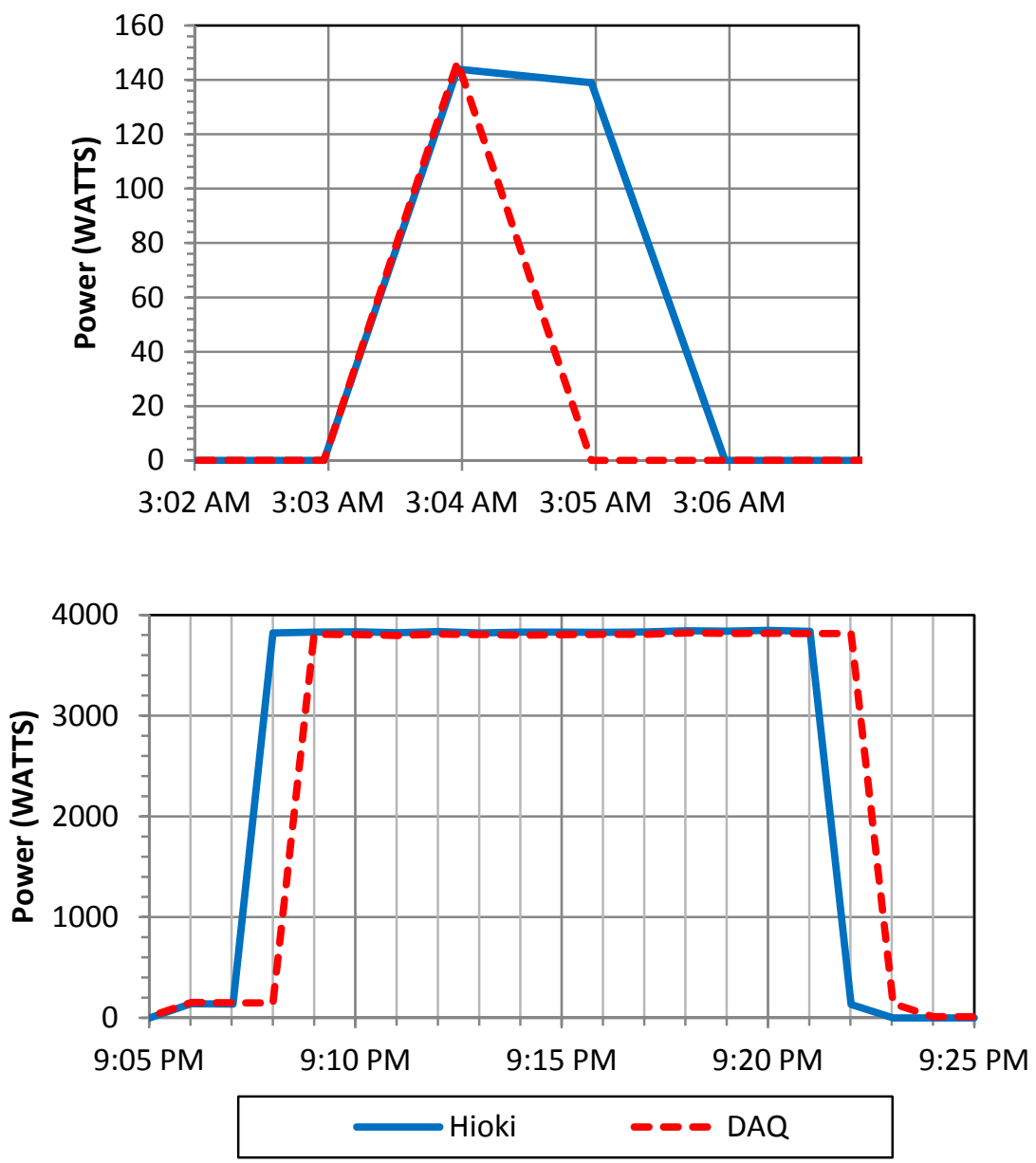

Figure C-1: Examples of "synchronization errors" caused by delay between the measurement of the NST-certified Hioki digital power analyzers and DAQ during the testing of spa B. The above plot shows the measurement of a short pump pulse. The lower plot shows the measurement of a heating cycle.

These synchronization errors are relatively uncommon compared to the total number of data points. For instance, in examining the data of spa B, 18 such points were identified compared with a total of 4,680 total data points. However, the magnitude of this synchronization errors, which can be on the order of 100 watts to 4,000 watts, far outweigh the actual error between the two systems, which is typically on the order of a couple of watts to 50 watts. So, synchronization errors were removed to keep these values from significantly skewing the comparison between the instantaneous powers as 
measured by each device. For each spa measured with both the Hioki power analyzers and DAQ, Table C-5 below lists the number of points excluded compared with the total number of measurements. In every case, less than 0.4 percent of the data points were removed from the error calculation.

Table C-5: Number of measurements excluded from error calculation due to mis-timing of the two power measurement tools.

\begin{tabular}{|c|c|c|c|}
\hline Spa & $\begin{array}{c}\text { Total } \\
\text { Measurements }\end{array}$ & $\begin{array}{l}\text { Measurements } \\
\text { Excluded }\end{array}$ & $\%$ Excluded \\
\hline$B$ & 4680 & 18 & $0.38 \%$ \\
\hline$C$ & 4988 & 18 & $0.36 \%$ \\
\hline$M$ & 4389 & 11 & $0.25 \%$ \\
\hline$R$ & 4669 & 3 & $0.06 \%$ \\
\hline $\boldsymbol{U}$ & 4507 & 2 & $0.04 \%$ \\
\hline$V$ & 4444 & 2 & $0.05 \%$ \\
\hline
\end{tabular}

With these data removed, the instantaneous error of the DAQ power measurements were then calculated as the difference between the power measured by each device for all of the remaining data. The error between the DAQ and Hioki readings for any power measurement can be assumed with $95 \%$ confidence to fall into the range given by The error between the DAQ and Fluke readings for any temperature measurement can be assumed with $95 \%$ confidence to fall into the range given by equation 24 from before.

$$
x=\bar{x} \pm t s \sqrt{\frac{1}{n}+1}
$$

This time the total number of measurements is quite large (over 4000 samples), making the $1 / \mathrm{n}$ term negligible. So equation 24 simplifies to

$$
x=\bar{x} \pm t s
$$

Where $x$ is the error between the instantaneous power measured by the DAQ and the Hioki devices, $\bar{x}$ is the mean error (or measurement offset) between the two devices, $t$ is 
the student- $t$ statistic for the sample size and confidence level $(t=1.960$ for sample size approaching infinity and $95 \%$ confidence), and $s$ is the standard deviation of the sample.

The calculated measurement offset, error standard deviation and population uncertainty for each spa are presented in Table C-6.

\section{Identification and Exclusion of Erroneous Power Measurements}

Early in the project, peculiar readings were noticed in the power measurements. The DAQ system was observed to record low levels of current when in fact no current was drawn by the spa circuits. For instance, during testing of a 120 volt spa current would be measured in the open 240 volt circuit. This appeared as a current of approximately 0 to 0.3 amps accompanied by a small, and sometimes negative, power factor $(<0.4)$. These values combined with the voltage to produce measured power values ranging from approximately -15 to +17 watts which appeared on both the 240 volt and 120 volt circuits of all three test chambers. When the power was measured simultaneously with the DAQ system and the Hioki digital power analyzers, the low levels of current were not detected by the Hioki power analyzers, confirming that the readings were erroneous.

These readings are assumed to be noise in the measurements caused by inaccuracies in the DTS 300 power meters and the MGL-SCT-0750-050 transformers. The transformers have a reported accuracy of $\pm 1 \%$ of the full scale current of $50 \mathrm{~A}$. In addition, the DTS 300 has a current accuracy of $\pm 0.5 \%$ of full scale current. Combining these by their root- 
sum-squared gives an uncertainty of $\pm 1.12 \%$ of full-scale current, or $\pm 0.56 \mathrm{~A}$. Therefore, the noise is within the reported error and can be attributed to the device errors.

The measurement noise has a zero-offset (mean error) component and a random component which is approximately normally distributed about the mean. While the noise has a relatively small effect on the instantaneous power measurements when the pumps and heaters are operating, the effect is relatively much greater when the spa draws little or no power. In addition, in the calculation of the total standby power, first the energy consumption at every point is calculated

$$
E_{i}[\text { watt }- \text { hour }]=\frac{P_{i}[\mathrm{watt}] * 1 \mathrm{~min}}{60[\mathrm{~min} / \mathrm{hr}]},
$$

and then the energy consumption of every measurement is summed and divided by the total duration (from equation 4)

$$
P_{\text {standby }}[\text { watts }]=\frac{\sum_{i=1}^{n} E_{i}[\text { watt }- \text { hours }]}{\text { Duration }[\text { hours }]}=\frac{\sum_{i=1}^{n} E_{i}[\text { watt }- \text { hours }]}{\frac{n[\text { samples }]}{60[\text { samples } / \text { hour }]}} .
$$

The zero-offset (mean) error, if left alone sums over every value of energy consumption and adds to the standby power.

To correct for this error, a data filter was applied to the power measurements whereby all power values were set equal to zero when the current was below a certain threshold. That threshold was selected specifically for each spa by looking at the pattern of current drawn by each spa, but in every case was somewhere between 0.3 and 0.4 amps. Table C-6 presents the zero-offset (mean) error, the standard deviation of the error, and the population uncertainty for the instantaneous power before and after the filter was applied. 
Table C-6: Error in instantaneous power reading (in watts) between the Data Acquisition System and the NIST-certified Hioki Digital Power Analyzers before and after applying a filter eliminating low power values. The calculation of the uncertainty of the error assumes a normal distribution of the error.

\begin{tabular}{|c|c|c|c|c|c|c|}
\hline \multirow[b]{2}{*}{ Spa } & \multicolumn{3}{|c|}{ Before Applying Data Filter } & \multicolumn{3}{|c|}{ After Applying Data Filter } \\
\hline & $\begin{array}{l}\text { Mean Error } \\
\left(P_{D A Q}-P_{\text {Hioki }}\right)\end{array}$ & $\begin{array}{c}\text { Error } \\
\text { Standard } \\
\text { Deviation }\end{array}$ & $\begin{array}{c}\text { Population } \\
\text { Uncertainty, } \\
\text { u (95\%) }\end{array}$ & $\begin{array}{c}\text { Mean } \\
\text { Error } \\
\left(\bar{x}_{\text {Hioki,DAQ }}\right) \\
\end{array}$ & $\begin{array}{c}\text { Error Standard } \\
\text { Deviation } \\
\left(\boldsymbol{s}_{\text {Hioki,DAQ }}\right)\end{array}$ & $\begin{array}{c}\text { Population } \\
\text { Uncertainty, } \\
\text { u (95\%) } \\
(\text { ts } \text { Hioki,DAQ })\end{array}$ \\
\hline$B$ & 9.0 & 7.2 & 14.1 & 0.2 & 3.2 & 6.3 \\
\hline$C$ & 5.5 & 2.7 & 5.2 & -0.2 & 2.0 & 3.8 \\
\hline$M$ & 7.2 & 7.6 & 14.8 & -0.4 & 6.8 & 13.3 \\
\hline$R$ & 20.8 & 13.0 & 25.5 & 13.9 & 12.9 & 25.3 \\
\hline$U$ & 3.1 & 5.7 & 11.2 & 0.4 & 4.8 & 9.5 \\
\hline $\boldsymbol{V}$ & 11.7 & 3.0 & 5.9 & -0.3 & 2.3 & 4.6 \\
\hline
\end{tabular}

If rather than treating each test run as a separate population all measurements from the above tests are considered as a single sample, the following uncertainties (shown in Table C-7) are calculated. These uncertainties are hereafter assumed to be representative of all of the spa measurements.

Table C-7: Error in instantaneous power reading (in watts) between the Data Acquisition System and the NIST-certified Hioki Digital Power Analyzers for the combined data measured during the testing of spas $\mathrm{B}, \mathrm{C}, \mathrm{M}, \mathrm{R}, \mathrm{U}$, and $\mathrm{V}$.

\begin{tabular}{|c|c|c|c|c|c|}
\hline \multicolumn{2}{|c|}{ Before Applying Data Filter } & \multicolumn{3}{c|}{ After Applying Data Filter } \\
\hline $\begin{array}{c}\text { Mean Error } \\
\left(\boldsymbol{P}_{\left.\text {DAQ }-\boldsymbol{P}_{\text {Hioki }}\right)}\right.\end{array}$ & $\begin{array}{c}\text { Error } \\
\text { Standard } \\
\text { Deviation }\end{array}$ & $\begin{array}{c}\text { Population } \\
\text { Uncertainty, } \\
\mathbf{u}(95 \%)\end{array}$ & $\begin{array}{c}\text { Mean } \\
\text { Error } \\
\left(\overline{\boldsymbol{x}}_{\text {Hioki,DAQ }}\right)\end{array}$ & $\begin{array}{c}\text { Error Standard } \\
\text { Deviation } \\
\left(\boldsymbol{s}_{\text {Hioki,DAQ}}\right)\end{array}$ & $\begin{array}{c}\text { Uncertainty, } \\
\text { Un (95\%) } \\
\left(\text { ts }_{\text {Hioki,DAQ}}\right)\end{array}$ \\
\hline 9.5 & 9.3 & 18.3 & 2.3 & 8.4 & 16.4 \\
\hline
\end{tabular}

\section{Accuracy of Instantaneous Power}

From these measurements, the DAQ measurement of the power can be determined as a function of the Hioki power measurement using the equation

$$
P_{i, D A Q}=P_{i, H i o k i}-\bar{x}_{H i o k i, D A Q} \pm t s_{H i o k i, D A Q}
$$


In addition, the actual instantaneous power can be determined from the measured Hioki power by the equation

$$
P_{i}=P_{i, H i o k i}+U_{H i o k i, P, i}
$$

Previously in Table A-2, the accuracy of the Hioki power measurement is described using the following equation.

$$
U_{\text {Hioki,P }}= \pm 0.2 \% \text { reading } \pm 0.1 \% \text { full scale }+U_{\text {clamp-on sensor }, P}
$$

The uncertainty of the clamp-on sensor is reported as $U_{\text {clamp-on sensor,P }}= \pm 0.3 \%$ reading $\pm 0.02 \%$ full scale. Assuming the $" \%$ of reading" components combine by the root-sum-squared, and the '\% of full scale" components combine by the root-sum-squared, the Hioki uncertainty can be calculated as

$$
\begin{gathered}
U_{\text {Hioki,P }}= \pm \sqrt{(0.2)^{2}+(0.3)^{2}} \% \text { reading } \pm \sqrt{(0.1)^{2}+(0.02)^{2}} \% \text { full scale } \\
U_{\text {Hioki, } P}= \pm 0.36 \% \text { reading } \pm 0.102 \% \text { full scale } \\
U_{\text {Hioki,P }}= \pm 0.36 \% \text { reading } \pm 15.3 \mathrm{~W}
\end{gathered}
$$

where the full-scale power is $15,000 \mathrm{~W}$.

Hioki does not report in the data sheet the confidence interval for the reported uncertainties. To be conservative, assume the reported uncertainties represent one standard deviation. For a confidence interval of $95 \%$ each uncertainty above must be multiplied by the student $t$-statistic $t=1.960$. Then, for any single power measurement $\mathrm{P}_{\mathrm{i}, \text { Hioki }}$ at $95 \%$ confidence, the accuracy is

$$
U_{\text {Hioki,P }, i}= \pm 0.00706 P_{i, H i o k i} \pm 29.99 \mathrm{~W} \text {. }
$$


Substituting equation 30 into equation 28 produces the following.

$$
P_{i}=P_{i, H i o k i} \pm 0.00706 P_{i, H i o k i} \pm 29.99 \mathrm{~W}
$$

Rearranging this equation to isolate $\mathrm{P}_{\mathrm{i}, \mathrm{Hioki}}$ gives equation 31 .

$$
P_{i, H i o k i}=\frac{P_{i} \pm 29.99 \mathrm{~W}}{1 \pm 0.00706}
$$

Equation 31 can be substituted into equation 27 above and rearranged to determine the actual instantaneous power as a function of the power measured by the DAQ.

$$
\begin{gathered}
P_{i, D A Q}=\frac{P_{i} \pm 29.99 \mathrm{~W}}{1 \pm 0.00706}-\bar{x}_{\text {Hioki,DAQ}} \pm t s_{\text {Hioki,DAQ }} \\
P_{i, D A Q}(1 \pm 0.00706)=P_{i} \pm 29.99 \mathrm{~W}+(1 \pm 0.00706)\left(-\bar{x}_{\text {Hioki,DAQ }} \pm t s_{\text {Hioki,DAQ }}\right) \\
P_{i}=(1 \pm 0.00706)\left(P_{i, D A Q}-\bar{x}_{H i o k i, D A Q} \pm t s_{H i o k i, D A Q}\right) \pm 29.99 \mathrm{~W}
\end{gathered}
$$

Consider that the $(1 \pm 0.00706)$ term will be normally distributed about 1 and in general variation in this term will have a smaller affect than the other terms. For simplicity this quantity can be assumed to be approximately equal to 1 .

$$
P_{i}=P_{i, D A Q}-\bar{x}_{H i o k i, D A Q} \pm t s_{\text {Hioki,DAQ }} \pm 29.99 \mathrm{~W}
$$

Now, substituting in the values of $\bar{x}_{H i o k i, D A Q}$ and $t s_{H i o k i, D A Q}$ from Table C-7, and combining the plus-minus terms using the root-sum-squared, the actual instantaneous power can be determined from the measured power using the following equation.

$$
P_{i}=P_{i, D A Q}-2.3 W \pm 34.2 W
$$

or, symbolically

$$
P_{i}=P_{i, D A Q}+U_{D A Q, o f f s e t} \pm U_{D A Q, \text { random }}
$$

In this equation $-2.3 \mathrm{~W}$ is the "measurement offset" and the $34.2 \mathrm{~W}$ is the "random error" with $95 \%$ confidence. 


\section{Accuracy of Measured Stand-by Power}

Substituting equations 33 and 3 into equation 4, the actual standby power can be written and rearranged as follows.

$$
\begin{gathered}
P_{\text {standby }}[\text { watt }]=\frac{\sum_{i=1}^{n} \frac{\left(P_{i, D A Q}+U_{D A Q, o f f s e t} \pm U_{D A Q, \text { random }}[\mathrm{watt}]\right) * 1 \mathrm{~min}}{60[\mathrm{~min} / \mathrm{hr}]}}{\frac{n[\mathrm{samples}]}{60[\text { samples } / \text { hour }]}} \\
P_{\text {standby }}[\mathrm{watt}]=\frac{1}{n} * \sum_{i=1}^{n}\left(P_{i, D A Q}+U_{D A Q, \text { offset }} \pm U_{D A Q, \text { random }}[\mathrm{watt}]\right) \\
P_{\text {standby }}[\mathrm{watt}]=\frac{1}{n} *\left(\sum_{i=1}^{n} P_{i, D A Q}+\sum_{i=1}^{n} U_{D A Q, \text { offset }}+\sum_{i=1}^{n} \pm U_{D A Q, \text { random }}\right)[\text { watt }]
\end{gathered}
$$

Notice that the terms can be easily simplified as shown here:

1) $\frac{1}{n} * \sum_{i=1}^{n} P_{i, D A Q}=P_{\text {standby,DAQ }}$

2) $U_{D A Q, \text { offset }}$ is a constant $(2.3 \mathrm{~W})$, so

$$
\frac{1}{n} * \sum_{\mathrm{i}=1}^{\mathrm{n}} \mathrm{U}_{\mathrm{DAQ}, \mathrm{offset}}=\frac{1}{\mathrm{n}}\left(n * \mathrm{U}_{\mathrm{DAQ}, \mathrm{offset}}\right)=U_{D A Q, \text { offset }}=2.3 \mathrm{~W} .
$$

3) $U_{D A Q \text {,random }}$ is a normally distributed random variable with a mean of zero. As $\mathrm{n}$ gets large, a sum of n samples of this normally distributed random variable will be a normal distribution with the same mean and standard deviation as the original variable. Therefore,

$$
\sum_{i=1}^{n} \pm U_{D A Q, \text { random }}= \pm U_{D A Q, \text { random }}= \pm 34.2 W(\text { with } 95 \% \text { confidence })
$$

The actual standby power can then be determined from the equation

$$
P_{\text {standby }}[\text { watt }]=P_{\text {standby,DAQ }}+U_{D A Q, \text { offset }} \pm U_{D A Q, \text { random }}[\text { watt }]
$$




$$
P_{\text {standby }}[\text { watt }]=P_{\text {standby, } D A Q}+2.3 W \pm 34.2 W
$$

\section{Accuracy of Allowable Standby Power}

The allowable standby power is given by equation 1 .

$$
P[\text { Watts }]=5 \frac{\text { Watts }^{2}}{\text { gallons }^{2 / 3}}(V[\text { gallons }])^{2 / 3}
$$

As was mentioned in the procedure section the volume was measured by taking the difference between the volume reading on the DLJ75 water meter before filling the spa $\left(V_{1}\right)$ and after filling the spa $\left(V_{2}\right)$. Substituting these into equation 1 gives the following.

$$
P[\text { Watts }]=5 \frac{\text { Watts }_{\text {gallons }}^{2 / 3}}{\text { Th }}\left(V_{2}[\text { gallons }]\right)^{2 / 3}
$$

The method of general uncertainty propagation will be used to determine the uncertainty in the allowable standby power. By this method, for a quantity that $\mathrm{R}\left(\mathrm{x}_{1}, \mathrm{x}_{2}, \ldots\right)$, the uncertainty $U_{R}$ is given by the equation

$$
U_{R}= \pm\left[\left(\frac{\partial R}{\partial x_{1}} U_{x_{1}}\right)^{2}+\left(\frac{\partial R}{\partial x_{2}} U_{x_{2}}\right)^{2}+\cdots\right]^{1 / 2} \text { (Thorncroft, 2005) }
$$

Substituting into this equation for the case of the allowable standby power gives the following.

$$
U_{P}= \pm\left[\left(\frac{\partial P}{\partial V_{1}} U_{V_{1}}\right)^{2}+\left(\frac{\partial P}{\partial V_{2}} U_{V_{2}}\right)^{2}\right]^{1 / 2}
$$

The uncertainties of $V_{1}$ and $V_{2}$ are equal to the uncertainty of the DLJ75 water meter.

$$
U_{V_{1}}=U_{V_{2}}= \pm 0.1 \text { gallon }
$$

Evaluating the partial derivatives gives the following:

$$
\frac{\partial P}{\partial V_{1}}=-\frac{10\left[\text { watt }^{\prime} / \text { gallon }^{2 / 3}\right]}{\left(V_{2}-V_{1}[\text { gallon }]\right)^{1 / 3}}
$$




$$
\frac{\partial P}{\partial V_{2}}=\frac{10\left[\text { watt }_{\text {gallon }}^{2 / 3}\right]}{\left(V_{2}-V_{1}[\text { gallon }]\right)^{1 / 3}}
$$

Inserting the partial derivative and uncertainties into equation 36 , and noting that by the definition earlier $V_{2}-V_{1}$ is equal to the measured volume, $V$, gives:

$$
U_{P}= \pm\left[\left(\frac{-10[\text { watt } / \text { gallon } 2 / 3]}{\left({\text { V }[\text { gallon }])^{1 / 3}}^{1 / 3}\right.}(0.1 \text { gallon })\right)^{2}+\left(\frac{10[\text { watt } / \text { gallon } 2 / 3]}{\left({\text { V }[\text { gallon }])^{1 / 3}}^{1 / 3}\right.}(0.1 \text { gallon })\right)^{2}\right]^{1 / 2}
$$

This simplifies to equation 37 .

$$
U_{P}=\frac{ \pm \sqrt{2}[\text { watt } / \text { gallon } 2 / 3]}{(V[\text { gallon }])^{1 / 3}}
$$

Table C-8 below presents the plus-minus uncertainty of the allowable standby power for each of the spas tested. 
Table C-8: Uncertainty in the allowable standby power for all twenty-seven spas measured.

\begin{tabular}{|c|c|c|c|}
\hline Spa & $\begin{array}{l}\text { Tested Volume } \\
\text { (gallons) }\end{array}$ & $\begin{array}{c}\text { Allowable Standby } \\
\text { Power (watt) }\end{array}$ & $U_{P}$ (watt) \\
\hline$A$ & 185 & 162 & \pm 0.25 \\
\hline B & 264 & 206 & \pm 0.22 \\
\hline C & 398 & 271 & \pm 0.19 \\
\hline $\mathrm{D}$ & 282 & 215 & \pm 0.22 \\
\hline$E$ & 440 & 289 & \pm 0.19 \\
\hline$F$ & 200 & 171 & \pm 0.24 \\
\hline G & 300 & 224 & \pm 0.21 \\
\hline $\mathrm{H}$ & 150 & 141 & \pm 0.27 \\
\hline 1 & 370 & 258 & \pm 0.20 \\
\hline$J$ & 334 & 241 & \pm 0.20 \\
\hline $\mathrm{K}$ & 142 & 136 & \pm 0.27 \\
\hline $\mathrm{L}$ & 220 & 182 & \pm 0.23 \\
\hline$M$ & 300 & 224 & \pm 0.21 \\
\hline $\mathrm{N}$ & 235 & 190 & \pm 0.23 \\
\hline $\mathrm{O}$ & 345 & 246 & \pm 0.20 \\
\hline$P$ & 247 & 197 & \pm 0.23 \\
\hline$Q$ & 439 & 289 & \pm 0.19 \\
\hline $\mathrm{R}$ & 296 & 222 & \pm 0.21 \\
\hline$S$ & 293 & 220 & \pm 0.21 \\
\hline $\mathrm{T}$ & 150 & 141 & \pm 0.27 \\
\hline U & 470 & 302 & \pm 0.18 \\
\hline V & 350 & 248 & \pm 0.20 \\
\hline W & 382 & 263 & \pm 0.19 \\
\hline$x$ & 422 & 281 & \pm 0.19 \\
\hline Y & 200 & 171 & \pm 0.24 \\
\hline Z & 260 & 204 & \pm 0.22 \\
\hline \multirow[t]{2}{*}{ AA } & 219 & 181 & \pm 0.23 \\
\hline & & $\begin{array}{l}\text { Minimum } U_{P} \\
\text { Maximum } U_{P}\end{array}$ & $\begin{array}{l} \pm 0.18 \\
\pm 0.27\end{array}$ \\
\hline
\end{tabular}




\section{Appendix D - Calculations}

\section{Evaporation Heat Loss Calculation}

From Table A-2 in Fundamentals of Engineering Thermodynamics the enthalpy of vaporization for saturated water at $40^{\circ} \mathrm{C}\left(104{ }^{\circ} \mathrm{F}\right)$ is $2406.7 \mathrm{~kJ} / \mathrm{kg}$, and the saturated liquid specific volume is $1.0078 \times 10^{-3} \mathrm{~m}^{3} / \mathrm{kg}$ (Moran \& Shapiro, p. 760). If evaporated water is lost through leaks between the spa and the cover, the amount of energy lost for a volume, $\mathrm{V}_{\text {evap}}$, would be:

$$
E=V \frac{h_{f g}}{v_{g}}=V \frac{2406.7 \frac{\mathrm{kJ}}{\mathrm{kg}}}{1.0078 * 10^{-3} \frac{\mathrm{m}^{3}}{\mathrm{~kg}}}=V_{\text {evap }}\left(2.3881 * 10^{6} \frac{\mathrm{kJ}}{\mathrm{m}^{3}}\right)\left[\frac{3.7854 * 10^{3} \mathrm{~m}^{3}}{\text { gallon }}\right]
$$

Table D-1 below presents the amount of energy lost and the affect this would have on standby power for different volumes of water escaping over a 72 hour test. The following equation is used to determine the increase in standby power.

$$
P+=\frac{E}{\text { time }}=\frac{E[K J]}{72 \text { hours }}\left[\frac{1 \text { hour }}{3600 \text { seconds }}\right]\left[\frac{1000 \mathrm{~W}}{\mathrm{~kJ} / \text { second }}\right]
$$

Table D-1: Energy and power lost for various volumes of liquid water escaping through evaporation during 72-hour test.

\begin{tabular}{|c|c|c|}
$\begin{array}{c}\text { Volume of Liquid Water Lost, } \\
\begin{array}{c}V_{\text {evap }} \\
\text { [gallons] }\end{array}\end{array}$ & $\begin{array}{c}\text { Energy } \\
{[\mathrm{kJ}]}\end{array}$ & $\begin{array}{c}\text { Standby Power Increase, } \\
\mathrm{P}+ \\
{[\text { watts] }}\end{array}$ \\
\hline 0.5 & 4520 & 17 \\
\hline 1 & 9040 & 35 \\
\hline 1.5 & 13560 & 52 \\
\hline 2 & 18080 & 70 \\
\hline 3 & 27119 & 105 \\
\hline 4 & 36159 & 140 \\
\hline 5 & 45199 & 174 \\
\hline
\end{tabular}




\section{Spa Surface Area Calculations}

For the calculation of the heat transfer coefficient in the analysis section, the external spa surface areas were calculated. The following are the calculated values for the spa surface area using the external dimension values presented in the spa user manuals. The shape of each spa is categorized as either rectangular $(R)$, circular $(C)$, or triangular $(T)$. The shape of the spa is used to determine the equation for calculating the surface area. The following equations for the external surface area are used:

$$
\begin{gathered}
A_{R}=2 W L+2 W H+2 L H \\
A_{C}=2\left(\frac{\pi}{4} W^{2}\right)+\pi W H \\
A_{T}=2\left(\frac{1}{2} W L\right)+W H+L H+H * \sqrt[2]{W^{2}+L^{2}}
\end{gathered}
$$

The dimensions were not available for spas $\mathrm{R}$ and $\mathrm{V}$ at the time of calculation.

In addition to calculating the surface area, I also calculated the ratio of the external surface area to the volume raised to the $2 / 3$ power. The following unit conversions were used:

$$
\frac{A}{V^{2 / 3}}=\frac{A\left[m^{2}\right]}{V^{2 / 3}\left[\text { gallon }^{2 / 3}\right]}
$$


Table D-2: Calculation of spa external surface area, A, and the ratio of the surface area to the volume raised to the $2 / 3$ power.

\begin{tabular}{|c|c|c|c|c|c|c|c|}
\hline Spa & Shape & $W[\mathrm{~m}]$ & $L[m]$ & $H[m]$ & $A\left[m^{2}\right]$ & $V$ [gal] & $\begin{array}{c}A / N^{2 / 3} \\
{\left[m^{2} /\left.g a\right|^{2 / 3}\right]}\end{array}$ \\
\hline$A$ & $\mathrm{R}$ & 1.45 & 1.90 & 0.76 & 9.892 & 185 & 0.3047 \\
\hline B & $\mathrm{R}$ & 1.79 & 2.18 & 0.97 & 13.462 & 264 & 0.3271 \\
\hline C & $\mathrm{R}$ & 2.26 & 2.26 & 0.97 & 15.549 & 398 & 0.2874 \\
\hline D & $\mathrm{R}$ & 1.98 & 1.98 & 0.89 & 12.989 & 282 & 0.3020 \\
\hline$E$ & $\mathrm{R}$ & 2.34 & 2.34 & 0.89 & 15.320 & 440 & 0.2650 \\
\hline $\mathrm{F}$ & $\mathrm{R}$ & 1.69 & 2.12 & 0.76 & 11.306 & 200 & 0.3304 \\
\hline G & $\mathrm{R}$ & 2.11 & 2.11 & 0.89 & 13.863 & 300 & 0.3093 \\
\hline $\mathrm{H}$ & $\mathrm{T}$ & 1.91 & 1.91 & 0.75 & 8.503 & 150 & 0.3012 \\
\hline I & $\mathrm{R}$ & 2.13 & 2.13 & 0.89 & 13.988 & 370 & 0.2714 \\
\hline$J$ & $\mathrm{R}$ & 2.13 & 2.13 & 0.91 & 14.205 & 334 & 0.2951 \\
\hline $\mathrm{K}$ & C & 1.52 & - & 0.61 & 6.567 & 142 & 0.2416 \\
\hline$L$ & C & 1.80 & - & 0.61 & 8.562 & 220 & 0.2350 \\
\hline$M$ & C & 1.98 & - & 0.69 & 10.434 & 300 & 0.2328 \\
\hline $\mathrm{N}$ & $\mathrm{R}$ & 2.13 & 2.01 & 0.97 & 14.267 & 235 & 0.3751 \\
\hline $\mathrm{O}$ & $\mathrm{R}$ & 2.34 & 2.34 & 1.02 & 16.509 & 345 & 0.3357 \\
\hline$P$ & $\mathrm{R}$ & 1.60 & 2.11 & 0.84 & 11.525 & 247 & 0.2930 \\
\hline$Q$ & $\mathrm{R}$ & 2.34 & 2.34 & 0.91 & 15.557 & 439 & 0.2693 \\
\hline $\mathrm{R}$ & $\mathrm{R}$ & - & - & - & - & 296 & - \\
\hline$S$ & $\mathrm{R}$ & 1.91 & 2.31 & 0.84 & 13.220 & 293 & 0.2999 \\
\hline $\mathrm{T}$ & $\mathrm{R}$ & 2.08 & 1.19 & 0.79 & 10.519 & 150 & 0.3726 \\
\hline U & $\mathrm{R}$ & 2.35 & 2.25 & 0.99 & 16.055 & 470 & 0.2656 \\
\hline V & $\mathrm{R}$ & - & - & - & - & 350 & - \\
\hline W & $\mathrm{R}$ & 2.36 & 2.26 & 0.91 & 15.439 & 382 & 0.2932 \\
\hline$x$ & $\mathrm{R}$ & 2.39 & 2.39 & 0.91 & 15.870 & 422 & 0.2822 \\
\hline$Y$ & $\mathrm{R}$ & 1.63 & 2.06 & 0.79 & 11.109 & 200 & 0.3248 \\
\hline Z & $\mathrm{R}$ & 2.03 & 1.57 & 0.81 & 11.502 & 260 & 0.2821 \\
\hline AA & $\mathrm{T}$ & 1.83 & 1.83 & 0.79 & 8.261 & 219 & 0.2277 \\
\hline & & & & & \multicolumn{2}{|c|}{$\left(\frac{A}{V^{2 / 3}}\right)_{\text {Avg,Rectangle }}$} & 0.3007 \\
\hline & & & & & \multicolumn{2}{|c|}{$\left(\frac{A}{V^{2 / 3}}\right)_{\text {Avg,Circle }}$} & 0.2364 \\
\hline & & & & & \multicolumn{2}{|c|}{$\left(\frac{A}{V^{2 / 3}}\right)_{\text {Ava Trianale }}$} & 0.2810 \\
\hline
\end{tabular}

Since the dimensions of spas $\mathrm{R}$ and $\mathrm{V}$ were not available, an approximate surface area was calculated for each of these using the spa volume and the value $\left(\frac{A}{V^{2 / 3}}\right)_{A v g, \text { Rectangle }}$. 


$$
\begin{aligned}
& A=V^{2 / 3}\left[\text { gallon }^{2 / 3}\right]\left(\frac{A}{V^{2 / 3}}\right)_{\text {Avg,Rectangle }}\left[\frac{m^{2}}{\text { gallon }^{2 / 3}}\right]
\end{aligned}
$$

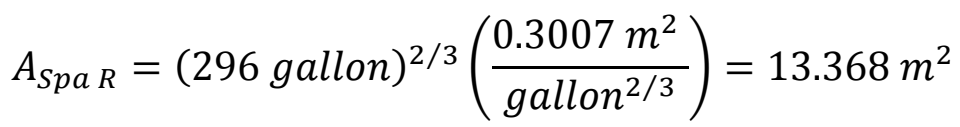

$$
\begin{aligned}
& A_{\text {Spa } V}=(350 \text { gallon })^{2 / 3}\left(\frac{0.3007 \mathrm{~m}^{2}}{\text { gallon }^{2 / 3}}\right)=14.937 \mathrm{~m}^{2}
\end{aligned}
$$

These values for the surface area were used to determine the heat transfer coefficient in the analysis section. 


\section{Thermocouple Sensitivity Calculation}

The sensitivity of the J-type thermocouple voltage to temperature over the tested range was desired. The tested range is defined as the range between the minimum air temperature encountered during all twenty seven tests, and the maximum water encountered during all twenty seven tests. The minimum air temperature was $47.76^{\circ} \mathrm{F}$, and the maximum water temperature was $105.73^{\circ} \mathrm{F}$.

Table D-3: J-Type thermocouple voltage for temperatures ranging from $46.4^{\circ} \mathrm{F}\left(8^{\circ} \mathrm{C}\right)$ to $105.8^{\circ} \mathrm{F}$ $\left(41^{\circ} \mathrm{C}\right)$ (Omega Engineering, Inc., Thermocouples).

\begin{tabular}{|c|c|c|c|}
\hline $\begin{array}{c}\text { Temperature } \\
{\left[{ }^{\circ} \mathrm{F}\right]}\end{array}$ & $\begin{array}{c}\text { J-Type } \\
\text { Thermocouple Voltage } \\
{[\mathrm{mV}]}\end{array}$ & $\begin{array}{c}\text { Temperature } \\
{\left[{ }^{\circ} \mathrm{F}\right]}\end{array}$ & $\begin{array}{c}\text { J-Type } \\
\text { Thermocouple Voltage } \\
{[\mathrm{mV}]}\end{array}$ \\
\hline 46.4 & 0.405 & 77.0 & 1.277 \\
\hline 48.2 & 0.456 & 78.8 & 1.329 \\
\hline 50.0 & 0.507 & 80.6 & 1.381 \\
\hline 51.8 & 0.558 & 82.4 & 1.433 \\
\hline 53.6 & 0.609 & 84.2 & 1.485 \\
\hline 55.4 & 0.660 & 86.0 & 1.537 \\
\hline 57.2 & 0.711 & 87.8 & 1.589 \\
\hline 59.0 & 0.762 & 89.6 & 1.641 \\
\hline 60.8 & 0.814 & 91.4 & 1.693 \\
\hline 62.6 & 0.865 & 93.2 & 1.745 \\
\hline 64.4 & 0.916 & 95.0 & 1.797 \\
\hline 66.2 & 0.968 & 96.8 & 1.849 \\
\hline 68.0 & 1.019 & 98.6 & 1.902 \\
\hline 69.8 & 1.071 & 100.4 & 1.954 \\
\hline 71.6 & 1.122 & 102.2 & 2.006 \\
\hline 73.4 & 1.174 & 104.0 & 2.059 \\
\hline 75.2 & 1.226 & 105.8 & 2.111 \\
\hline
\end{tabular}




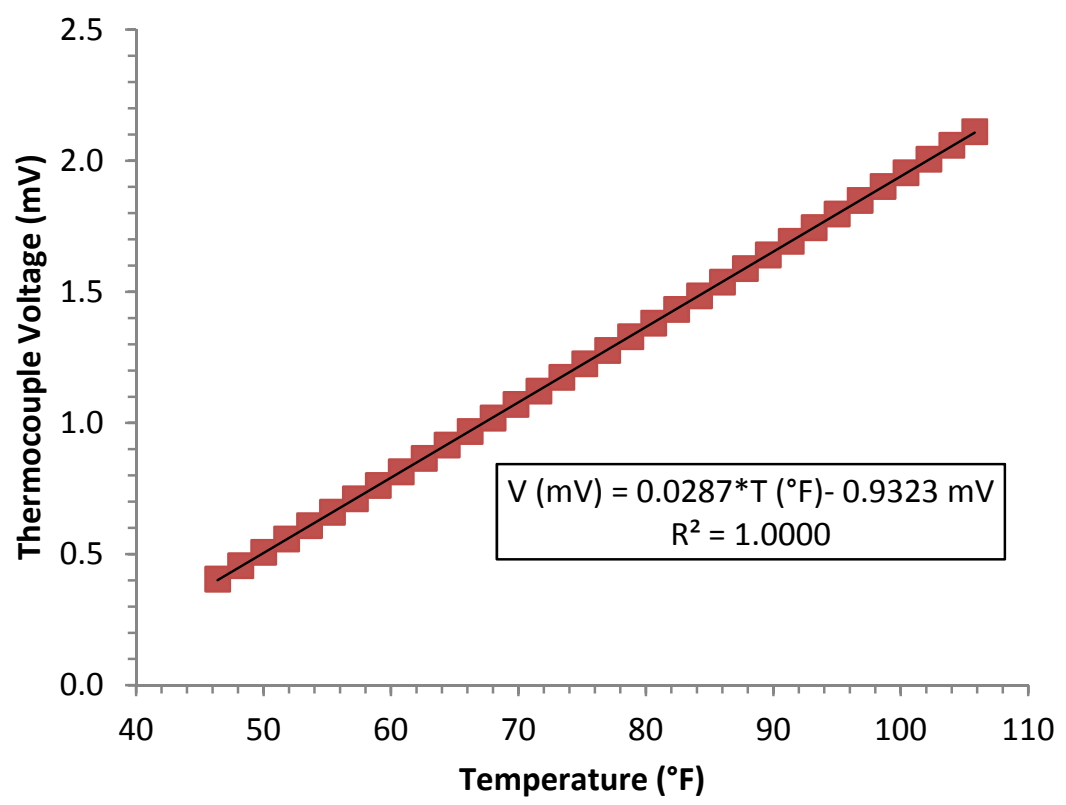

Figure D-1: Plot of J-type thermocouple voltage spanning the range of temperatures encountered during spa testing.

To determine the sensitivity of J-type thermocouples in the tested range the temperature and voltage were plotted and a linear curve fit generated. The thermocouple temperature and voltage data from Omega are displayed in Table D-3, and the data is plotted in Figure D-1. The slope of the linear curve fit, $0.0287 \mathrm{mV}$ per ${ }^{\circ} \mathrm{F}$, is the J-type thermocouple sensitivity over the desired range. 


\section{E. Appendix E - Spa Data}

Spa Test Data Sheets:

Spa Results Plots:
E-2 through E-28

E-29 through E-55 
Spa Characteristics

\begin{tabular}{|l|l|}
\hline Rating (\# of Persons) & $2+$ \\
\hline Voltage & 240 VAC $60 \mathrm{~Hz}$ \\
\hline Spa Volume (published) & 185 gallons \\
\hline Spa Volume (as tested) & 185 gallons \\
\hline Measured Total Spa Capacity & 220 gallons \\
\hline
\end{tabular}

\section{Spa Construction}

\begin{tabular}{|l|l|}
\hline Spa Construction/Insulation type $^{\mathbf{2}}$ & \\
\hline Filtration System $^{\mathbf{3}}$ & \\
\hline Cover Characteristics: $^{|l|}$ \\
\hline Material composition & \\
\hline Weight & \\
\hline Density & \\
\hline Thickness at center & \\
\hline Thickness at edge & \\
\hline R-value & \\
\hline Hinge width & \\
\hline Hinge fill material & \\
\hline
\end{tabular}

\section{Data Analysis}

\begin{tabular}{|c|c|}
\hline \multicolumn{2}{|l|}{ Water Temperature: } \\
\hline Minimum & $102^{\circ} \mathrm{F}$ \\
\hline Maximum & $104^{\circ} \mathrm{F}$ \\
\hline Average & $103^{\circ} \mathrm{F}$ \\
\hline \multicolumn{2}{|l|}{ Air Temperature: } \\
\hline Minimum & $56^{\circ} \mathrm{F}$ \\
\hline Maximum & $59^{\circ} \mathrm{F}$ \\
\hline Average & $58^{\circ} \mathrm{F}$ \\
\hline Average Temperature Difference & $44.9^{\circ} \mathrm{F}$ \\
\hline Duration of Test Record [hh:mm] & $74: 35$ \\
\hline Total energy used during Test Record & 10,500 Watt-hours \\
\hline Measured Stand-by Power in Watts & 141 Watts \\
\hline $\begin{array}{l}\text { Normalized Stand-by Power in Watts } \\
\text { (using } \Delta T_{\text {ideal }}=37^{\circ} \mathrm{F} \text { ) }\end{array}$ & 116 Watts \\
\hline \multicolumn{2}{|l|}{ CEC Allowable Stand-by Watts } \\
\hline at Tested Volume & 162 Watts \\
\hline at Published Volume & 162 Watts \\
\hline at Total Spa Capacity & 182 Watts \\
\hline
\end{tabular}

\footnotetext{
${ }^{2} \mathrm{FF}=$ full foam to spa cabinet, $\mathrm{PF}=$ partial foam shell and plumbing, $\mathrm{SF}=$ foamed shell, $\mathrm{ML}=$ insulated cabinet multi-layer, $\mathrm{SL}=$ insulated cabinet single layer, $\mathrm{NI}=$ no insulation, $\mathrm{OT}=$ other (describe)

${ }^{3} \mathrm{TSP}=$ two-speed pump, low speed, programmed cycles, $\mathrm{CP}=$ circulation pump operating $24 / 7, \mathrm{CPP}=$ circulation pump programmed cycles, $\mathrm{OT}=$ other (describe)
} 
Spa Characteristics

\begin{tabular}{|l|l|}
\hline Rating (\# of Persons) & $6-7$ \\
\hline Voltage & 240 VAC $60 \mathrm{~Hz}$ \\
\hline Spa Volume (published) & 264 gallons \\
\hline Spa Volume (as tested) & 264 gallons \\
\hline Measured Total Spa Capacity & 383 gallons \\
\hline
\end{tabular}

\section{Spa Construction}

\begin{tabular}{|l|l|}
\hline Spa Construction/Insulation type $^{4}$ & \\
\hline Filtration System & \\
\hline Cover Characteristics: & \\
\hline Material composition & \\
\hline Weight & \\
\hline Density & \\
\hline Thickness at center & \\
\hline Thickness at edge & \\
\hline R-value & \\
\hline Hinge width & \\
\hline Hinge fill material & \\
\hline
\end{tabular}

\section{Data Analysis}

\begin{tabular}{|c|c|}
\hline \multicolumn{2}{|l|}{ Water Temperature: } \\
\hline Minimum & $102^{\circ} \mathrm{F}$ \\
\hline Maximum & $104^{\circ} \mathrm{F}$ \\
\hline Average & $103^{\circ} \mathrm{F}$ \\
\hline \multicolumn{2}{|l|}{ Air Temperature: } \\
\hline Minimum & $54^{\circ} \mathrm{F}$ \\
\hline Maximum & $59^{\circ} \mathrm{F}$ \\
\hline Average & $57^{\circ} \mathrm{F}$ \\
\hline Average Temperature Difference & $46.0^{\circ} \mathrm{F}$ \\
\hline Duration of Test Record [hh:mm] & $77: 59$ \\
\hline Total energy used during Test Record & 12,717 Watt-hours \\
\hline Measured Stand-by Power in Watts & 163 Watts \\
\hline $\begin{array}{l}\text { Normalized Stand-by Power in Watts } \\
\text { (using } \Delta T_{\text {ideal }}=37^{\circ} \mathrm{F} \text { ) }\end{array}$ & 131 Watts \\
\hline \multicolumn{2}{|l|}{ CEC Allowable Stand-by Watts } \\
\hline at Tested Volume & 206 Watts \\
\hline at Published Volume & 206 Watts \\
\hline at Total Spa Capacity & 264 Watts \\
\hline
\end{tabular}

\footnotetext{
${ }^{4} \mathrm{FF}=$ full foam to spa cabinet, $\mathrm{PF}=$ partial foam shell and plumbing, $\mathrm{SF}=$ foamed shell, $\mathrm{ML}=$ insulated cabinet multi-layer, $\mathrm{SL}=$ insulated cabinet single layer, $\mathrm{NI}=$ no insulation, $\mathrm{OT}=$ other (describe)

${ }^{5} \mathrm{TSP}=$ two-speed pump, low speed, programmed cycles, $\mathrm{CP}=$ circulation pump operating $24 / 7, \mathrm{CPP}=$ circulation pump programmed cycles, OT $=$ other (describe)
} 
Spa Characteristics

\begin{tabular}{|l|l|}
\hline Rating (\# of Persons) & $6-8$ \\
\hline Voltage & 240 VAC $60 \mathrm{~Hz}$ \\
\hline Spa Volume (published) & 398 gallons \\
\hline Spa Volume (as tested) & 398 gallons \\
\hline Measured Total Spa Capacity & 554 gallons \\
\hline
\end{tabular}

\section{Spa Construction}

\begin{tabular}{|l|l|}
\hline Spa Construction/Insulation type $^{6}$ & \\
\hline Filtration System & \\
\hline Cover Characteristics: & \\
\hline Material composition & \\
\hline Weight & \\
\hline Density & \\
\hline Thickness at center & \\
\hline Thickness at edge & \\
\hline R-value & \\
\hline Hinge width & \\
\hline Hinge fill material & \\
\hline
\end{tabular}

\section{Data Analysis}

\begin{tabular}{|c|c|}
\hline \multicolumn{2}{|l|}{ Water Temperature: } \\
\hline Minimum & $102^{\circ} \mathrm{F}$ \\
\hline Maximum & $104^{\circ} \mathrm{F}$ \\
\hline Average & $103^{\circ} \mathrm{F}$ \\
\hline \multicolumn{2}{|l|}{ Air Temperature: } \\
\hline Minimum & $52^{\circ} \mathrm{F}$ \\
\hline Maximum & $60^{\circ} \mathrm{F}$ \\
\hline Average & $56^{\circ} \mathrm{F}$ \\
\hline Average Temperature Difference & $47.3^{\circ} \mathrm{F}$ \\
\hline Duration of Test Record [hh:mm] & $83: 07$ \\
\hline Total energy used during Test Record & 16,414 Watt-hours \\
\hline Measured Stand-by Power in Watts & 197 Watts \\
\hline $\begin{array}{l}\text { Normalized Stand-by Power in Watts } \\
\text { (using } \Delta T_{\text {ideal }}=37^{\circ} \mathrm{F} \text { ) }\end{array}$ & 154 Watts \\
\hline \multicolumn{2}{|l|}{ CEC Allowable Stand-by Watts } \\
\hline at Tested Volume & 271 Watts \\
\hline at Published Volume & 271 Watts \\
\hline at Total Spa Capacity & 337 Watts \\
\hline
\end{tabular}

\footnotetext{
${ }^{6} \mathrm{FF}=$ full foam to spa cabinet, $\mathrm{PF}=$ partial foam shell and plumbing, $\mathrm{SF}=$ foamed shell, $\mathrm{ML}=$ insulated cabinet multi-layer, $\mathrm{SL}=$ insulated cabinet single layer, $\mathrm{NI}=$ no insulation, $\mathrm{OT}=$ other (describe)

${ }^{7} \mathrm{TSP}=$ two-speed pump, low speed, programmed cycles, $\mathrm{CP}=$ circulation pump operating $24 / 7, \mathrm{CPP}=$ circulation pump programmed cycles, $\mathrm{OT}=$ other (describe)
} 
Spa Characteristics

\begin{tabular}{|l|l|}
\hline Rating (\# of Persons) & 4 \\
\hline Voltage & 240 VAC $60 \mathrm{~Hz}$ \\
\hline Spa Volume (published) & 300 gallons \\
\hline & $\begin{array}{l}282 \text { gallons (This spa had a full line molded onto } \\
\text { the spa. The water was filled to this line as } \\
\text { recommended by manufacturer's instructions) }\end{array}$ \\
\hline Measured Total Spa Capacity & 356 gallons \\
\hline
\end{tabular}

Spa Construction

\begin{tabular}{|l|l|}
\hline Spa Construction/Insulation type $^{8}$ & \multicolumn{2}{|l|}{} \\
\hline Filtration System $^{9}$ & \\
\hline Cover Characteristics: $^{|l|}$ \\
\hline Material composition & \\
\hline Weight & \\
\hline Density & \\
\hline Thickness at center & \\
\hline Thickness at edge & \\
\hline R-value & \\
\hline Hinge width & \\
\hline Hinge fill material & \\
\hline
\end{tabular}

Data Analysis

\begin{tabular}{|c|c|}
\hline \multicolumn{2}{|l|}{ Water Temperature: } \\
\hline Minimum & $102^{\circ} \mathrm{F}$ \\
\hline Maximum & $104^{\circ} \mathrm{F}$ \\
\hline Average & $103^{\circ} \mathrm{F}$ \\
\hline \multicolumn{2}{|l|}{ Air Temperature: } \\
\hline Minimum & $54^{\circ} \mathrm{F}$ \\
\hline Maximum & $60^{\circ} \mathrm{F}$ \\
\hline Average & $57^{\circ} \mathrm{F}$ \\
\hline Average Temperature Difference & $45.2^{\circ} \mathrm{F}$ \\
\hline Duration of Test Record [hh:mm] & $77: 34$ \\
\hline Total energy used during Test Record & 24,815 Watt-hours \\
\hline Measured Stand-by Power in Watts & 320 Watts \\
\hline $\begin{array}{l}\text { Normalized Stand-by Power in Watts } \\
\text { (using } \Delta T_{\text {ideal }}=37^{\circ} \mathrm{F} \text { ) }\end{array}$ & 262 Watts \\
\hline \multicolumn{2}{|l|}{ CEC Allowable Stand-by Watts } \\
\hline at Tested Volume & 215 Watts \\
\hline at Published Volume & 224 Watts \\
\hline at Total Spa Capacity & 251 Watts \\
\hline
\end{tabular}

\footnotetext{
${ }^{8} \mathrm{FF}=$ full foam to spa cabinet, $\mathrm{PF}=$ partial foam shell and plumbing, $\mathrm{SF}=$ foamed shell, $\mathrm{ML}=$ insulated cabinet multi-layer, $\mathrm{SL}=$ insulated cabinet single layer, $\mathrm{NI}=$ no insulation, $\mathrm{OT}=$ other (describe)

${ }^{9} \mathrm{TSP}=$ two-speed pump, low speed, programmed cycles, $\mathrm{CP}=$ circulation pump operating $24 / 7, \mathrm{CPP}=$ circulation pump programmed cycles, OT $=$ other (describe)
} 
Spa Characteristics

\begin{tabular}{|l|l|}
\hline Rating (\# of Persons) & 6 \\
\hline Voltage & 240 VAC $60 \mathrm{~Hz}$ \\
\hline Spa Volume (published) & 455 gallons \\
\hline & $\begin{array}{l}440 \text { gallons (This spa had a full line molded onto } \\
\text { the spa. The water was filled to this line as } \\
\text { recommended by manufacturer's instructions) }\end{array}$ \\
\hline Measured Total Spa Capacity & 562 gallons \\
\hline
\end{tabular}

Spa Construction

\begin{tabular}{|l|l|}
\hline Spa Construction/Insulation type & \multicolumn{2}{|l|}{} \\
\hline Filtration System $^{11}$ & \\
\hline Cover Characteristics: & \\
\hline Material composition & \\
\hline Weight & \\
\hline Density & \\
\hline Thickness at center & \\
\hline Thickness at edge & \\
\hline R-value & \\
\hline Hinge width & \\
\hline Hinge fill material & \\
\hline
\end{tabular}

Data Analysis

\begin{tabular}{|c|c|}
\hline \multicolumn{2}{|l|}{ Water Temperature: } \\
\hline Minimum & $102^{\circ} \mathrm{F}$ \\
\hline Maximum & $104^{\circ} \mathrm{F}$ \\
\hline Average & $103^{\circ} \mathrm{F}$ \\
\hline \multicolumn{2}{|l|}{ Air Temperature: } \\
\hline Minimum & $55^{\circ} \mathrm{F}$ \\
\hline Maximum & $60^{\circ} \mathrm{F}$ \\
\hline Average & $58^{\circ} \mathrm{F}$ \\
\hline Average Temperature Difference & $45.2^{\circ} \mathrm{F}$ \\
\hline Duration of Test Record [hh:mm] & $84: 02$ \\
\hline Total energy used during Test Record & 28,401 Watt-hours \\
\hline Measured Stand-by Power in Watts & 338 Watts \\
\hline $\begin{array}{l}\text { Normalized Stand-by Power in Watts } \\
\text { (using } \Delta T_{\text {ideal }}=37^{\circ} \mathrm{F} \text { ) }\end{array}$ & 277 Watts \\
\hline \multicolumn{2}{|l|}{ CEC Allowable Stand-by Watts } \\
\hline at Tested Volume & 289 Watts \\
\hline at Published Volume & 296 Watts \\
\hline at Total Spa Capacity & 341 Watts \\
\hline
\end{tabular}

${ }^{10} \mathrm{FF}=$ full foam to spa cabinet, $\mathrm{PF}=$ partial foam shell and plumbing, $\mathrm{SF}=$ foamed shell, $\mathrm{ML}=$ insulated cabinet multi-layer, $\mathrm{SL}=$ insulated cabinet single layer, $\mathrm{NI}=$ no insulation, $\mathrm{OT}=$ other (describe)

${ }^{11} \mathrm{TSP}=$ two-speed pump, low speed, programmed cycles, CP = circulation pump operating $24 / 7, \mathrm{CPP}=$ circulation pump programmed cycles, OT = other (describe) 
Spa Characteristics

\begin{tabular}{|l|l|}
\hline Rating (\# of Persons) & 3 \\
\hline Voltage & 240 VAC $60 \mathrm{~Hz}$ \\
\hline Spa Volume (published) & 200 gallons \\
\hline Spa Volume (as tested) & 200 gallons \\
\hline Measured Total Spa Capacity & 276 gallons \\
\hline
\end{tabular}

\section{Spa Construction}

\begin{tabular}{|l|l|}
\hline Spa Construction/Insulation type & FF \\
\hline Filtration System $^{\mathbf{1 3}}$ & $\mathrm{CP}$ \\
\hline Cover $^{\mathbf{2}}$ Characteristics: & Vinyl Covered Styrofoam \\
\hline Material composition & \\
\hline Weight & $2 \mathrm{lb} / \mathrm{ft}^{3}$ \\
\hline Density & 4 inch \\
\hline Thickness at center & 2 inch \\
\hline Thickness at edge & Ave. 12 \\
\hline R-value & 1 inch \\
\hline Hinge width & none \\
\hline Hinge fill material &
\end{tabular}

\section{Data Analysis}

\begin{tabular}{|c|c|}
\hline \multicolumn{2}{|l|}{ Water Temperature: } \\
\hline Minimum & $102^{\circ} \mathrm{F}$ \\
\hline Maximum & $104^{\circ} \mathrm{F}$ \\
\hline Average & $103^{\circ} \mathrm{F}$ \\
\hline \multicolumn{2}{|l|}{ Air Temperature: } \\
\hline Minimum & $53^{\circ} \mathrm{F}$ \\
\hline Maximum & $59^{\circ} \mathrm{F}$ \\
\hline Average & $56^{\circ} \mathrm{F}$ \\
\hline Average Temperature Difference & $46.8^{\circ} \mathrm{F}$ \\
\hline Duration of Test Record [hh:mm] & $72: 36$ \\
\hline Total energy used during Test Record & 15,840 Watt-hours \\
\hline Measured Stand-by Power in Watts & 218 Watts \\
\hline $\begin{array}{l}\text { Normalized Stand-by Power in Watts } \\
\text { (using } \Delta T_{\text {ideal }}=37^{\circ} \mathrm{F} \text { ) }\end{array}$ & 173 Watts \\
\hline \multicolumn{2}{|l|}{ CEC Allowable Stand-by Watts } \\
\hline at Tested Volume & 171 Watts \\
\hline at Published Volume & 171 Watts \\
\hline at Total Spa Capacity & 212 Watts \\
\hline
\end{tabular}

\footnotetext{
${ }^{12} \mathrm{FF}=$ full foam to spa cabinet, $\mathrm{PF}=$ partial foam shell and plumbing, $\mathrm{SF}=$ foamed shell, $\mathrm{ML}=$ insulated cabinet multi-layer, $\mathrm{SL}=$ insulated cabinet single layer, $\mathrm{NI}=$ no insulation, $\mathrm{OT}=$ other (describe)

${ }^{13} \mathrm{TSP}=$ two-speed pump, low speed, programmed cycles, $\mathrm{CP}=$ circulation pump operating $24 / 7, \mathrm{CPP}=$ circulation pump programmed cycles, $\mathrm{OT}=$ other $($ describe $)$
} 
Spa Characteristics

\begin{tabular}{|l|l|}
\hline Rating (\# of Persons) & $5+$ \\
\hline Voltage & 240 VAC $60 \mathrm{~Hz}$ \\
\hline Spa Volume (published) & 300 gallons \\
\hline Spa Volume (as tested) & 300 gallons \\
\hline Measured Total Spa Capacity & 420 gallons \\
\hline
\end{tabular}

\section{Spa Construction}

\begin{tabular}{|l|l|}
\hline Spa Construction/Insulation type ${ }^{14}$ & $\mathrm{FF}$ \\
\hline Filtration System $^{\mathbf{1 5}}$ & $\mathrm{CP}$ \\
\hline Cover Characteristics: & \\
\hline Material composition & Vinyl Covered Styrofoam \\
\hline Weight & \\
\hline Density & $2 \mathrm{Ib} / \mathrm{ft}^{3}$ \\
\hline Thickness at center & 4 inch \\
\hline Thickness at edge & 2 inch \\
\hline R-value & Ave. 12 \\
\hline Hinge width & 1 inch \\
\hline Hinge fill material & none \\
\hline
\end{tabular}

\section{Data Analysis}

\begin{tabular}{|c|c|}
\hline \multicolumn{2}{|l|}{ Water Temperature: } \\
\hline Minimum & $102^{\circ} \mathrm{F}$ \\
\hline Maximum & $103^{\circ} \mathrm{F}$ \\
\hline Average & $102^{\circ} \mathrm{F}$ \\
\hline \multicolumn{2}{|l|}{ Air Temperature: } \\
\hline Minimum & $54^{\circ} \mathrm{F}$ \\
\hline Maximum & $60^{\circ} \mathrm{F}$ \\
\hline Average & $58^{\circ} \mathrm{F}$ \\
\hline Average Temperature Difference & $44.3^{\circ} \mathrm{F}$ \\
\hline Duration of Test Record [hh:mm] & $82: 04$ \\
\hline Total energy used during Test Record & 15,744 Watt-hours \\
\hline Measured Stand-by Power in Watts & 192 Watts \\
\hline $\begin{array}{l}\text { Normalized Stand-by Power in Watts } \\
\text { (using } \Delta T_{\text {ideal }}=37^{\circ} \mathrm{F} \text { ) }\end{array}$ & 160 Watts \\
\hline \multicolumn{2}{|l|}{ CEC Allowable Stand-by Watts } \\
\hline at Tested Volume & 224 Watts \\
\hline at Published Volume & 224 Watts \\
\hline at Total Spa Capacity & 281 Watts \\
\hline
\end{tabular}

\footnotetext{
${ }^{14} \mathrm{FF}=$ full foam to spa cabinet, $\mathrm{PF}=$ partial foam shell and plumbing, $\mathrm{SF}=$ foamed shell, $\mathrm{ML}=$ insulated cabinet multi-layer, $\mathrm{SL}=$ insulated cabinet single layer, $\mathrm{NI}=$ no insulation, $\mathrm{OT}=$ other (describe)

${ }^{15} \mathrm{TSP}=$ two-speed pump, low speed, programmed cycles, $\mathrm{CP}=$ circulation pump operating $24 / 7, \mathrm{CPP}=$ circulation pump programmed cycles, $\mathrm{OT}=$ other $($ describe $)$
} 
Spa Characteristics

\begin{tabular}{|l|l|}
\hline Rating (\# of Persons) & $2-3$ \\
\hline Voltage & 120 VAC $60 \mathrm{~Hz}$ \\
\hline Spa Volume (published) & 150 gallons \\
\hline Spa Volume (as tested) & 150 gallons \\
\hline Measured Total Spa Capacity & 223 gallons \\
\hline
\end{tabular}

\section{Spa Construction}

\begin{tabular}{|l|l|}
\hline Spa Construction/Insulation type & \multicolumn{2}{|l|}{} \\
\hline Filtration System ${ }^{17}$ & \\
\hline Cover Characteristics: & \\
\hline Material composition & \\
\hline Weight & \\
\hline Density & \\
\hline Thickness at center & \\
\hline Thickness at edge & \\
\hline R-value & \\
\hline Hinge width & \\
\hline Hinge fill material & \\
\hline
\end{tabular}

\section{Data Analysis}

\begin{tabular}{|c|c|}
\hline \multicolumn{2}{|l|}{ Water Temperature: } \\
\hline Minimum & $103^{\circ} \mathrm{F}$ \\
\hline Maximum & $104^{\circ} \mathrm{F}$ \\
\hline Average & $104^{\circ} \mathrm{F}$ \\
\hline \multicolumn{2}{|l|}{ Air Temperature: } \\
\hline Minimum & $48^{\circ} \mathrm{F}$ \\
\hline Maximum & $56^{\circ} \mathrm{F}$ \\
\hline Average & $52^{\circ} \mathrm{F}$ \\
\hline Average Temperature Difference & $51.2^{\circ} \mathrm{F}$ \\
\hline Duration of Test Record [hh:mm] & $74: 32$ \\
\hline Total energy used during Test Record & 14,134 Watt-hours \\
\hline Measured Stand-by Power in Watts & 190 Watts \\
\hline $\begin{array}{l}\text { Normalized Stand-by Power in Watts } \\
\text { (using } \Delta T_{\text {ideal }}=37^{\circ} \mathrm{F} \text { ) }\end{array}$ & 137 Watts \\
\hline \multicolumn{2}{|l|}{ CEC Allowable Stand-by Watts } \\
\hline at Tested Volume & 141 Watts \\
\hline at Published Volume & 141 Watts \\
\hline at Total Spa Capacity & 184 Watts \\
\hline
\end{tabular}

\footnotetext{
${ }^{16} \mathrm{FF}=$ full foam to spa cabinet, $\mathrm{PF}=$ partial foam shell and plumbing, $\mathrm{SF}=$ foamed shell, $\mathrm{ML}=$ insulated cabinet multi-layer, $\mathrm{SL}=$ insulated cabinet single layer, $\mathrm{NI}=$ no insulation, $\mathrm{OT}=$ other (describe)

${ }^{17} \mathrm{TSP}=$ two-speed pump, low speed, programmed cycles, $\mathrm{CP}=$ circulation pump operating $24 / 7, \mathrm{CPP}=$ circulation pump programmed cycles, $\mathrm{OT}=$ other $($ describe $)$
} 
Spa Characteristics

\begin{tabular}{|l|l|}
\hline Rating (\# of Persons) & 7 \\
\hline Voltage & 240 VAC $60 \mathrm{~Hz}$ \\
\hline Spa Volume (published) & 370 gallons \\
\hline Spa Volume (as tested) & 370 gallons \\
\hline Measured Total Spa Capacity & 498 gallons \\
\hline
\end{tabular}

Spa Construction

\begin{tabular}{|c|c|}
\hline \multicolumn{2}{|l|}{ Spa Construction/Insulation type ${ }^{18}$} \\
\hline Filtration System $^{19}$ & \\
\hline \multicolumn{2}{|l|}{ Cover Characteristics: } \\
\hline Material composition & \\
\hline Weight & \\
\hline Density & \\
\hline Thickness at center & \\
\hline Thickness at edge & \\
\hline R-value & \\
\hline Hinge width & \\
\hline Hinge fill material & \\
\hline
\end{tabular}

\section{Data Analysis}

\begin{tabular}{|c|c|}
\hline \multicolumn{2}{|l|}{ Water Temperature: } \\
\hline Minimum & $103^{\circ} \mathrm{F}$ \\
\hline Maximum & $105^{\circ} \mathrm{F}$ \\
\hline Average & $104^{\circ} \mathrm{F}$ \\
\hline \multicolumn{2}{|l|}{ Air Temperature: } \\
\hline Minimum & $53^{\circ} \mathrm{F}$ \\
\hline Maximum & $60^{\circ} \mathrm{F}$ \\
\hline Average & $56^{\circ} \mathrm{F}$ \\
\hline Average Temperature Difference & $47.5^{\circ} \mathrm{F}$ \\
\hline Duration of Test Record [hh:mm] & $84: 02$ \\
\hline Total energy used during Test Record & 20,926 Watt-hours \\
\hline Measured Stand-by Power in Watts & 249 Watts \\
\hline $\begin{array}{l}\text { Normalized Stand-by Power in Watts } \\
\text { (using } \Delta T_{\text {ideal }}=37^{\circ} \mathrm{F} \text { ) }\end{array}$ & 194 Watts \\
\hline \multicolumn{2}{|l|}{ CEC Allowable Stand-by Watts } \\
\hline at Tested Volume & 258 Watts \\
\hline at Published Volume & 258 Watts \\
\hline at Total Spa Capacity & 314 Watts \\
\hline
\end{tabular}

\footnotetext{
${ }^{18} \mathrm{FF}=$ full foam to spa cabinet, $\mathrm{PF}=$ partial foam shell and plumbing, $\mathrm{SF}=$ foamed shell, $\mathrm{ML}=$ insulated cabinet multi-layer, $\mathrm{SL}=$ insulated cabinet single layer, $\mathrm{NI}=$ no insulation, $\mathrm{OT}=$ other (describe)

${ }^{19} \mathrm{TSP}=$ two-speed pump, low speed, programmed cycles, $\mathrm{CP}=$ circulation pump operating $24 / 7, \mathrm{CPP}=$ circulation pump programmed cycles, $\mathrm{OT}=$ other $($ describe $)$
} 


\section{Spa Characteristics}

\begin{tabular}{|l|l|}
\hline Rating (\# of Persons) & $4-5$ \\
\hline Voltage & 240 VAC $60 \mathrm{~Hz}$ \\
\hline Spa Volume (published) & 410 gallons \\
\hline & $\begin{array}{l}334 \text { gallons (The water was filled to } 6 \text { inches above } \\
\text { filter which is about half way up the skimmer opening. } \\
\text { The manufacturer's instructions recommend that the } \\
\text { water be filled to at least } 1 \text { inch above the filter) }\end{array}$ \\
\hline Measured Total Spa Capacity & 424 gallons \\
\hline
\end{tabular}

\section{Spa Construction}

\begin{tabular}{|l|l|}
\hline Spa Construction/Insulation type $^{\mathbf{2 0}}$ & $\mathrm{PF}, \mathrm{SL}$ \\
\hline Filtration System $^{\mathbf{2 1}}$ & $\mathrm{CPP}$ \\
\hline Cover Characteristics: & \\
\hline Material composition & Vinyl, aluminum support, foam \\
\hline Weight & 30 oz. cover material \\
\hline Density & $1.5-2 \mathrm{lb}$. \\
\hline Thickness at center & 3 inch \\
\hline Thickness at edge & 4 inch at seam, 3 inch at edge \\
\hline R-value & R19 Avg. \\
\hline Hinge width & 1 inch \\
\hline Hinge fill material & Foam rubber \\
\hline
\end{tabular}

Data Analysis

\begin{tabular}{|c|c|}
\hline \multicolumn{2}{|l|}{ Water Temperature: } \\
\hline Minimum & $103^{\circ} \mathrm{F}$ \\
\hline Maximum & $105^{\circ} \mathrm{F}$ \\
\hline Average & $104^{\circ} \mathrm{F}$ \\
\hline \multicolumn{2}{|l|}{ Air Temperature: } \\
\hline Minimum & $51^{\circ} \mathrm{F}$ \\
\hline Maximum & $57^{\circ} \mathrm{F}$ \\
\hline Average & $54^{\circ} \mathrm{F}$ \\
\hline Average Temperature Difference & $49.6^{\circ} \mathrm{F}$ \\
\hline Duration of Test Record [hh:mm] & $75: 31$ \\
\hline Total energy used during Test Record & 36,142 Watt-hours \\
\hline Measured Stand-by Power in Watts & 479 Watts \\
\hline $\begin{array}{l}\text { Normalized Stand-by Power in Watts } \\
\text { (using } \Delta T_{\text {ideal }}=37^{\circ} \mathrm{F} \text { ) }\end{array}$ & 357 Watts \\
\hline \multicolumn{2}{|l|}{ CEC Allowable Stand-by Watts } \\
\hline at Tested Volume & 241 Watts \\
\hline at Published Volume & 276 Watts \\
\hline at Total Spa Capacity & 282 Watts \\
\hline
\end{tabular}

\footnotetext{
${ }^{20} \mathrm{FF}=$ full foam to spa cabinet, $\mathrm{PF}=$ partial foam shell and plumbing, $\mathrm{SF}=$ foamed shell, $\mathrm{ML}=$ insulated cabinet multi-layer, $\mathrm{SL}=$ insulated cabinet single layer, $\mathrm{NI}=$ no insulation, $\mathrm{OT}=$ other (describe)

${ }^{21} \mathrm{TSP}=$ two-speed pump, low speed, programmed cycles, CP = circulation pump operating $24 / 7, \mathrm{CPP}=$ circulation pump programmed cycles, OT = other (describe)
} 
Spa Characteristics

\begin{tabular}{|l|l|}
\hline Rating (\# of Persons) & 2 \\
\hline Voltage & 120 VAC $60 \mathrm{~Hz}$ \\
\hline Spa Volume (published) & 140 gallons \\
\hline Spa Volume (as tested) & 142 gallons \\
\hline Measured Total Spa Capacity & 209 gallons \\
\hline
\end{tabular}

\section{Spa Construction}

\begin{tabular}{|l|l|}
\hline Spa Construction/Insulation type & \multicolumn{2}{|l|}{} \\
\hline Filtration System & \\
\hline Cover Characteristics: & \\
\hline Material composition & \\
\hline Weight & \\
\hline Density & \\
\hline Thickness at center & \\
\hline Thickness at edge & \\
\hline R-value & \\
\hline Hinge width & \\
\hline Hinge fill material & \\
\hline
\end{tabular}

\section{Data Analysis}

\begin{tabular}{|c|c|}
\hline \multicolumn{2}{|l|}{ Water Temperature: } \\
\hline Minimum & $102^{\circ} \mathrm{F}$ \\
\hline Maximum & $104^{\circ} \mathrm{F}$ \\
\hline Average & $102^{\circ} \mathrm{F}$ \\
\hline \multicolumn{2}{|l|}{ Air Temperature: } \\
\hline Minimum & $51^{\circ} \mathrm{F}$ \\
\hline Maximum & $58^{\circ} \mathrm{F}$ \\
\hline Average & $55^{\circ} \mathrm{F}$ \\
\hline Average Temperature Difference & $47.5^{\circ} \mathrm{F}$ \\
\hline Duration of Test Record [hh:mm] & $72: 14$ \\
\hline Total energy used during Test Record & 5,871 Watt-hours \\
\hline Measured Stand-by Power in Watts & 81 Watts \\
\hline $\begin{array}{l}\text { Normalized Stand-by Power in Watts } \\
\text { (using } \Delta T_{\text {ideal }}=37^{\circ} \mathrm{F} \text { ) }\end{array}$ & 63 Watts \\
\hline \multicolumn{2}{|l|}{ CEC Allowable Stand-by Watts } \\
\hline at Tested Volume & 136 Watts \\
\hline at Published Volume & 135 Watts \\
\hline at Total Spa Capacity & 176 Watts \\
\hline
\end{tabular}

\footnotetext{
${ }^{22} \mathrm{FF}=$ full foam to spa cabinet, $\mathrm{PF}=$ partial foam shell and plumbing, $\mathrm{SF}=$ foamed shell, $\mathrm{ML}=$ insulated cabinet multi-layer, $\mathrm{SL}=$ insulated cabinet single layer, $\mathrm{NI}=$ no insulation, $\mathrm{OT}=$ other (describe)

${ }^{23} \mathrm{TSP}=$ two-speed pump, low speed, programmed cycles, $\mathrm{CP}=$ circulation pump operating $24 / 7, \mathrm{CPP}=$ circulation pump programmed cycles, $\mathrm{OT}=$ other (describe)
} 
Spa Characteristics

\begin{tabular}{|l|l|}
\hline Rating (\# of Persons) & 4 \\
\hline Voltage & 120 VAC $60 \mathrm{~Hz}$ \\
\hline Spa Volume (published) & 220 gallons \\
\hline Spa Volume (as tested) & 220 gallons \\
\hline Measured Total Spa Capacity & 290 gallons \\
\hline
\end{tabular}

\section{Spa Construction}

\begin{tabular}{|l|l|}
\hline Spa Construction/Insulation type & \multicolumn{2}{|l|}{ (I) } \\
\hline Filtration System & \\
\hline Cover Characteristics: & \\
\hline Material composition & \\
\hline Weight & \\
\hline Density & \\
\hline Thickness at center & \\
\hline Thickness at edge & \\
\hline R-value & \\
\hline Hinge width & \\
\hline Hinge fill material & \\
\hline
\end{tabular}

\section{Data Analysis}

\begin{tabular}{|c|c|}
\hline \multicolumn{2}{|l|}{ Water Temperature: } \\
\hline Minimum & $102^{\circ} \mathrm{F}$ \\
\hline Maximum & $104^{\circ} \mathrm{F}$ \\
\hline Average & $103^{\circ} \mathrm{F}$ \\
\hline \multicolumn{2}{|l|}{ Air Temperature: } \\
\hline Minimum & $50^{\circ} \mathrm{F}$ \\
\hline Maximum & $58^{\circ} \mathrm{F}$ \\
\hline Average & $54^{\circ} \mathrm{F}$ \\
\hline Average Temperature Difference & $48.9^{\circ} \mathrm{F}$ \\
\hline Duration of Test Record [hh:mm] & $72: 45$ \\
\hline Total energy used during Test Record & 6,902 Watt-hours \\
\hline Measured Stand-by Power in Watts & 95 Watts \\
\hline $\begin{array}{l}\text { Normalized Stand-by Power in Watts } \\
\text { (using } \Delta T_{\text {ideal }}=37^{\circ} \mathrm{F} \text { ) }\end{array}$ & 72 Watts \\
\hline \multicolumn{2}{|l|}{ CEC Allowable Stand-by Watts } \\
\hline at Tested Volume & 182 Watts \\
\hline at Published Volume & 182 Watts \\
\hline at Total Spa Capacity & 219 Watts \\
\hline
\end{tabular}

\footnotetext{
${ }^{24} \mathrm{FF}=$ full foam to spa cabinet, $\mathrm{PF}=$ partial foam shell and plumbing, $\mathrm{SF}=$ foamed shell, $\mathrm{ML}=$ insulated cabinet multi-layer, $\mathrm{SL}=$ insulated cabinet single layer, $\mathrm{NI}=$ no insulation, $\mathrm{OT}=$ other (describe)

${ }^{25} \mathrm{TSP}=$ two-speed pump, low speed, programmed cycles, $\mathrm{CP}=$ circulation pump operating $24 / 7, \mathrm{CPP}=$ circulation pump programmed cycles, $\mathrm{OT}=$ other $($ describe $)$
} 
Spa Characteristics

\begin{tabular}{|l|l|}
\hline Rating (\# of Persons) & 6 \\
\hline Voltage & 120 VAC $60 \mathrm{~Hz}$ \\
\hline Spa Volume (published) & 300 gallons \\
\hline Spa Volume (as tested) & 300 gallons \\
\hline Measured Total Spa Capacity & 377 gallons \\
\hline
\end{tabular}

\section{Spa Construction}

\begin{tabular}{|l|l|}
\hline Spa Construction/Insulation type & \multicolumn{2}{|l|}{} \\
\hline Filtration System & \\
\hline Cover Characteristics: & \\
\hline Material composition & \\
\hline Weight & \\
\hline Density & \\
\hline Thickness at center & \\
\hline Thickness at edge & \\
\hline R-value & \\
\hline Hinge width & \\
\hline Hinge fill material & \\
\hline
\end{tabular}

\section{Data Analysis}

\begin{tabular}{|c|c|}
\hline \multicolumn{2}{|l|}{ Water Temperature: } \\
\hline Minimum & $102^{\circ} \mathrm{F}$ \\
\hline Maximum & $104^{\circ} \mathrm{F}$ \\
\hline Average & $103^{\circ} \mathrm{F}$ \\
\hline \multicolumn{2}{|l|}{ Air Temperature: } \\
\hline Minimum & $51^{\circ} \mathrm{F}$ \\
\hline Maximum & $60^{\circ} \mathrm{F}$ \\
\hline Average & $57^{\circ} \mathrm{F}$ \\
\hline Average Temperature Difference & $45.7^{\circ} \mathrm{F}$ \\
\hline Duration of Test Record [hh:mm] & $73: 08$ \\
\hline Total energy used during Test Record & 8,727 Watt-hours \\
\hline Measured Stand-by Power in Watts & 119 Watts \\
\hline $\begin{array}{l}\text { Normalized Stand-by Power in Watts } \\
\text { (using } \Delta T_{\text {ideal }}=37^{\circ} \mathrm{F} \text { ) }\end{array}$ & 97 Watts \\
\hline \multicolumn{2}{|l|}{ CEC Allowable Stand-by Watts } \\
\hline at Tested Volume & 224 Watts \\
\hline at Published Volume & 224 Watts \\
\hline at Total Spa Capacity & 261 Watts \\
\hline
\end{tabular}

\footnotetext{
${ }^{26} \mathrm{FF}=$ full foam to spa cabinet, $\mathrm{PF}=$ partial foam shell and plumbing, $\mathrm{SF}=$ foamed shell, $\mathrm{ML}=$ insulated cabinet multi-layer, $\mathrm{SL}=$ insulated cabinet single layer, $\mathrm{NI}=$ no insulation, $\mathrm{OT}=$ other (describe)

${ }^{27} \mathrm{TSP}=$ two-speed pump, low speed, programmed cycles, $\mathrm{CP}=$ circulation pump operating $24 / 7, \mathrm{CPP}=$ circulation pump programmed cycles, $\mathrm{OT}=$ other $($ describe $)$
} 
Spa Characteristics

\begin{tabular}{|l|l|}
\hline Rating (\# of Persons) & 4 \\
\hline Voltage & 240 VAC $60 \mathrm{~Hz}$ \\
\hline Spa Volume (published) & 275 gallons \\
\hline & $\begin{array}{l}235 \text { gallons (The water was filled to approximately } \\
\text { half way up the skimmer opening as } \\
\text { recommended by the manufacturer's instructions) }\end{array}$ \\
\hline Measured Total Spa Capacity & 343 gallons \\
\hline
\end{tabular}

\section{Spa Construction}

\begin{tabular}{|l|l|}
\hline Spa Construction/Insulation type & \multicolumn{1}{|l|}{} \\
\hline Filtration System & \multicolumn{2}{|l|}{} \\
\hline Cover Characteristics: & \\
\hline Material composition & \\
\hline Weight & \\
\hline Density & \\
\hline Thickness at center & \\
\hline Thickness at edge & \\
\hline R-value & \\
\hline Hinge width & \\
\hline Hinge fill material & \\
\hline
\end{tabular}

\section{Data Analysis}

\begin{tabular}{|c|c|}
\hline \multicolumn{2}{|l|}{ Water Temperature: } \\
\hline Minimum & $102^{\circ} \mathrm{F}$ \\
\hline Maximum & $104^{\circ} \mathrm{F}$ \\
\hline Average & $103^{\circ} \mathrm{F}$ \\
\hline \multicolumn{2}{|l|}{ Air Temperature: } \\
\hline Minimum & $52^{\circ} \mathrm{F}$ \\
\hline Maximum & $58^{\circ} \mathrm{F}$ \\
\hline Average & $55^{\circ} \mathrm{F}$ \\
\hline Average Temperature Difference & $47.7^{\circ} \mathrm{F}$ \\
\hline Duration of Test Record [hh:mm] & $76: 29$ \\
\hline Total energy used during Test Record & 21,221 Watt-hours \\
\hline Measured Stand-by Power in Watts & 277 Watts \\
\hline $\begin{array}{l}\text { Normalized Stand-by Power in Watts } \\
\text { (using } \Delta T_{\text {ideal }}=37^{\circ} \mathrm{F} \text { ) }\end{array}$ & 215 Watts \\
\hline \multicolumn{2}{|l|}{ CEC Allowable Stand-by Watts } \\
\hline at Tested Volume & 190 Watts \\
\hline at Published Volume & 211 Watts \\
\hline at Total Spa Capacity & 245 Watts \\
\hline
\end{tabular}

\footnotetext{
${ }^{1} \mathrm{FF}=$ full foam to spa cabinet, $\mathrm{PF}=$ partial foam shell and plumbing, $\mathrm{SF}=$ foamed shell, $\mathrm{ML}=$ insulated cabinet multi-layer, $\mathrm{SL}=$ insulated cabinet single layer, $\mathrm{NI}=$ no insulation, $\mathrm{OT}=$ other (describe)

${ }^{2} \mathrm{TSP}=$ two-speed pump, low speed, programmed cycles, $\mathrm{CP}=$ circulation pump operating $24 / 7, \mathrm{CPP}=$ circulation pump programmed cycles, OT $=$ other (describe)
} 
Spa Characteristics

\begin{tabular}{|l|l|}
\hline Rating (\# of Persons) & 6 \\
\hline Voltage & 240 VAC $60 \mathrm{~Hz}$ \\
\hline Spa Volume (published) & 384 gallons \\
\hline & $\begin{array}{l}345 \text { gallons (The water was filled to approximately } \\
\text { half way up the skimmer opening as } \\
\text { recommended by the manufacturer's instructions) }\end{array}$ \\
\hline Measured Total Spa Capacity & 500 gallons \\
\hline
\end{tabular}

Spa Construction

\begin{tabular}{|l|l|}
\hline Spa Construction/Insulation type & \multicolumn{2}{|l|}{} \\
\hline Filtration System $^{3 \mathbf{1}}$ & \\
\hline Cover Characteristics: & \\
\hline Material composition & \\
\hline Weight & \\
\hline Density & \\
\hline Thickness at center & \\
\hline Thickness at edge & \\
\hline R-value & \\
\hline Hinge width & \\
\hline Hinge fill material & \\
\hline
\end{tabular}

Data Analysis

\begin{tabular}{|c|c|}
\hline \multicolumn{2}{|l|}{ Water Temperature: } \\
\hline Minimum & $101^{\circ} \mathrm{F}$ \\
\hline Maximum & $103^{\circ} \mathrm{F}$ \\
\hline Average & $102^{\circ} \mathrm{F}$ \\
\hline \multicolumn{2}{|l|}{ Air Temperature: } \\
\hline Minimum & $52^{\circ} \mathrm{F}$ \\
\hline Maximum & $58^{\circ} \mathrm{F}$ \\
\hline Average & $55^{\circ} \mathrm{F}$ \\
\hline Average Temperature Difference & $47.7^{\circ} \mathrm{F}$ \\
\hline Duration of Test Record [hh:mm] & $77: 23$ \\
\hline Total energy used during Test Record & 25,570 Watt-hours \\
\hline Measured Stand-by Power in Watts & 330 Watts \\
\hline $\begin{array}{l}\text { Normalized Stand-by Power in Watts } \\
\text { (using } \Delta T_{\text {ideal }}=37^{\circ} \mathrm{F} \text { ) }\end{array}$ & 256 Watts \\
\hline \multicolumn{2}{|l|}{ CEC Allowable Stand-by Watts } \\
\hline at Tested Volume & 246 Watts \\
\hline at Published Volume & 264 Watts \\
\hline at Total Spa Capacity & 315 Watts \\
\hline
\end{tabular}

\footnotetext{
${ }^{30} \mathrm{FF}=$ full foam to spa cabinet, $\mathrm{PF}=$ partial foam shell and plumbing, $\mathrm{SF}=$ foamed shell, $\mathrm{ML}=$ insulated cabinet multi-layer, $\mathrm{SL}=$ insulated cabinet single layer, $\mathrm{NI}=$ no insulation, $\mathrm{OT}=$ other (describe)

${ }^{31} \mathrm{TSP}=$ two-speed pump, low speed, programmed cycles, $\mathrm{CP}=$ circulation pump operating $24 / 7, \mathrm{CPP}=$ circulation pump programmed cycles, OT = other (describe)
} 
Spa Characteristics

\begin{tabular}{|l|l|}
\hline Rating (\# of Persons) & $2-3$ \\
\hline Voltage & 240 VAC $60 \mathrm{~Hz}$ \\
\hline Spa Volume (published) & 180 gallons \\
\hline Spa Volume (as tested) & $\begin{array}{l}247 \text { gallons (The water was filled to } 4 \text { inches } \\
\text { above the top of the filter as recommended by } \\
\text { the manufacturer's instructions) }\end{array}$ \\
\hline Measured Total Spa Capacity & 322.4 gallons \\
\hline
\end{tabular}

Spa Construction

(Information not provided by manufacturer)

\begin{tabular}{|l|l|}
\hline Spa Construction/Insulation type & \multicolumn{2}{|l|}{} \\
\hline Filtration System & \\
\hline Cover Characteristics: & \\
\hline Material composition & \\
\hline Weight & \\
\hline Density & \\
\hline Thickness at center & \\
\hline Thickness at edge & \\
\hline R-value & \\
\hline Hinge width & \\
\hline Hinge fill material & \\
\hline
\end{tabular}

Data Analysis

\begin{tabular}{|c|c|}
\hline \multicolumn{2}{|l|}{ Water Temperature: } \\
\hline Minimum & $102^{\circ} \mathrm{F}$ \\
\hline Maximum & $105^{\circ} \mathrm{F}$ \\
\hline Average & $103^{\circ} \mathrm{F}$ \\
\hline \multicolumn{2}{|l|}{ Air Temperature: } \\
\hline Minimum & $52^{\circ} \mathrm{F}$ \\
\hline Maximum & $60^{\circ} \mathrm{F}$ \\
\hline Average & $57^{\circ} \mathrm{F}$ \\
\hline Average Temperature Difference & $46.1^{\circ} \mathrm{F}$ \\
\hline Duration of Test Record [hh:mm] & $78: 36$ \\
\hline Total energy used during Test Record & 18,691 Watt-hours \\
\hline Measured Stand-by Power in Watts & 238 Watts \\
\hline $\begin{array}{l}\text { Normalized Stand-by Power in Watts } \\
\text { (using } \Delta T_{\text {ideal }}=37^{\circ} \mathrm{F} \text { ) }\end{array}$ & 191 Watts \\
\hline \multicolumn{2}{|l|}{ CEC Allowable Stand-by Watts } \\
\hline at Tested Volume & 197 Watts \\
\hline at Published Volume & 159 Watts \\
\hline at Total Spa Capacity & 235 Watts \\
\hline
\end{tabular}

${ }^{32} \mathrm{FF}=$ full foam to spa cabinet, $\mathrm{PF}=$ partial foam shell and plumbing, $\mathrm{SF}=$ foamed shell, $\mathrm{ML}=$ insulated cabinet multi-layer, $\mathrm{SL}=$ insulated cabinet single layer, $\mathrm{NI}=$ no insulation, $\mathrm{OT}=$ other (describe)

${ }^{33} \mathrm{TSP}=$ two-speed pump, low speed, programmed cycles, $\mathrm{CP}=$ circulation pump operating $24 / 7, \mathrm{CPP}=$ circulation pump programmed cycles, OT = other (describe) 
Spa Characteristics

\begin{tabular}{|l|l|}
\hline Rating (\# of Persons) & $5-6$ \\
\hline Voltage & 240 VAC $60 \mathrm{~Hz}$ \\
\hline Spa Volume (published) & 400 gallons \\
\hline Spa Volume (as tested) & $\begin{array}{l}439 \text { gallons (The water was filled to } 4 \text { inches } \\
\text { above the top of the filter as recommended by } \\
\text { the manufacturer's instructions) }\end{array}$ \\
\hline Measured Total Spa Capacity & 566 gallons \\
\hline
\end{tabular}

Spa Construction

\begin{tabular}{|l|l|}
\hline Spa Construction/Insulation type & \multicolumn{2}{|l|}{} \\
\hline Filtration System $^{35}$ & \\
\hline Cover Characteristics: & \\
\hline Material composition & \\
\hline Weight & \\
\hline Density & \\
\hline Thickness at center & \\
\hline Thickness at edge & \\
\hline R-value & \\
\hline Hinge width & \\
\hline Hinge fill material & \\
\hline
\end{tabular}

Data Analysis

\begin{tabular}{|c|c|}
\hline \multicolumn{2}{|l|}{ Water Temperature: } \\
\hline Minimum & $103^{\circ} \mathrm{F}$ \\
\hline Maximum & $106^{\circ} \mathrm{F}$ \\
\hline Average & $104^{\circ} \mathrm{F}$ \\
\hline \multicolumn{2}{|l|}{ Air Temperature: } \\
\hline Minimum & $52^{\circ} \mathrm{F}$ \\
\hline Maximum & $59^{\circ} \mathrm{F}$ \\
\hline Average & $55^{\circ} \mathrm{F}$ \\
\hline Average Temperature Difference & $49.0^{\circ} \mathrm{F}$ \\
\hline Duration of Test Record [hh:mm] & $81: 31$ \\
\hline Total energy used during Test Record & 35,643 Watt-hours \\
\hline Measured Stand-by Power in Watts & 437 Watts \\
\hline $\begin{array}{l}\text { Normalized Stand-by Power in Watts } \\
\text { (using } \Delta T_{\text {ideal }}=37^{\circ} \mathrm{F} \text { ) }\end{array}$ & 330 Watts \\
\hline \multicolumn{2}{|l|}{ CEC Allowable Stand-by Watts } \\
\hline at Tested Volume & 289 Watts \\
\hline at Published Volume & 271 Watts \\
\hline at Total Spa Capacity & 342 Watts \\
\hline
\end{tabular}

${ }^{34} \mathrm{FF}=$ full foam to spa cabinet, $\mathrm{PF}=$ partial foam shell and plumbing, $\mathrm{SF}=$ foamed shell, $\mathrm{ML}=$ insulated cabinet multi-layer, $\mathrm{SL}=$ insulated cabinet single layer, $\mathrm{NI}=$ no insulation, $\mathrm{OT}=$ other (describe)

${ }^{35} \mathrm{TSP}=$ two-speed pump, low speed, programmed cycles, CP = circulation pump operating $24 / 7, \mathrm{CPP}=$ circulation pump programmed cycles, OT = other (describe) 
Spa Characteristics

\begin{tabular}{|l|l|}
\hline Rating (\# of Persons) & 7 \\
\hline Voltage & 240 VAC $60 \mathrm{~Hz}$ \\
\hline Spa Volume (published) & 290 gallons \\
\hline Spa Volume (as tested) & $\begin{array}{l}296 \text { gallons (The water was filled to } 0.5 \text { inches } \\
\text { below the bottom of the headrest as } \\
\text { recommended by manufacturer's instructions) }\end{array}$ \\
\hline Measured Total Spa Capacity & 458 gallons \\
\hline
\end{tabular}

Spa Construction

\begin{tabular}{|l|l|}
\hline Spa Construction/Insulation type $^{\mathbf{3 6}}$ & $\mathrm{ML}$ \\
\hline Filtration System $^{\mathbf{3 7}}$ & $\mathrm{CP}$ \\
\hline Cover Characteristics: & \\
\hline Material composition & Foam covered with vinyl \\
\hline Weight & $40 \mathrm{lbs}$ \\
\hline Density & $1 \mathrm{lbs}$ \\
\hline Thickness at center & 5 inch \\
\hline Thickness at edge & 3 inch \\
\hline R-value & 15 \\
\hline Hinge width & 1.5 inch \\
\hline Hinge fill material & \\
\hline
\end{tabular}

Data Analysis

\begin{tabular}{|c|c|}
\hline \multicolumn{2}{|l|}{ Water Temperature: } \\
\hline Minimum & $102^{\circ} \mathrm{F}$ \\
\hline Maximum & $103^{\circ} \mathrm{F}$ \\
\hline Average & $103^{\circ} \mathrm{F}$ \\
\hline \multicolumn{2}{|l|}{ Air Temperature: } \\
\hline Minimum & $53^{\circ} \mathrm{F}$ \\
\hline Maximum & $58^{\circ} \mathrm{F}$ \\
\hline Average & $56^{\circ} \mathrm{F}$ \\
\hline Average Temperature Difference & $47.0^{\circ} \mathrm{F}$ \\
\hline Duration of Test Record [hh:mm] & $77: 48$ \\
\hline Total energy used during Test Record & 32,000 Watt-hours \\
\hline Measured Stand-by Power in Watts & 411 Watts \\
\hline $\begin{array}{l}\text { Normalized Stand-by Power in Watts } \\
\text { (using } \Delta T_{\text {ideal }}=37^{\circ} \mathrm{F} \text { ) }\end{array}$ & 324 Watts \\
\hline \multicolumn{2}{|l|}{ CEC Allowable Stand-by Watts } \\
\hline at Tested Volume & 222 Watts \\
\hline at Published Volume & 219 Watts \\
\hline at Total Spa Capacity & 297 Watts \\
\hline
\end{tabular}

${ }^{36} \mathrm{FF}=$ full foam to spa cabinet, $\mathrm{PF}=$ partial foam shell and plumbing, $\mathrm{SF}=$ foamed shell, $\mathrm{ML}=$ insulated cabinet multi-layer, $\mathrm{SL}=$ insulated cabinet single layer, $\mathrm{NI}=$ no insulation, $\mathrm{OT}=$ other (describe)

${ }^{37} \mathrm{TSP}=$ two-speed pump, low speed, programmed cycles, CP $=$ circulation pump operating $24 / 7, \mathrm{CPP}=$ circulation pump programmed cycles, OT = other (describe) 
Spa Characteristics

\begin{tabular}{|l|l|}
\hline Rating (\# of Persons) & $4-5$ \\
\hline Voltage & 240 VAC $60 \mathrm{~Hz}$ \\
\hline Spa Volume (published) & 403 gallons \\
\hline Spa Volume (as tested) & $\begin{array}{l}293 \text { gallons (The water was filled to above the } \\
\text { highest jet and below the lowest headrest as } \\
\text { recommended by manufacturer's instructions) }\end{array}$ \\
\hline Measured Total Spa Capacity & 408 gallons \\
\hline
\end{tabular}

\section{Spa Construction}

\begin{tabular}{|l|l|}
\hline Spa Construction/Insulation type $^{\mathbf{3 8}}$ & $\mathrm{FF}$ \\
\hline Filtration System $^{\mathbf{3 9}}$ & $\mathrm{CP}$ \\
\hline Cover Characteristics: & \\
\hline Material composition & $\mathrm{PVC}$ \\
\hline Weight & \\
\hline Density & $1.5 \mathrm{lb}$ \\
\hline Thickness at center & $4.5 \mathrm{in}$ \\
\hline Thickness at edge & $2.25 \mathrm{in}$ \\
\hline R-value & 13.5 \\
\hline Hinge width & $1.25 \mathrm{in}$ \\
\hline Hinge fill material & $\mathrm{n} / \mathrm{a}$ \\
\hline
\end{tabular}

Data Analysis

\begin{tabular}{|c|c|}
\hline \multicolumn{2}{|l|}{ Water Temperature: } \\
\hline Minimum & $102^{\circ} \mathrm{F}$ \\
\hline Maximum & $104^{\circ} \mathrm{F}$ \\
\hline Average & $103^{\circ} \mathrm{F}$ \\
\hline \multicolumn{2}{|l|}{ Air Temperature: } \\
\hline Minimum & $52^{\circ} \mathrm{F}$ \\
\hline Maximum & $60^{\circ} \mathrm{F}$ \\
\hline Average & $55^{\circ} \mathrm{F}$ \\
\hline Average Temperature Difference & $47.3^{\circ} \mathrm{F}$ \\
\hline Duration of Test Record [hh:mm] & $74: 17$ \\
\hline Total energy used during Test Record & 23,604 Watt-hours \\
\hline Measured Stand-by Power in Watts & 318 Watts \\
\hline $\begin{array}{l}\text { Normalized Stand-by Power in Watts } \\
\text { (using } \Delta T_{\text {ideal }}=37^{\circ} \mathrm{F} \text { ) }\end{array}$ & 248 Watts \\
\hline \multicolumn{2}{|l|}{ CEC Allowable Stand-by Watts } \\
\hline at Tested Volume & 220 Watts \\
\hline at Published Volume & 273 Watts \\
\hline at Total Spa Capacity & 275 Watts \\
\hline
\end{tabular}

\footnotetext{
${ }^{38} \mathrm{FF}=$ full foam to spa cabinet, $\mathrm{PF}=$ partial foam shell and plumbing, $\mathrm{SF}=$ foamed shell, $\mathrm{ML}=$ insulated cabinet multi-layer, $\mathrm{SL}=$ insulated cabinet single layer, $\mathrm{NI}=$ no insulation, $\mathrm{OT}=$ other (describe)

${ }^{39} \mathrm{TSP}=$ two-speed pump, low speed, programmed cycles, $\mathrm{CP}=$ circulation pump operating $24 / 7, \mathrm{CPP}=$ circulation pump programmed cycles, OT = other (describe)
} 
Spa Characteristics

\begin{tabular}{|l|l|}
\hline Rating (\# of Persons) & 2 \\
\hline Voltage & 240 VAC $60 \mathrm{~Hz}$ \\
\hline Spa Volume (published) & 150 gallons \\
\hline Spa Volume (as tested) & 150 gallons \\
\hline Measured Total Spa Capacity & 187 gallons \\
\hline
\end{tabular}

\section{Spa Construction}

\begin{tabular}{|l|l|}
\hline Spa Construction/Insulation type $^{\mathbf{4 0}}$ & $\mathrm{ML}$ \\
\hline Filtration System $^{\mathbf{4 1}}$ & $\mathrm{CP}$ \\
\hline Cover Characteristics: & \\
\hline Material composition & Foam core covered with marine grade vinyl \\
\hline Weight & $33 \mathrm{lbs}$ \\
\hline Density & $2 \mathrm{lb}$ \\
\hline Thickness at center & 4 in \\
\hline Thickness at edge & 3 in \\
\hline R-value & 13.2 \\
\hline Hinge width & \\
\hline Hinge fill material & \\
\hline
\end{tabular}

\section{Data Analysis}

\begin{tabular}{|c|c|}
\hline \multicolumn{2}{|l|}{ Water Temperature: } \\
\hline Minimum & $102^{\circ} \mathrm{F}$ \\
\hline Maximum & $104^{\circ} \mathrm{F}$ \\
\hline Average & $103^{\circ} \mathrm{F}$ \\
\hline \multicolumn{2}{|l|}{ Air Temperature: } \\
\hline Minimum & $51^{\circ} \mathrm{F}$ \\
\hline Maximum & $60^{\circ} \mathrm{F}$ \\
\hline Average & $58^{\circ} \mathrm{F}$ \\
\hline Average Temperature Difference & $45.6^{\circ} \mathrm{F}$ \\
\hline Duration of Test Record [hh:mm] & $84: 00$ \\
\hline Total energy used during Test Record & 11,800 Watt-hours \\
\hline Measured Stand-by Power in Watts & 140 Watts \\
\hline $\begin{array}{l}\text { Normalized Stand-by Power in Watts } \\
\text { (using } \Delta T_{\text {ideal }}=37^{\circ} \mathrm{F} \text { ) }\end{array}$ & 114 Watts \\
\hline \multicolumn{2}{|l|}{ CEC Allowable Stand-by Watts } \\
\hline at Tested Volume & 141 Watts \\
\hline at Published Volume & 141 Watts \\
\hline at Total Spa Capacity & 163 Watts \\
\hline
\end{tabular}

\footnotetext{
${ }^{40} \mathrm{FF}=$ full foam to spa cabinet, $\mathrm{PF}=$ partial foam shell and plumbing, $\mathrm{SF}=$ foamed shell, $\mathrm{ML}=$ insulated cabinet multi-layer, $\mathrm{SL}=$ insulated cabinet single layer, $\mathrm{NI}=$ no insulation, $\mathrm{OT}=$ other (describe)

${ }^{41} \mathrm{TSP}=$ two-speed pump, low speed, programmed cycles, $\mathrm{CP}=$ circulation pump operating $24 / 7, \mathrm{CPP}=$ circulation pump programmed cycles, $\mathrm{OT}=$ other $($ describe $)$
} 
Spa Characteristics

\begin{tabular}{|l|l|}
\hline Rating (\# of Persons) & 7 \\
\hline Voltage & 240 VAC $60 \mathrm{~Hz}$ \\
\hline Spa Volume (published) & 470 gallons \\
\hline Spa Volume (as tested) & 470 gallons \\
\hline Measured Total Spa Capacity & 574 gallons \\
\hline
\end{tabular}

\section{Spa Construction}

\begin{tabular}{|l|l|}
\hline Spa Construction/Insulation type & \multicolumn{2}{|l|}{ (I2 } & \\
\hline Filtration System $^{43}$ & \\
\hline Cover Characteristics: & \\
\hline Material composition & \\
\hline Weight & \\
\hline Density & \\
\hline Thickness at center & \\
\hline Thickness at edge & \\
\hline R-value & \\
\hline Hinge width & \\
\hline Hinge fill material &
\end{tabular}

\section{Data Analysis}

\begin{tabular}{|c|c|}
\hline \multicolumn{2}{|l|}{ Water Temperature: } \\
\hline Minimum & $101^{\circ} \mathrm{F}$ \\
\hline Maximum & $103^{\circ} \mathrm{F}$ \\
\hline Average & $103^{\circ} \mathrm{F}$ \\
\hline \multicolumn{2}{|l|}{ Air Temperature: } \\
\hline Minimum & $54^{\circ} \mathrm{F}$ \\
\hline Maximum & $59^{\circ} \mathrm{F}$ \\
\hline Average & $57^{\circ} \mathrm{F}$ \\
\hline Average Temperature Difference & $46.0^{\circ} \mathrm{F}$ \\
\hline Duration of Test Record [hh:mm] & $75: 06$ \\
\hline Total energy used during Test Record & 22,816 Watt-hours \\
\hline Measured Stand-by Power in Watts & 304 Watts \\
\hline $\begin{array}{l}\text { Normalized Stand-by Power in Watts } \\
\text { (using } \Delta T_{\text {ideal }}=37^{\circ} \mathrm{F} \text { ) }\end{array}$ & 244 Watts \\
\hline \multicolumn{2}{|l|}{ CEC Allowable Stand-by Watts } \\
\hline at Tested Volume & 302 Watts \\
\hline at Published Volume & 302 Watts \\
\hline at Total Spa Capacity & 345 Watts \\
\hline
\end{tabular}

\footnotetext{
${ }^{42} \mathrm{FF}=$ full foam to spa cabinet, $\mathrm{PF}=$ partial foam shell and plumbing, $\mathrm{SF}=$ foamed shell, $\mathrm{ML}=$ insulated cabinet multi-layer, $\mathrm{SL}=$ insulated cabinet single layer, $\mathrm{NI}=$ no insulation, $\mathrm{OT}=$ other (describe)

${ }^{43} \mathrm{TSP}=$ two-speed pump, low speed, programmed cycles, $\mathrm{CP}=$ circulation pump operating $24 / 7, \mathrm{CPP}=$ circulation pump programmed cycles, $\mathrm{OT}=$ other (describe)
} 
Spa Characteristics

\begin{tabular}{|l|l|}
\hline Rating (\# of Persons) & 7 \\
\hline Voltage & $240 \mathrm{VAC} 60 \mathrm{~Hz}$ \\
\hline Spa Volume (published) & 350 gallons \\
\hline Spa Volume (as tested) & 350 gallons \\
\hline Measured Total Spa Capacity & 409 gallons \\
\hline
\end{tabular}

\section{Spa Construction}

\begin{tabular}{|l|l|}
\hline Spa Construction/Insulation type $^{44}$ & Frame-Acrylic/ foam fill \\
\hline Filtration System $^{45}$ & \\
\hline Cover Characteristics: $^{\text {Caterial composition }}$ & Compression Angle Hinge \\
\hline Mater & Vinyl clad EPS foam \\
\hline Weight & $40 \mathrm{lb}$ \\
\hline Density & $1.5 \mathrm{lb}$ foam \\
\hline Thickness at center & 4 inch \\
\hline Thickness at edge & 2.5 inch \\
\hline R-value & 13 \\
\hline Hinge width & None \\
\hline Hinge fill material & n/a \\
\hline
\end{tabular}

\section{Data Analysis}

\begin{tabular}{|c|c|}
\hline \multicolumn{2}{|l|}{ Water Temperature: } \\
\hline Minimum & $101^{\circ} \mathrm{F}$ \\
\hline Maximum & $103^{\circ} \mathrm{F}$ \\
\hline Average & $103^{\circ} \mathrm{F}$ \\
\hline \multicolumn{2}{|l|}{ Air Temperature: } \\
\hline Minimum & $51^{\circ} \mathrm{F}$ \\
\hline Maximum & $57^{\circ} \mathrm{F}$ \\
\hline Average & $54^{\circ} \mathrm{F}$ \\
\hline Average Temperature Difference & $48.1^{\circ} \mathrm{F}$ \\
\hline Duration of Test Record [hh:mm] & 74:03 \\
\hline Total energy used during Test Record & 10,088 Watt-hours \\
\hline Measured Stand-by Power in Watts & 136 Watts \\
\hline $\begin{array}{l}\text { Normalized Stand-by Power in Watts } \\
\text { (using } \Delta T_{\text {ideal }}=37^{\circ} \mathrm{F} \text { ) }\end{array}$ & 105 Watts \\
\hline \multicolumn{2}{|l|}{ CEC Allowable Stand-by Watts } \\
\hline at Tested Volume & 248 Watts \\
\hline at Published Volume & 248 Watts \\
\hline at Total Spa Capacity & 276 Watts \\
\hline
\end{tabular}

\footnotetext{
${ }^{44} \mathrm{FF}=$ full foam to spa cabinet, $\mathrm{PF}=$ partial foam shell and plumbing, $\mathrm{SF}=$ foamed shell, $\mathrm{ML}=$ insulated cabinet multi-layer, $\mathrm{SL}=$ insulated cabinet single layer, $\mathrm{NI}=$ no insulation, $\mathrm{OT}=$ other (describe)

${ }^{45} \mathrm{TSP}=$ two-speed pump, low speed, programmed cycles, $\mathrm{CP}=$ circulation pump operating $24 / 7, \mathrm{CPP}=$ circulation pump programmed cycles, $\mathrm{OT}=$ other (describe)
} 
Spa Characteristics

\begin{tabular}{|c|c|}
\hline Rating (\# of Persons) & 5 \\
\hline Voltage & $240 \mathrm{VAC} 60 \mathrm{~Hz}$ \\
\hline Spa Volume (published) & 450 gallons \\
\hline Spa Volume (as tested) & $\begin{array}{l}382 \text { gallons (The water level at published volume rose } \\
\text { over skimmer opening, so the tested volume reflects } \\
\text { level at just above the center of the skimmer opening) }\end{array}$ \\
\hline Measured Total Spa Capacity & 496 gallons \\
\hline
\end{tabular}

Spa Construction

\begin{tabular}{|l|l|}
\hline Spa Construction/Insulation type $^{46}$ & FF \\
\hline Filtration System $^{\mathbf{4 7}}$ & $\mathrm{CP}$ \\
\hline Cover Characteristics: & \\
\hline Material composition & Polystyrene \\
\hline Weight & -- \\
\hline Density & $1.5 \mathrm{Ib}$ \\
\hline Thickness at center & 3.5 inch \\
\hline Thickness at edge & 2.5 inch \\
\hline R-value & 13 \\
\hline Hinge width & 2 inch \\
\hline Hinge fill material & None \\
\hline
\end{tabular}

Data Analysis

\begin{tabular}{|c|c|}
\hline \multicolumn{2}{|l|}{ Water Temperature: } \\
\hline Minimum & $102^{\circ} \mathrm{F}$ \\
\hline Maximum & $103^{\circ} \mathrm{F}$ \\
\hline Average & $102^{\circ} \mathrm{F}$ \\
\hline \multicolumn{2}{|l|}{ Air Temperature: } \\
\hline Minimum & $53^{\circ} \mathrm{F}$ \\
\hline Maximum & $59^{\circ} \mathrm{F}$ \\
\hline Average & $56^{\circ} \mathrm{F}$ \\
\hline Average Temperature Difference & $46.2^{\circ} \mathrm{F}$ \\
\hline Duration of Test Record [hh:mm] & $76: 37$ \\
\hline Total energy used during Test Record & 17,342 Watt-hours \\
\hline Measured Stand-by Power in Watts & 226 Watts \\
\hline $\begin{array}{l}\text { Normalized Stand-by Power in Watts } \\
\text { (using } \Delta T_{\text {ideal }}=37^{\circ} \mathrm{F} \text { ) }\end{array}$ & 181 Watts \\
\hline \multicolumn{2}{|l|}{ CEC Allowable Stand-by Watts } \\
\hline at Tested Volume & 263 Watts \\
\hline at Published Volume & 294 Watts \\
\hline at Total Spa Capacity & 313 Watts \\
\hline
\end{tabular}

\footnotetext{
${ }^{46} \mathrm{FF}=$ full foam to spa cabinet, $\mathrm{PF}=$ partial foam shell and plumbing, $\mathrm{SF}=$ foamed shell, $\mathrm{ML}=$ insulated cabinet multi-layer, $\mathrm{SL}=$ insulated cabinet single layer, $\mathrm{NI}=$ no insulation, $\mathrm{OT}=$ other (describe)

${ }^{47} \mathrm{TSP}=$ two-speed pump, low speed, programmed cycles, $\mathrm{CP}=$ circulation pump operating $24 / 7, \mathrm{CPP}=$ circulation pump programmed cycles, OT = other (describe)
} 
Spa Characteristics

\begin{tabular}{|l|l|}
\hline Rating (\# of Persons) & 5 \\
\hline Voltage & 240 VAC $60 \mathrm{~Hz}$ \\
\hline Spa Volume (published) & 411 gallons \\
\hline & $\begin{array}{l}422 \text { gallons (This spa had a full line molded onto } \\
\text { the spa. The water was filled to this line as } \\
\text { recommended by manufacturer's instructions) }\end{array}$ \\
\hline Measured Total Spa Capacity & 556 gallons \\
\hline
\end{tabular}

Spa Construction

(Information not provided by manufacturer)

\begin{tabular}{|c|c|}
\hline \multirow{2}{*}{\multicolumn{2}{|c|}{ Spa Construction/Insulation type ${ }^{48}$}} \\
\hline & \\
\hline \multicolumn{2}{|l|}{ Cover Characteristics: } \\
\hline Material composition & \\
\hline Weight & \\
\hline Density & \\
\hline Thickness at center & \\
\hline Thickness at edge & \\
\hline R-value & \\
\hline Hinge width & \\
\hline Hinge fill material & \\
\hline
\end{tabular}

\section{Data Analysis}

\begin{tabular}{|c|c|}
\hline \multicolumn{2}{|l|}{ Water Temperature: } \\
\hline Minimum & $102^{\circ} \mathrm{F}$ \\
\hline Maximum & $104^{\circ} \mathrm{F}$ \\
\hline Average & $103^{\circ} \mathrm{F}$ \\
\hline \multicolumn{2}{|l|}{ Air Temperature: } \\
\hline Minimum & $53^{\circ} \mathrm{F}$ \\
\hline Maximum & $59^{\circ} \mathrm{F}$ \\
\hline Average & $56^{\circ} \mathrm{F}$ \\
\hline Average Temperature Difference & $46.3^{\circ} \mathrm{F}$ \\
\hline Duration of Test Record [hh:mm] & $76: 30$ \\
\hline Total energy used during Test Record & 23,933 Watt-hours \\
\hline Measured Stand-by Power in Watts & 313 Watts \\
\hline $\begin{array}{l}\text { Normalized Stand-by Power in Watts } \\
\text { (using } \Delta T_{\text {ideal }}=37^{\circ} \mathrm{F} \text { ) }\end{array}$ & 250 Watts \\
\hline \multicolumn{2}{|l|}{ CEC Allowable Stand-by Watts } \\
\hline at Tested Volume & 281 Watts \\
\hline at Published Volume & 276 Watts \\
\hline at Total Spa Capacity & 338 Watts \\
\hline
\end{tabular}

\footnotetext{
${ }^{48} \mathrm{FF}=$ full foam to spa cabinet, $\mathrm{PF}=$ partial foam shell and plumbing, $\mathrm{SF}=$ foamed shell, $\mathrm{ML}=$ insulated cabinet multi-layer, $\mathrm{SL}=$ insulated cabinet single layer, $\mathrm{NI}=$ no insulation, $\mathrm{OT}=$ other (describe)

${ }^{49} \mathrm{TSP}=$ two-speed pump, low speed, programmed cycles, CP $=$ circulation pump operating $24 / 7, \mathrm{CPP}=$ circulation pump programmed cycles, OT = other (describe)
} 
Spa Characteristics

\begin{tabular}{|l|l|}
\hline Rating (\# of Persons) & 3 \\
\hline Voltage & 240 VAC $60 \mathrm{~Hz}$ \\
\hline Spa Volume (published) & 200 gallons \\
\hline Spa Volume (as tested) & 200 gallons \\
\hline Measured Total Spa Capacity & 259 gallons \\
\hline
\end{tabular}

\section{Spa Construction}

(Information not provided by manufacturer)

\begin{tabular}{|c|c|}
\hline \multicolumn{2}{|l|}{ Spa Construction/Insulation type ${ }^{50}$} \\
\hline Filtration System $^{51}$ & \\
\hline \multicolumn{2}{|l|}{ Cover Characteristics: } \\
\hline Material composition & \\
\hline Weight & \\
\hline Density & \\
\hline Thickness at center & \\
\hline Thickness at edge & \\
\hline R-value & \\
\hline Hinge width & \\
\hline Hinge fill material & \\
\hline
\end{tabular}

\section{Data Analysis}

\begin{tabular}{|c|c|}
\hline \multicolumn{2}{|l|}{ Water Temperature: } \\
\hline Minimum & $102^{\circ} \mathrm{F}$ \\
\hline Maximum & $105^{\circ} \mathrm{F}$ \\
\hline Average & $104^{\circ} \mathrm{F}$ \\
\hline \multicolumn{2}{|l|}{ Air Temperature: } \\
\hline Minimum & $53^{\circ} \mathrm{F}$ \\
\hline Maximum & $60^{\circ} \mathrm{F}$ \\
\hline Average & $58^{\circ} \mathrm{F}$ \\
\hline Average Temperature Difference & $46.0^{\circ} \mathrm{F}$ \\
\hline Duration of Test Record [hh:mm] & $72: 30$ \\
\hline Total energy used during Test Record & 19,599Watt-hours \\
\hline Measured Stand-by Power in Watts & 270 Watts \\
\hline $\begin{array}{l}\text { Normalized Stand-by Power in Watts } \\
\text { (using } \Delta T_{\text {ideal }}=37^{\circ} \mathrm{F} \text { ) }\end{array}$ & 218 Watts \\
\hline \multicolumn{2}{|l|}{ CEC Allowable Stand-by Watts } \\
\hline at Tested Volume & 171 Watts \\
\hline at Published Volume & 171 Watts \\
\hline at Total Spa Capacity & 203 Watts \\
\hline
\end{tabular}

\footnotetext{
${ }^{50} \mathrm{FF}=$ full foam to spa cabinet, $\mathrm{PF}=$ partial foam shell and plumbing, $\mathrm{SF}=$ foamed shell, $\mathrm{ML}=$ insulated cabinet multi-layer, $\mathrm{SL}=$ insulated cabinet single layer, $\mathrm{NI}=$ no insulation, $\mathrm{OT}=$ other (describe)

${ }^{51} \mathrm{TSP}=$ two-speed pump, low speed, programmed cycles, $\mathrm{CP}=$ circulation pump operating $24 / 7, \mathrm{CPP}=$ circulation pump programmed cycles, $\mathrm{OT}=$ other (describe)
} 
Spa Characteristics

\begin{tabular}{|l|l|}
\hline Rating (\# of Persons) & 4 \\
\hline Voltage & $120 \mathrm{VAC} 60 \mathrm{~Hz}$ \\
\hline Spa Volume (published) & 260 gallons \\
\hline Spa Volume (as tested) & 260 gallons \\
\hline Measured Total Spa Capacity & 311 gallons \\
\hline
\end{tabular}

\section{Spa Construction}

\begin{tabular}{|l|l|}
\hline Spa Construction/Insulation type & \multicolumn{2}{|l|}{} \\
\hline Filtration System & \\
\hline Cover Characteristics: & \\
\hline Material composition & \\
\hline Weight & \\
\hline Density & \\
\hline Thickness at center & \\
\hline Thickness at edge & \\
\hline R-value & \\
\hline Hinge width & \\
\hline Hinge fill material & \\
\hline
\end{tabular}

\section{Data Analysis}

\begin{tabular}{|c|c|}
\hline \multicolumn{2}{|l|}{ Water Temperature: } \\
\hline Minimum & $102^{\circ} \mathrm{F}$ \\
\hline Maximum & $104^{\circ} \mathrm{F}$ \\
\hline Average & $103^{\circ} \mathrm{F}$ \\
\hline \multicolumn{2}{|l|}{ Air Temperature: } \\
\hline Minimum & $53^{\circ} \mathrm{F}$ \\
\hline Maximum & $58^{\circ} \mathrm{F}$ \\
\hline Average & $56^{\circ} \mathrm{F}$ \\
\hline Average Temperature Difference & $47.3^{\circ} \mathrm{F}$ \\
\hline Duration of Test Record [hh:mm] & $77: 17$ \\
\hline Total energy used during Test Record & 17,230 Watt-hours \\
\hline Measured Stand-by Power in Watts & 223 Watts \\
\hline $\begin{array}{l}\text { Normalized Stand-by Power in Watts } \\
\text { (using } \Delta T_{\text {ideal }}=37^{\circ} \mathrm{F} \text { ) }\end{array}$ & 174 Watts \\
\hline \multicolumn{2}{|l|}{ CEC Allowable Stand-by Watts } \\
\hline at Tested Volume & 204 Watts \\
\hline at Published Volume & 204 Watts \\
\hline at Total Spa Capacity & 229 Watts \\
\hline
\end{tabular}

\footnotetext{
${ }^{52} \mathrm{FF}=$ full foam to spa cabinet, $\mathrm{PF}=$ partial foam shell and plumbing, $\mathrm{SF}=$ foamed shell, $\mathrm{ML}=$ insulated cabinet multi-layer, $\mathrm{SL}=$ insulated cabinet single layer, $\mathrm{NI}=$ no insulation, $\mathrm{OT}=$ other (describe)

${ }^{53} \mathrm{TSP}=$ two-speed pump, low speed, programmed cycles, $\mathrm{CP}=$ circulation pump operating $24 / 7, \mathrm{CPP}=$ circulation pump programmed cycles, $\mathrm{OT}=$ other $($ describe $)$
} 
Spa Characteristics

\begin{tabular}{|l|l|}
\hline Rating (\# of Persons) & 3 \\
\hline Voltage & 120 VAC $60 \mathrm{~Hz}$ \\
\hline Spa Volume (published) & 200 gallons \\
\hline Spa Volume (as tested) & $\begin{array}{l}219 \text { gallons (This spa had a full line inscribed } \\
\text { onto the spa. The water was filled to this line } \\
\text { as recommended by manufacturer's } \\
\text { instructions) }\end{array}$ \\
\hline Measured Total Spa Capacity & 267 gallons \\
\hline
\end{tabular}

\section{Spa Construction}

\begin{tabular}{|l|l|}
\hline Spa Construction/Insulation type & \multicolumn{2}{|l|}{} \\
\hline Filtration System & \\
\hline Cover Characteristics: & \\
\hline Material composition & \\
\hline Weight & \\
\hline Density & \\
\hline Thickness at center & \\
\hline Thickness at edge & \\
\hline R-value & \\
\hline Hinge width & \\
\hline Hinge fill material & \\
\hline
\end{tabular}

Data Analysis

\begin{tabular}{|c|c|}
\hline \multicolumn{2}{|l|}{ Water Temperature: } \\
\hline Minimum & $102^{\circ} \mathrm{F}$ \\
\hline Maximum & $104^{\circ} \mathrm{F}$ \\
\hline Average & $103^{\circ} \mathrm{F}$ \\
\hline \multicolumn{2}{|l|}{ Air Temperature: } \\
\hline Minimum & $52^{\circ} \mathrm{F}$ \\
\hline Maximum & $60^{\circ} \mathrm{F}$ \\
\hline Average & $56^{\circ} \mathrm{F}$ \\
\hline Average Temperature Difference & $47.1^{\circ} \mathrm{F}$ \\
\hline Duration of Test Record [hh:mm] & 73:00 \\
\hline Total energy used during Test Record & 18,339 Watt-hours \\
\hline Measured Stand-by Power in Watts & 251 Watts \\
\hline $\begin{array}{l}\text { Normalized Stand-by Power in Watts } \\
\text { (using } \Delta T_{\text {ideal }}=37^{\circ} \mathrm{F} \text { ) }\end{array}$ & 198 Watts \\
\hline \multicolumn{2}{|l|}{ CEC Allowable Stand-by Watts } \\
\hline at Tested Volume & 181 Watts \\
\hline at Published Volume & 171 Watts \\
\hline at Total Spa Capacity & 207 Watts \\
\hline
\end{tabular}

\footnotetext{
${ }^{54} \mathrm{FF}=$ full foam to spa cabinet, $\mathrm{PF}=$ partial foam shell and plumbing, $\mathrm{SF}=$ foamed shell, $\mathrm{ML}=$ insulated cabinet multi-layer, $\mathrm{SL}=$ insulated cabinet single layer, $\mathrm{NI}=$ no insulation, $\mathrm{OT}=$ other (describe)

${ }^{55} \mathrm{TSP}=$ two-speed pump, low speed, programmed cycles, $\mathrm{CP}=$ circulation pump operating $24 / 7, \mathrm{CPP}=$ circulation pump programmed cycles, $\mathrm{OT}=$ other $($ describe $)$
} 

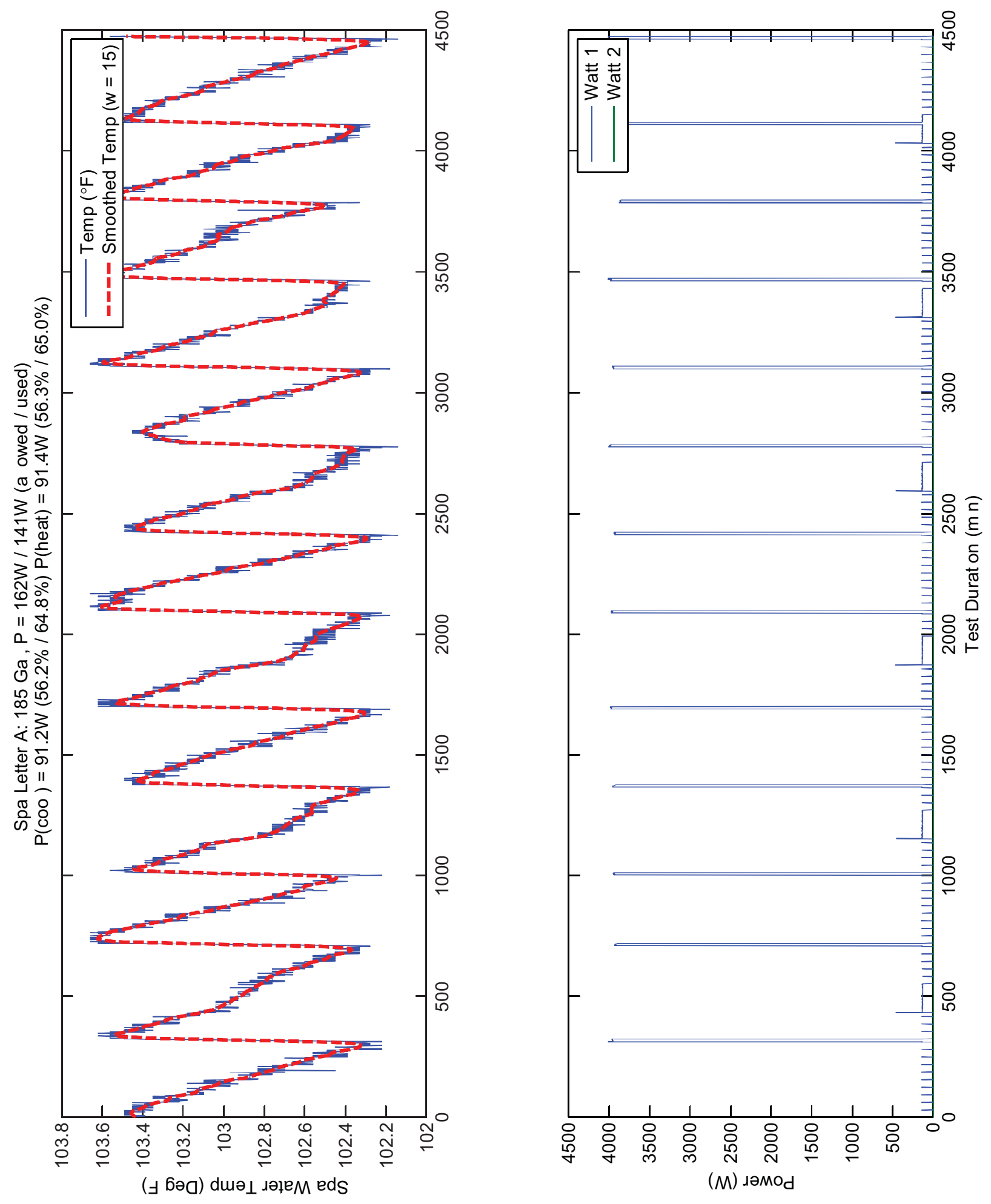
E-30
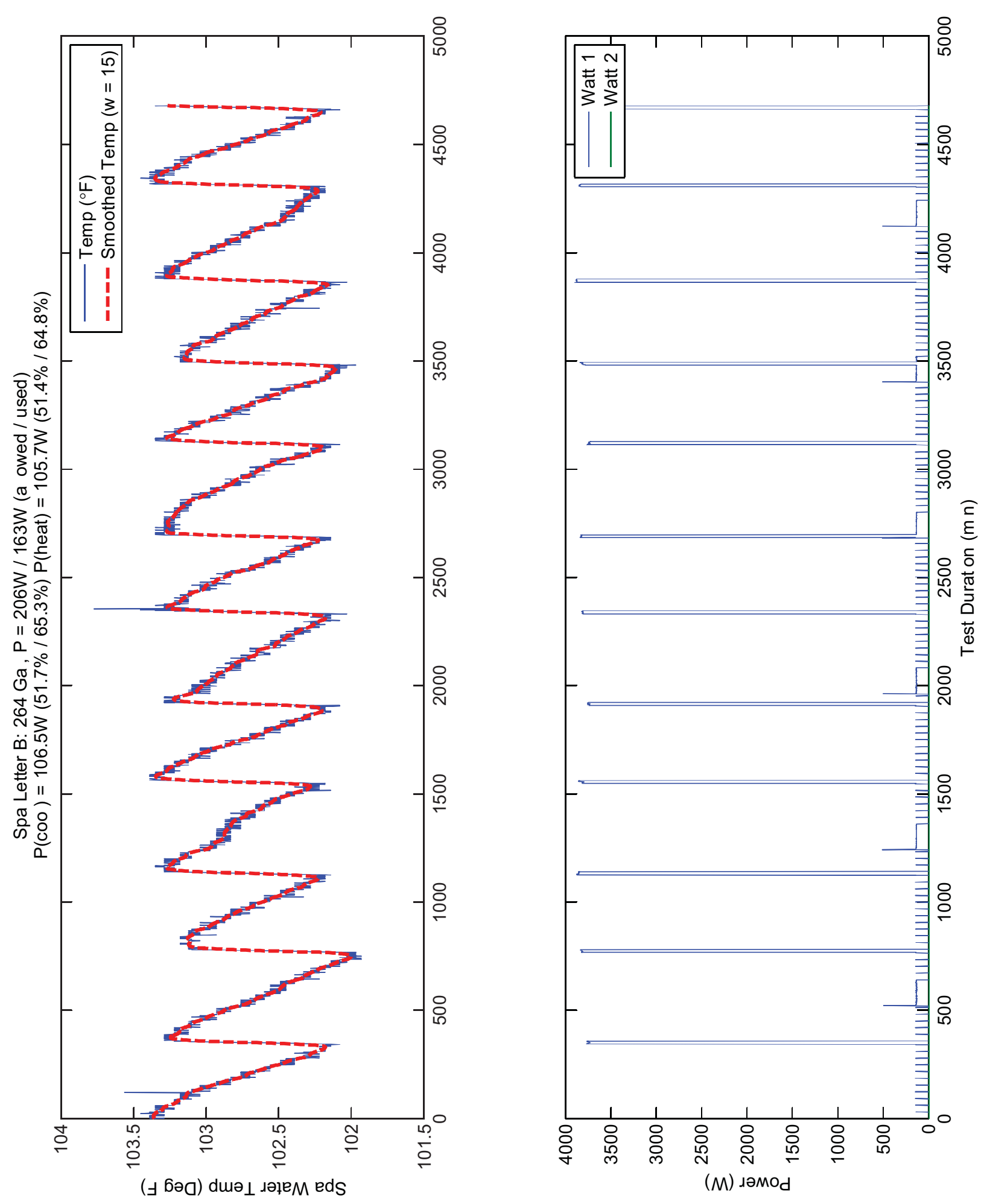
E-31
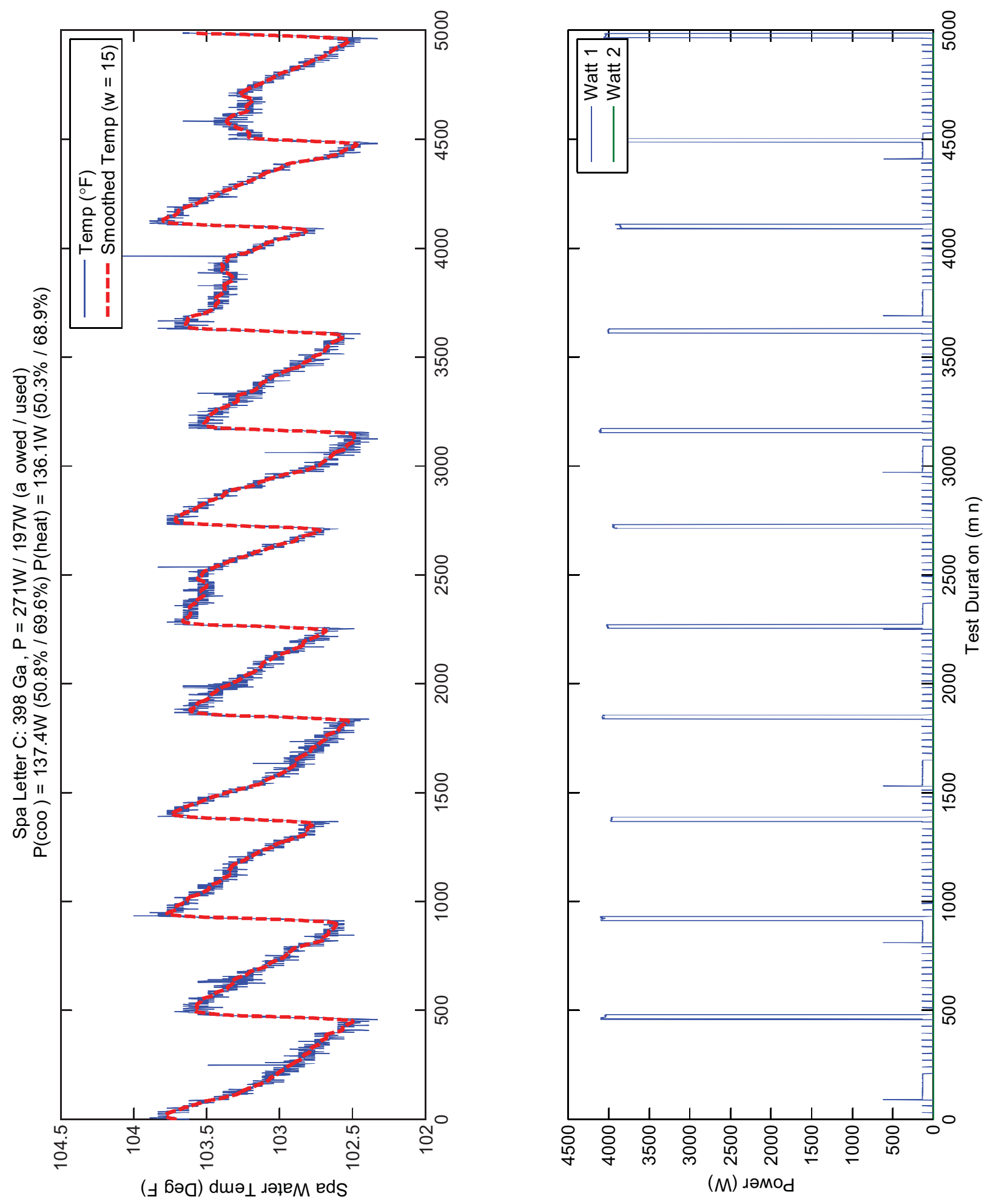
E-32
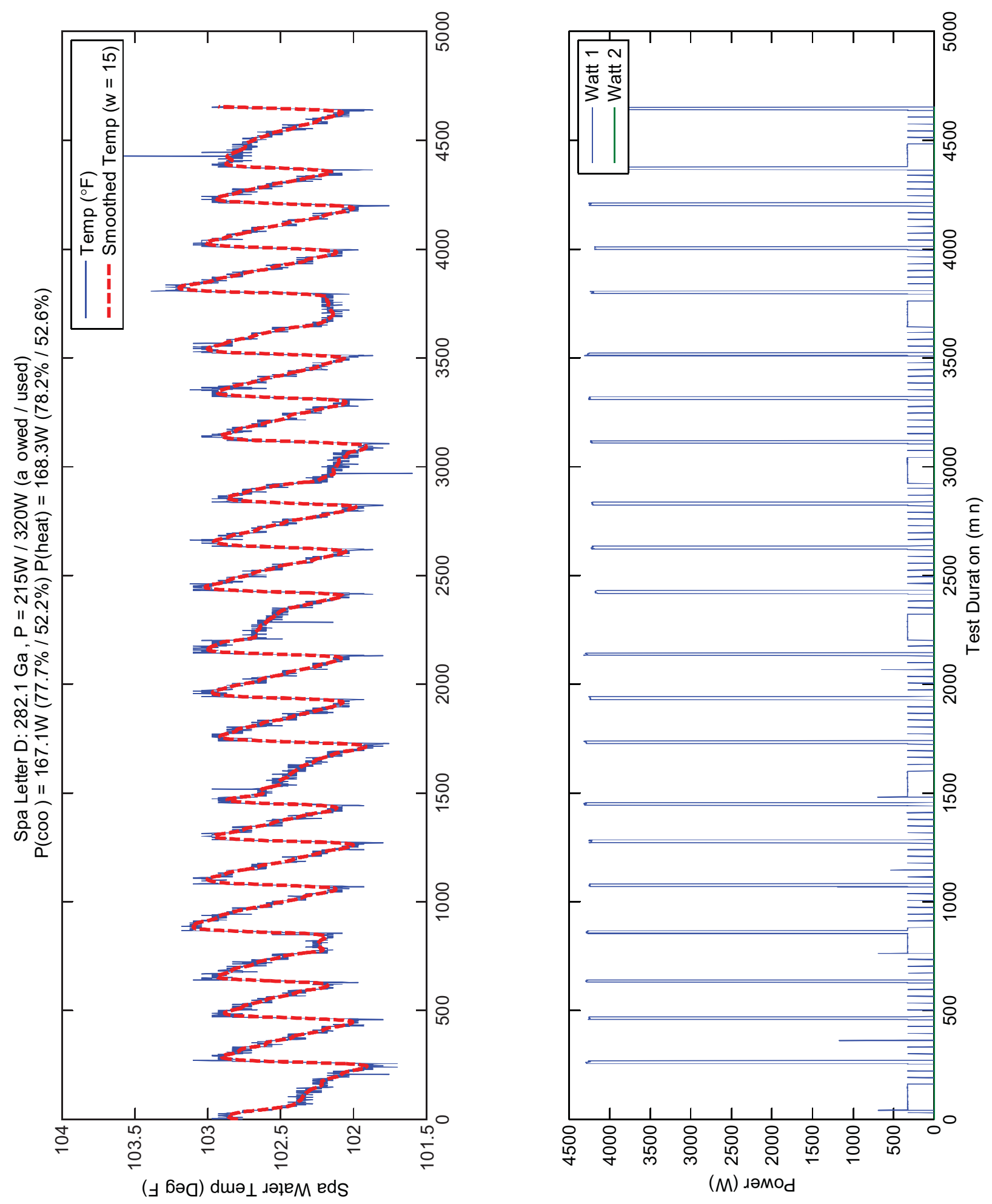
E-33
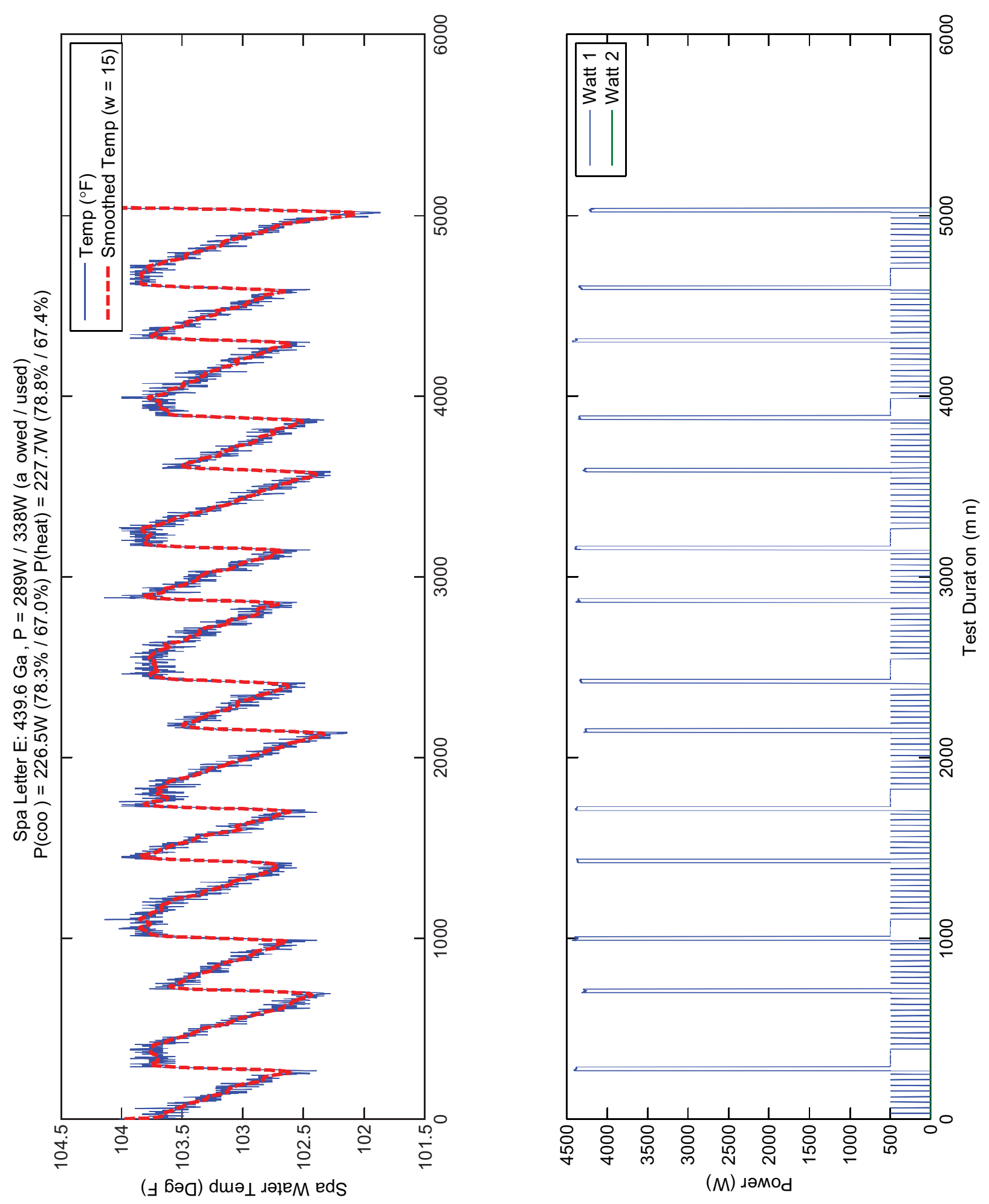
E-34
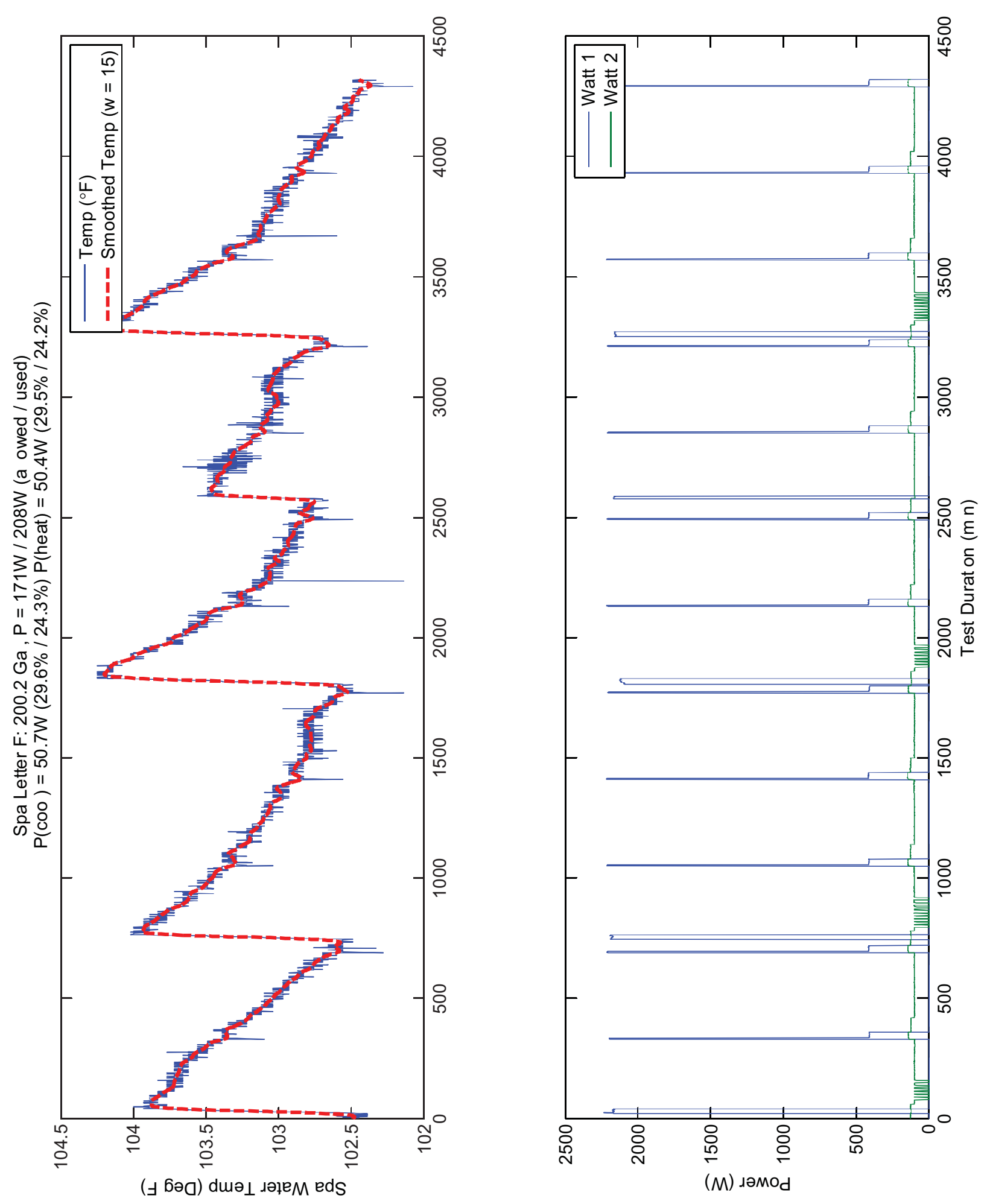
E-35
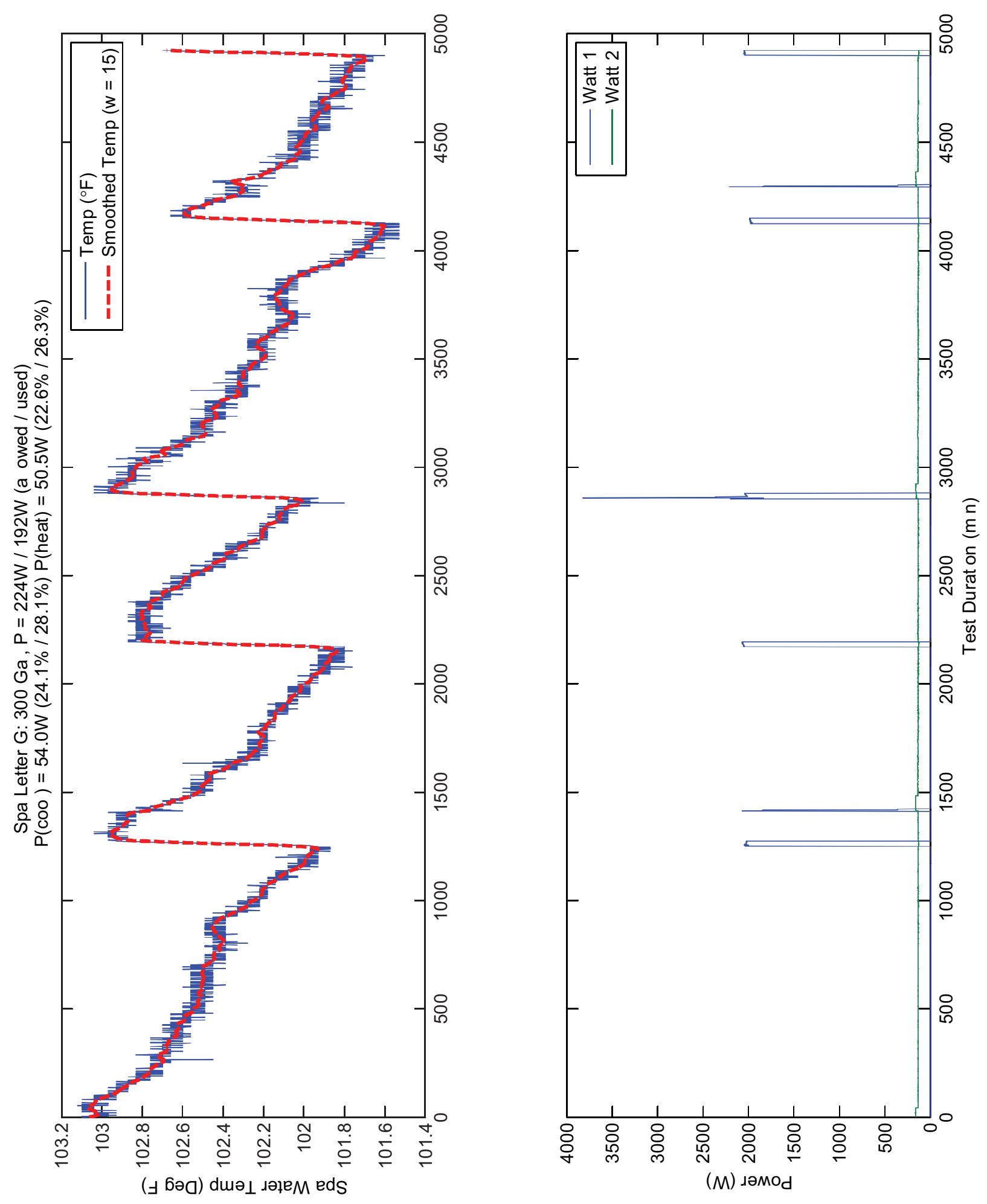
E-36
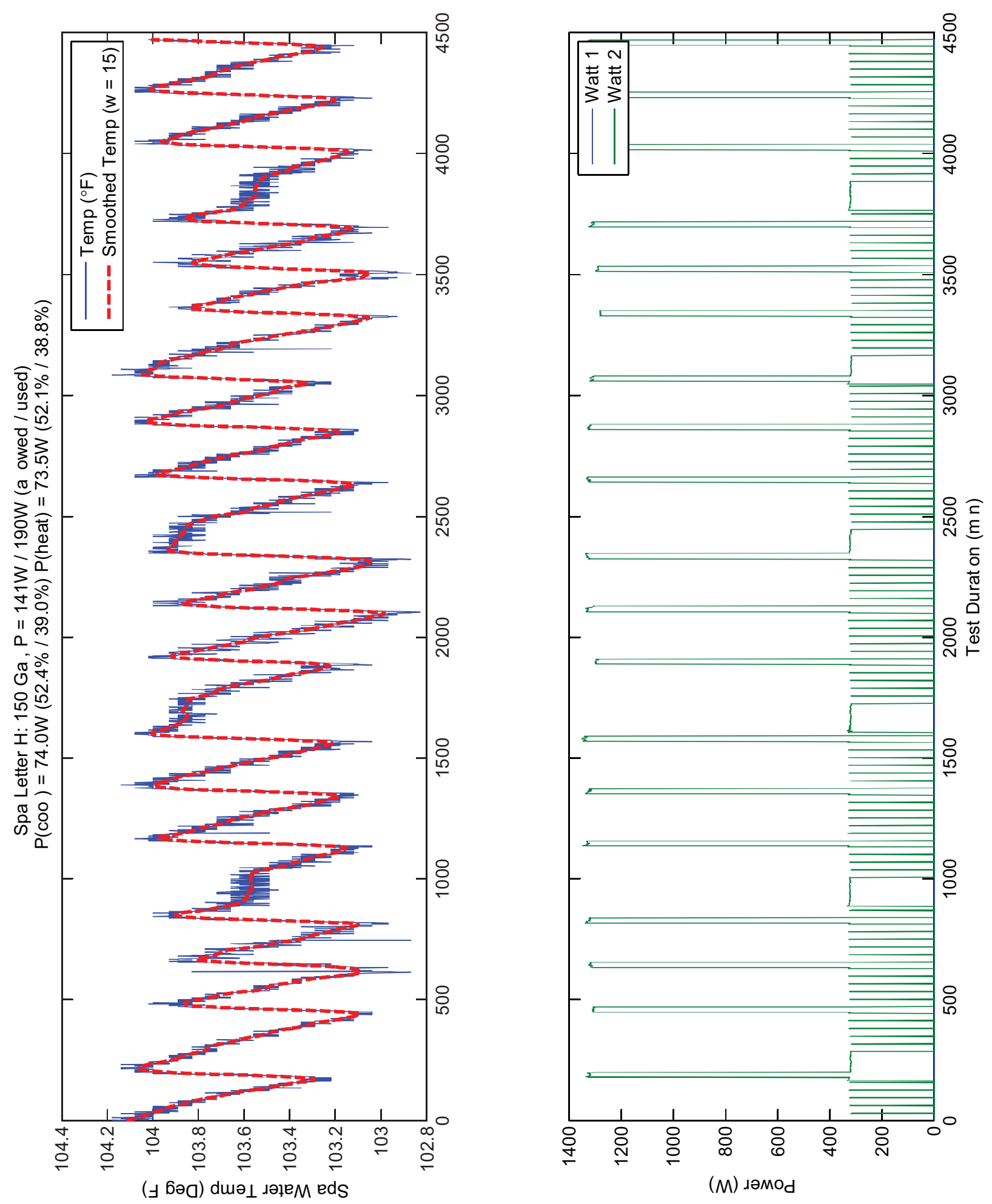

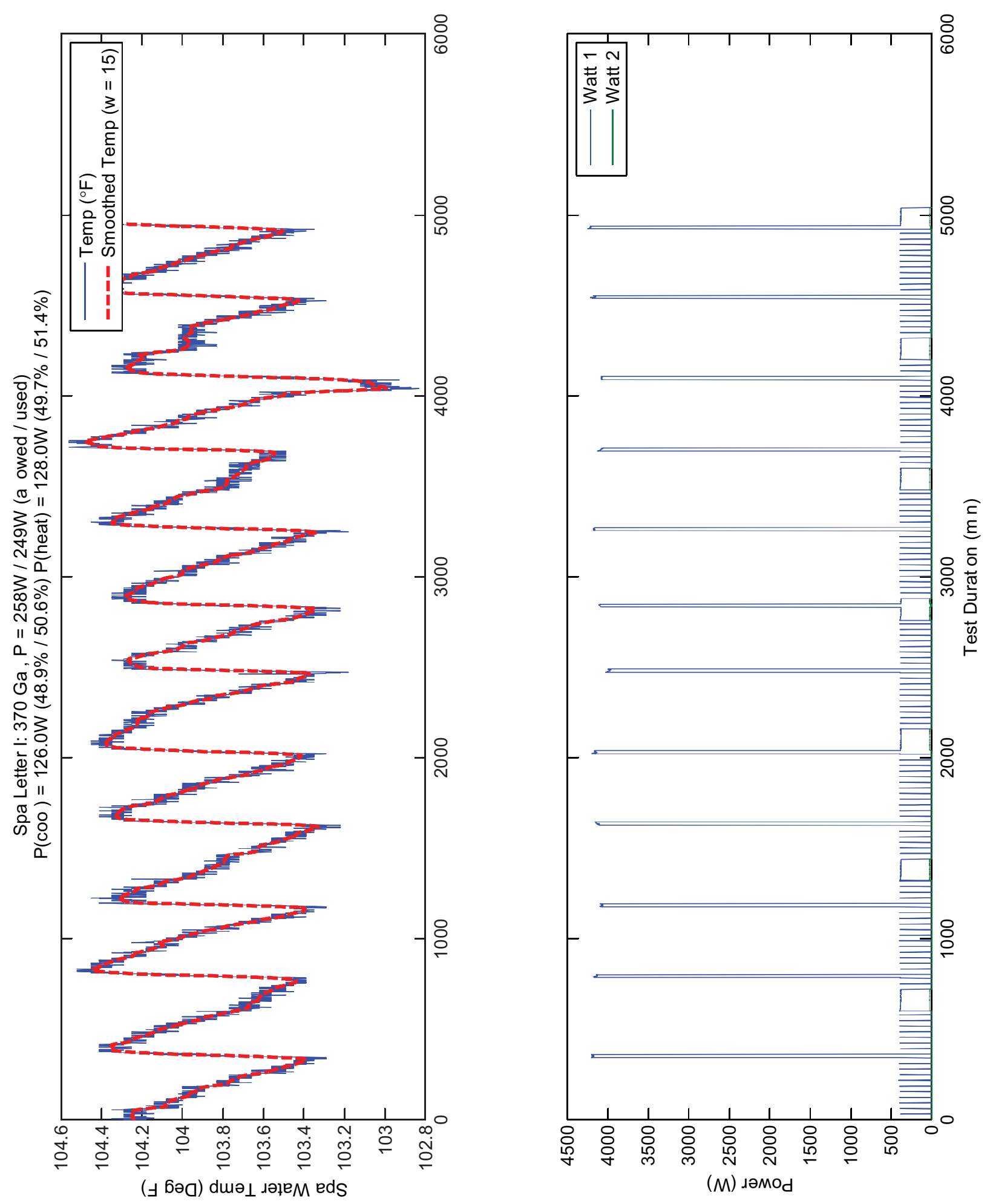
E-38
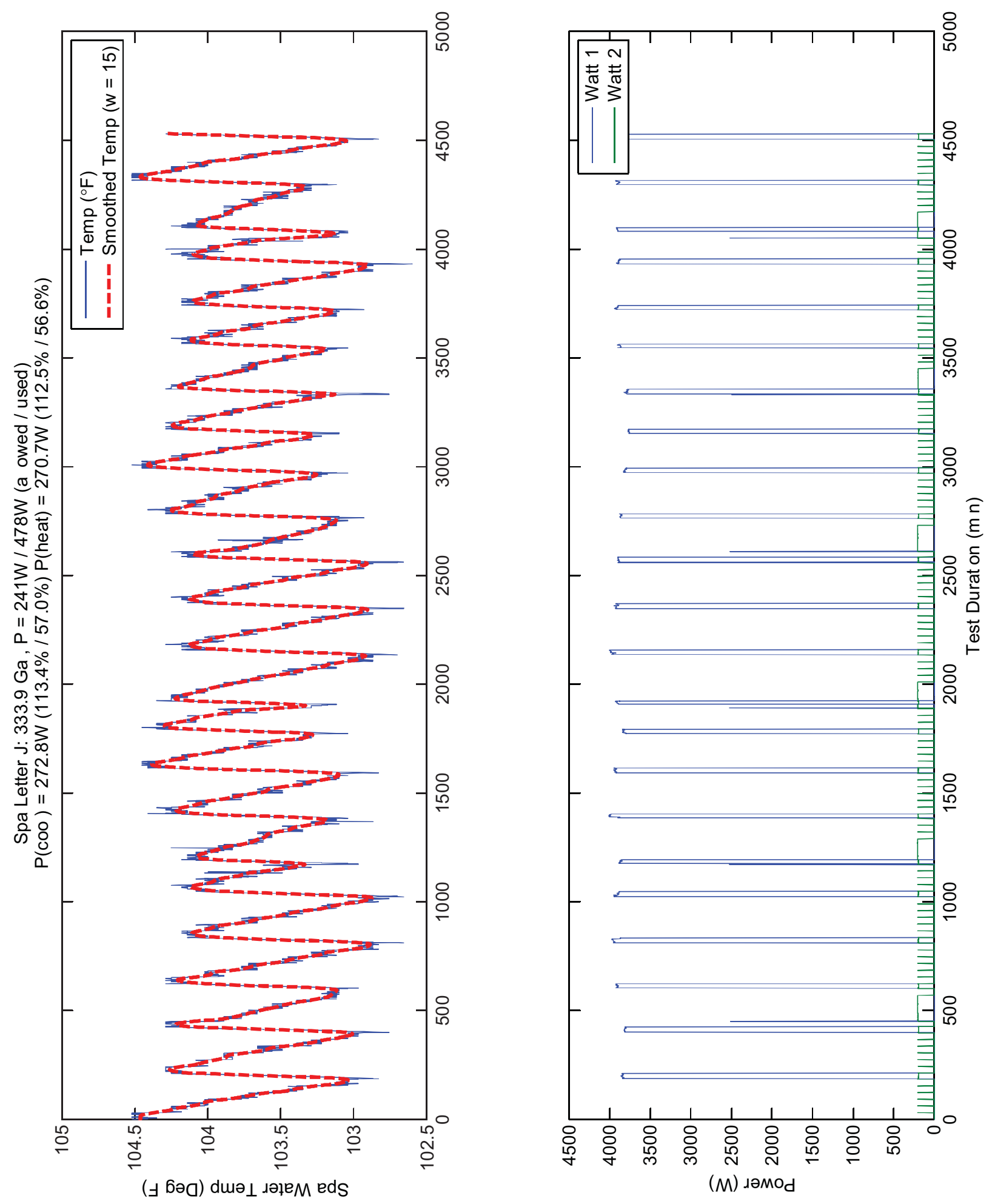
E-39
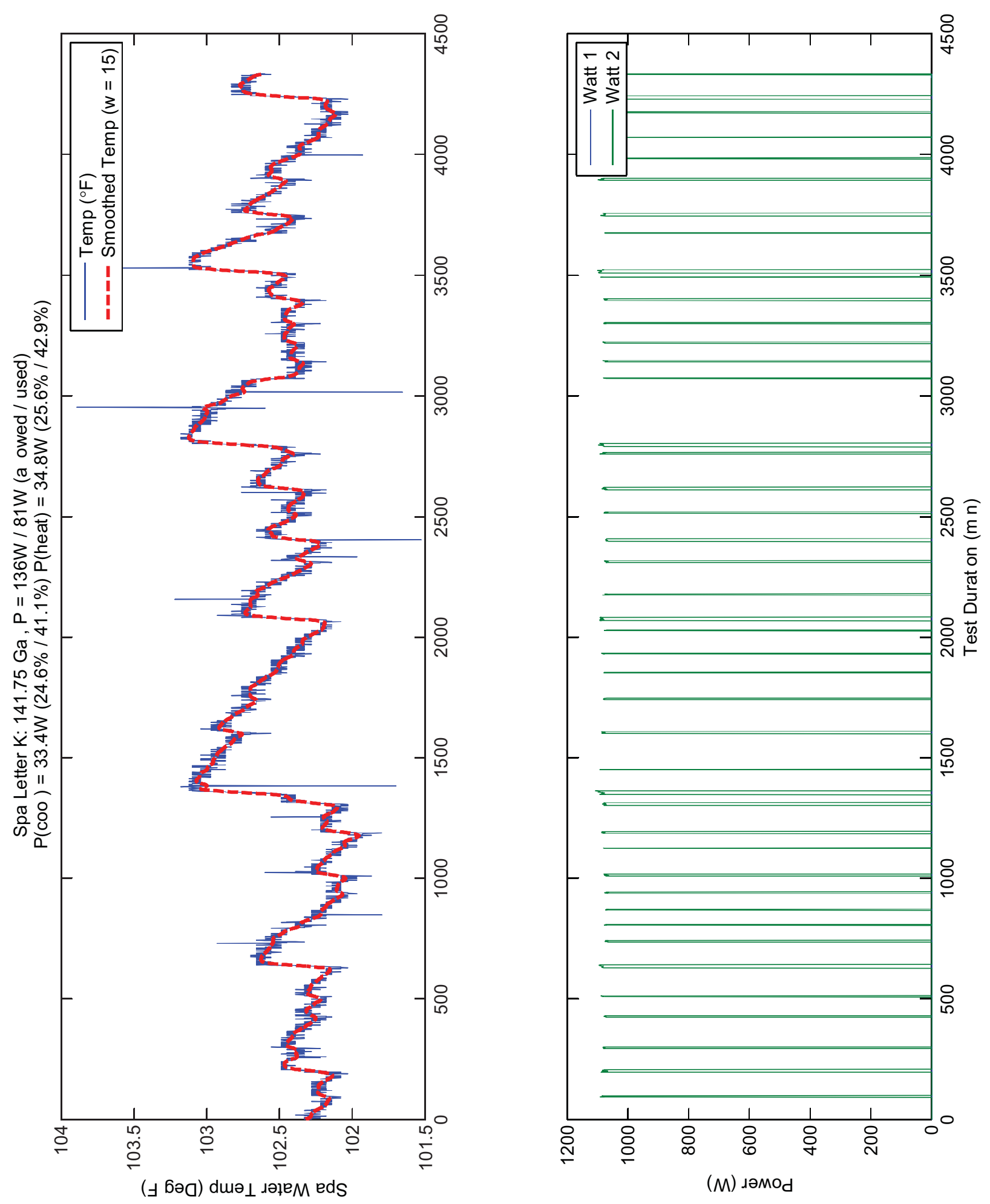

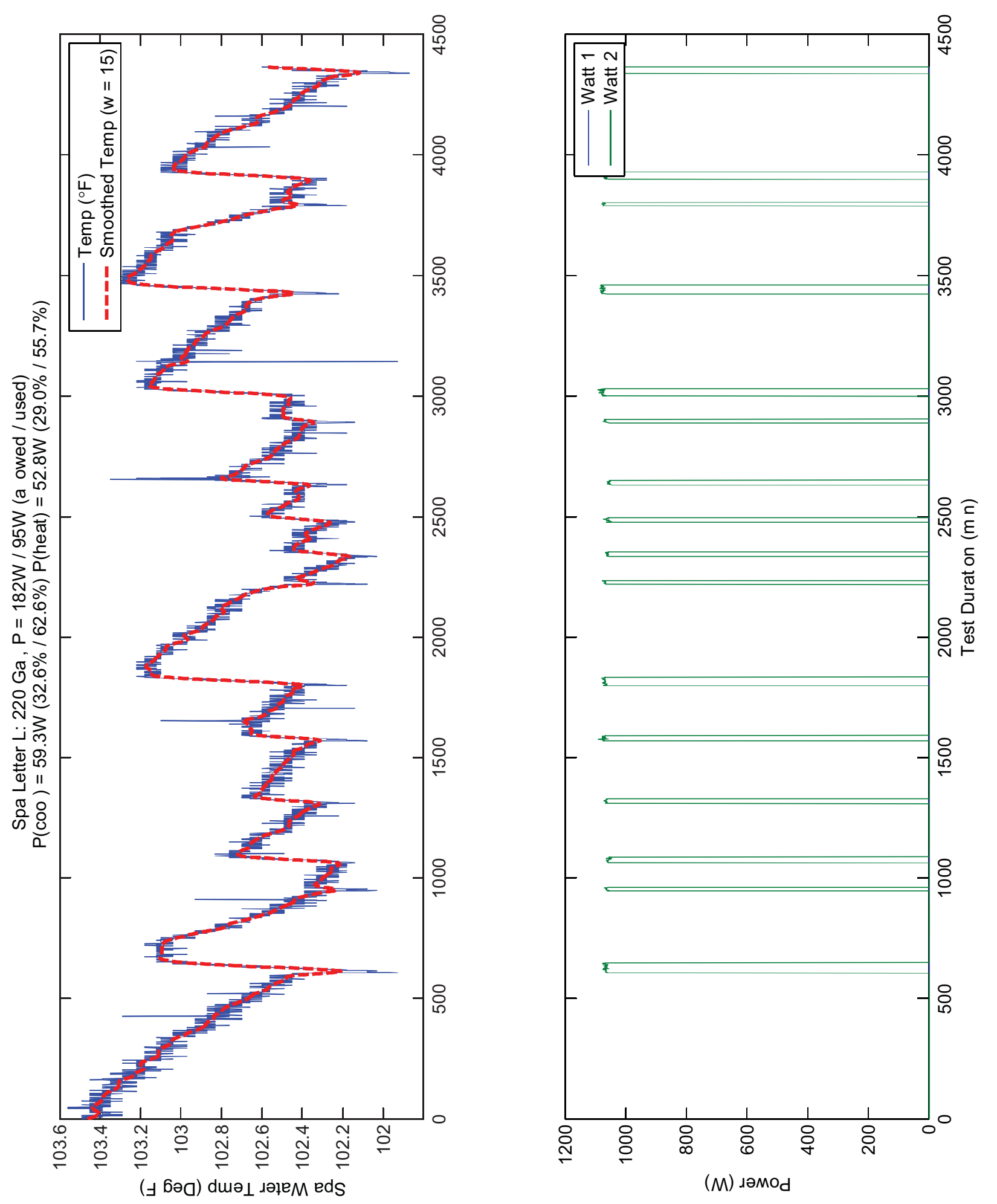

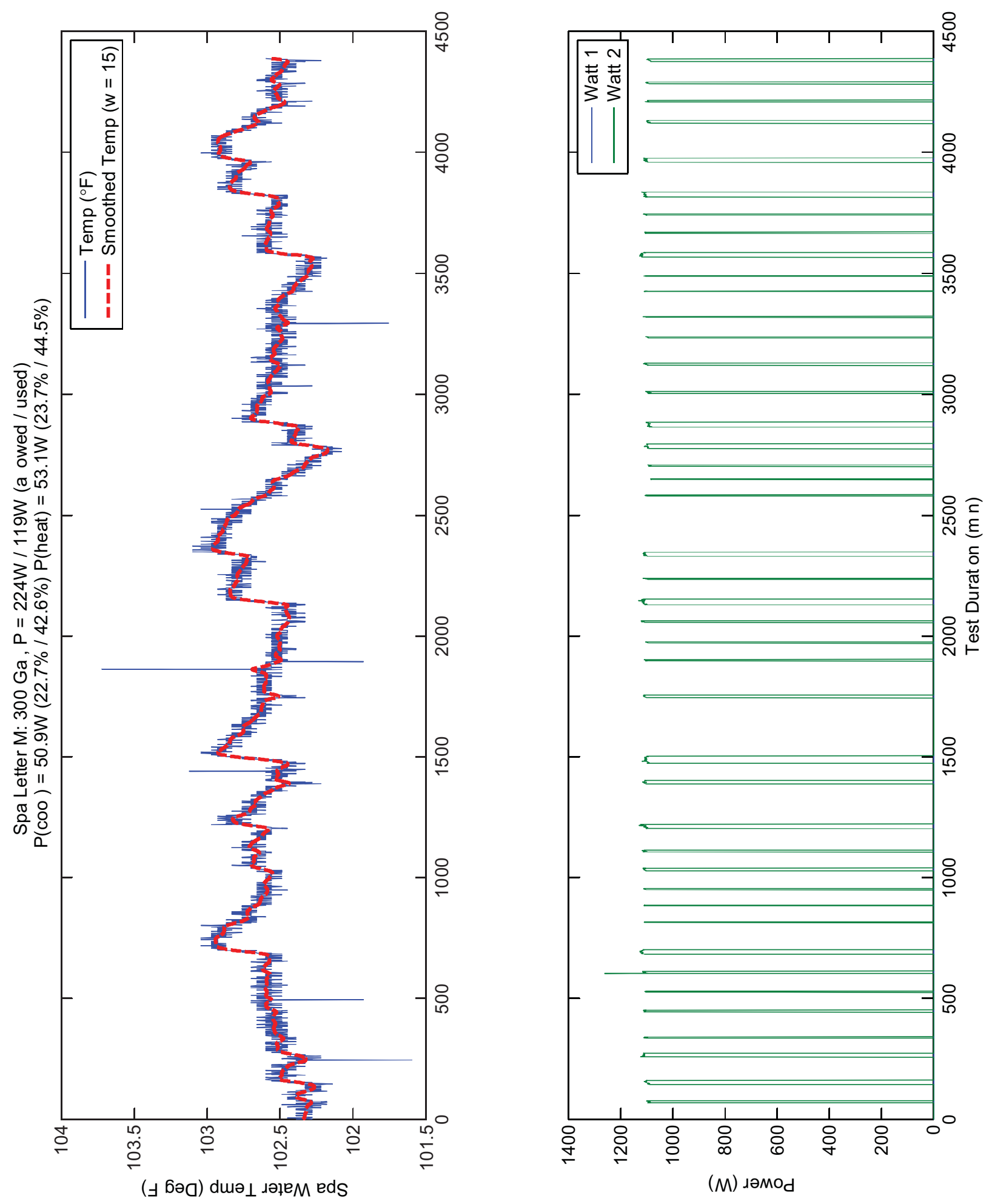

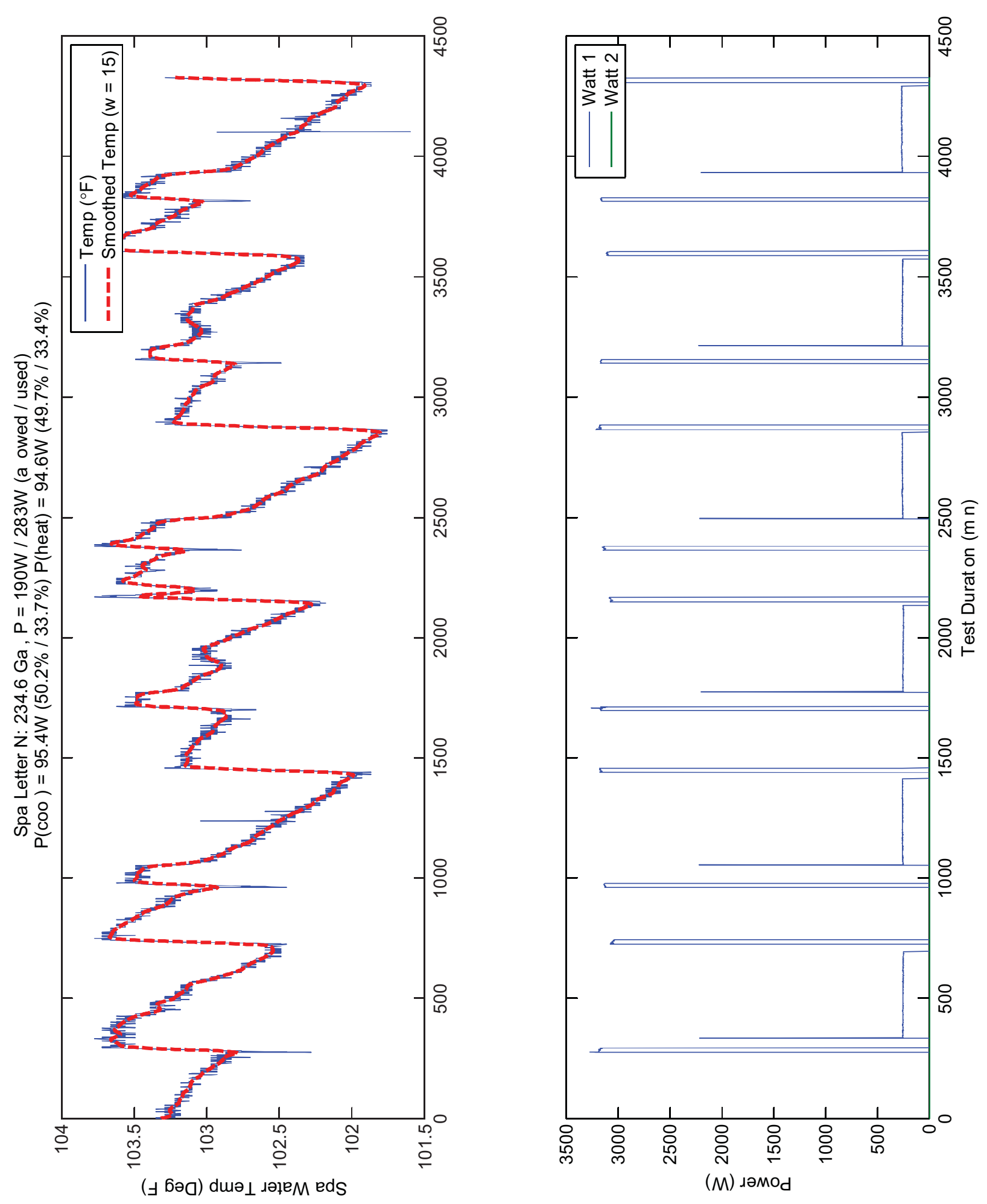

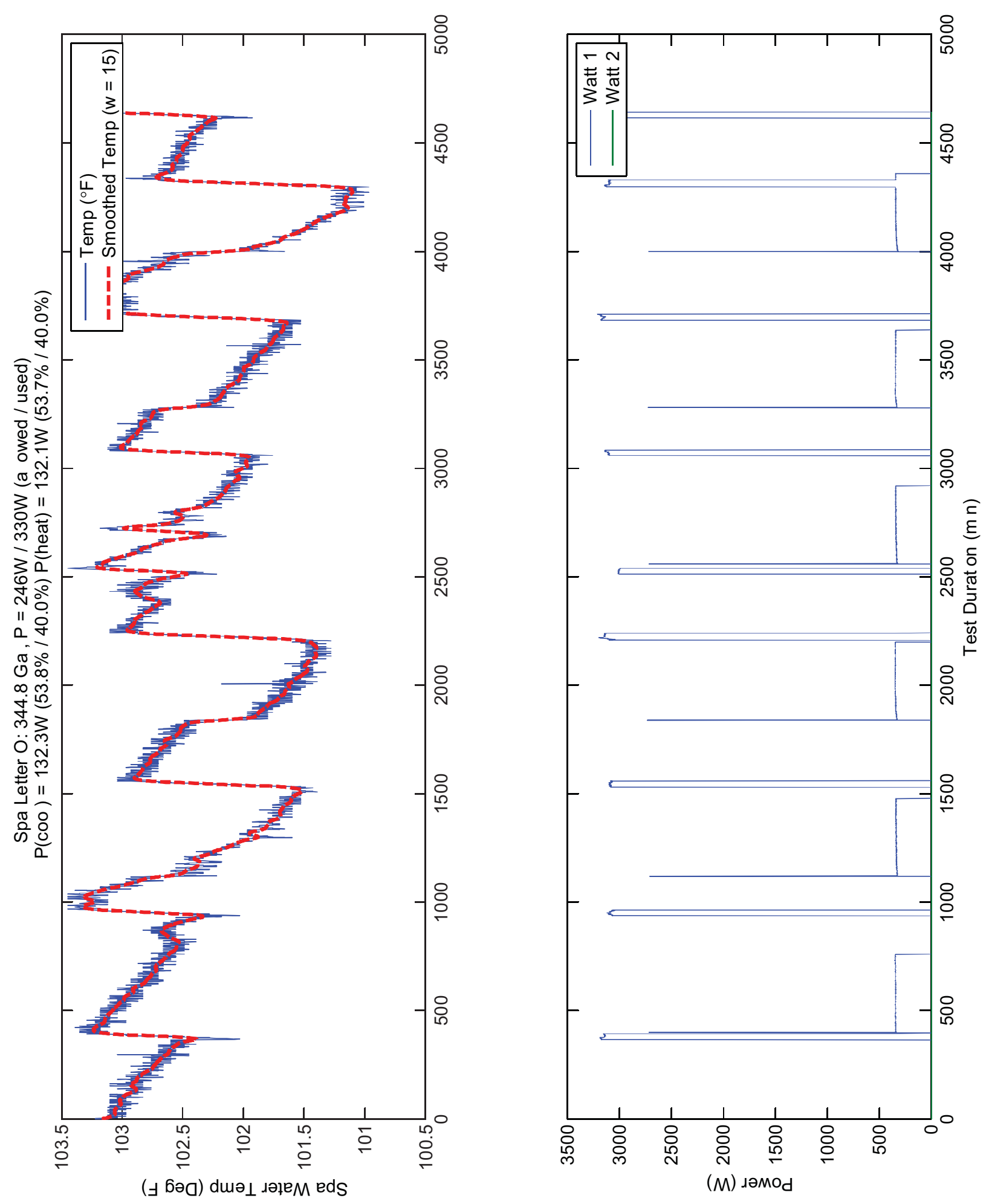

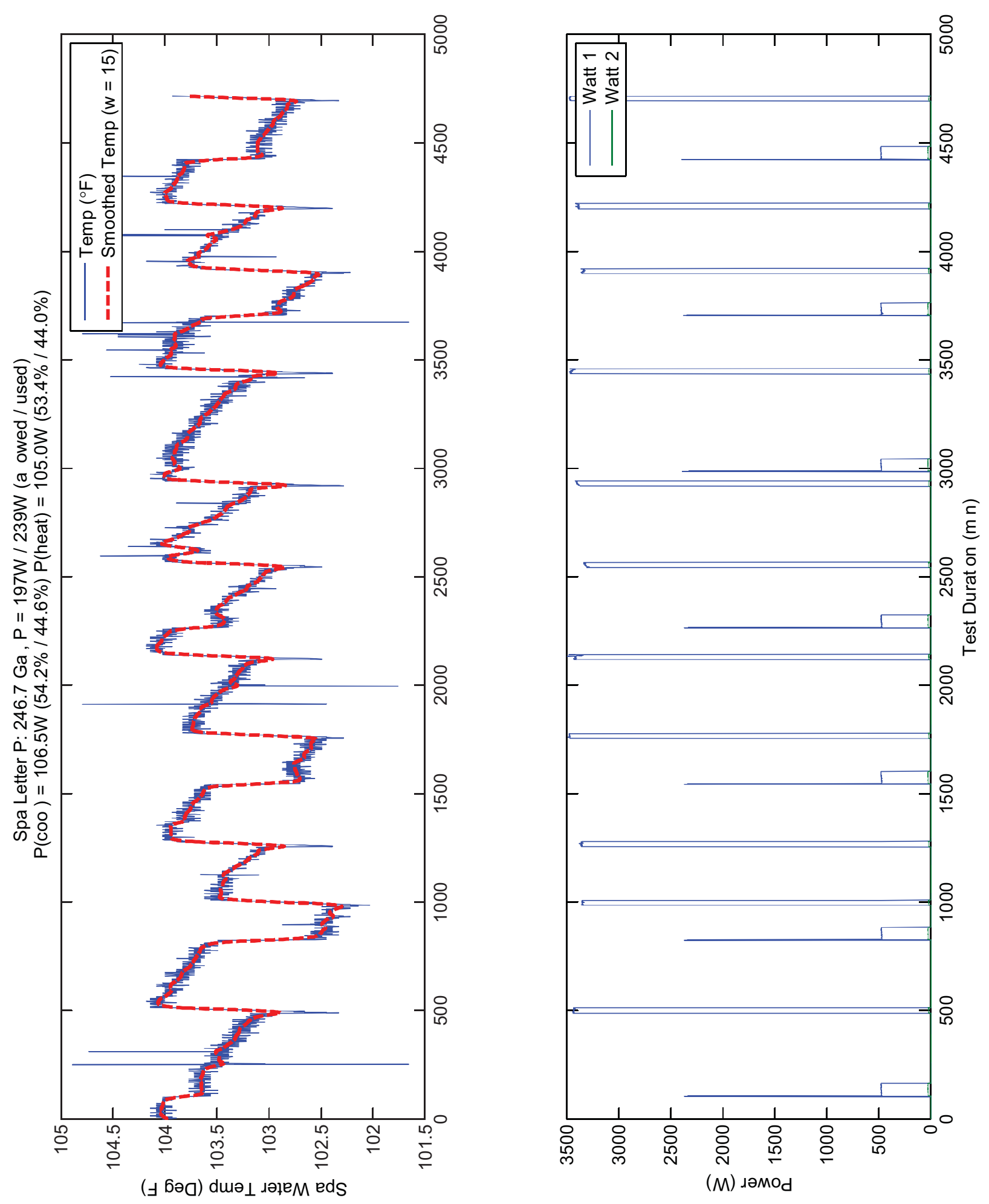

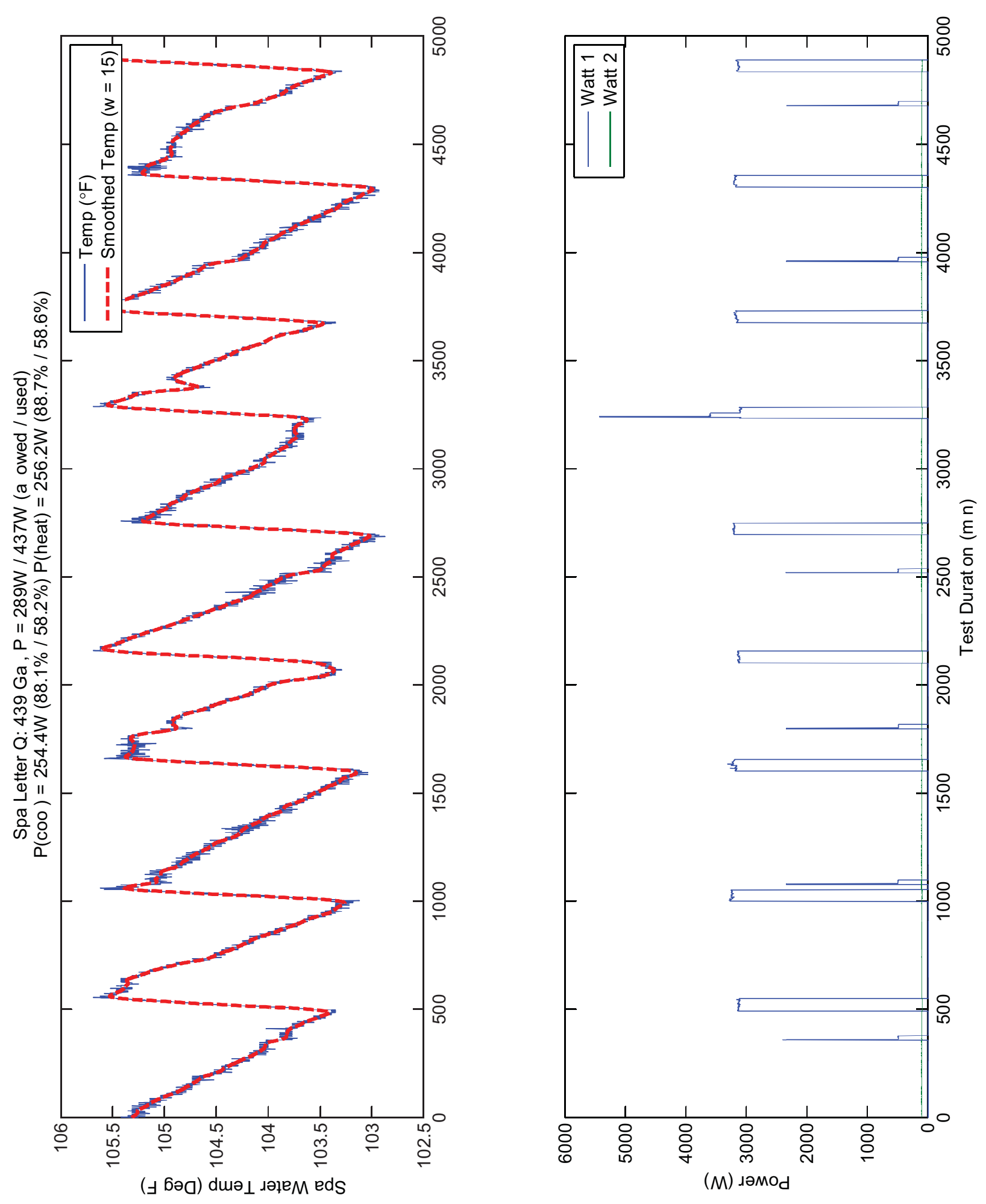
E-46
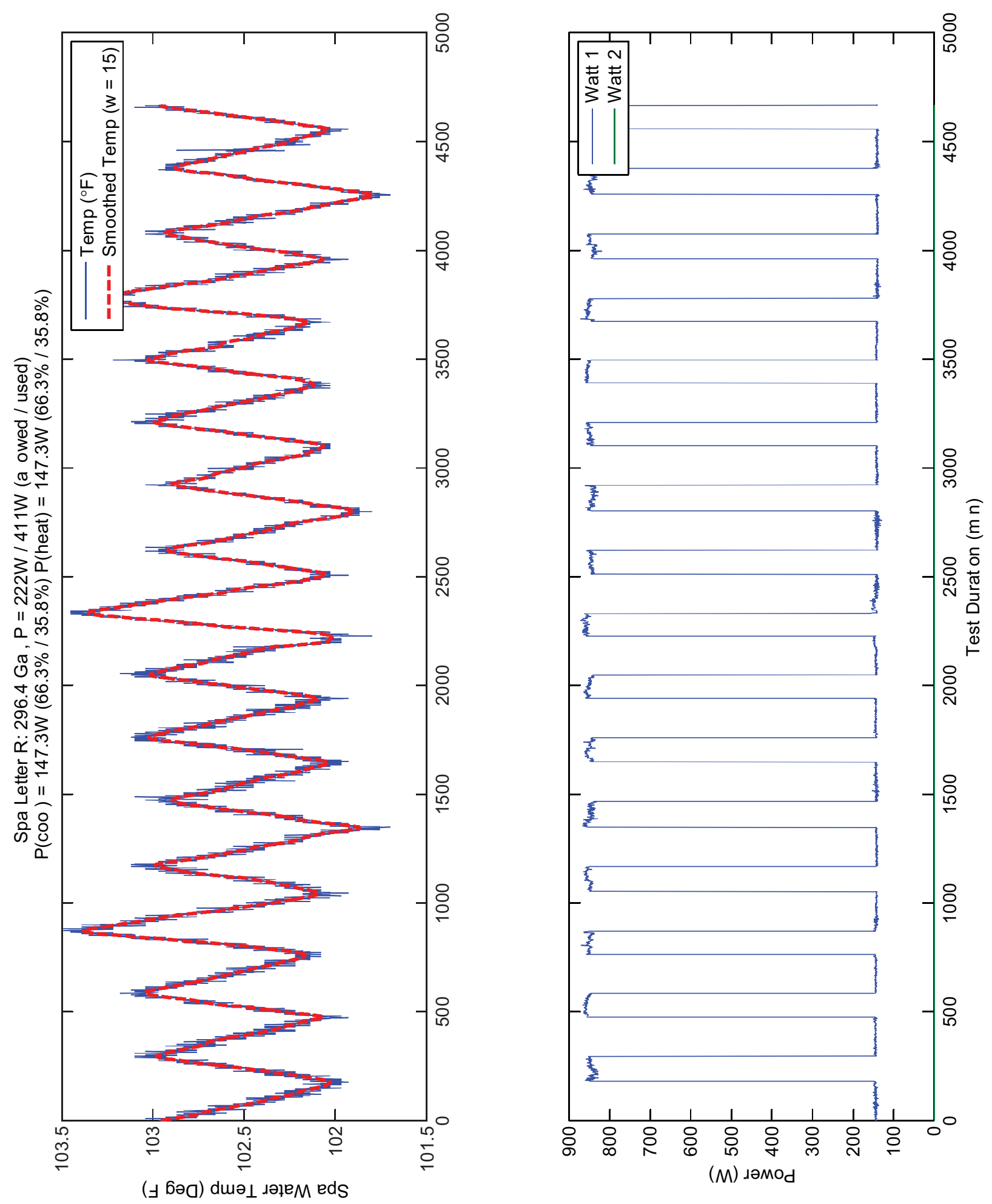

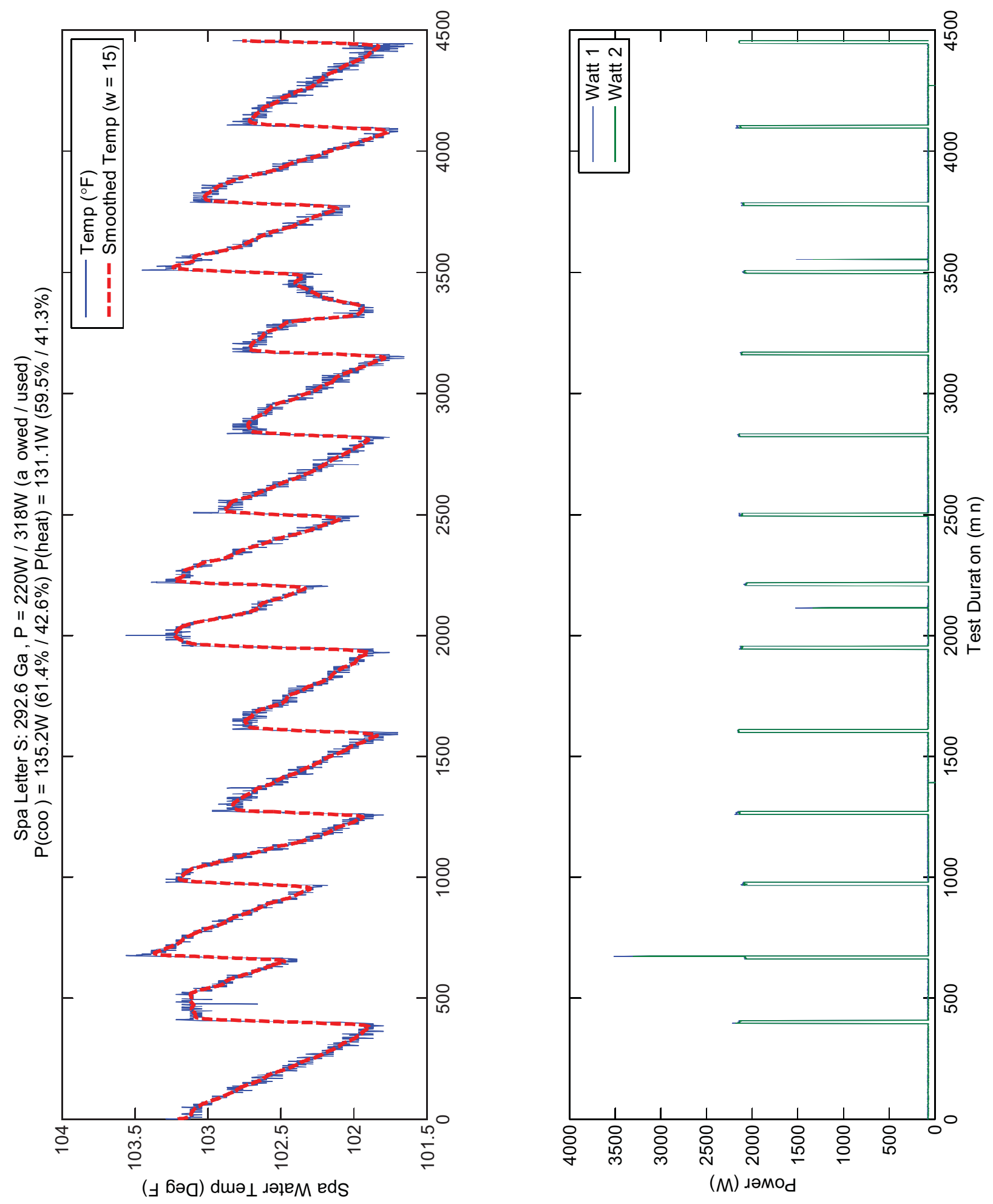

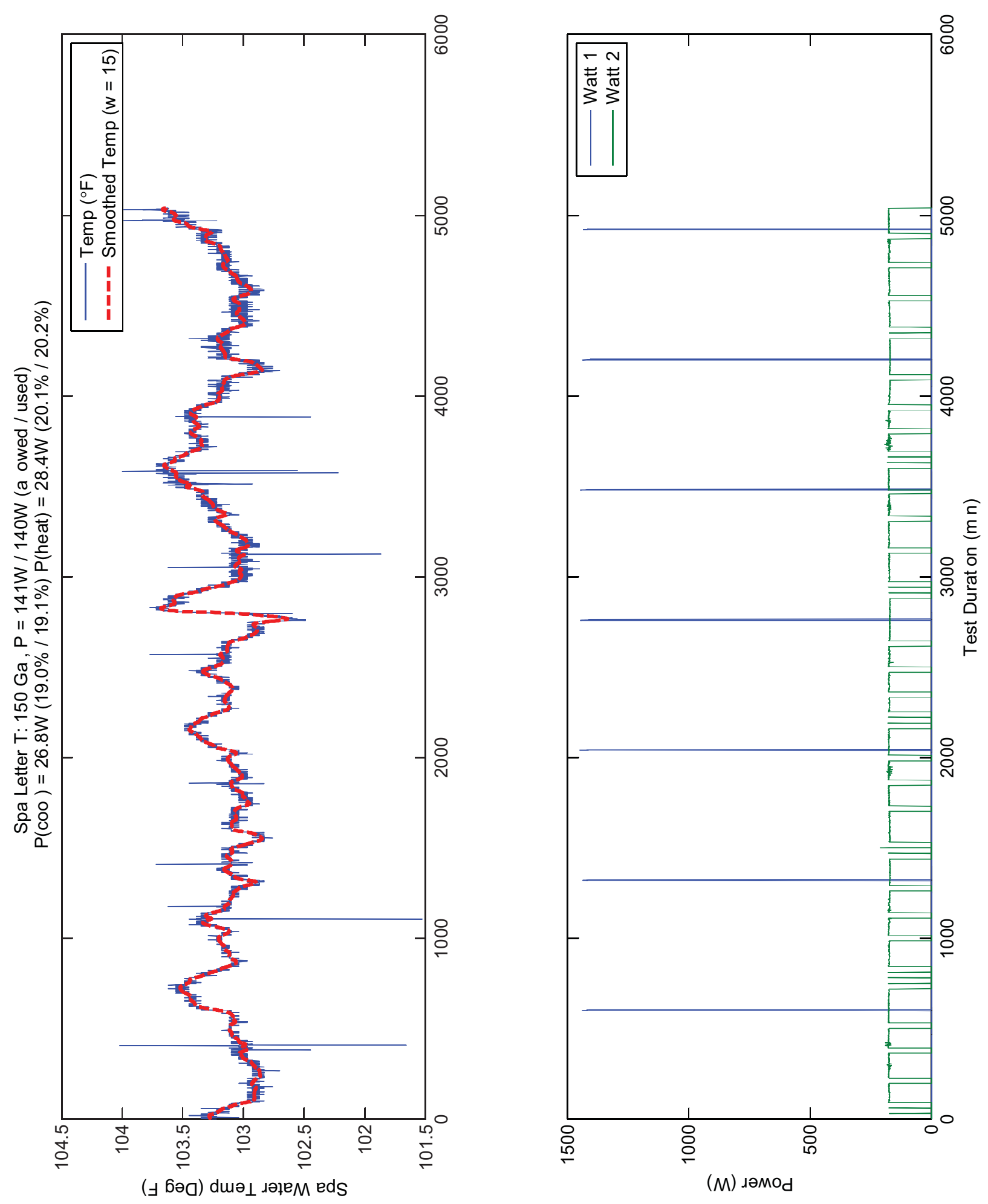

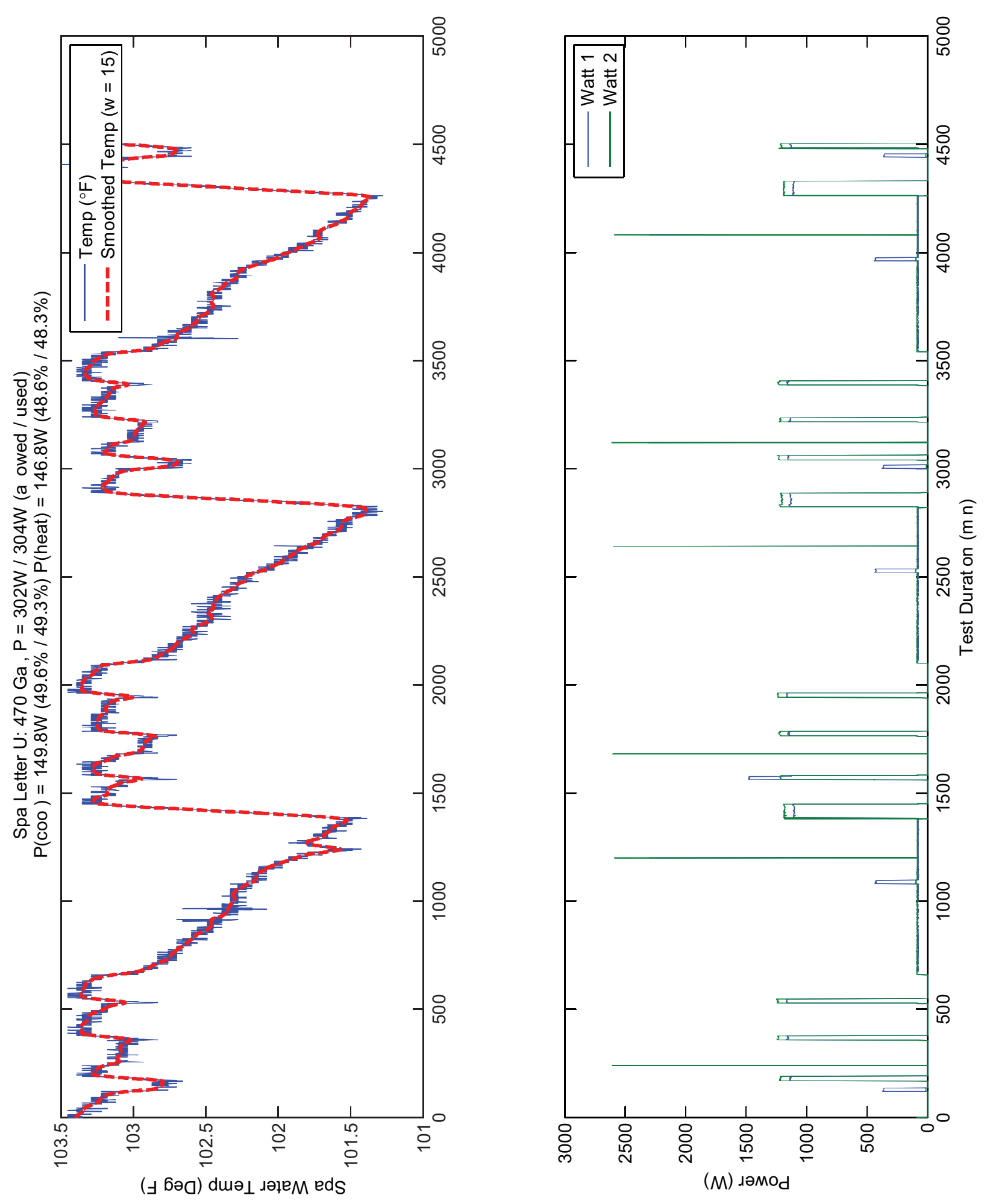

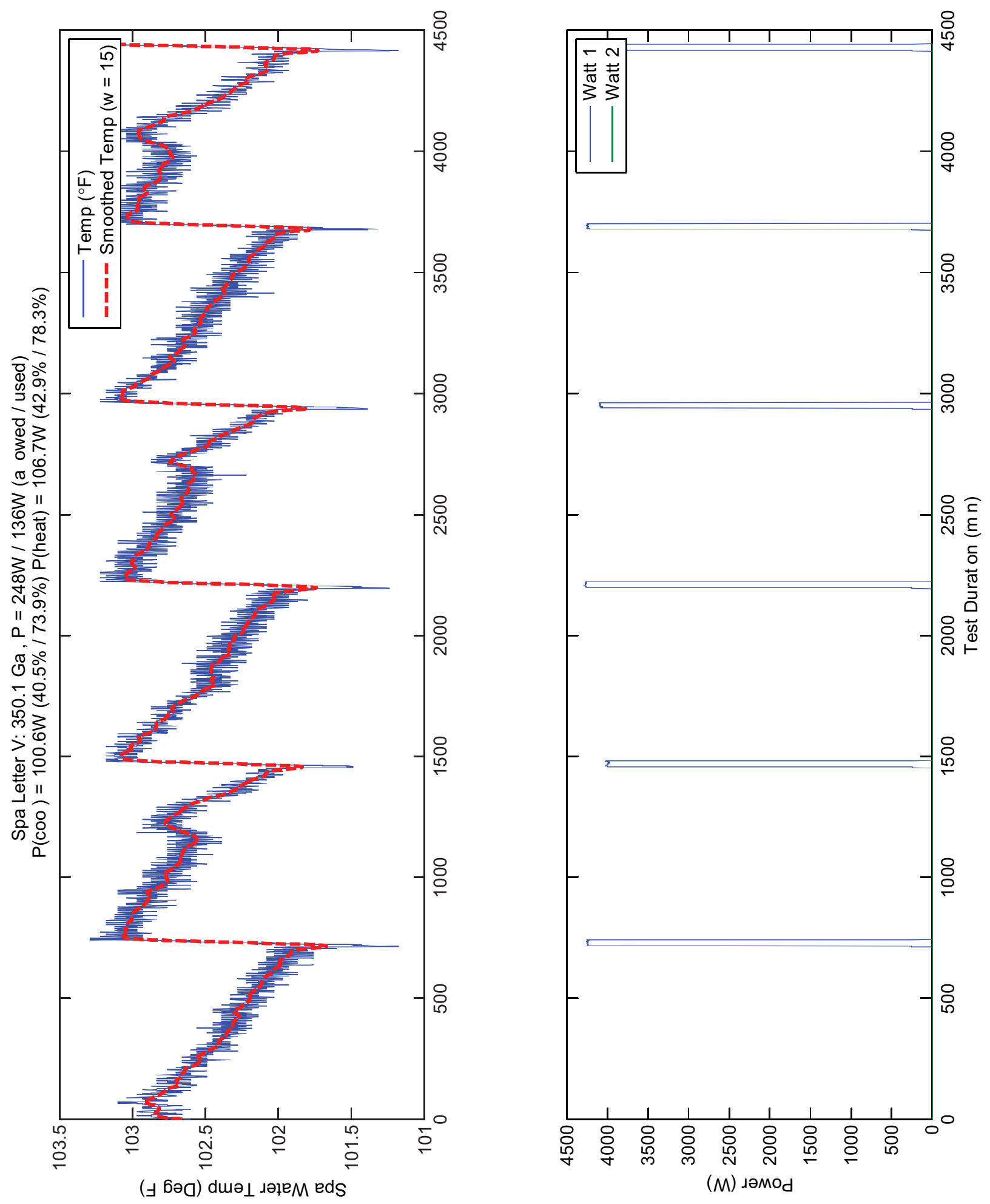
E-51
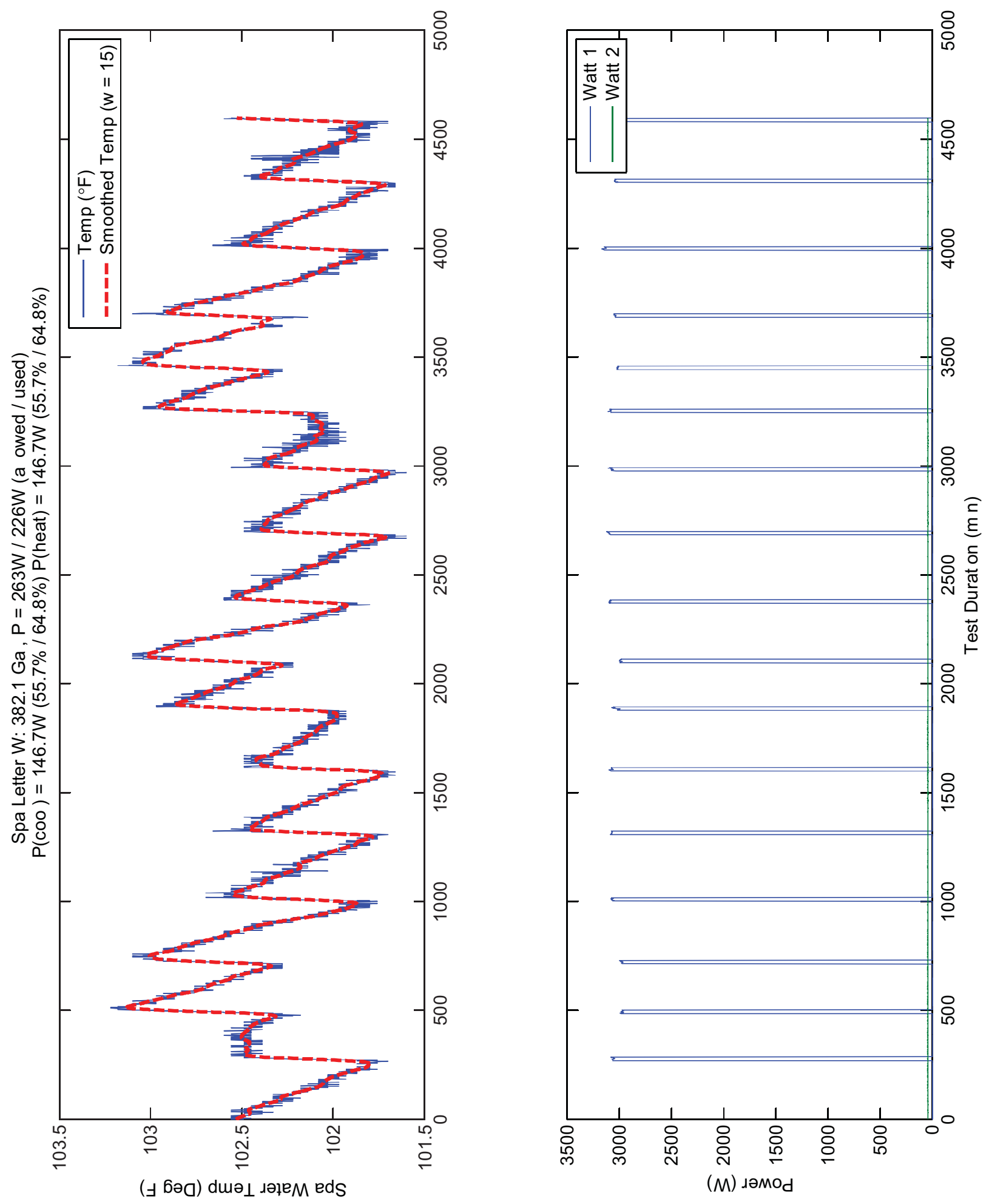
E-52
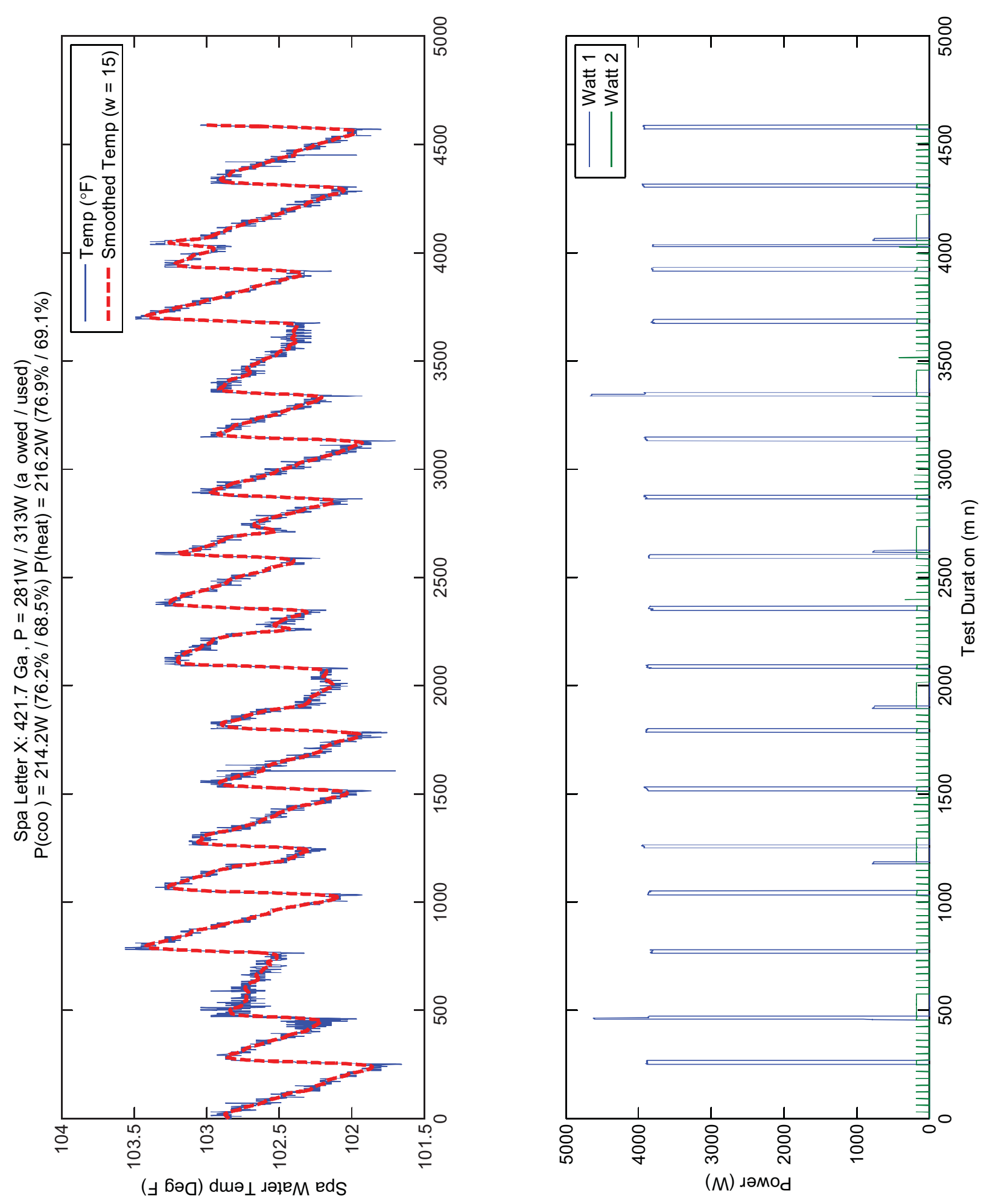
E-53
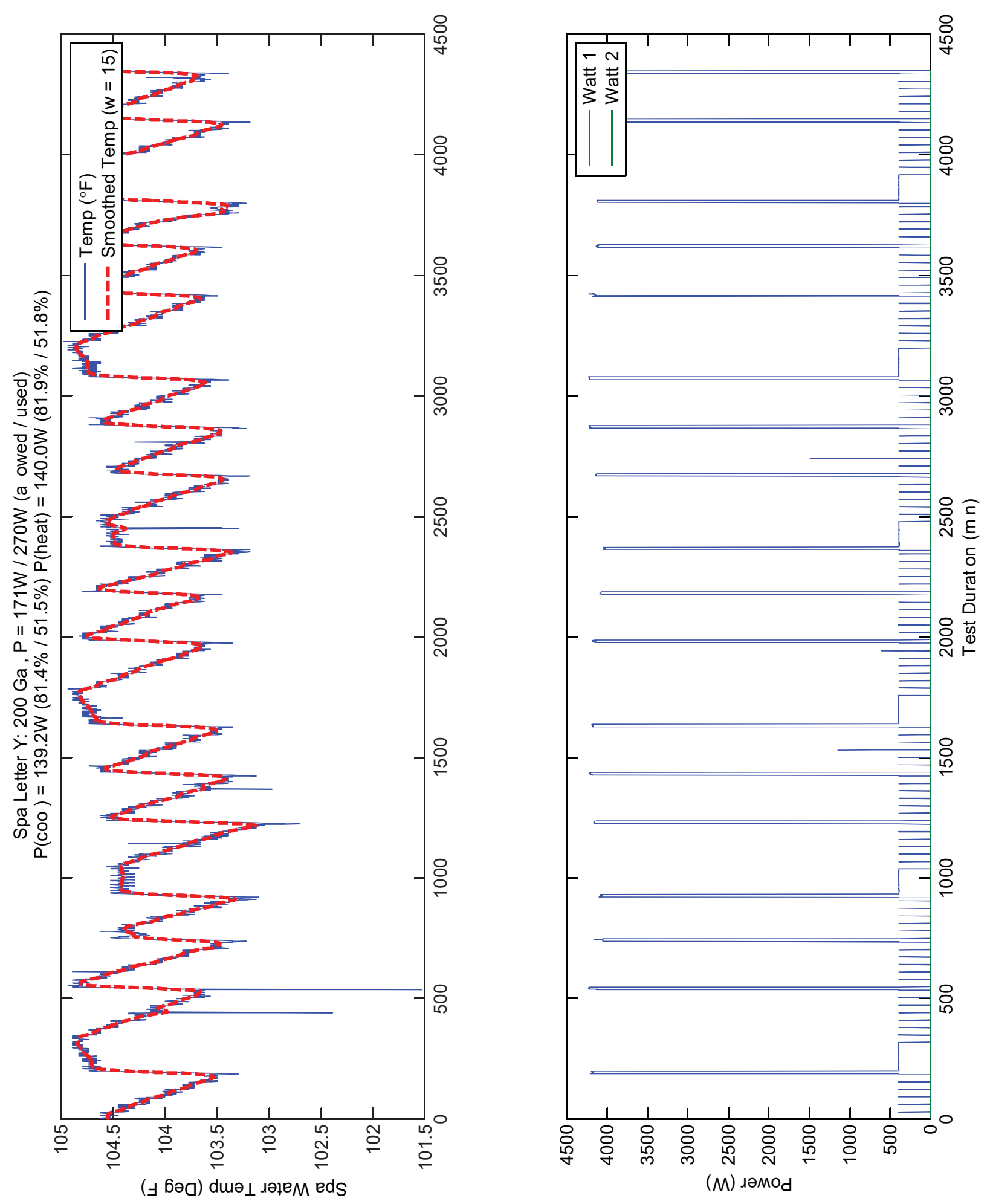
E-54
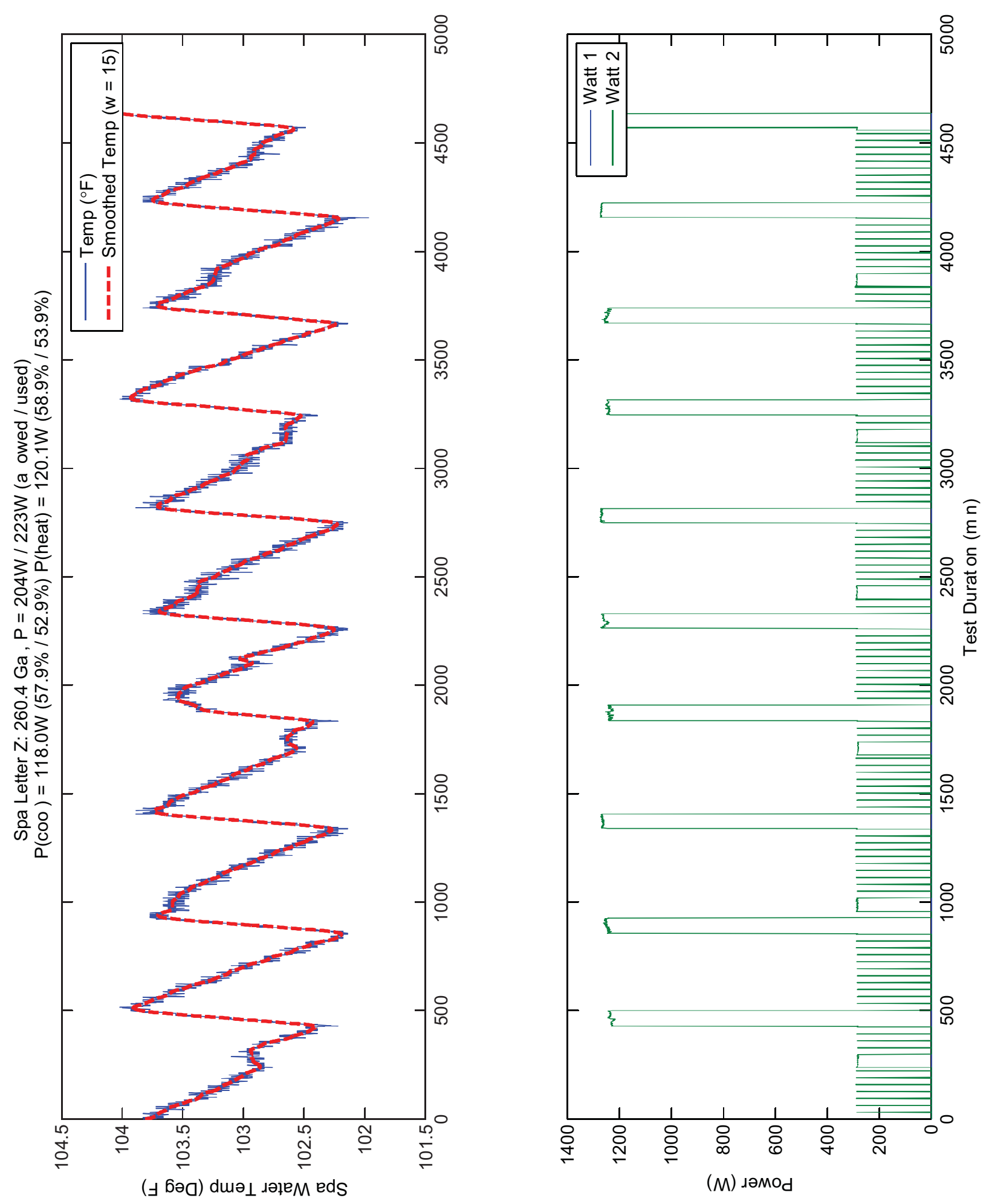
E-55
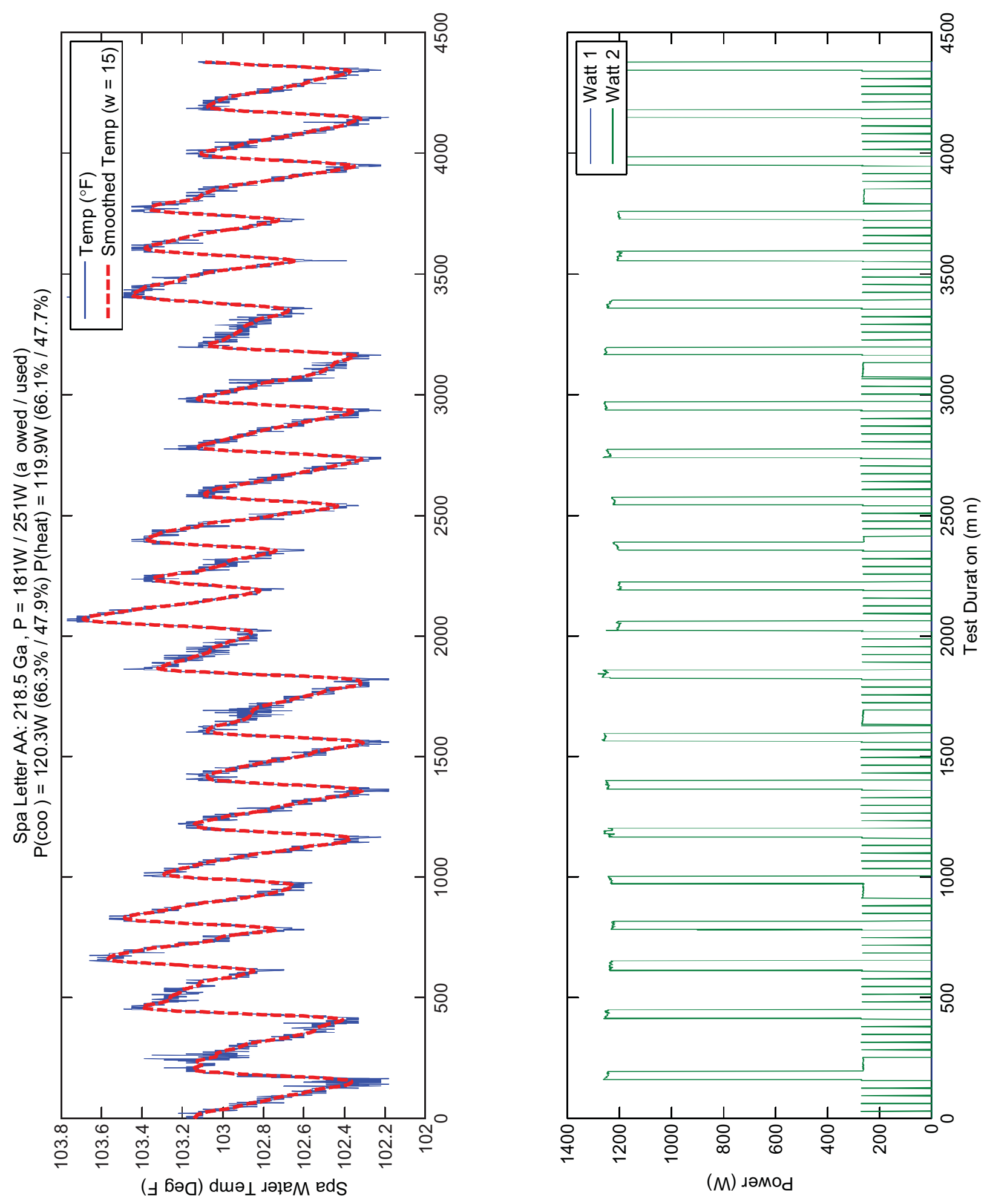


\section{F. Appendix F - Matlab Code}

read_spa_file_r5.m :

calc_heating_cooling_r5:
F-2 through F-7

F-8 through F-13 


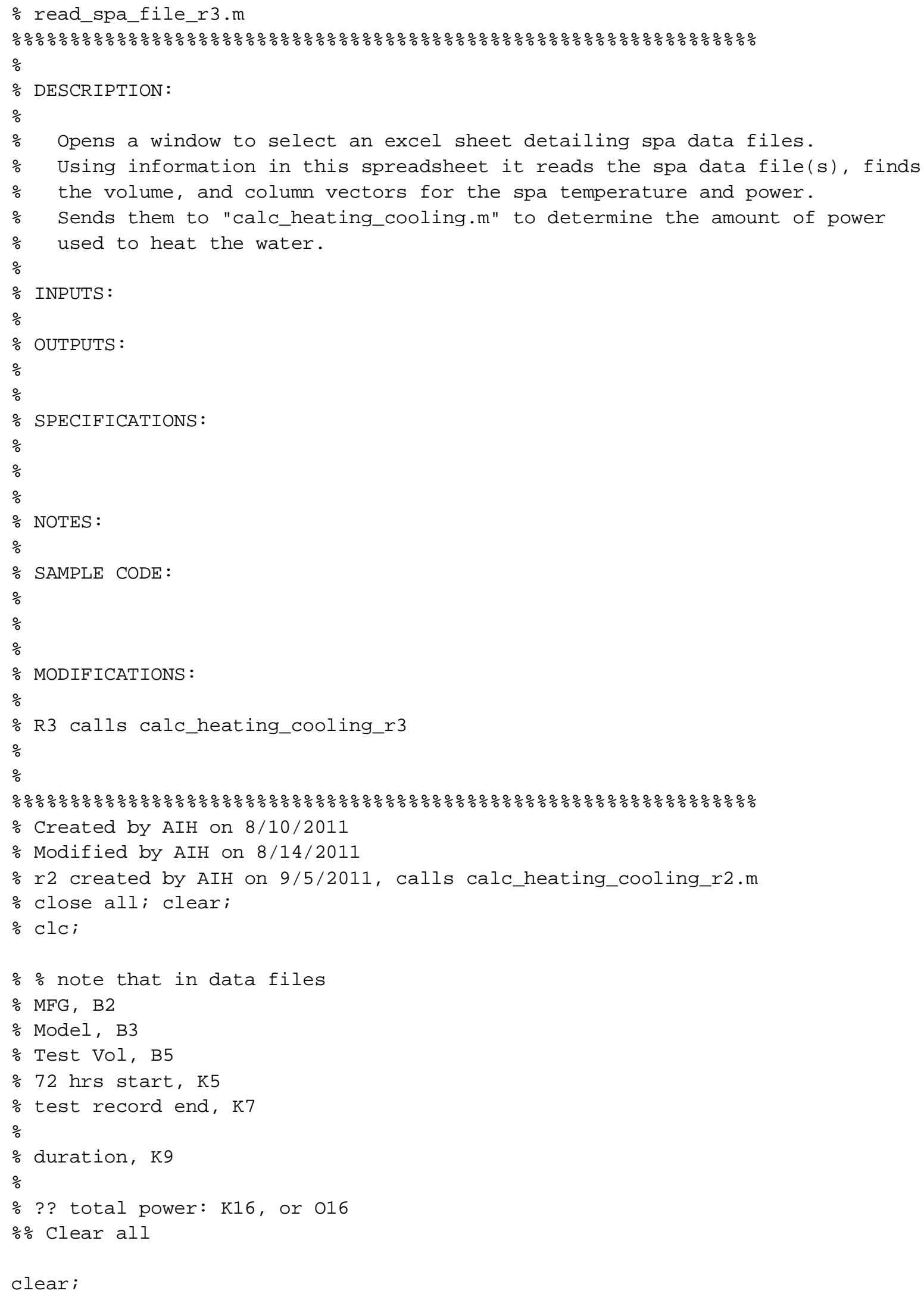




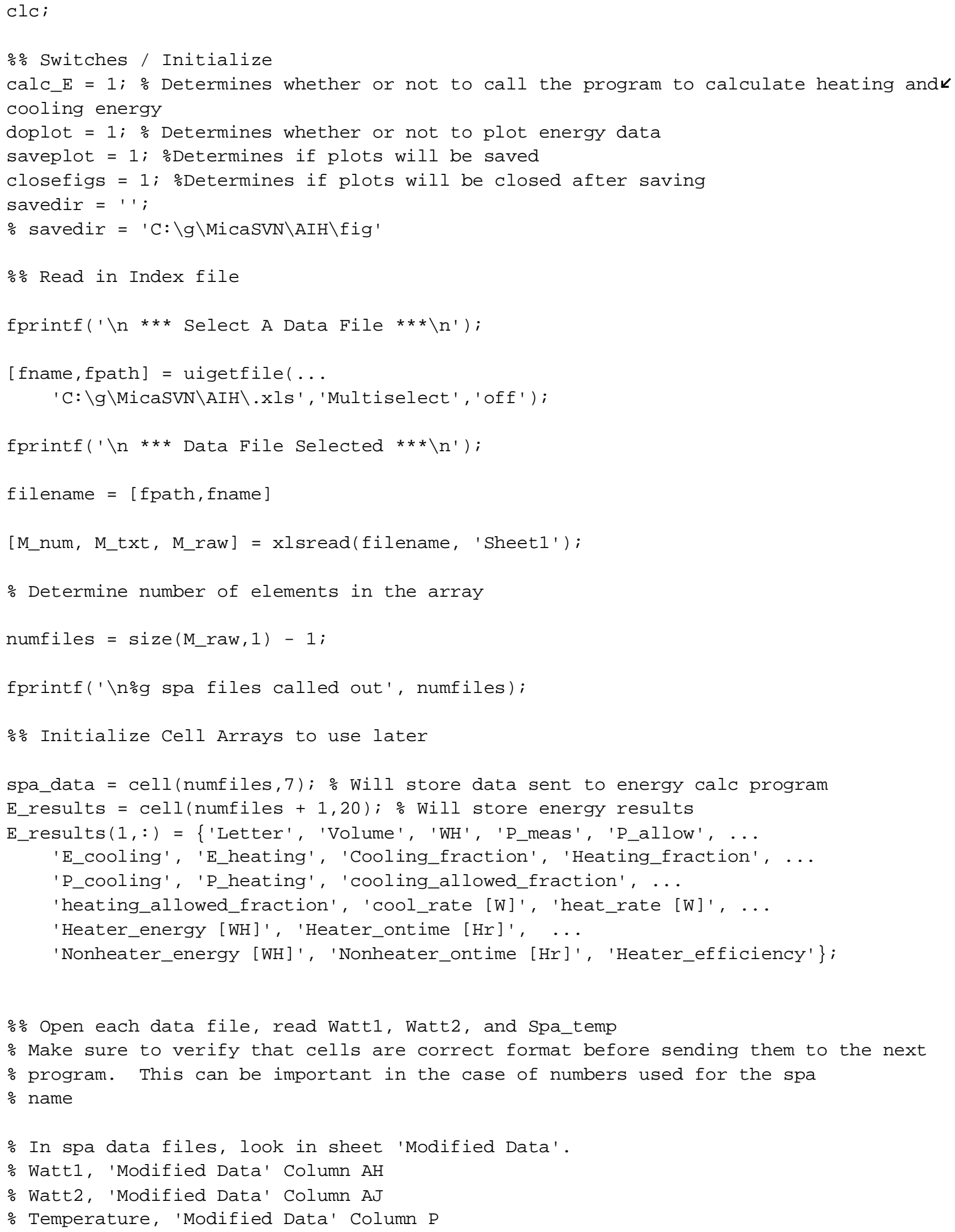




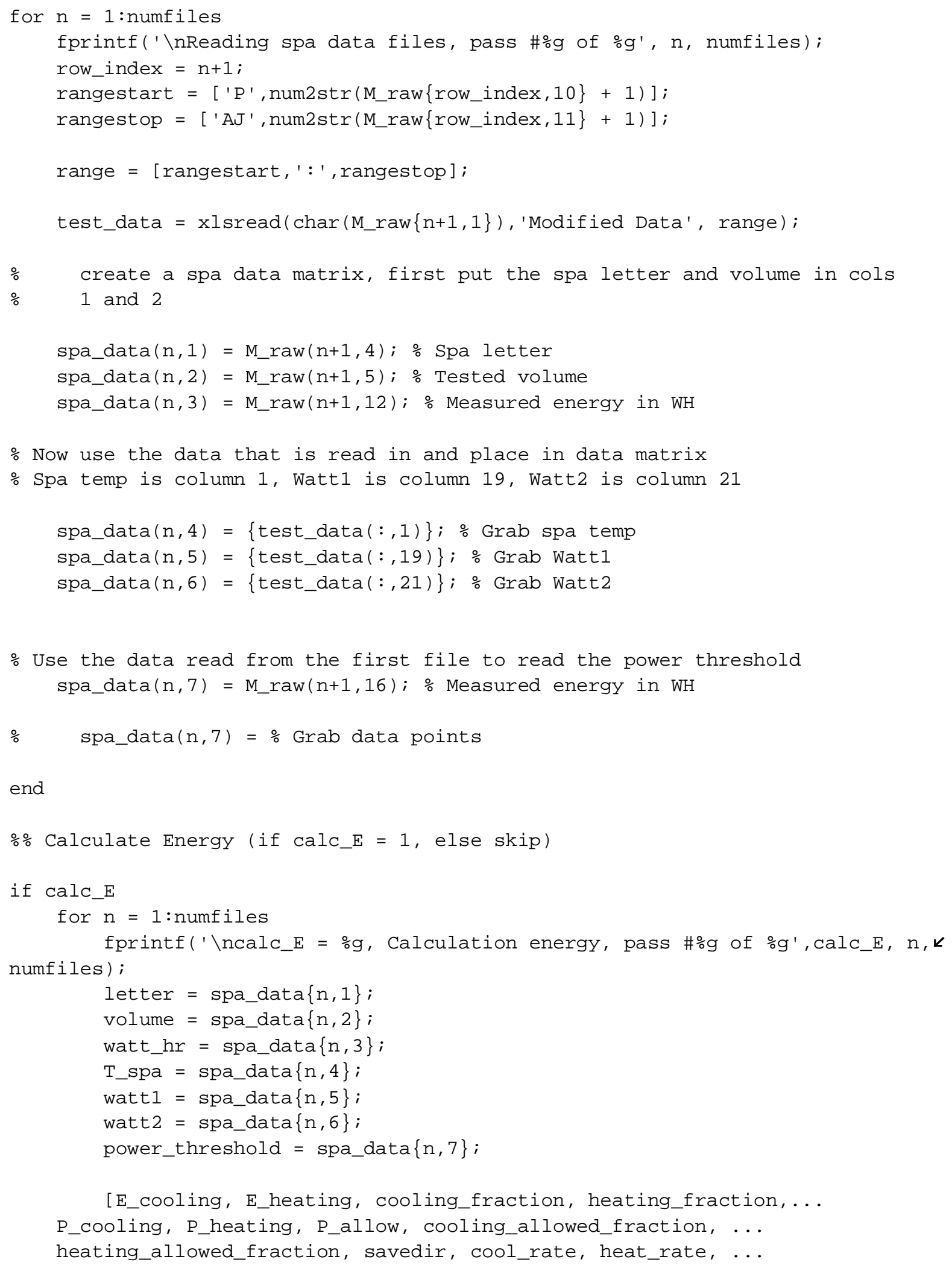


Heater_energy, Heater_ontime, Nonheater_energy, ...

Nonheater_ontime] $=\ldots$

calc_heating_cooling_r5(letter, volume, T_spa, watt1, watt2,...

watt_hr, power_threshold, doplot, saveplot, savedir, closefigs);

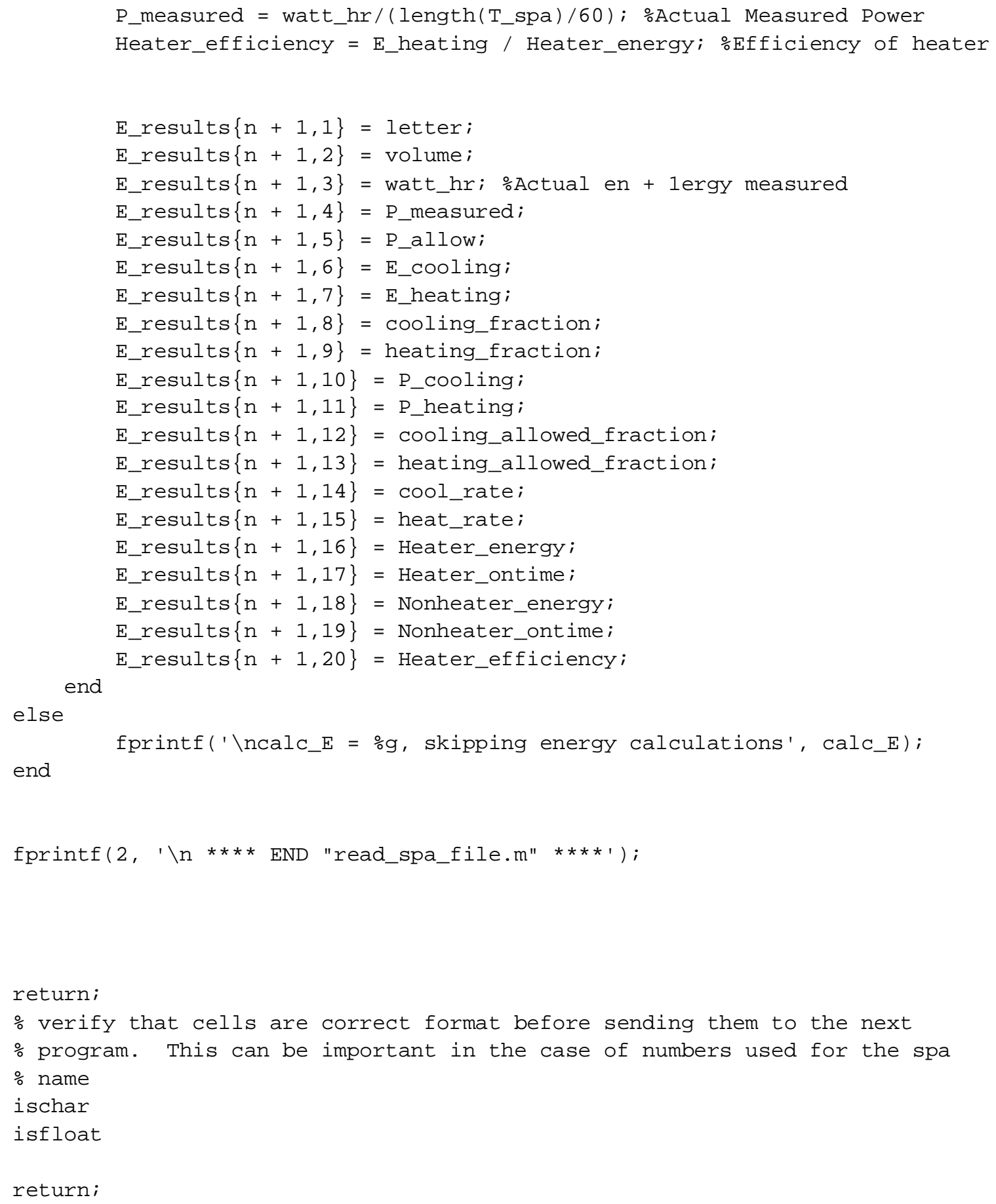




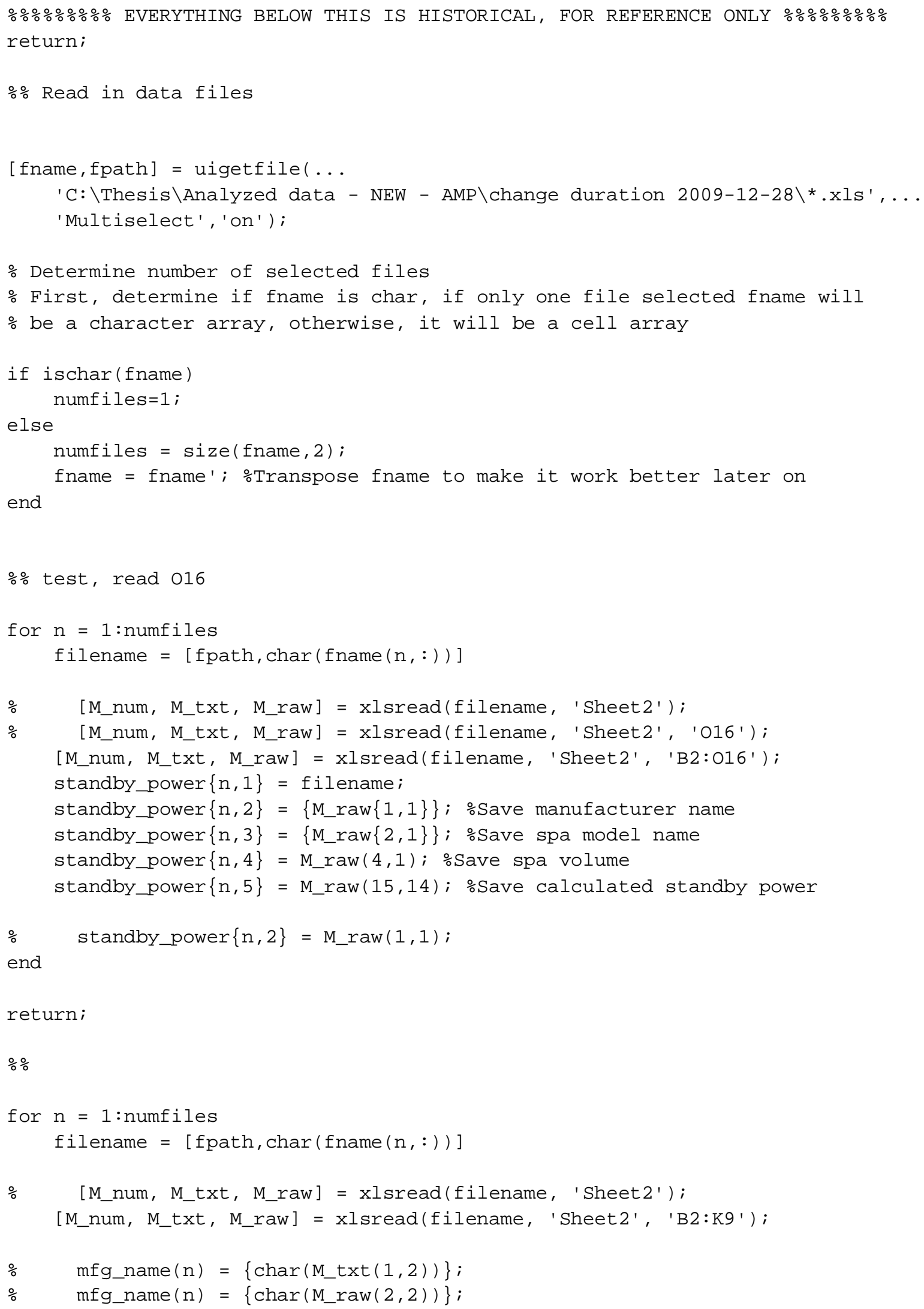




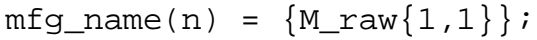

o spa_name $(\mathrm{n})=\{$ M_txt $(2,2)\}$;

o spa_name $(\mathrm{n})=\left\{\operatorname{char}\left(\mathrm{M} \_r a w(3,2)\right)\right\}$;

spa_name $(n)=\{$ M_raw $\{2,1\}\}$;

\% spa_vol $(\mathrm{n})=\{\operatorname{str} 2 \operatorname{num}(\operatorname{char}(\mathrm{M}(5,2)))\}$;

o spa_vol $(\mathrm{n})=\left\{\mathrm{M} \_n u m(4,1)\right\}$;

spa_vol $(\mathrm{n})=$ M_raw $(4,1)$;

end 


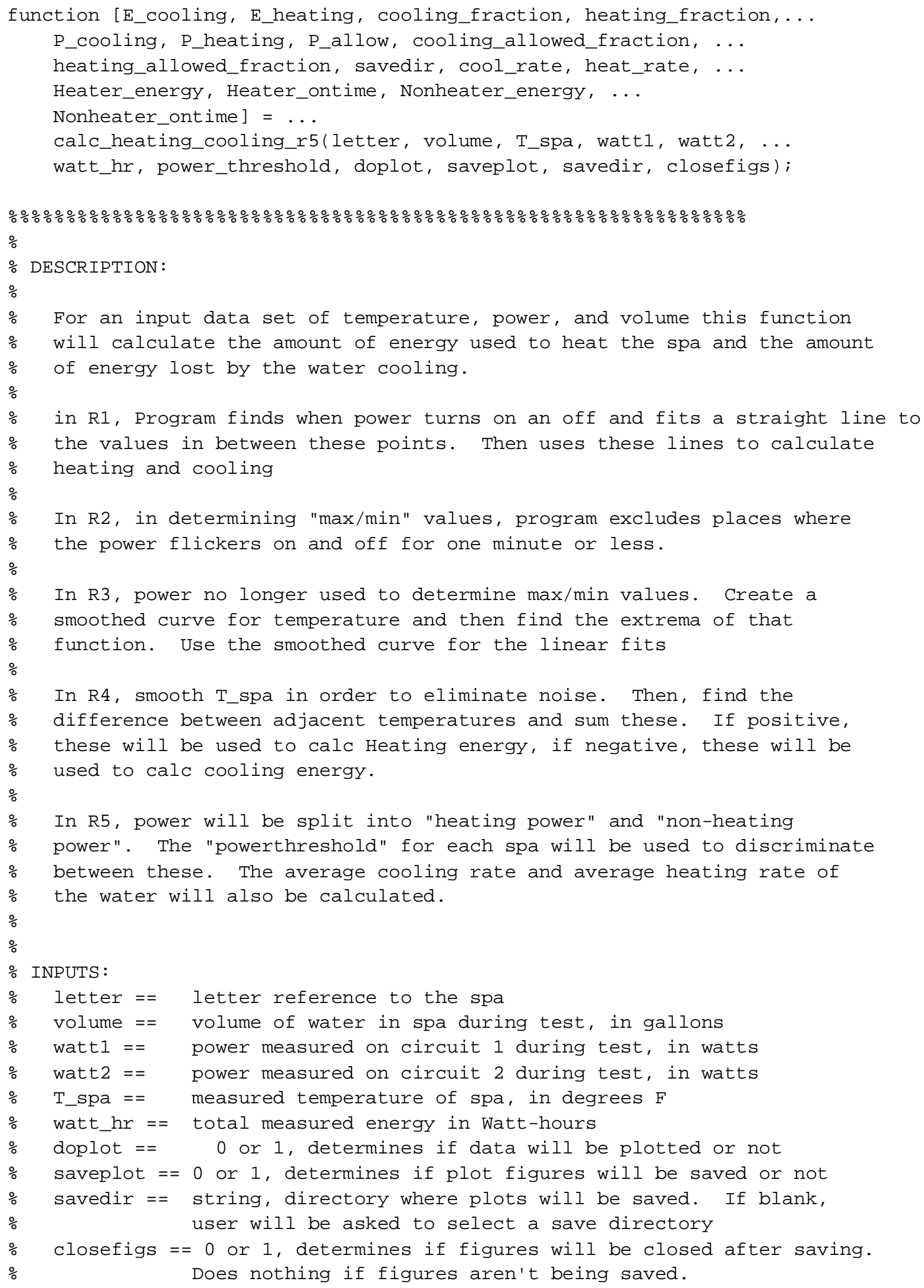


$\frac{\circ}{0}$

OUTPUTS :

응

응

응

응

NOTES :

․ Use subplot $(m, n, p)$, plot $(x, y)$ to create plots of power and of temperature, flagging \% the local maxima/minima

- save plots using saveas (h, 'h.fig')

SAMPLE CODE:

\%

$\circ$

$\circ$

MODIFICATIONS :

응

응

응

응

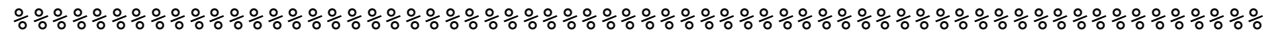

당 Created by AIH on 8/10/2011

ㅇ R1 created by AIH on $9 / 5 / 2011$

R2 created by AIH on 9/5/2011

o close all; clear;

$\circ \mathrm{ClC}$;

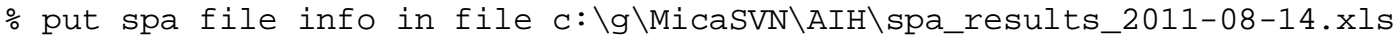

\% Filename (col A), Mfg (B), Name (C), Letter (D), Vol (E), Allowable power

\% (F), Measured power (G), Duration (I), data point start (J), data point

$\circ$ end $(K)$

o In spa data files, look in sheet 'Modified Data'.

․ Watt1, 'Modified Data' Column AH

\% Watt2, 'Modified Data' Column AJ

o Temperature, 'Modified Data' Column P

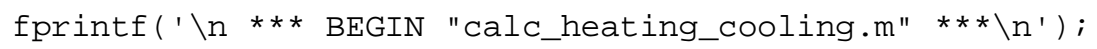

figure_post_text = '_r5'; \%append text onto figure name to indicate program used 


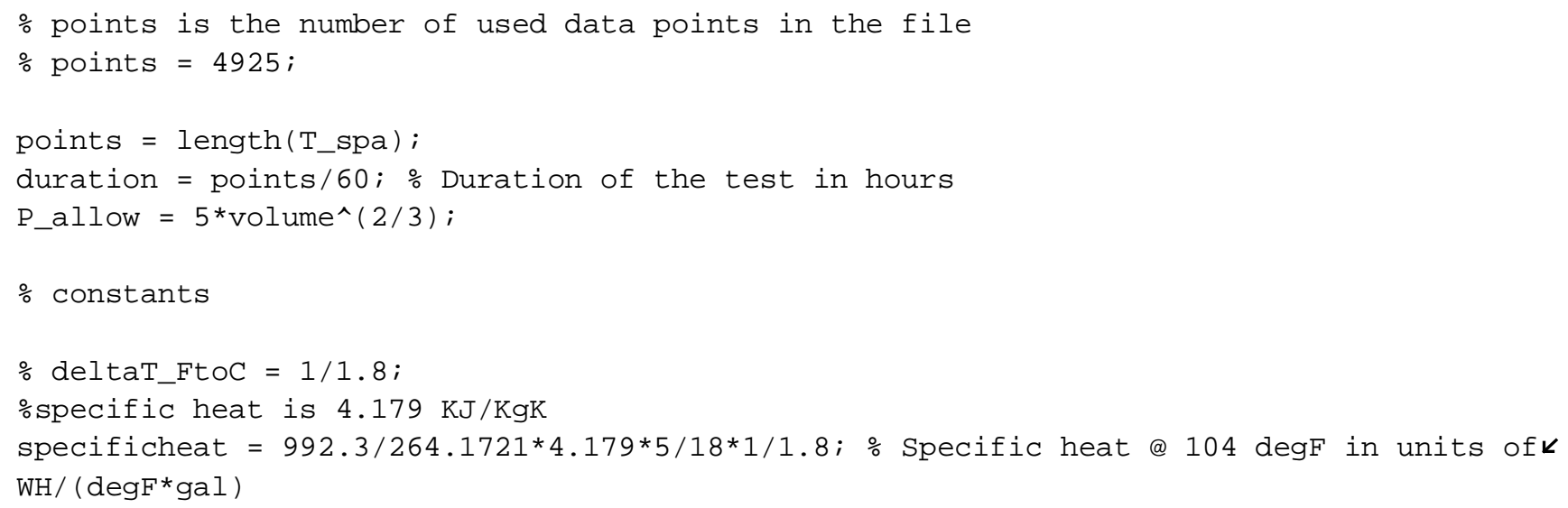




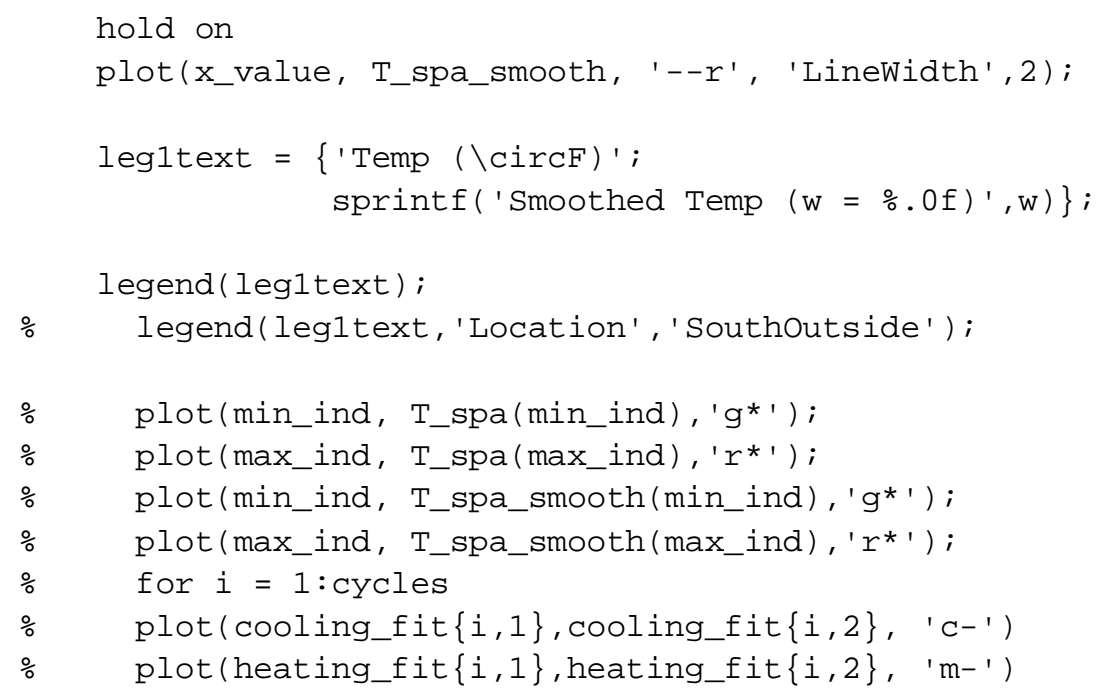


if isempty (savedir)

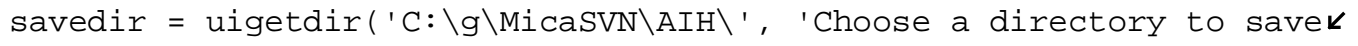

figures')

end

fig_filename = sprintf('\%s\%s.fig', letter, figure_post_text);

fig_fullname $=$ [savedir,'\',fig_filename $]$;

fprintf('\nSaving Spa \%s data to: \%s... \n', letter, fig_fullname); saveas(h,fig_fullname); $\%$ save figure

if closefigs

close (h);

end

end

end

응 saveas(h, 'h.fig'); 응 save figure

$\because$ End function

fprintf $(2, ' \backslash n * \star \star$ END OF FUNCTION "calc_heating_cooling.m" $\star \star \star \backslash n ')$; 
Hamill G-1

G. Appendix G - Other Applicable Documents 
Final Report:

\title{
Experimental Study of Portable Electric Spa Stand-by Power
}

\author{
By \\ Andrew I. Hamill \\ Andrew J. Kean, Ph.D. \\ Glen E. Thorncroft, Ph.D. \\ California Polytechnic State University \\ San Luis Obispo, CA 93407 \\ Submitted to \\ Carvin DiGiovanni \\ Association of Pool and Spa Professionals \\ and \\ Lianne Williams \\ Pacific Gas and Electric Corporation
}

September 24, 2008

\section{Introduction}

The purpose of this report is to present the results of power tests of portable electric spas, performed at the National Pool Industry Research Center (NPIRC) at Cal Poly State University. This work was funded by the Association of Pool and Spa Professionals (APSP), and includes power tests of 27 portable residential spas. Test reports for these spas are attached to this report (Appendix A).

Testing was performed using three environmentally-controlled test chambers and instrumentation provided by APSP, and follows a test protocol finalized June 13, 2008 (Appendix B). The test protocol is based on the Codes and Standards Enhancement Initiative (CASE) Report, "Analysis of Standards Options for Portable Electric Spas” (Appendix C).

\section{Scope of Testing}

As per the test protocol, testing focused solely on stand-by operation of the spas. The spas were operated at a fixed temperature set point, with a water temperature of $102{ }^{\circ} \mathrm{F}$ or above $^{1}$, and the ambient (chamber) temperature maintained at or below $60{ }^{\circ} \mathrm{F}$. Power and temperature data were recorded after the spas warmed up, and at least four hours after conditions stabilized. Data collection began at the end of a filter cycle, purge cycle, or heat cycle, and the

\footnotetext{
${ }^{1}$ Due to uncertainty in temperature measurement $\left( \pm 1^{\circ} \mathrm{F}\right)$, a slightly higher temperature was sought so that the water temperature did not drop below $102^{\circ} \mathrm{F}$. A similar approach was taken for the ambient (chamber) temperature.
} 
end of a test record was the end of a corresponding filter cycle, purge cycle, or heat cycle occurring 72 or more hours after the test recording began.

\section{Results}

Spa Test Reports for each of the 27 spa models are attached to this report (Appendix A). The make and model of the spas are not included; instead each spa was given a letter designation. The tested spas ranged in volume from 142 to 470 gallons, and the measured standby power ranged from 81 to 479 Watts ( 712 to $4,192 \mathrm{kWh} /$ year).

Figure 1 compares the stand-by power for the spas tested as a function of spa volume. In keeping with the CASE report, the annual stand-by energy use is also presented. The dashed line represents the allowable stand-by power, as recommended in the CASE report:

$$
P_{\text {allow }}=5 V^{2 / 3}
$$

where $P_{\text {allow }}$ is the allowable stand-by power in Watts, and $\mathrm{V}$ is the water volume in gallons. For Figure 1, the water volume at the recommended fill level was used. See Appendix A for the allowable stand-by power calculated at different volumes for each tested spa.

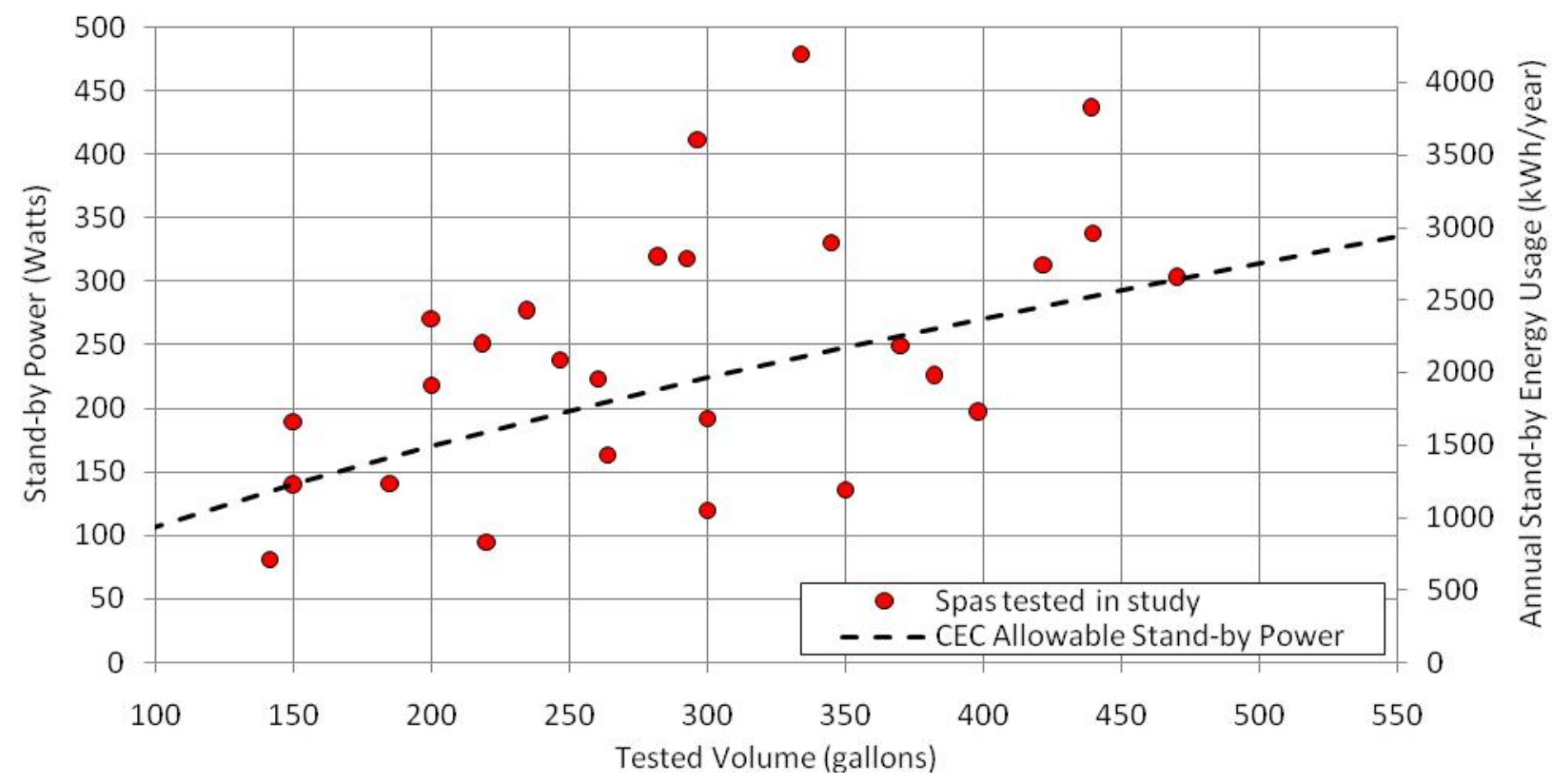

Figure 1: Measured stand-by power compared with CEC allowable stand-by power. The corresponding values of the annual stand-by energy use are also presented.

One concern that has been raised is the fairness of Equation (1), specifically that the equation may disadvantage lower-volume spas. Some energy use is independent of spa volume, meaning that there is some baseline power use required for any spa. It has been suggested that a constant (offset) could be applied to the equation in order to accommodate this baseline power use. However, the application of an offset may neither be prudent nor necessary for several 
reasons. First, a baseline power value would be difficult to establish. Mathematically, the offset value represents the power use of a spa when its volume is reduced to zero. Theoretically, as the volume is reduced to zero, the heating and pumping requirements are also reduced to zero, making an offset unnecessary. Second, the volumes of the smallest spas are far enough away from the origin in Figure 1 that a constant added to Equation (1) is not required. Finally, examining the test results in Figure 1, the smaller spas tested meet the current power standard at a similar rate to the larger spas.

Table 1 displays a summary of the results for each spa tested. The measured stand-by power was determined by dividing the total energy consumption during the test by the test duration as specified in the test protocol (Appendix B). The right-most column lists the percent difference between the measured and the allowable stand-by power.

Table 1: Summary of (non-temperature-normalized) test results

\begin{tabular}{|c|c|c|c|c|}
\hline \multirow{2}{*}{ Spa } & \multirow{2}{*}{$\begin{array}{c}\text { Tested } \\
\text { Volume (gal) }\end{array}$} & \multicolumn{2}{|c|}{ Stand-by Power (Watts) } & \multirow{2}{*}{$\begin{array}{c}\% \text { above or } \\
\text { below } \\
\text { Allowable }\end{array}$} \\
\hline & & Measured & Allowable & \\
\hline$A$ & 185 & 141 & 162 & $-13 \%$ \\
\hline B & 264 & 163 & 206 & $-21 \%$ \\
\hline C & 398 & 197 & 271 & $-27 \%$ \\
\hline D & 282 & 320 & 215 & $49 \%$ \\
\hline $\mathrm{E}$ & 440 & 338 & 289 & $17 \%$ \\
\hline $\mathrm{F}$ & 200 & 218 & 171 & $28 \%$ \\
\hline G & 300 & 192 & 224 & $-14 \%$ \\
\hline $\mathrm{H}$ & 150 & 190 & 141 & $34 \%$ \\
\hline 1 & 370 & 249 & 258 & $-3 \%$ \\
\hline J & 334 & 479 & 241 & $99 \%$ \\
\hline K & 142 & 81 & 136 & $-40 \%$ \\
\hline $\mathrm{L}$ & 220 & 95 & 182 & $-48 \%$ \\
\hline M & 300 & 119 & 224 & $-47 \%$ \\
\hline $\mathrm{N}$ & 235 & 277 & 190 & $46 \%$ \\
\hline $\mathrm{O}$ & 345 & 330 & 246 & $34 \%$ \\
\hline$P$ & 247 & 238 & 197 & $21 \%$ \\
\hline$Q$ & 439 & 437 & 289 & $51 \%$ \\
\hline $\mathrm{R}$ & 296 & 411 & 222 & $85 \%$ \\
\hline$S$ & 293 & 318 & 220 & $44 \%$ \\
\hline$T$ & 150 & 140 & 141 & $0 \%$ \\
\hline U & 470 & 304 & 302 & $1 \%$ \\
\hline $\mathrm{V}$ & 350 & 136 & 248 & $-45 \%$ \\
\hline W & 382 & 226 & 263 & $-14 \%$ \\
\hline$x$ & 422 & 313 & 281 & $11 \%$ \\
\hline$Y$ & 200 & 270 & 171 & $58 \%$ \\
\hline Z & 260 & 223 & 204 & $9 \%$ \\
\hline AA & 219 & 251 & 181 & $38 \%$ \\
\hline
\end{tabular}


A second concern arose due to the consistency of the water and chamber air temperatures from test to test. The average water temperature varied minimally from test to test - about 1 to 2 ${ }^{\circ} \mathrm{F}$ from the target value of $102{ }^{\circ} \mathrm{F}$. However, the average chamber air temperature sometimes fell significantly below the target value of $60^{\circ} \mathrm{F}$ - as low as $52^{\circ} \mathrm{F}$ on average during one test. This behavior was a result of limitations in the climate control equipment used in the chambers, which were commercial window air conditioners that had been modified by APSP. The importance of this issue is that the heat lost from each spa increases as the difference between the water and the chamber temperatures increases. It is therefore crucial that the measured temperature difference be taken into account, so that spas are judged consistently, and that no spa "fails" merely because the temperature difference is different than ideal conditions.

As a result of this concern, APSP and PG\&E are discussing the possibility of normalizing the stand-by power using the average temperature difference. This technique is discussed in the CASE report, where some test data were normalized to an average air temperature of $60^{\circ} \mathrm{F}$. APSP and PG\&E have suggested this method, using the following equation:

$$
P_{\text {norm }}=P_{\text {meas }} \frac{\Delta T_{\text {ideal }}}{\Delta T_{\text {meas }}} \text {, }
$$

where $\Delta T_{\text {ideal }}$ is some idealized temperature difference between the water and ambient temperatures, $\Delta T_{\text {meas }}$ is the measured temperature difference, and $P_{\text {meas }}$ is the measured stand-by power.

APSP and PG\&E are considering $37^{\circ} \mathrm{F}$ for the value of $\Delta T_{\text {ideal }}$. This value is based on temperature tolerances being proposed for the air and water temperatures. The current test protocol does not specify tolerances on the air and water temperatures - instead, it specifies that the water temperature must be maintained at $102^{\circ} \mathrm{F}$ or above, and the air temperature must be maintained at $60{ }^{\circ} \mathrm{F}$ or below. APSP and PG\&E are considering specifying a tolerance of $\pm 2^{\circ} \mathrm{F}$ to the water temperature and $\pm 3^{\circ} \mathrm{F}$ for the air temperature. If these tolerances are adopted in a future revision of the test protocol, the minimum allowable temperature difference would be 37 ${ }^{\circ} \mathrm{F}$.

This normalization is only an approximation, based on the assumption that the heat loss (and therefore, to a large extent the power demand) is linearly proportional to the temperature difference. Certainly other factors, such as spa insulation/construction and spa geometry will also affect this relationship, although the effects are not known precisely. Regardless, this technique may be useful as a first approximation, and is in fact supported in the CASE report.

Applying a $37^{\circ} \mathrm{F}$ normalization to all of the spas gives the following results shown in Figure 2 and Table 2. It is important to note that applying the normalization allowed six of the tested spas (E, H, I, P, X, and Z) that initially did not comply with the CEC allowable power (Eqn. 1) to meet the stand-by power requirement. 


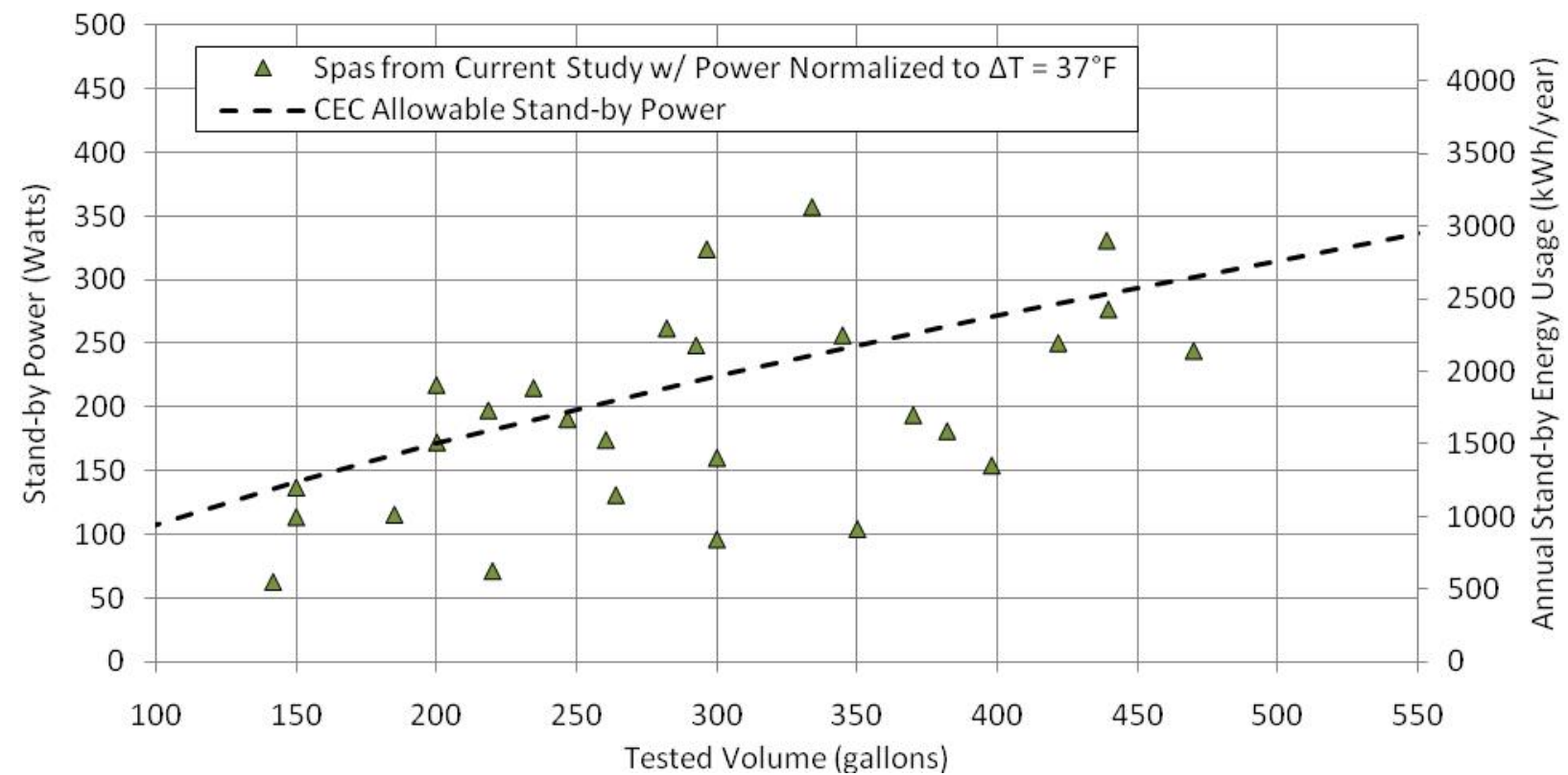

Figure 2: Plot of the stand-by power for the tested spas. The power was normalized using equation (2) with $\Delta T_{\text {ideal }}$ equal to $37^{\circ} \mathrm{F}$.

\section{NIST Traceability}

As required by the test protocol, the accuracies of the temperature and power measurement equipment were verified against NIST (National Institute of Standards and Technology) certified equipment. We verified the accuracy of the test equipment by comparing temperature, voltage, current, and power factor data with those recorded with the NIST-traceable equipment during the tests of six spas. It should be noted that a verification of accuracy was performed, not a calibration. A calibration would have involved the test equipment and NISTtraceable equipment being compared across the range of the voltage, current, and power factor values. The equipment necessary to vary the load, and particularly the power factor, was not available. Further, the project schedule and the limited time we had the NIST-traceable equipment did not allow a full calibration.

The temperature measurements for all three test chambers were found to fall within $\pm 1^{\circ} \mathrm{F}$ of the NIST-traceable measurements. Therefore, no adjustments to the temperature measurements were required.

The instantaneous power for all three test chambers was found to be within $\pm 2 \%$ of fullscale when compared with the NIST-traceable equipment (the data acquisition, or DAQ, systems supplied by APSP have a listed accuracy of $\pm 0.5 \%$ of full scale). One issue that arose was that at zero power demand, the DAQ system read a small non-zero reading (approximately 5-10 W), while the NIST-traceable equipment read zero power. In addition, the same non-zero power reading was present even when no spa was electrically connected to the DAQ system. To correct this error, all power readings below $20 \mathrm{~W}$ were set to zero for all of the spas in the study. 
Table 2: Spa test results with the power normalized using $\Delta T_{\text {ideal }}$ equal to $37^{\circ} \mathrm{F}$.

\begin{tabular}{|c|c|c|c|c|}
\hline \multirow{2}{*}{ Spa } & \multicolumn{2}{|c|}{ Stand-by Power (Watts) } & \multirow{2}{*}{$\begin{array}{l}\text { Normalized } \\
\text { Power (Watts) }\end{array}$} & \multirow{2}{*}{$\begin{array}{c}\% \text { above or } \\
\text { below } \\
\text { Allowable }\end{array}$} \\
\hline & Measured & Allowable & & \\
\hline$A$ & 141 & 162 & 116 & $-29 \%$ \\
\hline B & 163 & 206 & 131 & $-36 \%$ \\
\hline C & 197 & 271 & 154 & $-43 \%$ \\
\hline D & 320 & 215 & 262 & $22 \%$ \\
\hline $\mathrm{E}$ & 338 & 289 & 277 & $-4 \%$ \\
\hline $\mathrm{F}$ & 218 & 171 & 173 & $1 \%$ \\
\hline G & 192 & 224 & 160 & $-28 \%$ \\
\hline $\mathrm{H}$ & 190 & 141 & 137 & $-3 \%$ \\
\hline 1 & 249 & 258 & 194 & $-25 \%$ \\
\hline J & 479 & 241 & 357 & $48 \%$ \\
\hline K & 81 & 136 & 63 & $-53 \%$ \\
\hline $\mathrm{L}$ & 95 & 182 & 72 & $-61 \%$ \\
\hline M & 119 & 224 & 97 & $-57 \%$ \\
\hline $\mathrm{N}$ & 277 & 190 & 215 & $13 \%$ \\
\hline $\mathrm{O}$ & 330 & 246 & 256 & $4 \%$ \\
\hline$P$ & 238 & 197 & 191 & $-3 \%$ \\
\hline$Q$ & 437 & 289 & 330 & $14 \%$ \\
\hline $\mathrm{R}$ & 411 & 222 & 324 & $46 \%$ \\
\hline$S$ & 318 & 220 & 248 & $13 \%$ \\
\hline$T$ & 140 & 141 & 114 & $-19 \%$ \\
\hline U & 304 & 302 & 244 & $-19 \%$ \\
\hline V & 136 & 248 & 105 & $-58 \%$ \\
\hline W & 226 & 263 & 181 & $-31 \%$ \\
\hline$x$ & 313 & 281 & 250 & $-11 \%$ \\
\hline$Y$ & 270 & 171 & 218 & $27 \%$ \\
\hline Z & 223 & 204 & 174 & $-14 \%$ \\
\hline AA & 251 & 181 & 198 & $9 \%$ \\
\hline
\end{tabular}

Table 3 compares the energy consumption $(\mathrm{kWh})$ measured by the DAQ system with that recorded by the NIST-traceable equipment. For five of the six spas, the measured energy consumption was within $\pm 2 \%$ of the value measured with NIST-traceable equipment. Notably, for one spa, Spa R, the DAQ system read an energy consumption that was 3.3\% higher than the NIST-traceable standard. The larger error can be explained by the fact that the accuracy of the DAQ system is based on the full-scale range of the device. The full-scale power measured by the DAQ system is $12,000 \mathrm{~W}$. Even at the claimed accuracy of $\pm 0.5 \%$ of full scale, the uncertainty in any particular power reading is $\pm 60 \mathrm{~W}$. This uncertainty has a larger relative 
effect when the measured power is lower. Except for Spa R, all spas listed in Table 3 had a peak power demand between 1,000 and 5,000 W, and also spent a significant amount of time drawing zero power. Spa R, however, operated at two lower-power settings, $900 \mathrm{~W}$ and $150 \mathrm{~W}$, and never drew zero power. As a result, the uncertainty as a percentage of reading was higher, and any error accumulates as the energy consumption is added up over time.

This issue raises the importance of the accuracy of the power measurement, and several approaches can be taken to improve the accuracy of power measurements in future testing. One option is to obtain power measurement equipment that is accurate to a percentage of reading, not full-scale. A second option is to use two power meters, with one meter limited to a lower range of power. Finally, a third option is to perform a full-range calibration against high-accuracy NIST-traceable equipment like those used in this study, an approach that would require additional equipment and time.

Table 3. NIST comparison results for energy consumption performed on six spas across the three test chambers.

\begin{tabular}{c|r|r|r} 
SPA & \multicolumn{2}{|c|}{$\begin{array}{c}\text { Energy Consumption during test } \\
\text { (kWh) }\end{array}$} & \% Err \\
& NIST & DAQ & \\
B & 12.5 & 12.7 & $1.6 \%$ \\
C & 16.4 & 16.4 & $0.3 \%$ \\
M & 8.7 & 8.7 & $-0.2 \%$ \\
R & 31.0 & 32.0 & $3.3 \%$ \\
U & 22.8 & 22.8 & $0.3 \%$ \\
V & 10.2 & 10.1 & $-1.4 \%$ \\
\hline
\end{tabular}

\section{Recommendations and Conclusions}

During the course of this study 27 spas of various sizes were tested. Without applying normalization the measured stand-by power of 11 spas was below the maximum power allowed by the CEC requirement, while the remaining 16 spas used more power than allowed by the requirement. Normalizing the measured power using the average temperature difference and an ideal temperature difference of $37^{\circ} \mathrm{F}$ increased the number of spas with stand-by power below the requirement to 17 , with the remaining 10 spas still exceeding the requirement. By looking at the plots with and without normalization one can see that there does not seem to be a greater passing rate among either the larger, midsized, or smaller spas. While concerns may still exist that the CEC requirement biases certain spas depending on the size, that bias has not been demonstrated in this study.

Our experience with testing has brought up several issues which should be taken into consideration to improve testing in the future. First, the standard window air conditioners used to control the chamber air temperature are not sufficiently precise to maintain the proposed air temperature tolerance. More precise temperature control equipment can be obtained and would be more suitable than window air conditioners for future tests. Second, a full calibration of the 
power equipment with NIST-traceable equipment could also be carried out as mentioned above. This will decrease the error on the power measurements and ensure greater certainty in the data, especially at low power levels. Third, the effect of using test durations below 72 hours should be investigated. If the effect of shortening the test duration is negligible to the measured stand-by power values than an argument could be made to decrease the test time allowing for quicker testing of spas.

Several potential topics for future testing have also come up during the study. Investigation into these topics will improve the collective understanding of test performance and spa energy usage. The influence of the cover on overall spa performance is once such topic. Tests could include the addition of foam insulation to the hinge of a cover that does not have any insulation at the hinge. A floating pool cover cut to sit on the surface of the spa water could also be tested to determine its effect. In addition, complete replacement of the cover with a Coverplay cover which does not have a gap in the fill material at the hinge could also be done. Included with these tests could also be a parametric study of the relative effect of changing various other spa parameters (shell insulation, pumps, controls, etc.).

Other testing could be carried out to investigate the effect of the average temperature difference and water level on spa stand-by power. For the temperature test, one spa could be tested at several different air and water set temperatures and the measured stand-by power compared with these differences in temperature. Such tests could help to assess the use of temperature normalization in handling power differences due to differences in the average test temperature. Similarly, a single spa could also be tested at different water levels, keeping the set temperatures the same. This would help to determine the actual relationship between water volume and stand-by power for a particular spa.

A final test to consider would be to test spas outside in real-world conditions. It is important to remember that the test chamber is an idealized situation, and the results of such testing may not accurately reflect performance outdoors. The purpose of this test was to develop a standard, not necessarily to simulate real-world conditions precisely. However, the test data obtained in this study are not a guarantee of performance in the home. Three key differences exist between the current tests and real-world conditions.

1. Heat lost to radiation would be larger outdoors, as the spa will radiate heat to the sky as opposed to the walls of the test chamber, which are maintained at around $60{ }^{\circ} \mathrm{F}$.

2. Forced convection would have a greater effect on spa performance in outdoor conditions due to greater wind speeds.

3. Humidity levels are different between the test chamber and outdoor conditions. How ambient humidity affects spa performance is difficult to predict, but the presence of humidity in the air is likely to affect evaporative heat loss.

Discussions with APSP and PG\&E have suggested that outside testing may be of value. In such a test, the energy consumption ( $\mathrm{kWh}$ ) could be tracked alongside local weather conditions such as temperature, relative humidity, and wind speed. 


\title{
Final Version (DRAFT \#10)
}

\author{
June 13, 2008 \\ Portable Electric Spa Stand-by Energy Test Protocol \\ APSP CEC/Spa Advisory Group
}

Rev. 20080613

\section{Purpose:}

To measure the energy consumption of a portable electric spa in stand-by mode, using repeatable and reproducible environmental and testing controls. Said results will be utilized to calculate the standby power demand, which will be used to determine how spas perform relative to the California Energy Commission Title 20 maximum standby power requirement.

\section{Definitions:}

Stand-by mode - All settings at default as shipped by the manufacturer, except water temperature which may be adjusted to meet the test conditions.

Spa Volume - The advertised and marketed water fill capacity of the tub in gallons. This measurement is generally found on the tub specification label on the tub, in the owner's manual or within advertising of the tub.

Total Spa Capacity - The total fill capacity of the tub in gallons (this measurement is greater than the Spa Volume). This is measured by filling the tub to the point where the entire vessel is full, at the threshold of spilling out of the tub.

\section{Test Equipment:}

Note: All equipment shall be calibrated and traceable to the National Institute of Standards and Technology (NIST).

Recording Watt Hour meter - Accuracy: Class-2 or better.

Temperature measurement system - Accuracy: $+/-1^{\circ} \mathrm{F}$

Water meter to measure fill water in gallons - Accuracy: +/- 1.5\%

\section{Test Conditions:}

Chamber internal dimensions

Minimum 7 feet high

Minimum 1 foot from spa to chamber wall or other internal barrier 
$\underline{\text { Air Flow }}$

If air circulation from the air temperature control equipment is intermittent, install 1 fan in one corner of the chamber, 6 feet from the floor. Direct toward the center of the floor. The fan should move at least 80 CFM of air, and not more than 100 CFM. If the air temperature control equipment continuously circulates air in the chamber, no fan is required.

\section{Chamber Insulation}

Walls shall be insulated adequately to maintain proper ambient temperatures. 2" thick Dow TUFF-R Commercial Insulating Sheathing, or equivalent will create an adequate insulation barrier for a chamber that is located indoors.

Chamber Floor

The floor shall be insulated with 2” thick Dow TUFF-R Commercial Insulating Sheathing, or equivalent ( $\mathrm{R}-13$ polisocyanurate with radiant barrier on both sides). This insulation shall be laid directly on a level concrete floor or slab or other firm, level surface created for it. The insulating layer shall be sheeted with minimum 1/2" thick

ACX plywood to protect the insulation layer and provide a smooth surface to properly position the spas to be tested.

One ambient chamber temperature thermocouple location

Maximum of 1.5 feet above spa cover level.

Minimum of 1 foot above spa cover level

6 inches from chamber wall, out of the direct air flow from air temperature control system or circulation fan.

Water temperature thermocouple locations

Primary thermocouple -

Between 5 and 6 inches below the water surface

1 foot from skimmer

If spa has no skimmer, the water temperature sensor will be

centrally located relative to the shape of the vessel

Redundant thermocouple -

Within 3 to 6 inches radius of the primary thermocouple, on the same horizontal plane relative to water depth.

\section{Test Parameters:}

Ambient air temperature shall remain at or below $60^{\circ} \mathrm{F}$ during the test. Water temperature shall remain at or above $102^{\circ} \mathrm{F}$ during the test. Spa in Stand-by mode as shipped by the manufacturer to the customer

\section{Test Procedure:}

Place Spa in chamber directly on the chamber floor.

The spa shall be centered in the chamber.

Do not leave the spa on a skid or pallet.

Fill Spa with water to manufacturer's specified Spa Water Capacity.

Install manufacturer-supplied cover.

Connect electrical power, meters, and thermocouples 
Set controls to meet test parameters, if required.

Allow spa to heat to finish the initial heat cycle (warm up).

Record the set temperature on the control system.

Allow temperatures to stabilize for a minimum of 4 hours.

NO additional temperature adjustments may be made during or after the

stabilization period until the end of the test.

Begin the Test Period.

Begin the Test Record at the end of a filter cycle, purge cycle or a heat cycle after the Test Period begins.

* NOTE:

"Some hot tubs utilize non-conventional methodologies to either supply all of the heat to the tub or as a supplementary or secondary heat source to help maintain heat. During the initial heat up (bringing the water from the water supply temperature to set temperature, ie. 102) the tub may operate in a heat call or the heater will be running. Once the desired temperature is met, the tub may not go into a "heat call" or formal heating cycle at all or ever. The system being employed to circulate the water and/or filter the water may have sufficient heating abilities (either by design or as a by-product of the system) to maintain the desired temperature of the water. For this reason, a formal "heat call" or heat cycle may not be entered in to. It is for this reason that the procedure for ending the test period was modified."

The end of the Test Record is the end of a corresponding filter cycle, purge cycle or a heat call that occurs 72 hours or more after the start of the Test Record. End Test Period.

Fill spa to top (near overflowing) to determine Spa Volume

\section{Data Recording:}

Temperatures at a maximum interval of 4 minutes.

Voltage, current, and power factor at a maximum interval of 4 minutes.

Watt-hours used during entire Test Period.

Elapsed time during Test Record.

\section{Spa characteristics}

Manufacturer

Brand name

Model name or \#

Volts VAC 60 HZ (1)

Spa Volume (see Definitions above) and note (2) below

Spa Water Capacity (see Definitions above and note (1) below)

Rating for \# of persons (1)

Spa construction/ insulation type (3)

Spa cover height in inches (2)

Center

Edge

Spa cover density (lbs per cubit ft.) (1)

Filtration system $(1,4)$

Number of spa volume turnovers per 24 hours (2)

Standby test Watts (1)

Standby Watts std. (5) 
1- MFG'S PUBLISHED RATING

2- ACTUAL TEST MEASUREMENT

3- $F F=$ FULL FOAM TO SPA CABINET

PF $=$ PARTIAL FOAM SHELL AND PLUMBING

SF $=$ FOAMED SHELL

$M L=$ INSULATED CABINET MULTI LAYER

$\mathrm{SL}=$ INSULATED CABINET SINGLE LAYER

$\mathrm{NI}=\mathrm{NO}$ INSULATION

OT = OTHER, DESCRIBE

4- TSP = TWO SPEED PUMP , LOW SPEED, PROGRAMMED CYCLES

CP $=$ CIRCULATION PUMP OPERATING $24 / 7$

CPP $=$ CIRCULATION PUMP PROGRAMMED CYCLES

OT = OTHER, DESCRIBE

5- AS CALCULATED UNDER CEC GUIDELINES

\section{Cover characteristics}

Material composition

Weight

Thickness

$\mathrm{R}$ value

Hinge width

Hinge fill material

\section{Data Analysis:}

Determine minimum, maximum and mean temperatures for the test duration.

The primary thermocouple measurements will be used to validate the test.

The redundant thermocouple will be considered a backup.

Verify all temperatures meet the acceptability standards for a good test.

Divide watt hours used during the Test Record by the hours of the Test Record.

\section{Data Reporting:}

Spa Manufacturer and Model

Spa Volume

Total Spa Capacity

Hours of Test Record

Total energy used during Test Record

Standby Power in Watts.

The total Watt-hours of energy used during the Test, divided by the duration of the Test in hours (rounded to the nearest $1 / 60^{\text {th }}$ hour).

Calculated allowable Watts for vessel (CEC Title 20 formula) - 5( $\mathrm{V}^{2 / 3}$ ) where $\mathrm{V}$ is the spa volume measurement gallons.

Calculated Watts using Total Spa Capacity $-5\left(\mathrm{~V}^{2 / 3}\right)$ where V is Total Spa 